US Army Corps of Engineers $s_{\circledast}$

Engineer Research and

Development Center

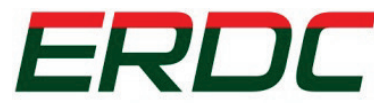

INNOVATIVE SOLUTIONS for a safer, better world

\title{
Integrated Assessment of Vegetation and Soil Conditions Following Herbicide Application
}

Nathan R. Beane, Christine M. VanZomeren, Cynthia L. Price, July 2017

Jennifer M. Seiter-Moser, Jeremy L. Conkle,

Brooke N. Stevens, and Jacob F. Berkowitz 
The U.S. Army Engineer Research and Development Center (ERDC) solves the nation's toughest engineering and environmental challenges. ERDC develops innovative solutions in civil and military engineering, geospatial sciences, water resources, and environmental sciences for the Army, the Department of Defense, civilian agencies, and our nation's public good. Find out more at www.erdc.usace.army.mil.

To search for other technical reports published by ERDC, visit the ERDC online library at http://acwc.sdp.sirsi.net/client/default. 


\section{Integrated Assessment of Vegetation and Soil Conditions Following Herbicide Application}

Nathan R. Beane, Christine M. VanZomeren, Cynthia L. Price, Jennifer M. Seiter-Moser, Brooke N. Stevens, and Jacob F. Berkowitz

Environmental Laboratory

U.S. Army Engineer Research and Development Center 3909 Halls Ferry Road

Vicksburg, MS 39180-6199

Jeremy L. Conkle

Texas A\&M University Corpus Christi

Department of Physical \& Environmental Sciences

Room 103 Harte Research Institute

Corpus Christi, TX 78412

Final report

Approved for public release; distribution is unlimited.

Prepared for U.S. Army Corps of Engineers

Washington, DC 20314-1000

Under Project 15-158. "Plot Herbicide Effectiveness and Environmental Assessment" 


\section{Abstract}

Vegetation and soil conditions were evaluated prior to, and following herbicide application implemented to control woody vegetation and maintain open grassland areas at Fort Hood, TX. Herbicide application resulted in a decreased rate of vegetation resprout compared with areas where herbicide was not used. Specifically, herbicide mixtures containing Remedy Ultra and methylated seed oil (RU-MSO) outperformed treatments in which no herbicide was applied and areas receiving herbicide and diesel fuel oil treatments (RU-diesel) across each of the three soils evaluated. Field monitoring assessed herbicide concentrations in soil and water. Herbicides were not observed in creeks and ponds adjacent to treatment areas. In soils, herbicide concentrations decreased by $72 \%$ over one month, likely due to microbial degradation, and with distance from the point of application. Monitoring results suggest that limited lateral and/or vertical transport occurred under field conditions. Laboratory studies evaluated potential fate and transport of herbicide compounds, identifying herbicide affinity for the soil surface. Additionally, RU-MSO treatments were strongly bound to soil surfaces at environmentally relevant concentrations. Further, laboratory column studies also suggest that potential transport in soil remained limited. Incorporating periodic herbicide applications into an integrated vegetation management plan will maintain grassland habitats in support of the mission.

DISCLAIMER: The contents of this report are not to be used for advertising, publication, or promotional purposes. Citation of trade names does not constitute an official endorsement or approval of the use of such commercial products. All product names and trademarks cited are the property of their respective owners. The findings of this report are not to be construed as an official Department of the Army position unless so designated by other authorized documents. 


\section{Contents}

Abstract........................................................................................................................ if

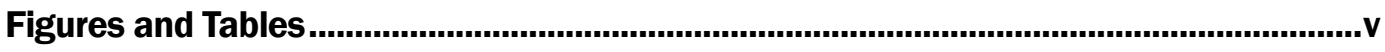

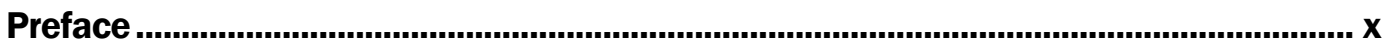

Acronyms and Abbreviations................................................................................................ xi

Unit Conversion Factors........................................................................................... xiii

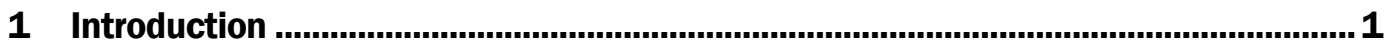

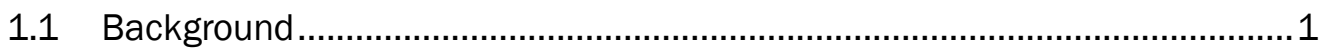

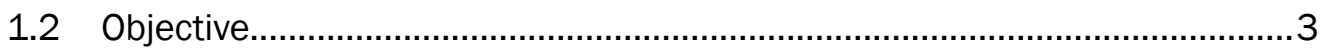

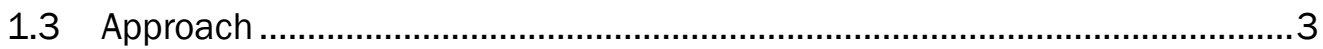

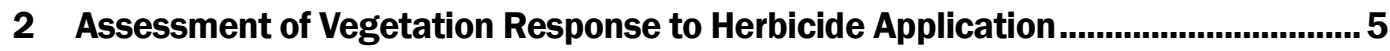

2.1 Vegetation distribution at Fort Hood ............................................................ 5

2.2 Vegetation assessment objective ............................................................. 6

2.3 Vegetation assessment methods .......................................................... 6

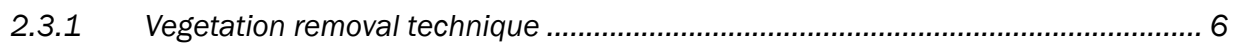

2.3.2 Vegetation assessment approach..................................................................10

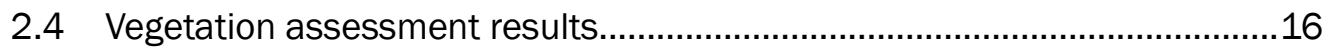

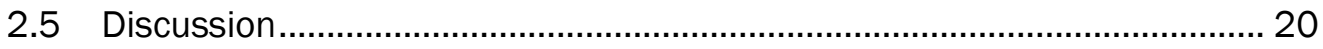

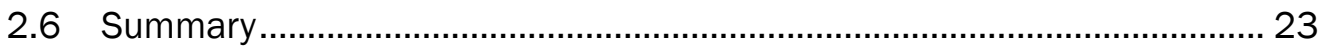

\section{Field Assessment of Soil and Water Resources Following Herbicide}

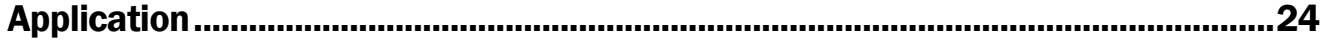

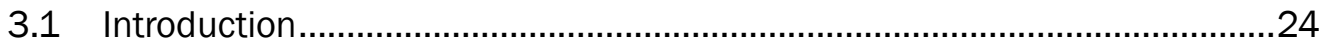

3.2 Purpose of the field assessment of soil and water resources...................... 25

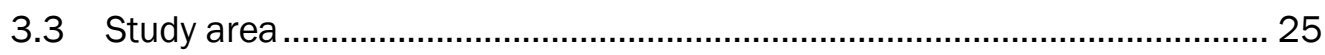

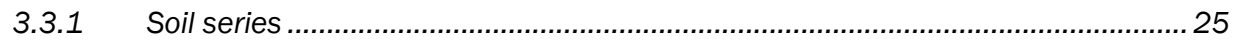

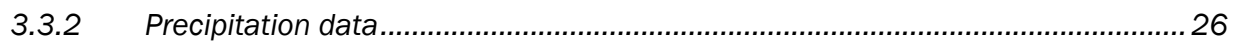

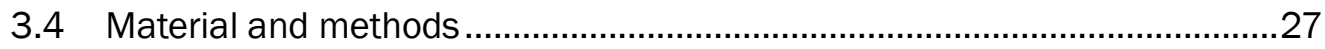

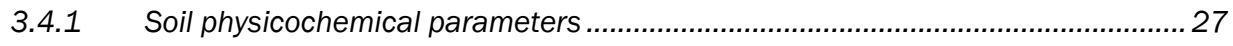

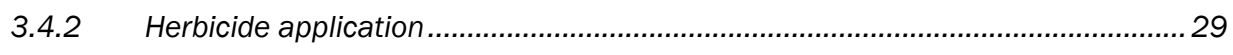

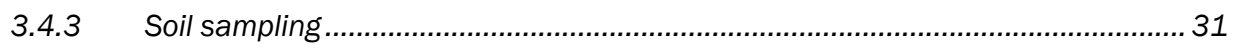

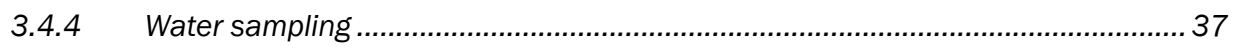

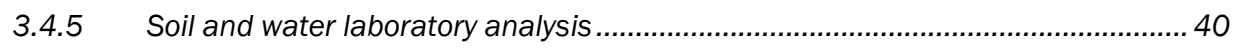

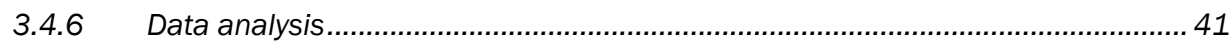

3.5 Results.....................................................................................41

3.5.1 Soil physicochemical parameters .................................................................... 41

3.5.2 Herbicide concentration in soil ........................................................................... 43

3.5.3 Herbicide concentration reduction over time ....................................................... 44

3.5.4 Herbicide concentration within each soil series .................................................. 45

3.5.5 Treatment effect on herbicide concentrations in soils ........................................... 51 


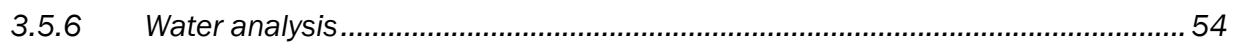

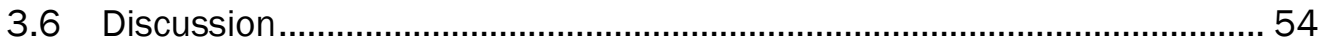

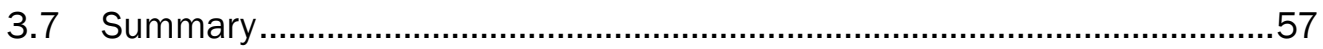

4 Laboratory Investigation of Herbicide Soil Affinity and Degradation ....................58

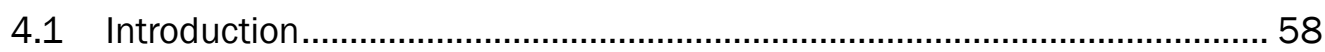

4.2 Objective of laboratory soil affinity and degradation studies .....................60 60

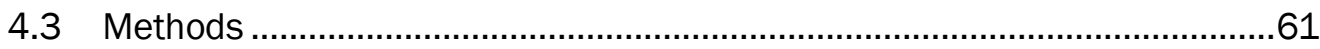

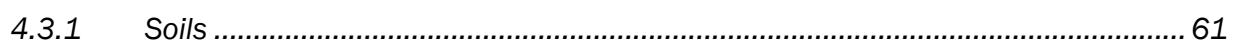

4.3.2 Soil affinity, concentration effects, and desorption ............................................ 61

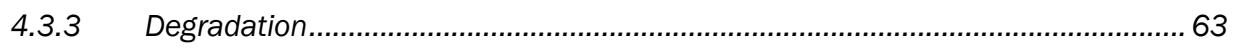

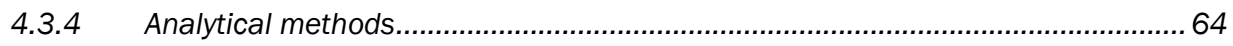

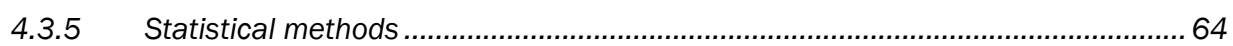

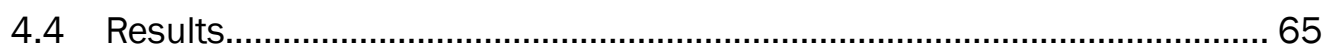

4.4.1 Soil affinity, concentration effects and desorption ..............................................65

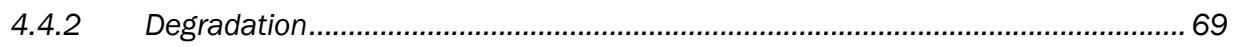

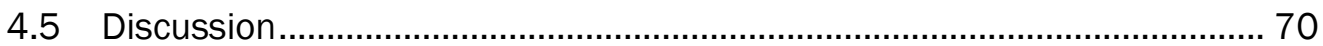

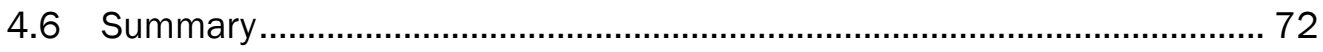

5 Column Experiments to Assess Herbicide Mobility in Soils ................................... 74

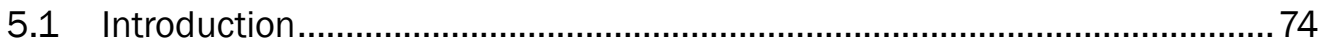

5.2 Objective of herbicide mobility column experiments ..................................74

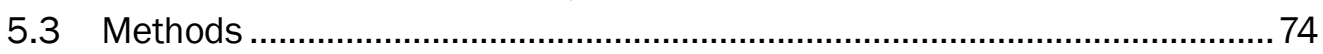

5.3.1 Saturated column studies .................................................................................. 74

5.3.2 Unsaturated column studies .............................................................................. 77

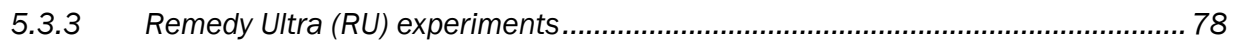

5.4 Column experiment results ............................................................. 79

5.4.1 Saturated column leaching experiment results ................................................... 79

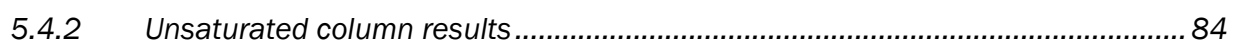

5.4.3 Column soils herbicide concentration results ......................................................... 85

5.4.4 Soil $\mathrm{pH}$ and electrical conductivity results........................................................... 91

5.4.5 Remedy Ultra solution experiment results ........................................................ 92

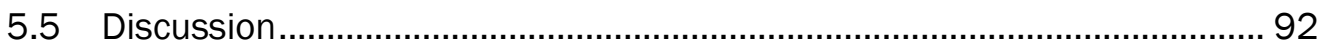

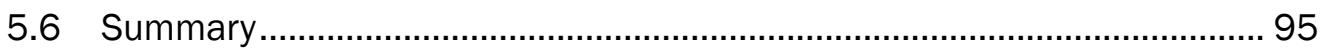

6 Data Synthesis and Management Recommendations ........................................96

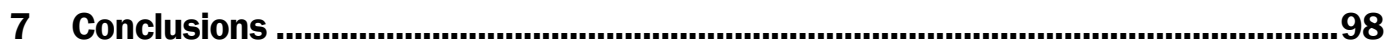

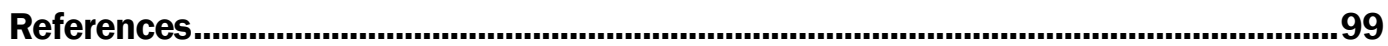

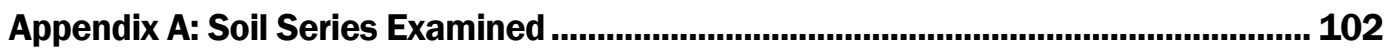

Appendix B: Soil Herbicide and Physicochemical Parameters...................................... 113

Appendix C: Herbicide Mobility Column Study Results............................................. 125

Report Documentation Page 


\section{Figures and Tables}

\section{Figures}

Figure 1. Map of Fort Hood Military Reservation located in central Texas showing Training Area boundaries.

Figure 2. Cattle grazing adjacent to roadway within Training Area 42 at Fort Hood, Texas.

Figure 3. Woody species encroachment into a grassland community.................................. 3

Figure 4. Grassland Community at Fort Hood, Texas. .......................................................... 5

Figure 5. Herbs, snow-on-the-prairie (Euphorbia bicolor) (left) and Leavenworth's eryngo (Eryngium leavenworthii) (right), in full display within a grassland community at Fort Hood, Texas.

Figure 6. Mechanical shearing of a cedar elm (UImus crassifolia Nutt.) sapling prior to herbicide application. Note: hand pruners were used to cut smaller-sized stems.

Figure 7. Herbicide containing a blue dye was applied to freshly sheared stumps of hardwood species. Note the drip lines of herbicide prior to and following individual treatment sprays as well as soil disturbances caused by mechanical removal techniques.

Figure 8 . The mechanical mulching head and machinery used to prepare site after vegetation cutting.

Figure 9. Representative photo of a portion of the study area following clearing, herbicide application, and mulching. Note that this location was populated by dense woody vegetation prior to clearing; trees larger than $12.7 \mathrm{~cm}$ DBH were not disturbed.

Figure 10. Location of treatment areas by soil series (Bosque, Cho, Nuff). Inset map highlights location of TA 42 in relation to other TA's on the installation.

Figure 11. Treatment area (control, RU-diesel, RU-MSO) boundaries for the Bosque site.

Figure 12. Treatment area (control, RU-diesel, RU-MSO) boundaries for the Cho and Nuff sites.

Figure 13. Location of trees for assessing resprouting behavior within the Bosque site.

Figure 14. Location of trees for assessing resprouting behavior within the Cho and Nuff site.

Figure 15. Resprouting of flame-leaf sumac approximately one year following treatment.

Figure 16. Resprouting behavior by species within the control, RU-diesel, and RUMSO treated areas (patterned display) as well as combined data for each species across all study areas (solid fill display).

Figure 17. Excessive disturbance with mulching head used for clearing. This level of disturbance excavated stems and roots prohibiting reassessment within the vegetation treatment areas. 
Figure 18. Frequency of species observed prior to and approximately one-year following mechanical clearing and herbicide application across all treatment and soil series.

Figure 19. Daily measured precipitation events at Stillhouse Hollow Dam (Bell County, TX) weather station for 2015 (upper) and 2016 (lower). The black line is the normal precipitation; dashed lines are $\pm 30 \%$.

Figure 20. Triclopyr-treated single cut stump in Bosque soil (22 September 2015).

Figure 21. Triclopyr-treated group of cut stumps in Bosque soil (22 September 2015).

Figure 22. Soil sampling locations in the Bosque soil. Center of plot is represented as X; soil sampling locations at identified cut stumps are represented as bull's eye.

Figure 23. Soil sampling locations in the Cho soil. Center of plot is represented as $X$; soil sampling locations at identified cut stumps are represented as bull's eye.

Figure 24. Soil sampling locations in the Nuff soil. Center of plot is represented as X; soil sampling locations at identified cut stumps are represented as bull's eye.

Figure 25. Example of soil sampling design for herbicide-treated stumps. Soil was sampled at $0 \mathrm{~cm}, 30.5 \mathrm{~cm}$, and $61 \mathrm{~cm}$ away from the edge of a treated stump.

Figure 26 . Soil was sampled $61 \mathrm{~cm}, 30.5 \mathrm{~cm}$, and $0 \mathrm{~cm}$ from an herbicidetreated stump.

Figure 27. Example of soil sampling design for cut stumps in the control treatment.

Figure 28. Example of water collection at Cowhouse Creek located next to Bosque soil.

Figure 29. Water collection locations to establish concentrations of herbicide and related compounds pre- and post- treatment at the Bosque site.

Figure 30. Water collection locations to establish concentrations of herbicide and related compounds pre- and post- treatment at the Cho and Nuff sites.

Figure 31. Mean ( \pm SE) concentration of triclopyr + TBEE (upper) and TCP (lower) across all soils by treatment and distance from the cut stump.

Figure 32. Mean ( \pm SE) concentration of triclopyr + TBEE in soils located adjacent to treated stumps $(0 \mathrm{~cm})$ by treatment in each soil series and across all soil series.

Figure 33. Mean $( \pm$ SE) concentration of triclopyr + TBEE in soils located $30.5 \mathrm{~cm}$ from treated stumps by treatment in each soil series and across all soil series.

Figure 34. Mean ( \pm SE) concentration of TCP in soils located $30.5 \mathrm{~cm}$ from treated stumps by treatment in each soil series and across all soil series.

Figure 35. Mean $( \pm$ SE) concentration of triclopyr + TBEE in soils located $61 \mathrm{~cm}$ from treated stumps by treatment in each soil series and across all soil series.

Figure 36. Mean ( \pm SE) concentration of TCP in soils located $61 \mathrm{~cm}$ from treated stumps by treatment in each soil series and across all soil series.

Figure 37. Mean concentration of triclopyr + TBEE $( \pm$ SE) by treatment, RU-diesel (left) RU-MSO (right) over time and distance $(\mathrm{cm})$ within each soil series 
Figure 38. Mean concentration of TCP ( \pm SE) by treatment RU-diesel (left), RUMSO (right) over time and distance $(\mathrm{cm})$ by soil series and over all soil series.

Figure 39. Daily measured precipitation events with soil sampling events (black arrows) at Stillhouse Hollow Dam (Bell County, TX) weather station for 2015. The black line is the normal precipitation and the dashed lines are $\pm 30 \%$.

Figure 40. Triclopyr butoxyethyl ester (TBEE) as found in Remedy Ultra (RU), the precursor to the active ingredient triclopyr and its degradation pathways in soil and water. Adapted from Ganapathy 1997.

Figure 41. The white suspension formed when mixing Remedy Ultra (RU) with water.

Figure 42. Triclopyr + TBEE affinity for each treatment within soil type. Capital letters represent significant differences and error bars are standard error. Control: Remedy Ultra (RU); RU-MSO: RU with Methylated Seed Oil; RU-diesel: RU with Diesel Fuel.

Figure 43. Triclopyr + TBEE affinity for each treatment across soil type. Capital letters represent significant differences and error bars are standard error. Control: Remedy UItra (RU); RU-MSO: RU with Methylated Seed Oil; RU-diesel: RU with Diesel Fuel.

Figure 44. The effect of concentration on affinity for each of the three treatments in Bosque soil. Capital letters represent significant differences and error bars are standard error. Control: Remedy Ultra (RU); RU-MSO: RU with Methylated Seed Oil; RU-diesel: RU with Diesel Fuel......

Figure 45. The effect of concentration on affinity across the three treatments. Capital letters represent significant differences and error bars are standard error. Control: Remedy Ultra (RU); RU-MSO: RU with Methylated Seed Oil; RU-diesel: RU with Diesel Fuel.

Figure 46. Freundlich isotherms for each treatment in the Bosque soil. Control: Remedy Ultra (RU); RU-MSO: RU with Methylated Seed Oil; RU-diesel: RU with Diesel Fuel.

Figure 47. Partitioning values for affinity and desorption in the Bosque soils. No values are provided for RU D as the amount that partitioned to the soil all desorbed. Control: Remedy Ultra (RU); RU-MSO: RU with Methylated Seed Oil; RUdiesel: RU with Diesel Fuel

Figure 48. Change in the total concentrations (sum of soil and water concentrations) of triclopyr normalized to the initial value for each of the treatments in Bosque, Nuff, and Cho soils. Error bars represent standard error. 72

Figure 49. Packed chromatography column..................................................................75

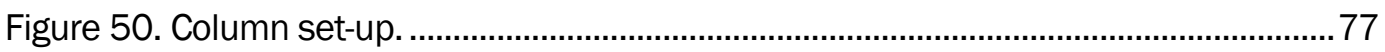

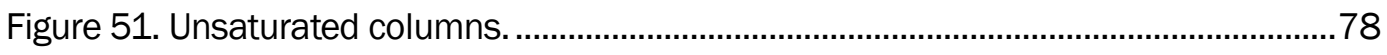

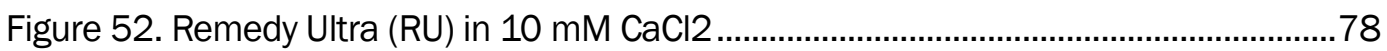

Figure 53. Column leaching results for the Bosque soil with RU-MSO treatment. $\mathrm{C} / \mathrm{C}_{0}$ is the concentration of analyte measured in the leachate solution (C) divided by the initial spiking concentration $\left(\mathrm{C}_{0}\right)$ and is unitless. Pore volumes are expressed as the volume of leachate collected $(\mathrm{V})$ divided by the maximum pore volume in the column $\left(\mathrm{V}_{0}\right)$ and is unitless.

Figure 54. Column leaching results for the Bosque soil with RU-diesel treatment. $\mathrm{C} / \mathrm{C}_{0}$ is the concentration of analyte measured in the leachate solution (C) 
divided by the initial spiking concentration $\left(\mathrm{C}_{0}\right)$ and is unitless. Pore volumes are expressed as the volume of leachate collected $(\mathrm{V})$ divided by the maximum pore volume in the column $\left(V_{0}\right)$ and is unitless.

Figure 55. Column leaching results for the $75 \%$ Sand and $25 \%$ Cho soil with RUMSO treatment. $\mathrm{C} / \mathrm{C}_{0}$ is the concentration of analyte measured in the leachate solution (C) divided by the initial spiking concentration ( $\left.\mathrm{C}_{0}\right)$ and is unitless. Pore volumes are expressed as the volume of leachate collected $(\mathrm{V})$ divided by the maximum pore volume in the column $\left(\mathrm{V}_{0}\right)$ and is unitless.

Figure 56. Column leaching results for the $75 \%$ Sand and $25 \%$ Cho soil with RUdiesel treatment. $\mathrm{C} / \mathrm{C}_{0}$ is the concentration of analyte measured in the leachate solution $(\mathrm{C})$ divided by the initial spiking concentration $\left(\mathrm{C}_{0}\right)$ and is unitless. Pore volumes are expressed as the volume of leachate collected $(\mathrm{V})$ divided by the maximum pore volume in the column $\left(\mathrm{V}_{0}\right)$ and is unitless.

Figure 57 . Column leaching results for the $75 \%$ Sand and $25 \%$ Nuff soil with RUMSO treatment. $\mathrm{C} / \mathrm{C}_{0}$ is the concentration of analyte measured in the leachate solution $(\mathrm{C})$ divided by the initial spiking concentration $\left(\mathrm{C}_{0}\right)$ and is unitless. Pore volumes are expressed as the volume of leachate collected $(\mathrm{V})$ divided by the maximum pore volume in the column $\left(\mathrm{V}_{0}\right)$ and is unitless.

Figure 58. Column leaching results for the $75 \%$ Sand and $25 \%$ Nuff soil with RUdiesel treatment. $\mathrm{C} / \mathrm{C}_{0}$ is the concentration of analyte measured in the leachate solution $(\mathrm{C})$ divided by the initial spiking concentration $\left(\mathrm{C}_{0}\right)$ and is unitless. Pore volumes are expressed as the volume of leachate collected $(\mathrm{V})$ divided by the maximum pore volume in the column $\left(\mathrm{V}_{0}\right)$ and is unitless.

Figure 59. Soil concentrations of triclopyr, TBEE, and TCP in Bosque column soils spiked with RU-MSO. Soils were sampled in one inch increments. Sample 1 is from the beginning of the column or the spiked triclopyr plug, while sample 7 is at the end of the column.

Figure 60. Soil concentrations of triclopyr and TBEE (upper) and TCP (lower)in Bosque column soils spiked with RU-diesel. Soils were sampled in one inch increments. Sample 1 is from the beginning of the column or the spiked triclopyr plug, while sample 7 is at the end of the column.

Figure 61. Soil concentrations of triclopyr and TBEE (upper) and TCP (lower) in Cho column soils spiked with RU-MSO. Soils were sampled in one inch increments. Sample 1 is from the beginning of the column or the spiked triclopyr plug, while sample 7 is at the end of the column.

Figure 62.Soil concentrations of triclopyr and TBEE (upper) and TCP (lower) in Cho column soils spiked with RU-diesel. Soils were sampled in one inch increments. Sample 1 is from the beginning of the column or the spiked triclopyr plug, while sample 7 is at the end of the column.

Figure 63. Soil concentrations of triclopyr and TBEE (upper) and TCP (lower) in Nuff column soils spiked with RU-MSO. Soils were sampled in one inch increments. Sample 1 is from the beginning of the column or the spiked triclopyr plug, while sample 7 is at the end of the column. Pyridinol was not seen in the soil in these treatments.

Figure 64. Soil concentrations of triclopyr and TBEE (upper) and TCP (lower) in Nuff column soils spiked with RU-diesel. Soils were sampled in one inch increments. Sample 1 is from the beginning of the column or the spiked triclopyr plug, while sample 7 is at the end of the column. 


\section{Tables}

Table 1. Area (ha) of each soil series and treatment examined during the vegetation assessment.

Table 2. List of species evaluated across the Bosque, Cho, and Nuff study areas.

Table 3. Average diameter and height by species, in order by frequency observed, measured within the BOSQUE site prior to vegetation clearing.

Table 4. Average diameter and height by species, in order by frequency observed, measured within the Cho site prior to vegetation clearing.

Table 5. Average diameter and height by species, in order by frequency observed, measured within the Nuff site prior to vegetation clearing.

Table 6. Individual trees evaluated and resprout rate within each treatment.

Table 7. Date of woody vegetation management activities for each soil series and treatment in 2015.

Table 8. Number of soil samples collected for each sampling date.

Table 9. Number of water samples collected for each sampling date.

Table 10. Physicochemical properties of each soil series (mean $\pm \mathrm{SE}$ ). All measurements were completed in triplicate except for moisture measurements. CEC, cation exchange capacity; POM, particulate organic matter; TC, total carbon; TIC, total inorganic carbon; TOC, total organic carbon; $\mathrm{KCl}$, potassium chloride; $\mathrm{CaCl}_{2}$ calcium chloride; EC, electrical conductivity; FC, soil moisture at Field Capacity; PWP, soil moisture at permanent wilting point.

Table 11. Number of samples containing triclopyr + TBEE or TCP in each soil series, treatment, and distance from treated stump (cm). TBEE, triclopyr-2butoxy-ethylester; TCP, 3,5,6-Trichloro-2-pyridinol.

Table 12. Average percent reduction of triclopyr + TBEE over the seven month study period. TBEE, triclopyr 2-butoxyethyl ester.

Table 13. Soil treatments used during the sorption, desorption and degradation microcosm studies. The RU-MSO and RU-diesel treatments with wetting agents were mixed at a 75:25 ratio.

Table 14. First order rate constants ( $k$ ) and half-life values for the three treatment across all soil types. Bosque and Nuff soils were tested over 30 days, while Cho was tested for 60 days. RU-control: Remedy Ultra (RU); RU-MSO: RU with Methylated Seed Oil; RU-diesel: RU with Diesel Fuel 70

Table 15. Percent herbicide species in the separation experiment. 92

Table 16. Concentration of triclopyr compounds in pure Remedy Ultra (RU). 


\section{Preface}

This study was conducted for the U.S. Army Garrison - Fort Hood. The technical monitor was Mr. Timothy Buchanan, Chief, Natural and Cultural Resources, Directorate of Public Works (DPW,) Environmental, Fort Hood, Texas.

The work was performed by the Wetlands and Coastal Ecology Branch (EE-W) of the Ecological Engineering Division (EE), and the Environmental Processes Branch (EP-P) of the Environmental Processes Division (EP), U.S. Army Engineer Research and Development Center, Environmental Laboratory (ERDC-EL). At the time of publication, Ms. Patricia Tolley was Chief, CEERD-EE-W and Mr. Mark Farr was Chief, CEERD-EE; Dr. Brandon Lafferty was Chief, CEERD-EP-P; Mr. Warren Lorentz was Chief, CEERD-EP; and Dr. Elizabeth Ferguson was the Technical Director for Environmental Quality and Installations (CEERDEM-J). The Deputy Director of ERDC-EL was Dr. Jack Davis and the Director was Dr. Beth Fleming.

Mr. Kevin Philley, Dr. Jacob Jung, Mr. Darrell Evans, Mr. Jason Pietroski, Ms. Carra Carrillo, Mr. John Newton, Mr. Casey Ehorn and staff members from U.S. Army Garrison - Fort Hood provided logistical support during the project. Mr. Kevin Philley and Dr. Jacob Jung provided a technical review of the report.

The Commander of ERDC was COL Bryan S. Green and the Director was Dr. David W. Pittman. 


\section{Acronyms and Abbreviations}

\begin{tabular}{|c|c|}
\hline $\mathrm{CaCl} 2$ & Calcium chloride \\
\hline CEC & Cation exchange capacity \\
\hline $\mathrm{CI}$ & Contract Inspector \\
\hline COR & Contracting Officer Representative \\
\hline DAREM & Direct antecedent rainfall evaluation method \\
\hline $\mathrm{DBH}$ & Diameter at breast height \\
\hline EC & Electrical conductivity \\
\hline $\mathrm{FC}$ & Field capacity \\
\hline HBCT & Heavy Brigade Combat Team \\
\hline $\mathrm{KCl}$ & Potassium chloride \\
\hline MSO & Methylated seed oil \\
\hline OECD & Organization for Economic Cooperation and Development \\
\hline POM & Particulate organic matter \\
\hline PWP & Permanent wilting point \\
\hline RU & Remedy Ultra \\
\hline SPE & Solid phase extraction \\
\hline TADDS & Training Aides Devices Simulators and Systems \\
\hline $\mathrm{TC}$ & Total carbon \\
\hline TCP & 3,5,6-trichloro-2-pyridinol \\
\hline
\end{tabular}


TBEE Triclopyr 2-butoxyethyl ester

TIC Total inorganic carbon

TOC Total organic carbon 


\section{Unit Conversion Factors}

\begin{tabular}{|c|c|c|}
\hline Multiply & By & To Obtain \\
\hline acres & $4,046.873$ & square meters \\
\hline degrees Fahrenheit & $(\mathrm{F}-32) / 1.8$ & degrees Celsius \\
\hline feet & 0.3048 & meters \\
\hline hectares & $1.0 \mathrm{E}+04$ & square meters \\
\hline inches & 0.0254 & meters \\
\hline miles (U.S. statute) & $1,609.347$ & meters \\
\hline square feet & 0.09290304 & square meters \\
\hline
\end{tabular}




\section{Introduction}

\subsection{Background}

The Fort Hood Military Reservation (hereafter Fort Hood), located in Bell and Coryell counties of central Texas, encompasses 86,994 ha (Figure 1). Fort Hood remains the largest active-duty armored post in the United States Armed Forces and is the only installation capable of stationing and training two Armored Divisions. The installation provides support to a diverse community of over 297,000 soldiers, family members and retirees (Fort Hood Fact Sheet No. 0703). Fort Hood was originally established as Camp Hood in 1942 to prepare soldiers for tank destroyer combat during World War II. In 1951, the Camp was renamed to Fort Hood, and made a permanent Army installation. Today, Fort Hood serves as one of the Army's premier installations to train and deploy heavy forces (Fort Hood Fact Sheet No. 0702).

Figure 1. Map of Fort Hood Military Reservation located in central Texas showing Training Area boundaries.

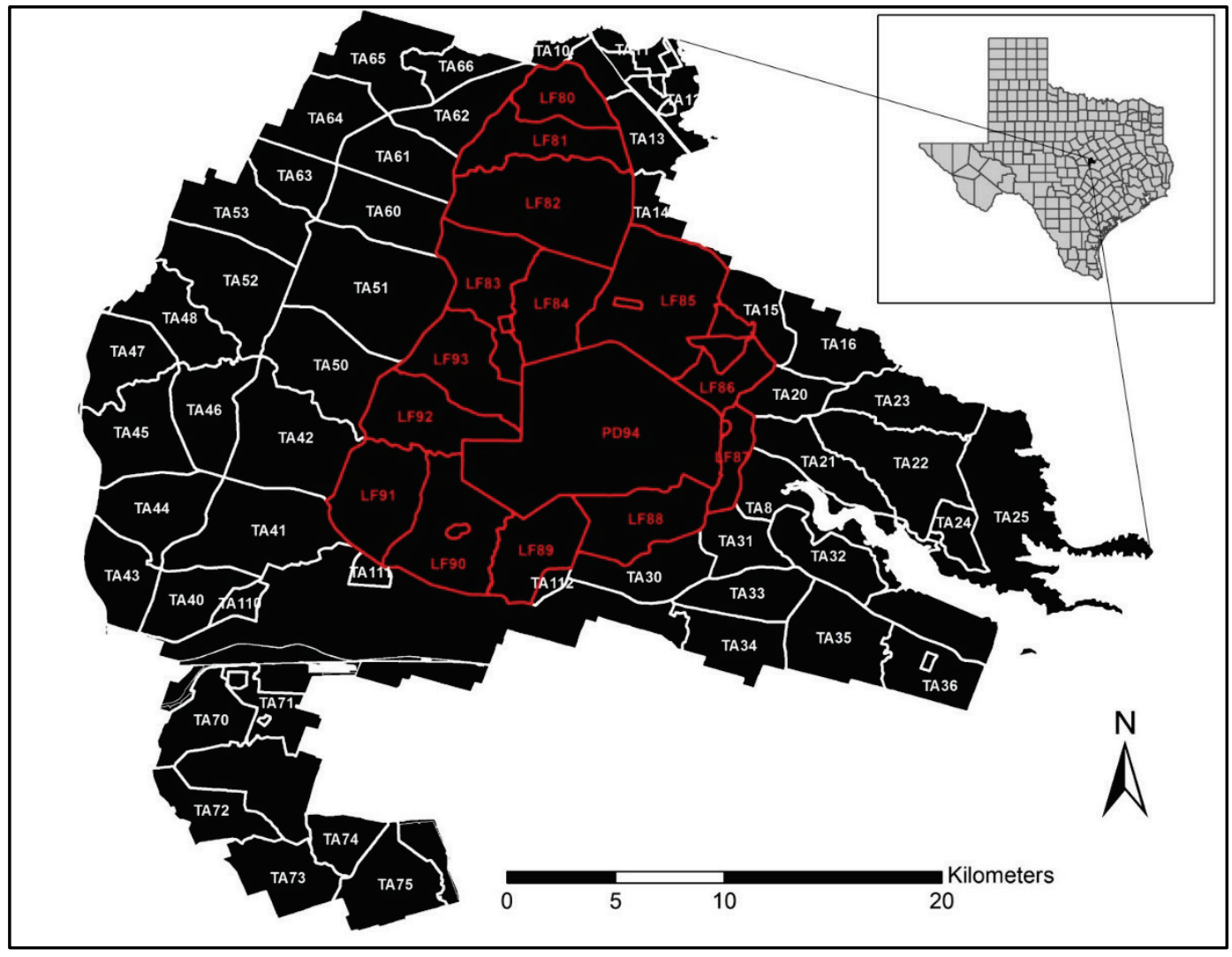


With an expanse of rolling, semi-arid terrain, Fort Hood is ideal for multifaceted training and testing of military units and individuals (Fort Hood Fact Sheet No. 0703). Additional land uses include the Belton Lake Recreation Area, roadways, easements, and cattle grazing (INRMP 2013). Cattle grazing is permitted on Fort Hood via a lease agreement with the Central Texas Cattlemen's Association which requires the lessee not to impact endangered species, historical, archaeological, architectural, or other cultural features and to maintain compliance with local, state, and federal water pollution regulations (Figure 2).

Figure 2. Cattle grazing adjacent to roadway within Training Area 42 at Fort Hood, Texas.

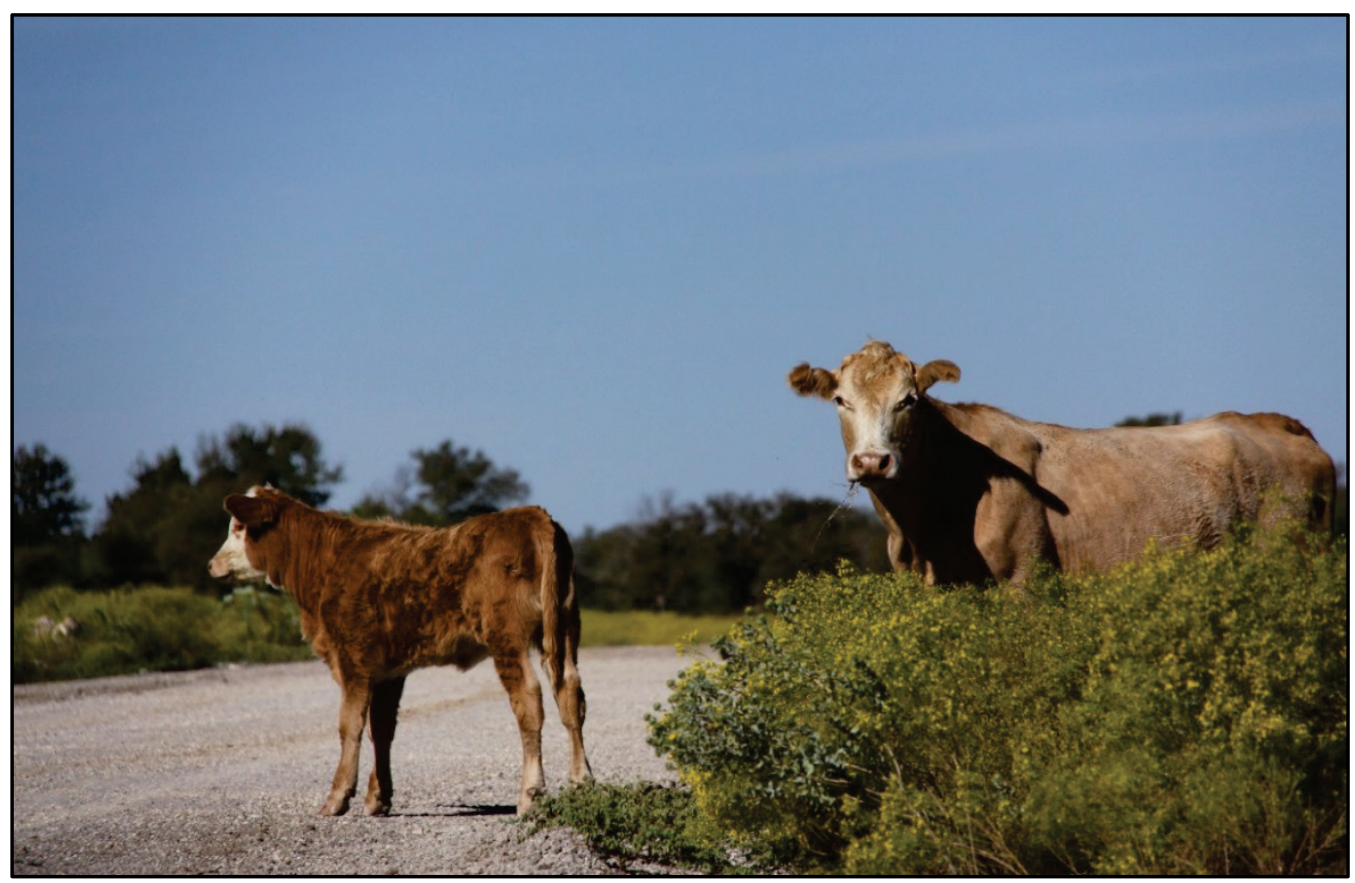

The wide variety of training activities (e.g., maneuver exercises, live weapons firing, and aviation training) requires the maintenance of specific environments to support the installations mission. Grassland communities occupy approximately 28,00o ha of the Fort Hood installation. As open environments, grassland and herbaceous communities play an important role in Fort Hood's training activities. Additionally, grassland communities are preferred by cattlemen for livestock grazing. As a result, chemical and mechanical woody vegetation removal practices are implemented to create and maintain open landscapes. Without vegetation management, forest and woodland communities rapidly expand into grassland communities, impacting training activities. Fire suppression and continuous grazing by livestock can further exacerbate encroachment of wood vegetation into grasslands (Figure 3) (INRMP 2013). 
Figure 3. Woody species encroachment into a grassland community.

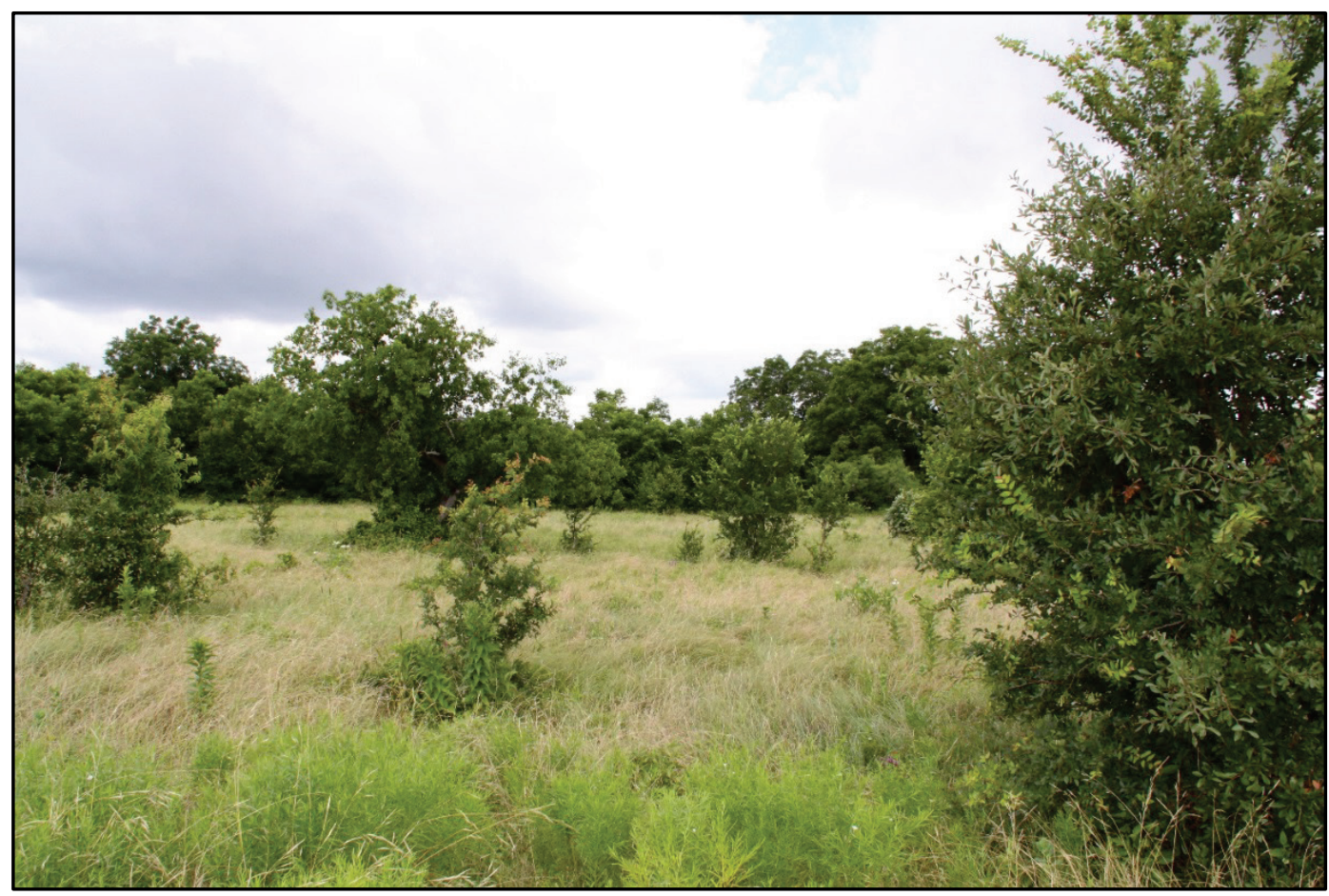

\subsection{Objective}

The current report assesses vegetation and soil conditions prior to and following Remedy Ultra (RU) herbicide applications designed to control woody vegetation to maintain open grassland environments in support of training objectives and range management within Fort Hood. Remedy Ultra controls woody vegetation by inducing uncontrolled growth leading to vegetation damage and death. Field and laboratory studies document herbicide effectiveness and examine potential fate and transport of herbicides and related compounds within the environment.

\subsection{Approach}

The following sections examine the outcomes of herbicide application through an integrated combination of field and laboratory studies. Vegetation was assessed at Fort Hood to determine the herbicide application success on vegetation growth (i.e., resprout rate) and identify the most effective herbicide treatment. Field sampling monitored the concentration of herbicide and associated compounds in soil and water over time, evaluating the fate and potential transport to offsite resources. Laboratory studies further investigate herbicide fate and transport. Specifically, the affinity of the herbicide treatments to bind with soil 
particles provides insight into potential transport; if herbicides are strongly attracted to soil particles, potential transport is unlikely. Similarly, soil column studies further document the potential for herbicide to move through the environment. Both field efforts and laboratory studies were conducted using three soil types (Bosque, Nuff, and Cho) and three herbicide treatments including 1) stump cutting, no herbicide application (control treatment), 2) stump cutting with herbicide, RU-diesel added as surfactant (RU-diesel treatment), and 3) stump cutting with herbicide, methylated seed oil added as surfactant (RU-MSO treatment). 


\section{Assessment of Vegetation Response to Herbicide Application}

\subsection{Vegetation distribution at Fort Hood}

A vegetation mapping effort conducted in 2008 identified the following vegetative cover types and associated percentages: Forest (15\%), Woodland (34\%), Shrubland 8\%, Grassland (33\%), and Not-Vegetated (10\%) (INRMP 2013). Grasslands most commonly occur in areas where wildfires and other training activities (i.e., live fire activities) reduce the establishment and encroachment of woody vegetation (Figure 4) (INRMP 2013). Common grass species within the grassland community include: King Ranch bluestem (Bothriocloa ischaemum), little bluestem (Schizachyrium scoparium), hairy gramma (Bouteloua hirsuta), and sideoats grama (Bouteloua curtipendula); and in remnant patches of tallgrass prairie, also, yellow Indiangrass (Sorghastrum nutans), and big bluestem (Andropogon gerardii). Common forbs within the grassland community include: broomweeds (Amphiachyris spp.), ragweed (Ambrosia artemisiifolia), snow-on-the-prairie (Euphorbia bicolor), and Leavenworth's eryngo (Eryngium leavenworthii) (Figure 5).

Figure 4. Grassland Community at Fort Hood, Texas.

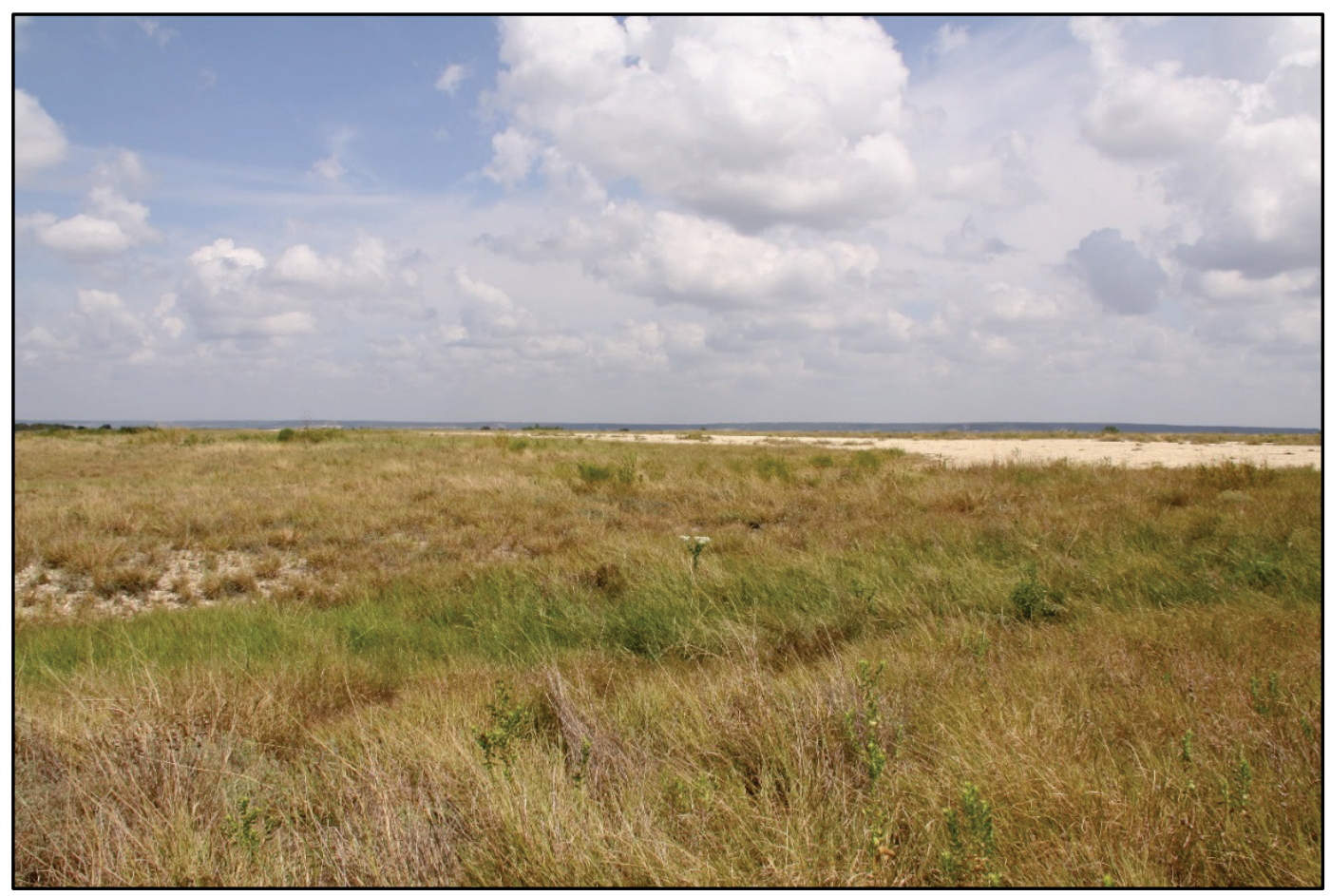


Figure 5. Herbs, snow-on-the-prairie (Euphorbia bicolor) (left) and Leavenworth's eryngo (Eryngium leavenworthii) (right), in full display within a grassland community at Fort Hood, Texas.

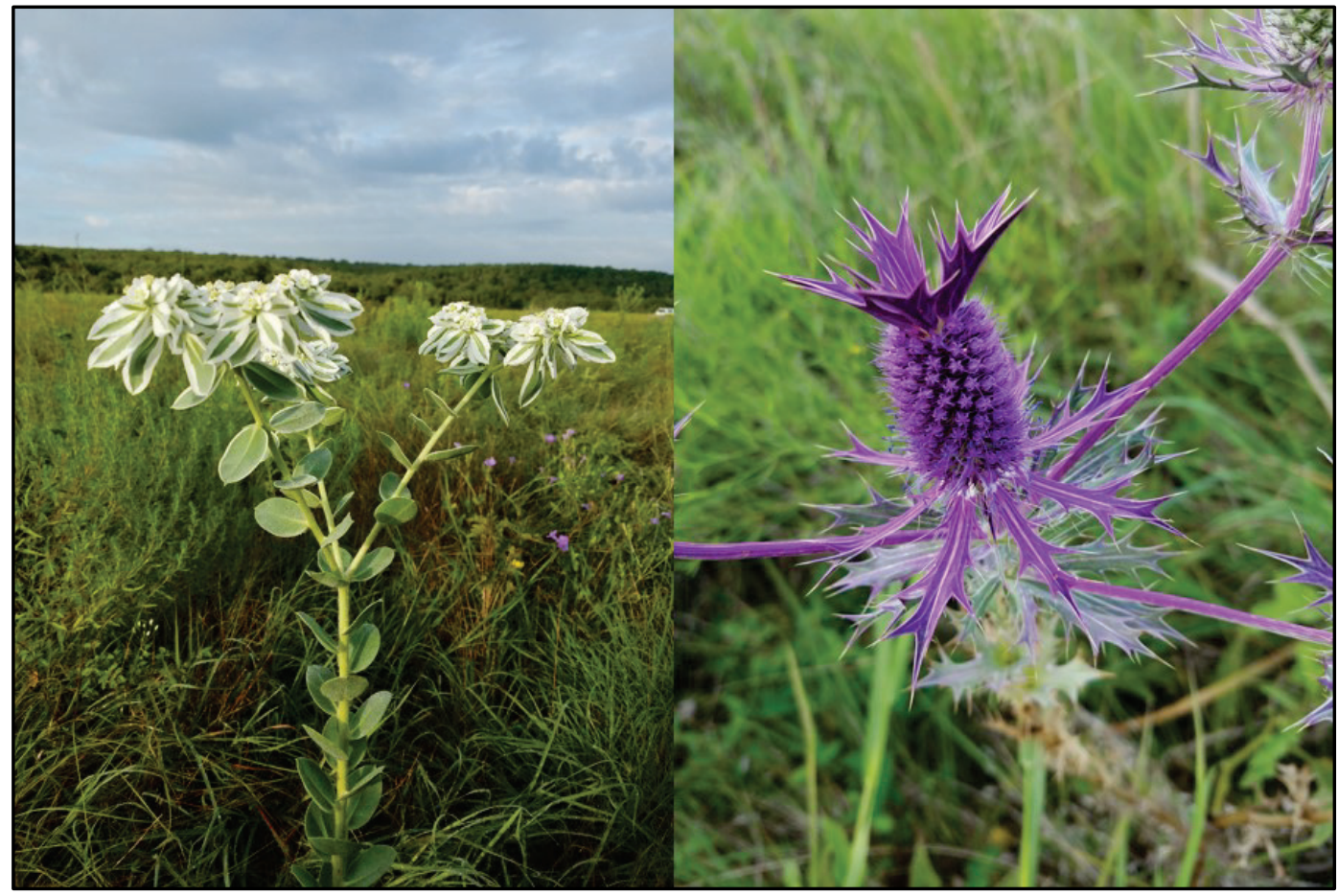

\subsection{Vegetation assessment objective}

Objectives of this study were to perform a vegetation assessment prior to and following a management activity where woody vegetation was removed. The evaluation included the effectiveness of herbicide application in reducing woody species resprouting following treatment. The goal of the assessment was to determine which herbicide application technique was most effective.

\subsection{Vegetation assessment methods}

\subsubsection{Vegetation removal technique}

To support Heavy Brigade Combat Team (HBCT) and Training Aids

Devices Simulators and Systems (TADDS) training, grassland maintenance/management actions were implemented from May-August 2015 within several training areas on Fort Hood. Contractors performed the management actions which included cutting hardwoods at ground level from all trees or shrubs $<12.7 \mathrm{~cm}$ diameter at breast height (DBH) (Figure 6). Additionally, a subset of the cut stumps were treated with the herbicide triclopyr (trade name Remedy Ultra) containing either MSO or 
diesel as a surfactant. A dye was added to all herbicide mixtures to determine areas treated and to prohibit repeat application to a cut stump within the study area (Figure 7). All Ashe's juniper (Juniperus ashei J. Buchholz) $<12.7 \mathrm{~cm}$ DBH were cut; however, no herbicide was applied to this species as it does not typically resprout after felling. All woody debris derived from cutting was mulched on-site to create an open environment supportive of re-establishment of grasses and forbs (Figure 8; Figure 9). All trees larger than $12.7 \mathrm{~cm} \mathrm{DBH}$ were not cut as they were considered established vegetation on each site.

The following protocol was applied by contractors responsible for implementing the management action:

Protocol A, Cut stump description:

All hardwood / mesquite $<12.7 \mathrm{~cm} \mathrm{DBH}$ within the designated work area were cut and sprayed according to the Cut Stump Treatment Section of the Remedy Ultra label. The cut surface of the stump was left smooth, parallel to the ground and did not exceed $5 \mathrm{~cm}$ in height above the surface of the ground. All cut wood and dead wood lying on the ground that was $<12.7$ $\mathrm{cm}$ in diameter was mulched. No pushing with blades, dozers or any equipment that creates intentional ground disturbance was allowed. Mulched pieces did not exceed $7.5-38 \mathrm{~cm}$ in length and width. At least $85 \%$ of the mulch was $5-38 \mathrm{~cm}$ in length and width. The material was spread over the landscape no thicker than a two inch layer except where it was used to slow soil erosion on banks and slopes. In this case, mulch did not exceed $15 \mathrm{~cm}$ in depth. This was at the direction of the Contract Inspector (CI) or the Contracting Officer Representative (COR). The herbicide mixture was applied within 10 minutes after cutting with a sprayer using low pressure and a solid cone or flat fan nozzle. The herbicide mixture was sprayed on the root collar area, sides of the stump, and the outer portion of the cut surface, including the cambium, until thoroughly wet, but not to the point of runoff. The herbicide mixture consisted of 25\% Remedy Ultra (EPA Reg. No. 62719-552) (no substitutions will be permitted), and 75\% surfactant (diesel fuel or methylated seed oil) with a dye. 
Protocol B, Juniper treatment description:

Contractors cut all Ashe's juniper plants $<12.7 \mathrm{~cm}$ DBH, including small seedlings within the designated work area. No herbicide was used on juniper. The cut surface of the stump was left smooth, parallel to the ground and did not exceed $5 \mathrm{~cm}$ in height above the surface of the ground. If there was a limb that was left on the stump it was removed. All cut juniper and dead wood lying on the ground that was $<12.7 \mathrm{~cm}$ in diameter was mulched. No pushing with blades, dozers or any equipment that created intentional ground disturbance was allowed. Mulched pieces did not exceed $7.5-38 \mathrm{~cm}$ in length and width and at least $85 \%$ of the mulch was $7.5^{-20} \mathrm{~cm}$ in length and width. The material was spread over the landscape no thicker than a $5 \mathrm{~cm}$ inch layer except where it was used to slow soil erosion on banks and slopes. In this case, mulch did not exceed $15 \mathrm{~cm}$ in depth. This was at the direction of CI or the COR. No posting of juniper was permitted.

Figure 6. Mechanical shearing of a cedar elm (UImus crassifolia Nutt.) sapling prior to herbicide application. Note: hand pruners were used to cut smaller-sized stems.

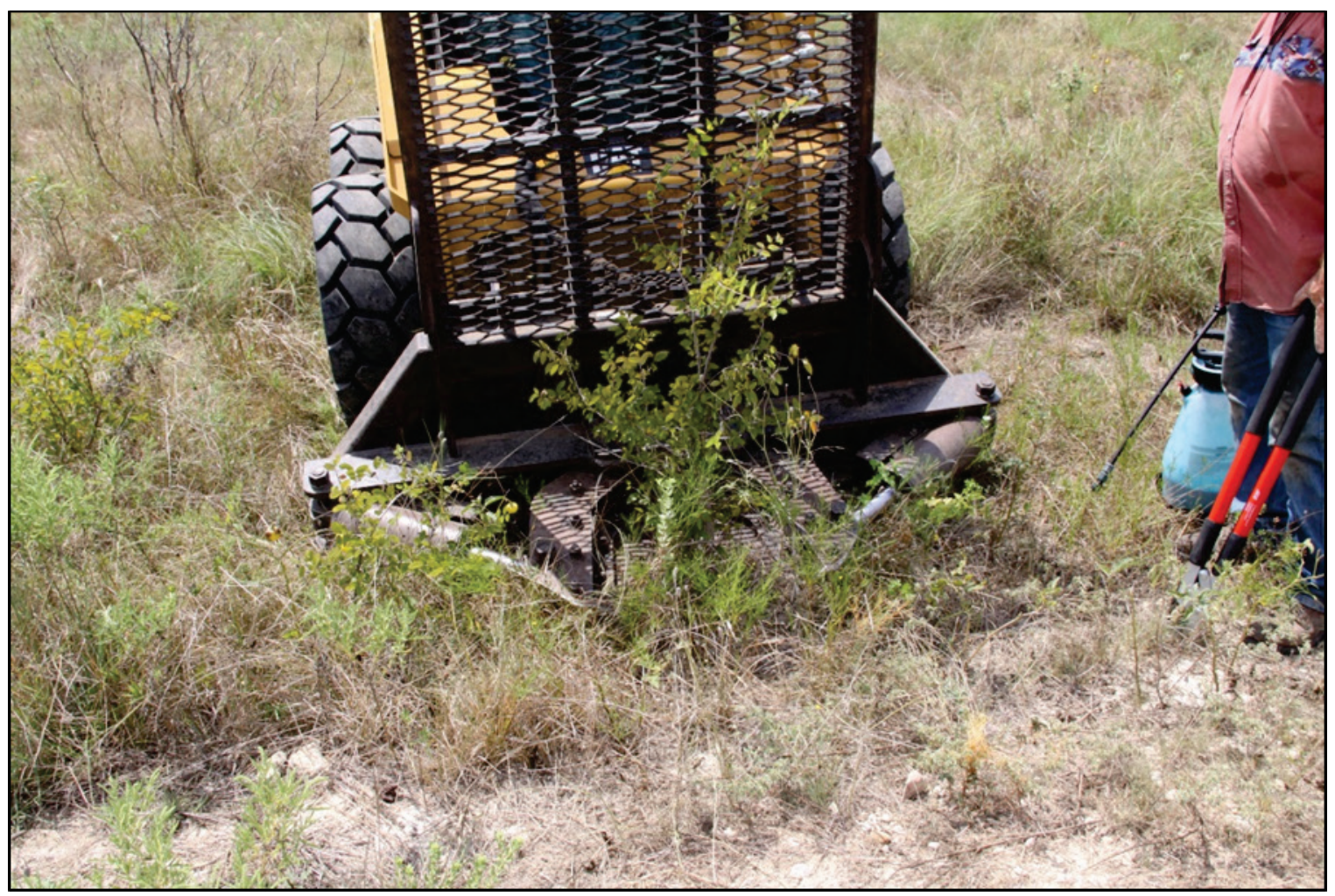


Figure 7. Herbicide containing a blue dye was applied to freshly sheared stumps of hardwood species. Note the drip lines of herbicide prior to and following individual treatment sprays as well as soil disturbances caused by mechanical removal techniques.

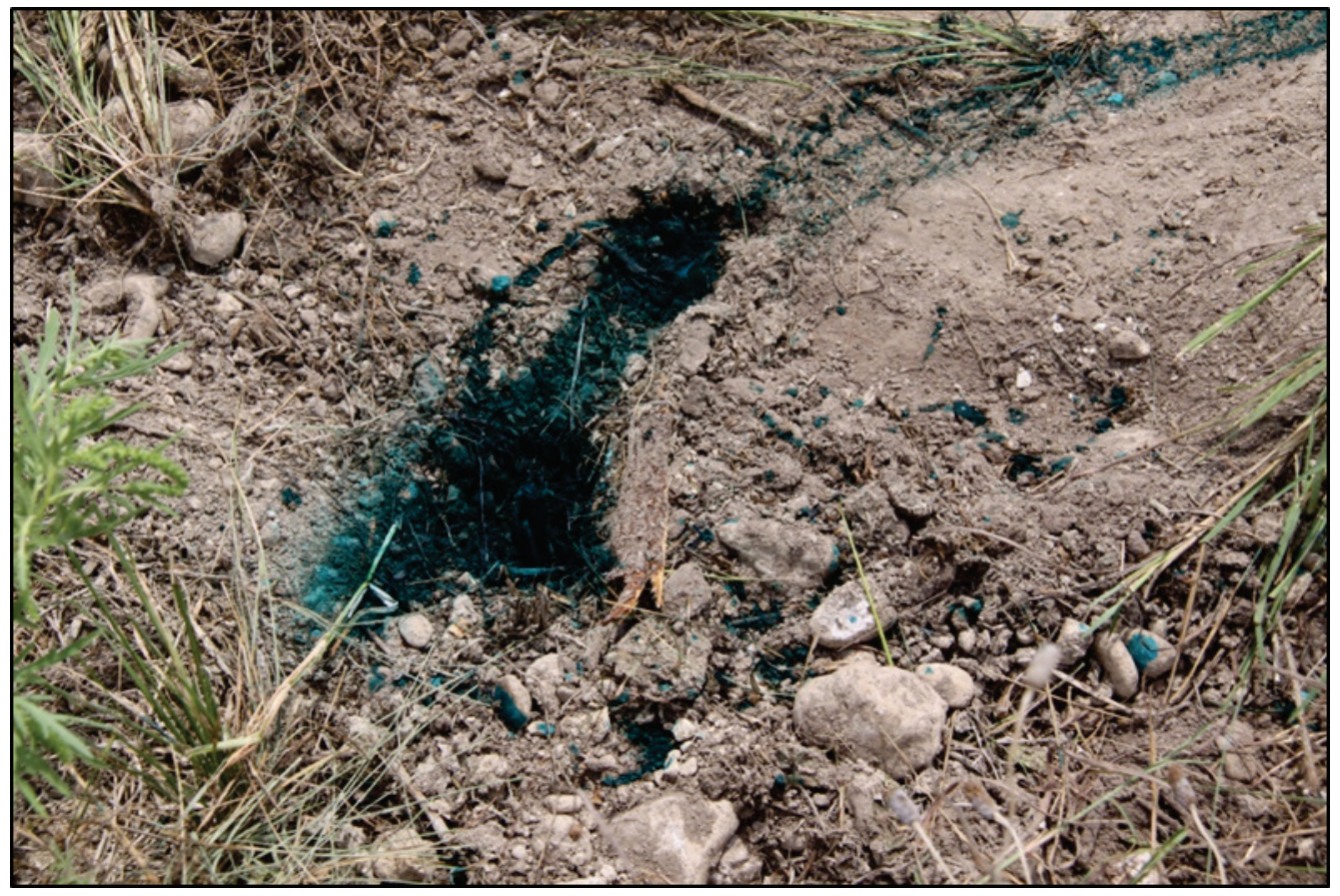

Figure 8. The mechanical mulching head and machinery used to prepare site after vegetation cutting.

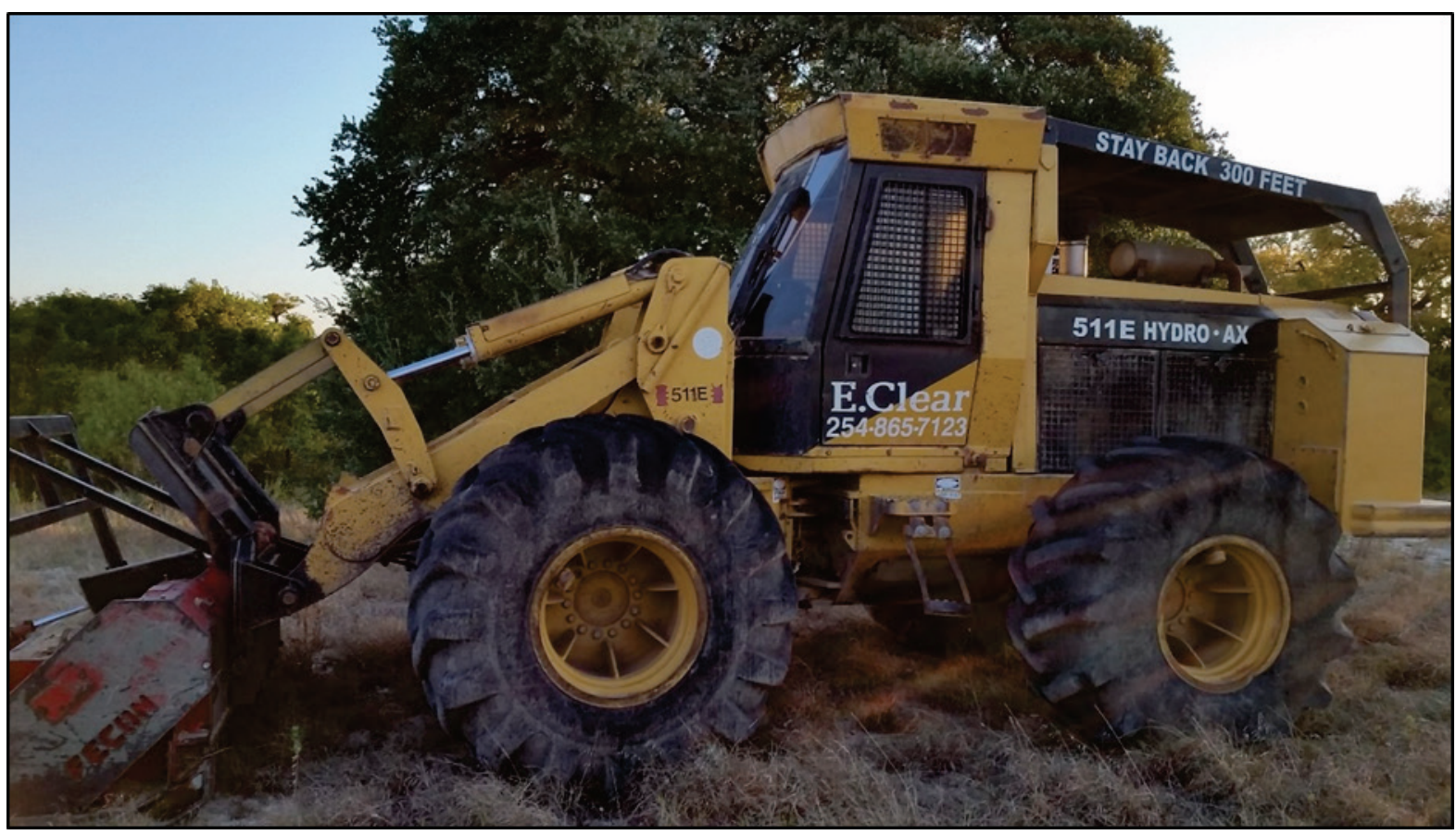


Figure 9. Representative photo of a portion of the study area following clearing, herbicide application, and mulching. Note that this location was populated by dense woody vegetation prior to clearing; trees larger than $12.7 \mathrm{~cm}$ DBH were not disturbed.

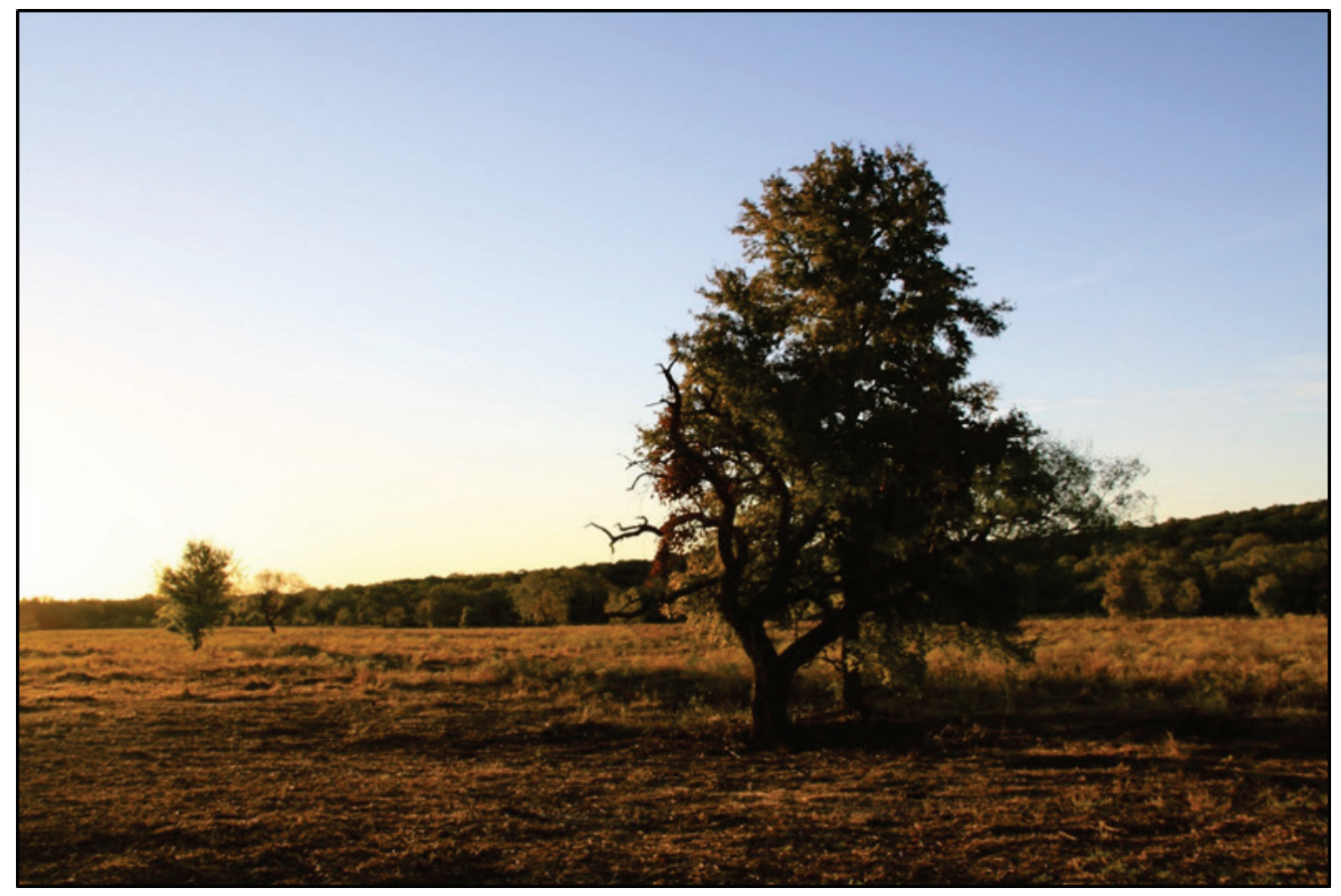

\subsubsection{Vegetation assessment approach}

Two pilot treatment areas were established to assess vegetation following herbicide application within selected areas of Training Area 42 (Figure 10). The Bosque study area was located on a floodplain and stream terrace landscape position adjacent to Cowhouse Creek (Figure 10; Figure 11). The second study area was located within a high-fenced parcel containing a gravel landing strip. Both Nuff and Cho soil series occurred within the fenced areas, occupying an alluvial terrace and interstream divide landscape positions. The Nuff soil series occurred more frequently within the fenced area (Figure 12). The total study area was 57.5 ha (Table 1).

Table 1. Area (ha) of each soil series and treatment examined during the vegetation assessment.

\begin{tabular}{|c|c|c|c|c|}
\hline Soil Series/Site & Control & RU-diesel & RU-MSO & Total \\
\hline Bosque & 7.71 & 7.01 & 7.10 & 21.82 \\
\hline Cho & 1.44 & 1.73 & 1.83 & 5.00 \\
\hline Nuff & 9.18 & 11.25 & 10.23 & 30.66 \\
\hline
\end{tabular}


Figure 10. Location of treatment areas by soil series (Bosque, Cho, Nuff). Inset map highlights location of TA 42 in relation to other TA's on the installation.

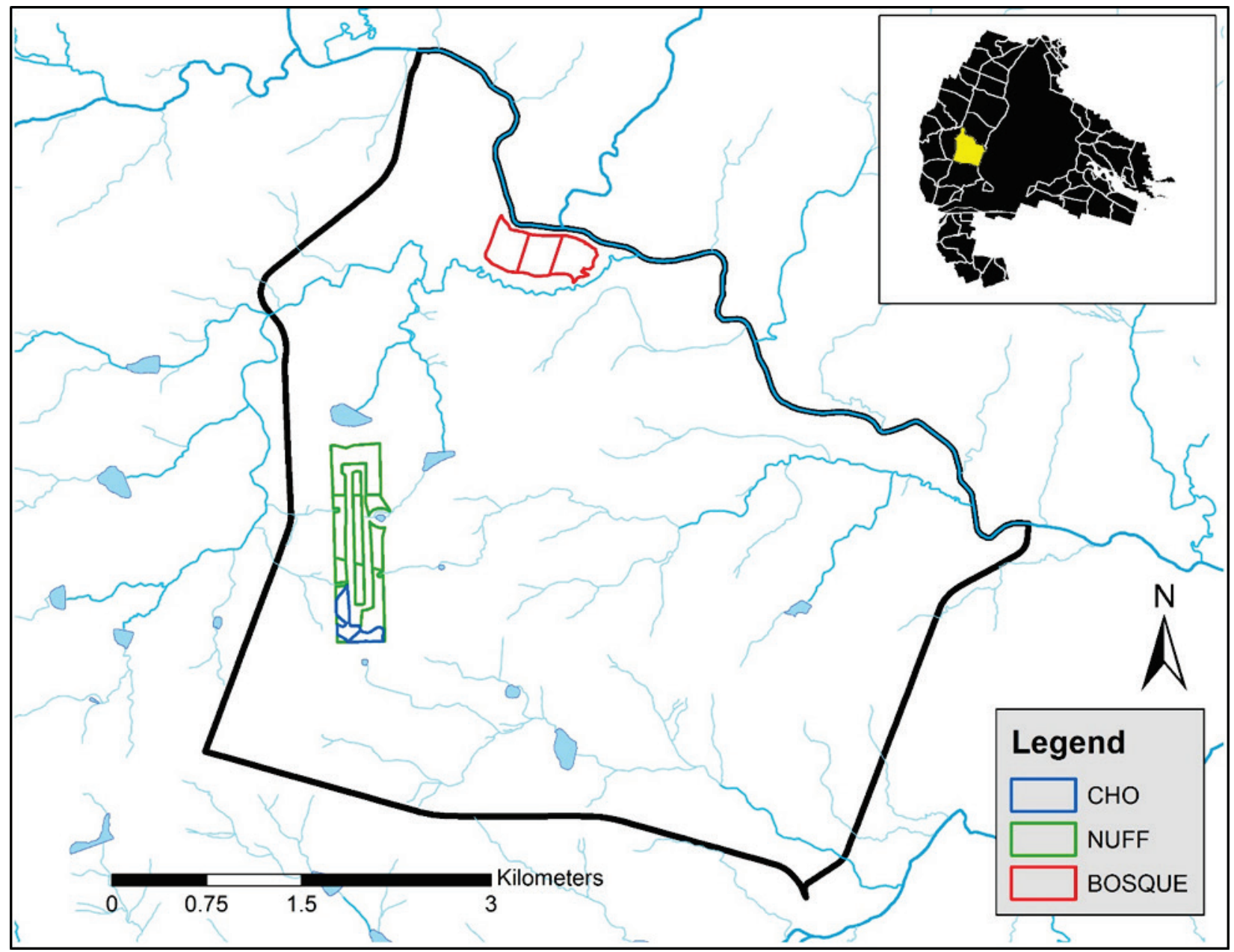


Figure 11. Treatment area (control, RU-diesel, RU-MSO) boundaries for the Bosque site.

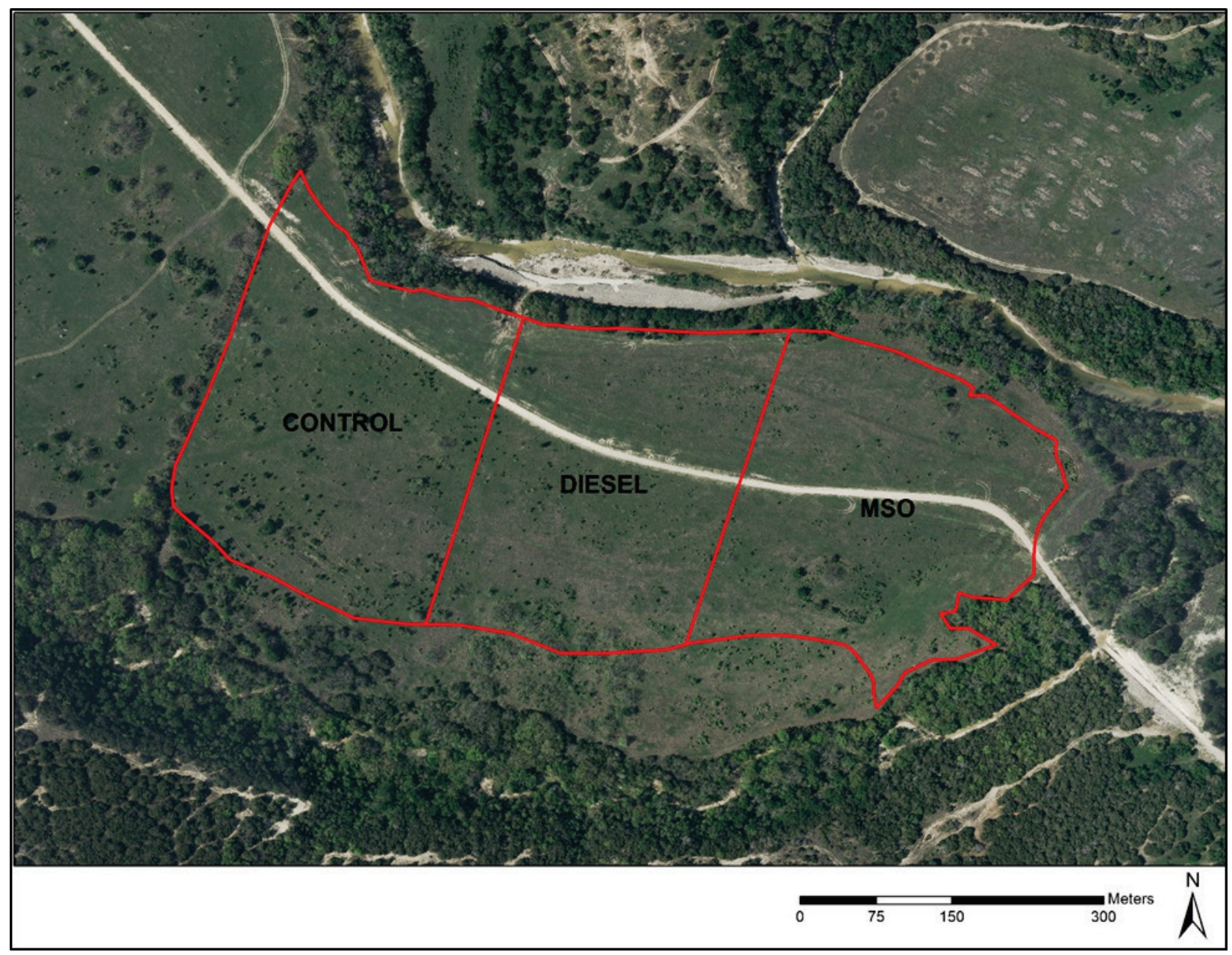


Figure 12. Treatment area (control, RU-diesel, RU-MSO) boundaries for the Cho and Nuff sites.

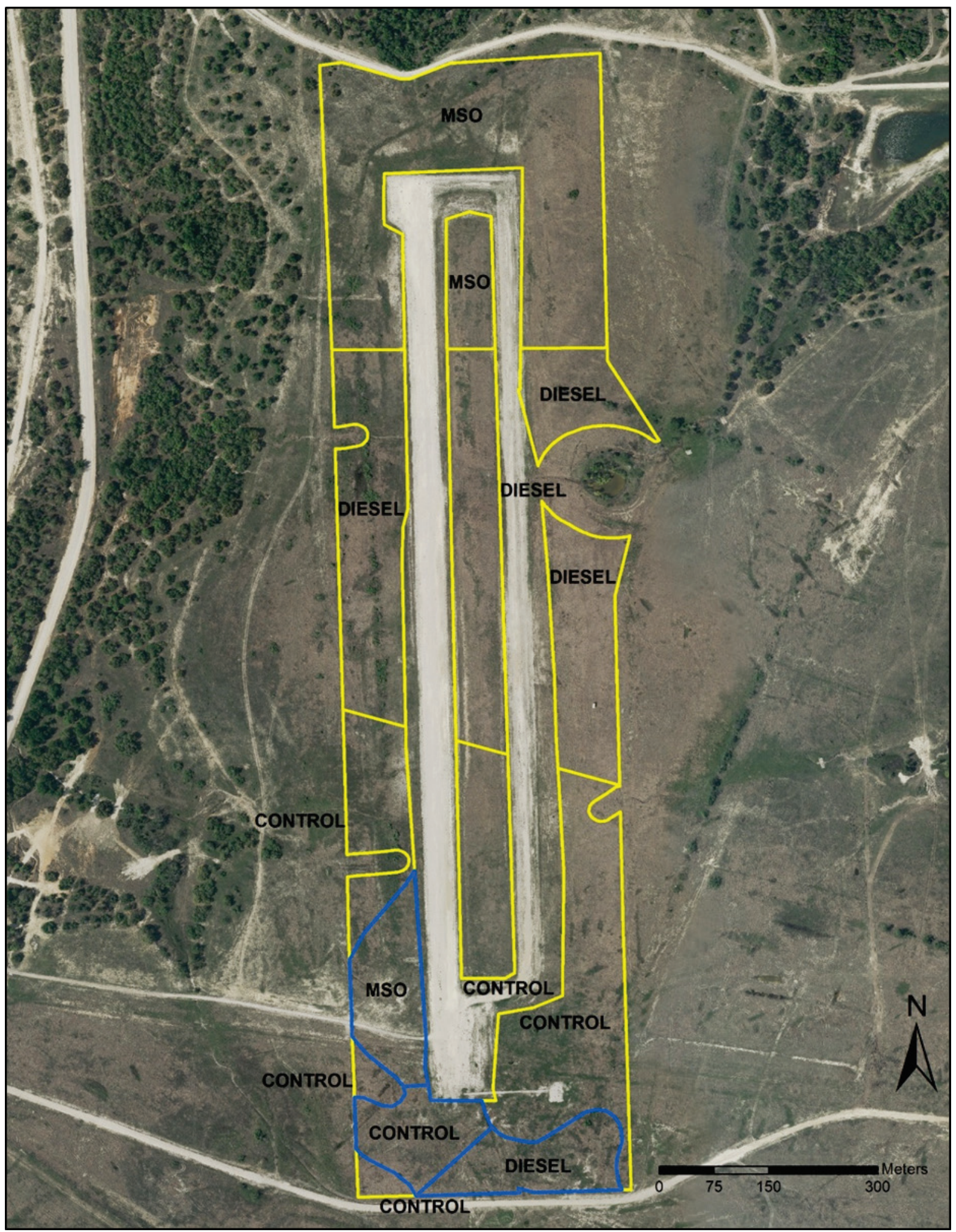


To perform the vegetation assessment, 5 replicate 0.2 ha fixed area sample plots were established. Vegetation data was collected within each treatment area prior to- and after cutting, and herbicide application occurred. Vegetation species composition, basal diameter, and total height were recorded within each plot. Collectively, 15 sample locations for each soil series (Bosque, Cho, Nuff; 45 sample locations total) were evaluated.

Additionally, 156 individual trees with $\mathrm{DBH}<12.7 \mathrm{~cm}$ were evaluated across all three sites and treatments (Figure 13; Figure 14). Each tree's geographic location was recorded and tallied by species, basal diameter and total height. Each tree was then revisited one year after cutting to assess resprout behavior.

Figure 13. Location of trees for assessing resprouting behavior within the Bosque site.

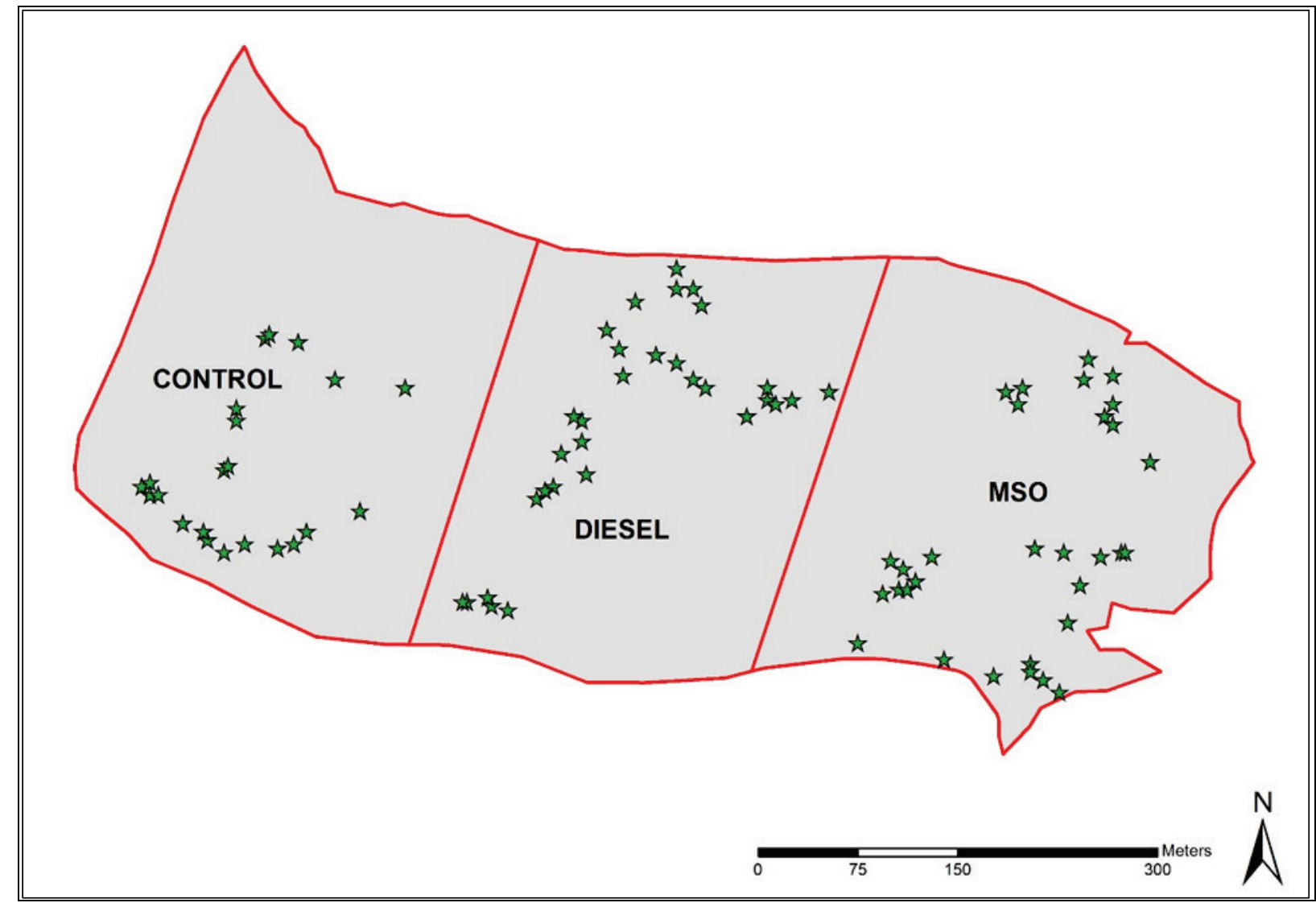


Figure 14. Location of trees for assessing resprouting behavior within the Cho and Nuff site.

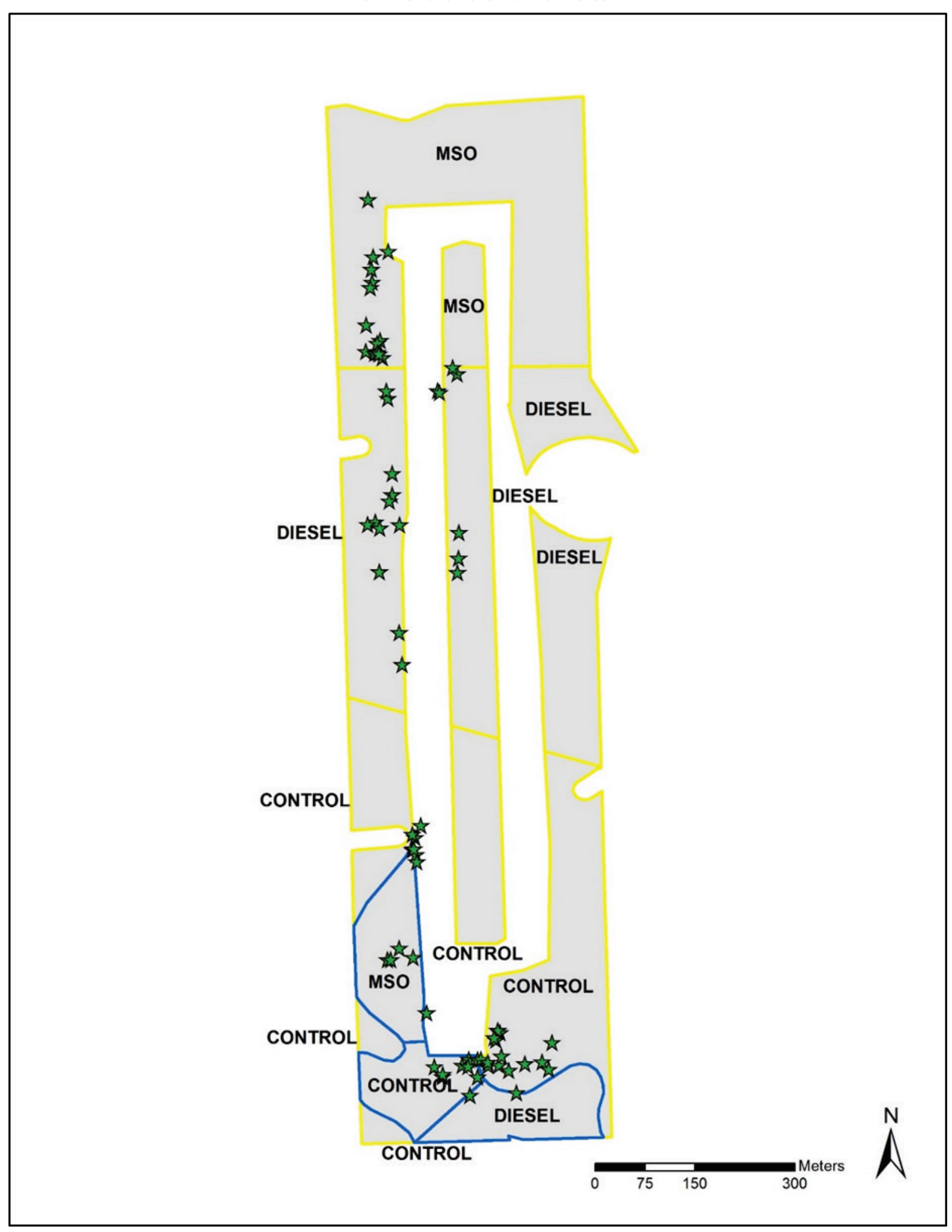




\subsection{Vegetation assessment results}

A total of 18 woody species were identified across the Bosque, Cho, and Nuff sites (Table 2). During the initial assessment, prior to any cutting, 1,071 woody plants were present across all three sites. The species most frequently encountered were gum bumelia (Sideroxylon lanuginosum Michx.) (37\%), cedar elm (Ulmus crassifolia Nutt.) (22\%), honey mesquite (Prosopis glandulosa Torr.) (13\%), flame-leaf sumac (Rhus lanceolata (A. Gray) Britton) (10\%), and sugarberry (Celtis laevigata Willd.) (9\%). All other species comprised $<5 \%$ of relative frequency. Average basal diameter for all stems measured was $2.57 \mathrm{~cm}(\mathrm{sd}=1.17 \mathrm{~cm})$, with an average height of $2.0 \mathrm{~m}(\mathrm{sd}=0.7 \mathrm{~m})$.

Table 2. List of species evaluated across the Bosque, Cho, and Nuff study areas.

\begin{tabular}{|c|c|c|}
\hline Common Name & Scientific Name & Family \\
\hline false indigo bush & Amorpha fruticosa L. & Fabaceae \\
\hline Rooseveltweed & Baccharis neglecta Britton & Asteraceae \\
\hline pecan & Carya illinoinensis (Wangenh.) K. Koch & Juglandaceae \\
\hline sugarberry & Celtis laevigata Willd. & Ulmaceae \\
\hline roughleaf dogwood & Cornus drummondii C.A. Mey. & Cornaceae \\
\hline elbow-bush & Forestiera pubescens Nutt. & Oleaceae \\
\hline Carolina buckthorn & Frangula caroliniana (Walter) A. Gray & Rhamnaceae \\
\hline possumhaw & Ilex decidua Walter & Aquifoliaceae \\
\hline Ashe's juniper & Juniperus ashei J. Buchholz & Cupressaceae \\
\hline honey mesquite & Prosopis glandulosa Torr. & Fabaceae \\
\hline Mexican plum & Prunus mexicana S. Watson & Rosaceae \\
\hline Texas live oak & Quercus fusiformis Small & Fagaceae \\
\hline post oak & Quercus stellata Wangenh. & Fagaceae \\
\hline flame-leaf sumac & Rhus lanceolata (A. Gray) Britton & Anacardiaceae \\
\hline skunkbush sumac & Rhus trilobata Nutt. & Anacardiaceae \\
\hline gum bumelia & Sideroxylon lanuginosum Michx. & Sapotaceae \\
\hline cedar elm & Ulmus crassifolia Nutt. & Ulmaceae \\
\hline Texas Hercules' club & Zanthoxylum hirsutum Buckley & Rutaceae \\
\hline
\end{tabular}

At the Bosque site, 545 trees were measured (Table 3). The most commonly encountered species were cedar elm, gum bumelia, sugarberry, pecan (Carya illinoinensis (Wangenh.) K. Koch), and honey mesquite, respectively. Cedar elm and gum bumelia comprised nearly $75 \%$ of the vegetation identified. Average diameter at the Bosque site was $3.02 \mathrm{~cm}$ $(\mathrm{sd}=1.47 \mathrm{~cm})$, with an average total height of $2.2 \mathrm{~m}(\mathrm{sd}=0.8 \mathrm{~m})$. 
Table 3. Average diameter and height by species, in order by frequency observed, measured within the BOSQUE site prior to vegetation clearing.

\begin{tabular}{|c|c|c|c|}
\hline Species & Count & Average Diameter $(\mathrm{cm})$ & Average Height $(\mathrm{m})$ \\
\hline cedar elm & 214 & 3.3 & 2.3 \\
\hline gum bumelia & 194 & 2.8 & 2.0 \\
\hline sugarberry & 46 & 3.6 & 3.0 \\
\hline pecan & 34 & 4.8 & 3.3 \\
\hline honey mesquite & 29 & 1.5 & 1.2 \\
\hline elbow-bush & 11 & 1.5 & 1.7 \\
\hline Ashe's juniper & 7 & 4.1 & 2.5 \\
\hline Mexican plum & 3 & 5.6 & 2.9 \\
\hline roughleaf dogwood & 2 & 1.3 & 1.4 \\
\hline post oak & 2 & 2.0 & 1.1 \\
\hline false indigo bush & 1 & 1.3 & 0.5 \\
\hline Carolina buckthorn & 1 & 1.3 & 1.8 \\
\hline Texas live oak & 1 & 1.3 & 1.7 \\
\hline
\end{tabular}

At the Cho site, 221 trees were measured (Table 4). The most commonly encountered species were gum bumelia, honey mesquite, flame-leaf sumac, sugarberry, and cedar elm, respectively. Approximately $75 \%$ of the vegetation measured at the Cho site was comprised of gum bumelia, honey mesquite, and flame-leaf sumac. Average diameter at the Cho site was $2.01 \mathrm{~cm}(\mathrm{sd}=0.64 \mathrm{~cm})$, with an average total height of $1.5 \mathrm{~m}(\mathrm{sd}=0.5 \mathrm{~m})$.

Table 4. Average diameter and height by species, in order by frequency observed, measured within the Cho site prior to vegetation clearing.

\begin{tabular}{|c|c|c|c|}
\hline Species & Count & Average Diameter (cm) & Average Height (m) \\
\hline gum bumelia & 71 & 2.5 & 1.6 \\
\hline honey mesquite & 54 & 2 & 1.3 \\
\hline flame-leaf sumac & 38 & 1.5 & 1.8 \\
\hline sugarberry & 25 & 1.8 & 1.5 \\
\hline cedar elm & 16 & 2.3 & 1.7 \\
\hline Texas Hercules' club & 8 & 1.3 & 0.6 \\
\hline Rooseveltweed & 6 & 1.3 & 1.7 \\
\hline false indigo bush & 2 & 1.3 & 0.5 \\
\hline Mexican plum & 1 & 3.3 & 2.1 \\
\hline
\end{tabular}


At the Nuff site, 305 individual trees were measured (Table 5). The most commonly encountered species were gum bumelia, flame-leaf sumac, honey mesquite, sugarberry, and Texas live oak, respectively. Gum bumelia, flame-leaf sumac, and honey mesquite comprised over $80 \%$ of the species encounter for this assessment. Average diameter at the Nuff site was $2.16 \mathrm{~cm}(\mathrm{sd}=0.86 \mathrm{~cm})$, with an average total height of $0.3 \mathrm{~m}$ $(\mathrm{sd}=0.1 \mathrm{~m})$.

Table 5. Average diameter and height by species, in order by frequency observed, measured within the Nuff site prior to vegetation clearing.

\begin{tabular}{|c|c|c|c|}
\hline Species & Count & Average Diameter $(\mathbf{c m})$ & Average Height $(\mathbf{m})$ \\
\hline gum bumelia & 130 & 2 & 1.8 \\
\hline flame-leaf sumac & 66 & 2.3 & 1.6 \\
\hline honey mesquite & 51 & 1.8 & 1.3 \\
\hline sugarberry & 21 & 2.3 & 2 \\
\hline Texas live oak & 12 & 4.3 & 3 \\
\hline false indigo bush & 11 & 2 & 1.6 \\
\hline elbow-bush & 7 & 1.3 & 1.8 \\
\hline Mexican plum & 2 & 2 & 1.6 \\
\hline skunkbush sumac & 2 & 1.3 & 1.9 \\
\hline Texas Hercules' club & 2 & 1.3 & 1.3 \\
\hline cedar elm & 1 & 1.3 & 1.1 \\
\hline
\end{tabular}

Individual trees $(\mathrm{n}=156)$ sampled across all sites and treatments to assess reprouting included 10 species. Each tree was reevaluated approximately one year after cutting to determine if resprouting had occurred (Figure 15). Fifty trees of the 156 evaluated displayed evidence of resprouting (6). The resprout percentages and number of resprouts by treatment across all three treatments were: control ( $45 \% ; n=26)$, RU-diesel $(37 \% ; n=16)$, and RU-MSO ( $15 \% ; n=8$ ) (Table 6). Collectively, $24 \%$ of trees within both herbicide treatments (i.e., RU-diesel and RU-MSO) resprouted compared to $45 \%$ for the control; an increase in resprout rate of $55 \%$ for untreated trees. 
Table 6. Individual trees evaluated and resprout rate within each treatment.

\begin{tabular}{|c|c|c|c|c|c|c|}
\hline $\begin{array}{c}\text { Species } \\
\text { observed }\end{array}$ & Count & $\begin{array}{c}\text { Resprout rate } \\
(\%)\end{array}$ & Count & $\begin{array}{c}\text { Resprout rate } \\
(\%)\end{array}$ & Count & $\begin{array}{c}\text { Resprout rate } \\
(\%)\end{array}$ \\
\hline Rooseveltweed & 1 & $100 \%$ & 0 & - & 3 & $33 \%$ \\
\hline $\begin{array}{c}\text { flame-leaf } \\
\text { sumac }\end{array}$ & 2 & $100 \%$ & 3 & $67 \%$ & 4 & $75 \%$ \\
\hline $\begin{array}{c}\text { honey } \\
\text { mesquite }\end{array}$ & 23 & $61 \%$ & 14 & $14 \%$ & 16 & $13 \%$ \\
\hline gum bumelia & 12 & $50 \%$ & 11 & $73 \%$ & 14 & $7 \%$ \\
\hline cedar elm & 9 & $33 \%$ & 5 & $60 \%$ & 7 & $14 \%$ \\
\hline pecan & 6 & $0 \%$ & 6 & $0 \%$ & 5 & $0 \%$ \\
\hline sugarberry & 4 & $0 \%$ & 4 & $25 \%$ & 0 & - \\
\hline Mexican plum & 1 & $0 \%$ & 0 & - & 2 & $0 \%$ \\
\hline Ashe's juniper & 0 & - & 0 & - & 3 & $0 \%$ \\
\hline Texas redbud & 0 & - & 0 & - & 1 & $0 \%$ \\
\hline Total & 58 & $45 \%$ & 43 & $37 \%$ & 55 & $15 \%$ \\
\hline
\end{tabular}

Figure 15. Resprouting of flame-leaf sumac approximately one year following treatment.

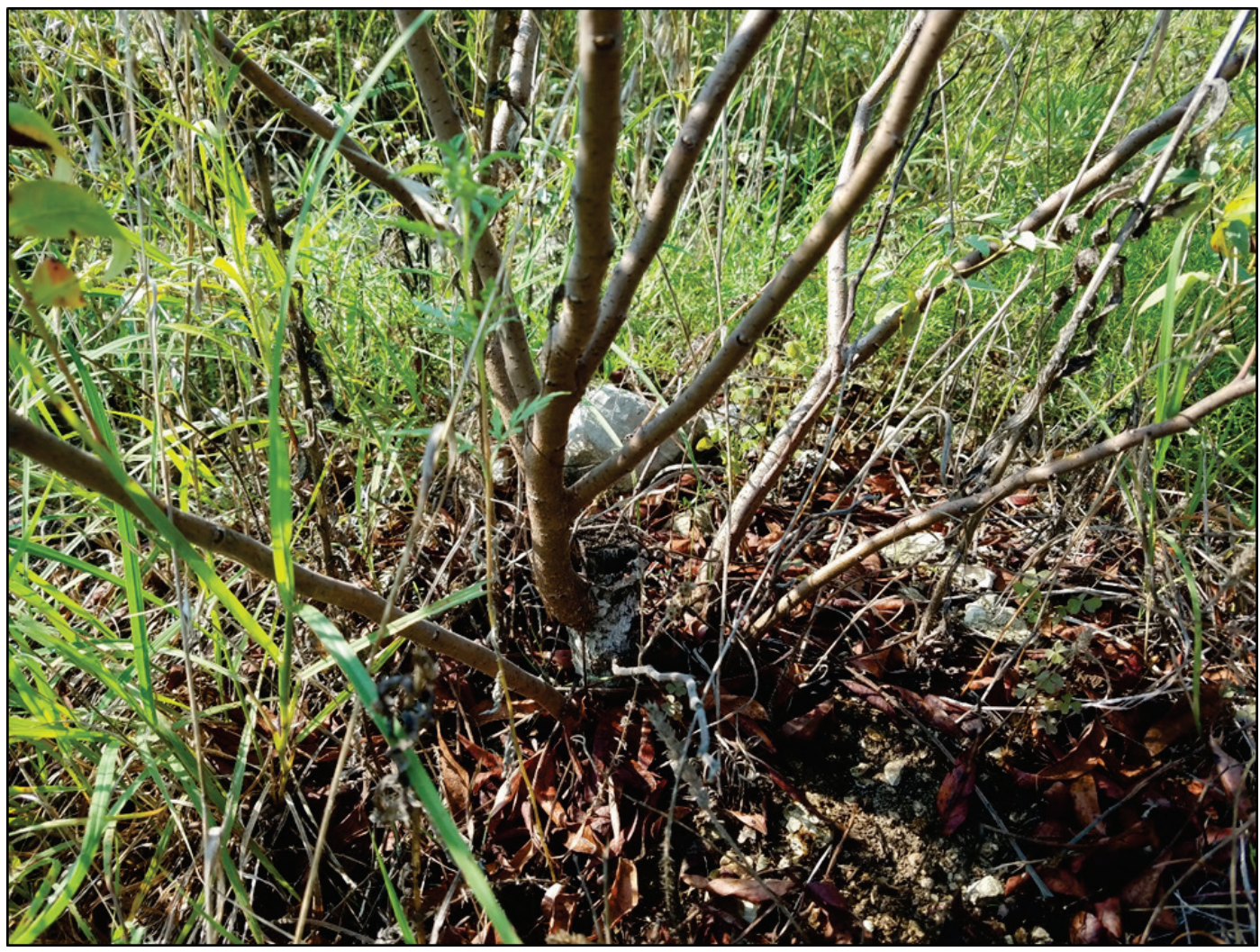


Figure 16. Resprouting behavior by species within the control, RU-diesel, and RU-MSO treated areas (patterned display) as well as combined data for each species across all study areas (solid fill display).

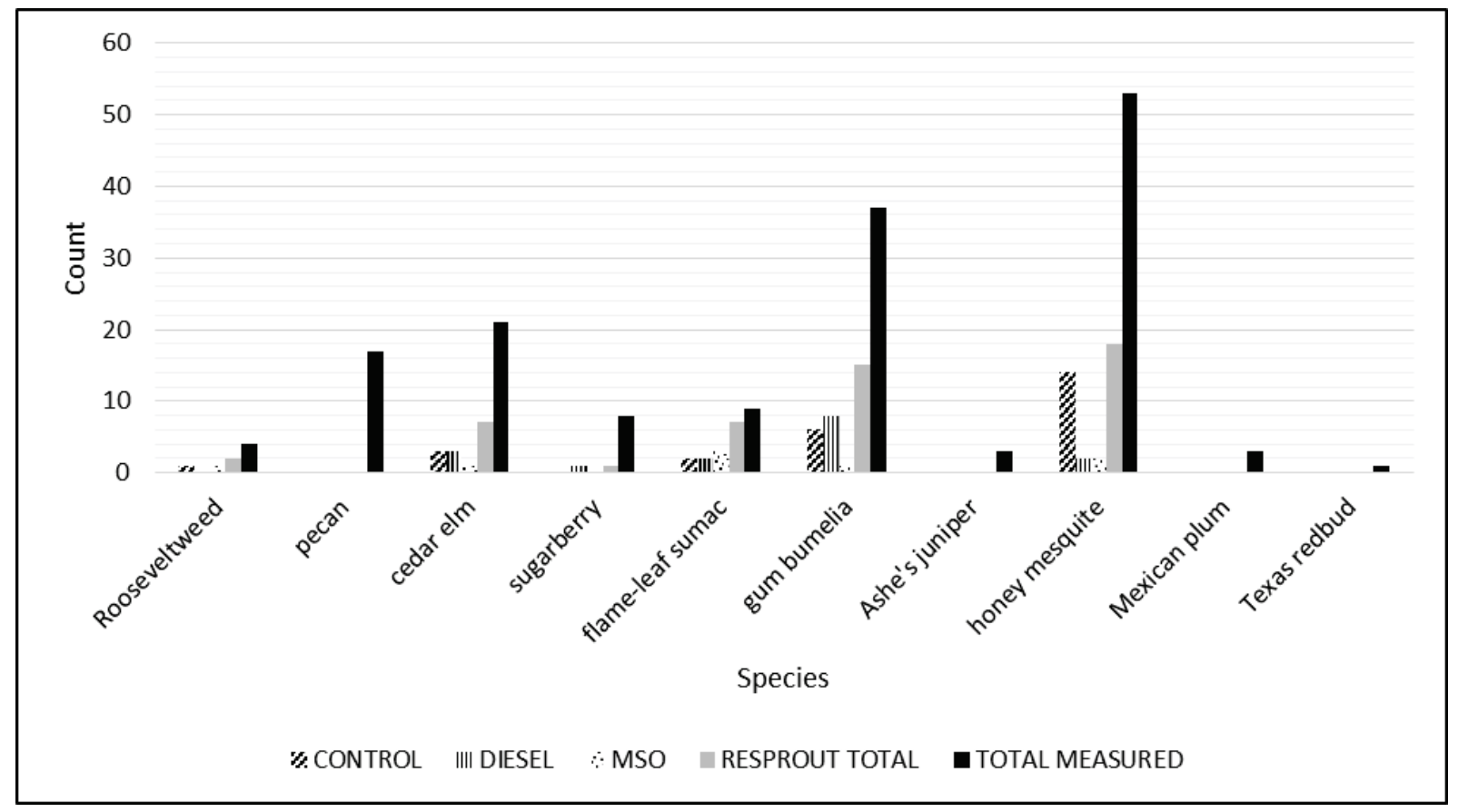

Statistical results evaluated significant differences between treatments. Results suggest significant differences occurred between treatments utilizing a 95\% confidence interval ( $\mathrm{p}$-value=0.03). When paired, control vs. RU-diesel displayed no significant difference ( $p$-value=0.44), suggesting that those treatments were equally effective at preventing resprout. Notably, the RU-MSO treatment significantly decreased resprouting compared with both the RU-diesel $(p$-value=0.01) and control (p-value $=0.0005)$ treatments.

\subsection{Discussion}

The vegetation assessment evaluated the success of using herbicide application in combination with mechanical clearing of vegetation. Overall, the data suggests that herbicide application with MSO was an effective technique to limit resprouting of aggressive hardwood species, promoting the use of cut-stump herbicide applications to decrease resprouting rates. The control sites displayed a 55\% higher resprout rates compared with study areas receiving herbicide application. Further, the RU-MSO treatment most successfully prevented resprout, providing the best management technique evaluated in the current study. Honey mesquite, which resprouts readily if untreated with herbicide, responded 
well to herbicide application. For example, the resprout rate for honey mesquite was $61 \%$ in the control treatment area compared to below $15 \%$ on areas undergoing herbicide application. Cedar elm, another prolific species within the study area, responded well under the RU-MSO treatment (14\% resprout rate), but performed poorly under RU-diesel treatments with approximately $60 \%$ of stumps resprouting.

Overall, the RU-MSO treatment outperformed RU-diesel and control treatments, displaying effectiveness on each of the soil series examined. For example, the RU-MSO treatment limited resprouting to $15 \%$ within the study area. Further, if Roosevelt weed and flame-leaf sumac are removed from the analysis, RU-MSO applications resprout rates decrease to less than $5 \%$. Based upon the assessment results, the RU-MSO is recommended for herbicide applications and should be incorporated into future grassland management activities utilizing cut stump treatments.

Several observations made during the collection of field data have the potential to impact treatment effectiveness and the outcomes of management activities. For example, woody vegetation removal resulted in excessive ground disturbance during vegetation cutting and mulching. Excessive ground disturbance, as shown in Figure 17, potentially decreases treatment effectiveness. Exposed bare ground creates ideal conditions for the establishment of early successional species (e.g., flame-leaf sumac). If mulching occurs immediately after cut stump treatment, herbicides may not have sufficient time for absorption into the stem. Also, treated stumps may be separated from the root systems, limiting herbicide effectiveness on species capable of resprouting from lateral roots. In addition to potential limitations associated with ground disturbance, staff members observed small trees that were not cut as described in the protocol above and several trees that were cut did not receive herbicide application within the RU-MSO and RU-diesel treatments based upon the lack of dye on the stump surface.

Based upon these observations, follow-up measurements within the 0.2 ha sample plots were not evaluated statistically. However, species composition within the study area did not significantly shift following clearing and herbicide application (Figure 18). However, an increased abundance of flame-leaf sumac was evident, supported by a $228 \%$ overall increase in occurrence. Additionally, several species including skunkbush displayed increased abundance following the clearing and herbicide application. 
Figure 17. Excessive disturbance with mulching head used for clearing. This level of disturbance excavated stems and roots prohibiting reassessment within the vegetation treatment areas.

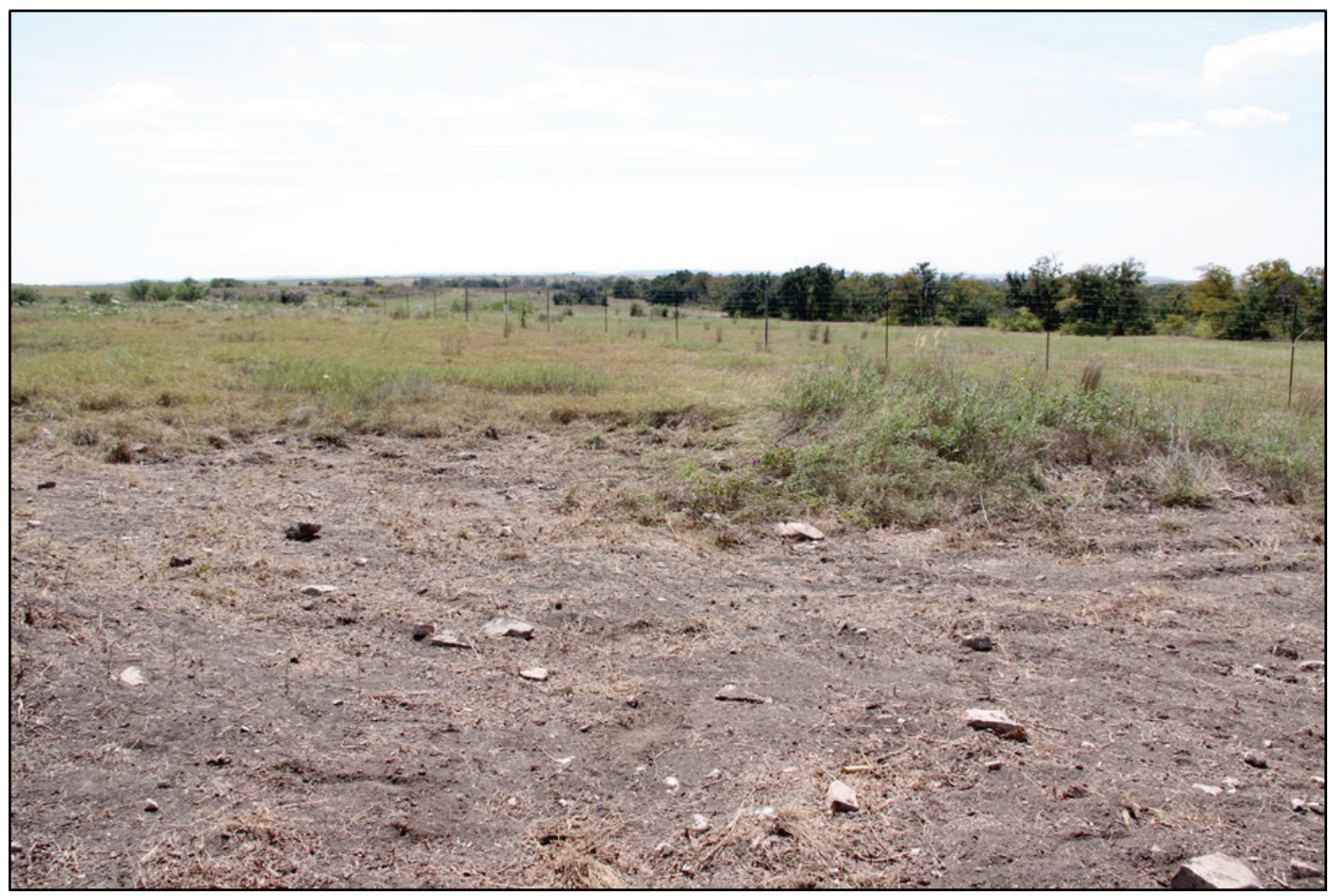

Figure 18. Frequency of species observed prior to and approximately one-year following mechanical clearing and herbicide application across all treatment and soil series.

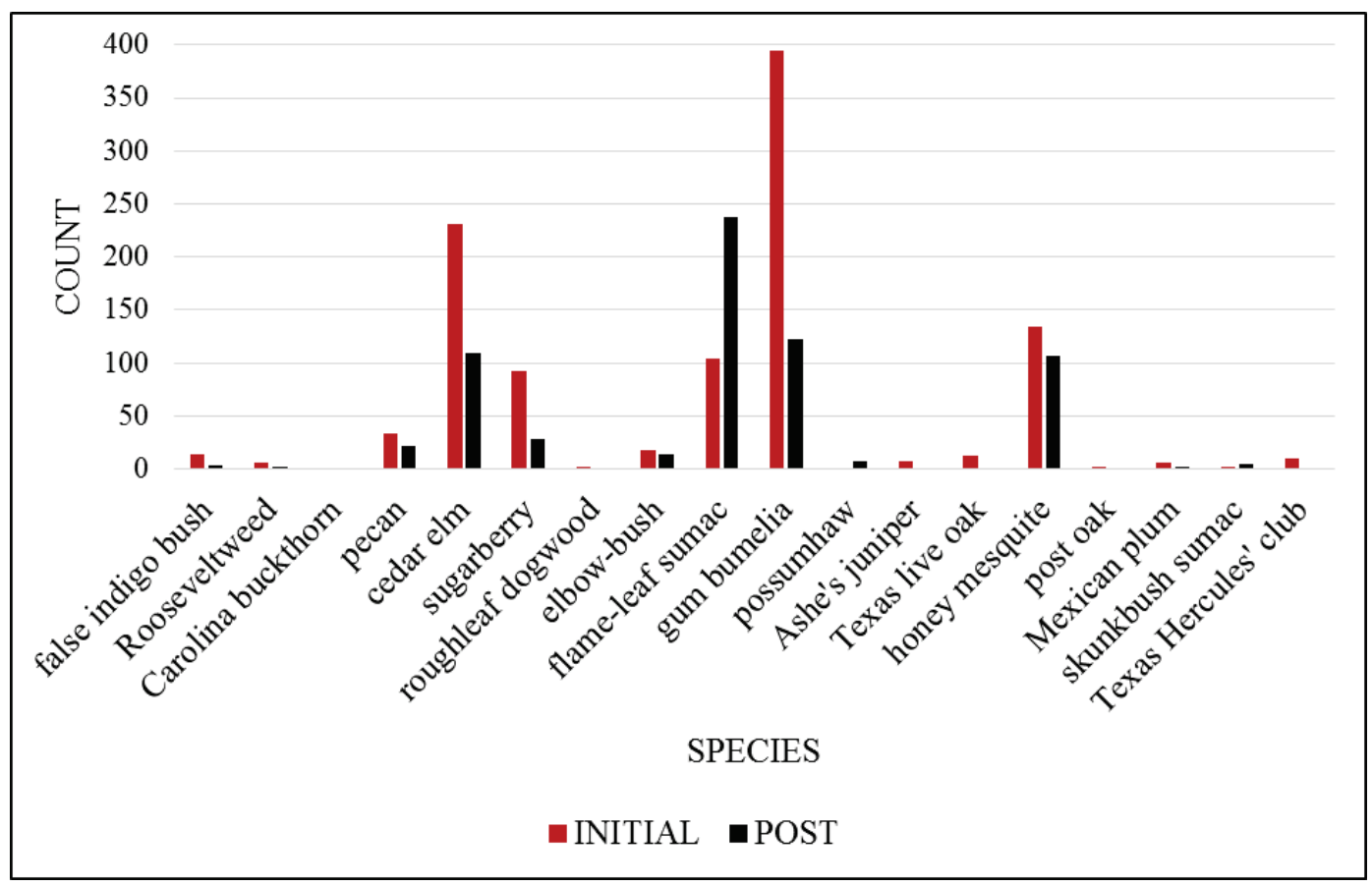




\subsection{Summary}

The RU-MSO treatment proved most effective at preventing resprout in cut-stump herbicide applications, outperforming both control and RUdiesel treatments. While the RU-diesel treatment appeared more effective than the control treatment, no statistical difference was observed. The most resilient species with regard to resprouting tendencies included cedar elm, flame-leaf sumac, gum bumelia, and honey mesquite. These species, with the exception of flame-leaf sumac, likely have a low browse preference to cattle and wildlife on the sites. Flame-leaf sumac, because of its prolific fecundity, although browsed, still readily regenerates and resprouts when damaged and not treated with an herbicide. The shrubby tendencies of these species and there increased ability to resprout after coppicing make them problematic to control without the effective application of herbicide. Prescribed burning staggered in 3-5 year windows may provide a means of further reducing the frequency and expense of mechanical clearing and herbicide application in the future. Additional studies examining the role of prescribed fire in combination with treatment methods described herein could inform future woody vegetation control activities. 


\section{Field Assessment of Soil and Water Resources Following Herbicide Application}

\subsection{Introduction}

Open habitat areas are maintained at Fort Hood for military training by management of woody vegetation. The cut stump treatment method, where herbicide is sprayed on and around freshly cut stumps, remains a common technique utilized in woody vegetation management. Cut stump herbicide application can result in herbicide application onto the soil directly located around the treated stump via direct application onto the soil. Triclopyr, the active ingredient in Remedy Ultra (RU), is frequently used to treat woody vegetation via the cut stump method. The RU is applied as a mixture of triclopyr 2-butoxyethyl ester (TBEE) with a variety of surfactants (e.g., diesel; methylated seed oil). Following application, the TBEE rapidly converts to the active ingredient triclopyr which leads to vegetation damage and death following herbicide induced uncontrolled growth. Specifically, triclopyr mimics the hormone auxin causing uncontrolled and disorganized plant growth causing death (Tu et al. 2001). In soils, triclopyr is degraded by microbial metabolism to 3,5,6-trichloro-2-pyridinol (TCP) (Ganapathy 1997). The reported half-life for triclopyr ranges from 3.7 to 314 days, with an average of 30 days ( $\mathrm{Tu}$ et al. 2001); warm, moist conditions increase triclopyr degradation by microbial metabolism.

Triclopyr and related compounds such as TBEE and TCP have the potential for vertical and lateral movement in soils under certain conditions, including soil with low organic matter content (Ganapathy 1997), high pH (Pusino et al. 1994), or in areas receiving excessive rain fall during or shortly after application (Tu et al. 2001). Therefore, the following section evaluated background concentrations of TBEE, triclopyr, and its breakdown product (TCP) and assessed herbicide concentrations in soils and water under field conditions following woody vegetation management. The study examined three soil types located within the study area and three woody vegetation treatments including: 1) stump cutting, no RU herbicide application (control treatment), 2) stump cutting with RU herbicide, diesel added as surfactant (RU-diesel treatment), and 3) stump cutting with RU herbicide, methylated seed oil (MSO) added as surfactant (RU-MSO treatment). 


\subsection{Purpose of the field assessment of soil and water resources}

The following section evaluates herbicide concentrations in soils and water under field conditions, documenting potential movement of herbicide within the environment. The field studies also inform future management decisions and provide data to support laboratory studies designed to further evaluate potential herbicide fate and transport (described below).

Important topics that control potential movement and degradation of herbicides are addressed including soil type, surfactant, and hydrologic events (i.e., rainfall).

\subsection{Study area}

The study area is described in the vegetation assessment in Section 2.0 above. During 2015, approximately 142 acres underwent management to maintain open grassland habitat using the cut stump method. The study area was divided into control, RU-MSO, and RU-diesel sections as described above. Three soil series, Bosque, Cho, and Nuff, were identified for assessment (Appendix A). Examining three distinct soil types allows resource managers to assess the role of soil properties in the potential movement and degradation of the herbicide under field conditions.

\subsubsection{Soil series}

The study area contained approximately 54 acres of Bosque soil (fine-loamy, mixed, superactive, thermic Cumulic Haplustolls). The Bosque series consists of loamy, calcareous alluvial sediment that are very deep, well drained, and moderately permeable. This soil is typically located within floodplains with $<1 \%$ slope. Soil texture is loam, sandy clay loam, or clay loam. Clay content ranges from 20 to $35 \%$. A typical pedon of the Bosque soil contains a thick A horizon of up to $100 \mathrm{~cm}$ (Soil Survey Staff 2016).

The study area contained approximately 12 acres of Cho soil (loamy, carbonatic, thermic, shallow Petrocalcic Calciustolls). Cho soil consists of shallow soil or shallow soil to a petrocalcic horizon. Soils are well drained and form in loamy calcareous gravelly alluvium. Typical locations for Cho soil are remnant alluvial plain stream terraces and alluvial fans with slopes ranging between $\mathrm{O}$ and $8 \%$. Soil texture is loam or clay loam containing 15-35\% clay in the A horizon. Depth to petrocalcic horizon varies from $18-50 \mathrm{~cm}$ (Soil Survey Staff 2016). 
The study area contained approximately 76 acres of Nuff soil (Fine-silty, carbonatic, thermic Udic Calciustolls). The Nuff series consists of moderately deep to shallow well drained soils. Nuff soil is formed in interbedded marl, limestone, and shale with slopes ranging between 1 and $6 \%$. This soil is formed on erosional upland areas with low hills, ridgetops, or narrow stream divides. Calcium carbonate concretions are found throughout the soil, with up to $30 \%$ pebbles, cobbles, and stone in the surface layer (Soil Survey Staff 2016).

\subsubsection{Precipitation data}

The study area has a warm humid temperate climate with hot summers and no pronounced dry season (USDA NRCS 2006). Precipitation during the study period (June 2015-April 2016) was documented using the Stillhouse Hollow Dam (Bell County, TX) weather station. Note that several large rain events occurred during the monitoring period (Figure 19). Precipitation data was evaluated through the application of the Direct Antecedent Rainfall Evaluation Method (DAREM) (Sumner and Miller 1996). The DAREM method examines rainfall patterns during the previous three months to determine if field conditions during each month of the monitoring period were normal, above normal, or below normal compared to the 30th and 70th percentile averages based on long-term (i.e., 30-year) average precipitation records provided in WETS tables developed by the USDA-NRCS National Water and Climate Center (Sprecher and Warne 2000; Berkowitz and Noble 2015). 
Figure 19. Daily measured precipitation events at Stillhouse Hollow Dam (Bell County, TX) weather station for 2015 (upper) and 2016 (lower). The black line is the normal precipitation; dashed lines are $\pm 30 \%$.
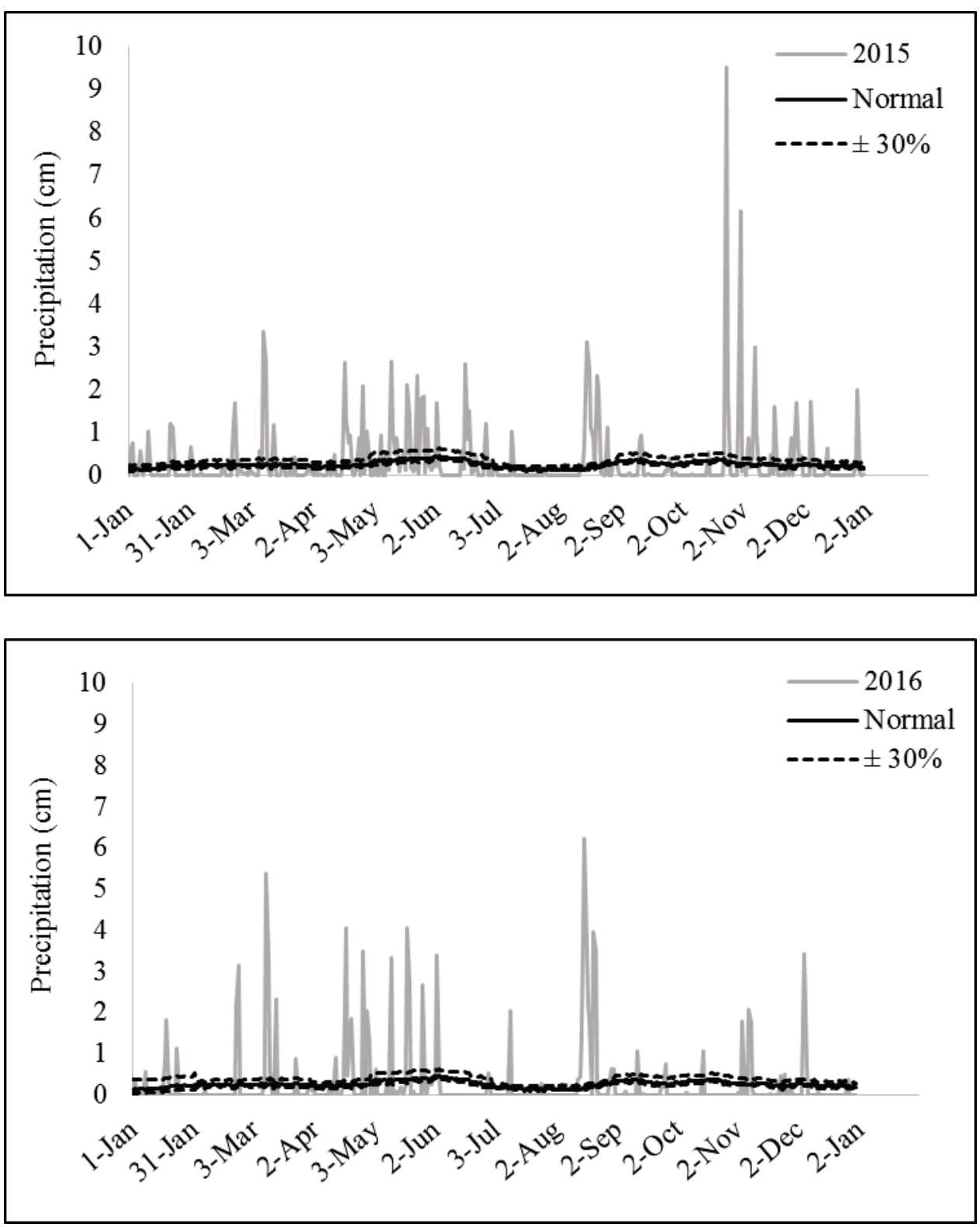

\subsection{Material and methods}

\subsubsection{Soil physicochemical parameters}

Physicochemical parameters were assessed for each soil series by homogenizing bulk soil samples prior to herbicide application. Soil analysis included $\mathrm{pH}$, electrical conductivity (EC), total carbon (TC), total inorganic C (TIC), total organic C (TOC), water extractable metals, 
bioavailable metals, cation exchange capacity (CEC), texture, particulate organic matter (POM), and moisture capacity.

Soil $\mathrm{pH}$ was determined in water, potassium chloride, and calcium chloride solutions in order to mimic realistic soil conditions (Thomas 1996). Electrical conductivity was determined using a method adapted from Rhoades (1996). The EC can be an important indicator of potential soil activity and is commonly linked to soil texture, soil moisture capacity, and cation exchange capacity. For instance, the higher the clay content generally the higher the $\mathrm{EC}$ value. Total C, TIC, and TOC were determined using light element analysis on a CN628 Carbon/Nitrogen Determinator. Carbon content is an important indicator of soil fertility and often drives contaminant transport in soil and subsurface environments.

The Mehlich III extraction was used to determine bioavailable metals and fertility levels in the soils (Reed and Martens 1996). The water soluble extractions were used to determine which metals and ions were readily available or easily mobile in the soils. These values were determined using the standard methods in the Methods of Soil Analysis Part 3 - Chemical Methods (Sparks 1996). Cation Exchange Capacity (CEC) was calculated using values generated from the Mehlich III Extraction for exchangeable elements (Ba, Ca, Mg, K, Na) (Sumner and Miller 1996). The CEC is an important indicator of soil activity. The higher the CEC the greater ability a soil has to retain certain compounds. In addition, CEC is often times associated with higher organic matter and clay content in soils, since these surfaces tend to retain soil nutrients and other compounds.

Soil texture or the percentage of sand, silt and clay is a commonly measured soil property. The traditional hydrometer method was used to determine soil texture. Texture is critical to understanding transport of herbicides in soils. In general, sandy soils exhibit less retention than soils with higher clay content. The particulate organic matter (POM) or small organic matter in the form of particles within a soil represents a potentially important portion of the soil matrix. These organic particles can be highly reactive to contaminants and other compounds found in soils. The POM was determined using the methods found in Kettler et al. (2001). Soil moisture capacity was determined for field capacity (-1/3 bar) and permanent wilting point ( $-15 \mathrm{bar})$. Permanent wilting point is the minimum moisture level a plant requires not to wilt, while field capacity is generally the amount of moisture contained in the soil 2-3 days after a 
rain event. The higher the field capacity the more water the soil will retain. These values are often linked to soil texture. A soil with high sand content will have a lower overall moisture capacity than a soil that is high in clay content. These values were determined using the approach described by Klute (1986).

\subsubsection{Herbicide application}

Herbicide was sprayed on woody stumps following the cut stump herbicide method in August and September 2015 (Table 7). The herbicide was applied following cutting with a low pressure sprayer. Herbicide applications sprayed the root collar area, sides of the stump, and outer portion of the cut surface. The application process resulted in herbicide application to approximately 2.5 to $5 \mathrm{~cm}$ of soil directly surrounding a single cut stump (Figure 20) or a group of cut stumps (Figure 21). Herbicide was applied in a mixture of 25\% Remedy Ultra (RU) and 75\% surfactant with a dye in treatment areas. The surfactant was either diesel (RU-diesel treatment) or MSO (RU-MSO treatment). The control treatment was stump cutting without herbicide application.

Table 7. Date of woody vegetation management activities for each soil series and treatment in 2015.

\begin{tabular}{|c|c|c|}
\hline Soil series & Treatment & Management activity dates \\
\hline Nuff & RU-MSO & 29-30 August \\
\hline & DU-diesel & 31 August-3 September, 5-6 September \\
\hline & Control & 29 August-6 September \\
\hline Cho & RU-MSO & 3 September \\
\hline & DU-diesel & 5-6 September \\
\hline & Control & 3-6 September \\
\hline Bosque & RU-MSO & 10-11, 14-15 September \\
\hline & DU-diesel & $16-17,21,24$ September \\
\hline & Control & $10-24$ September \\
\hline
\end{tabular}


Figure 20. Triclopyr-treated single cut stump in Bosque soil (22 September 2015).

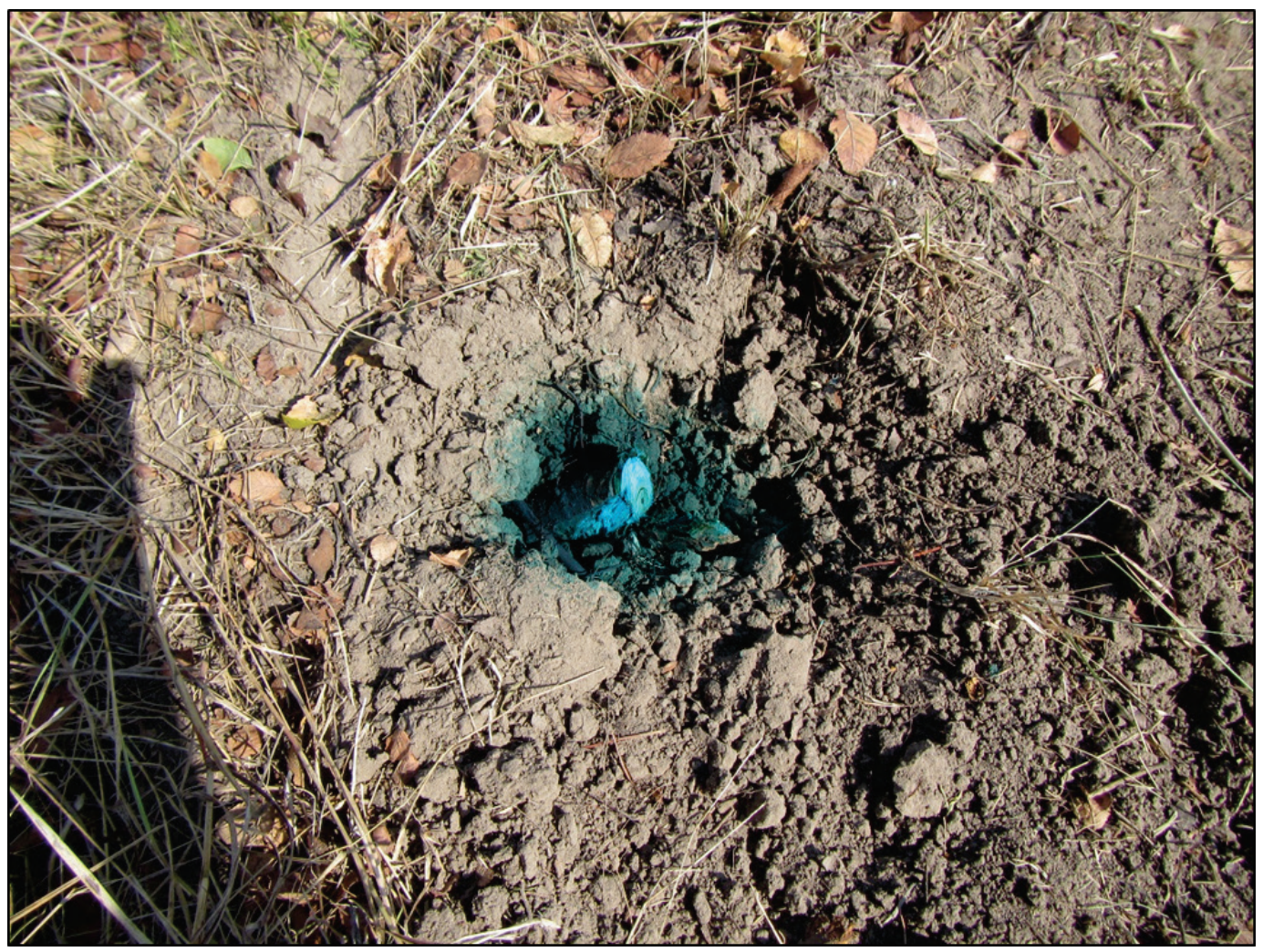

Figure 21. Triclopyr-treated group of cut stumps in Bosque soil (22 September 2015).

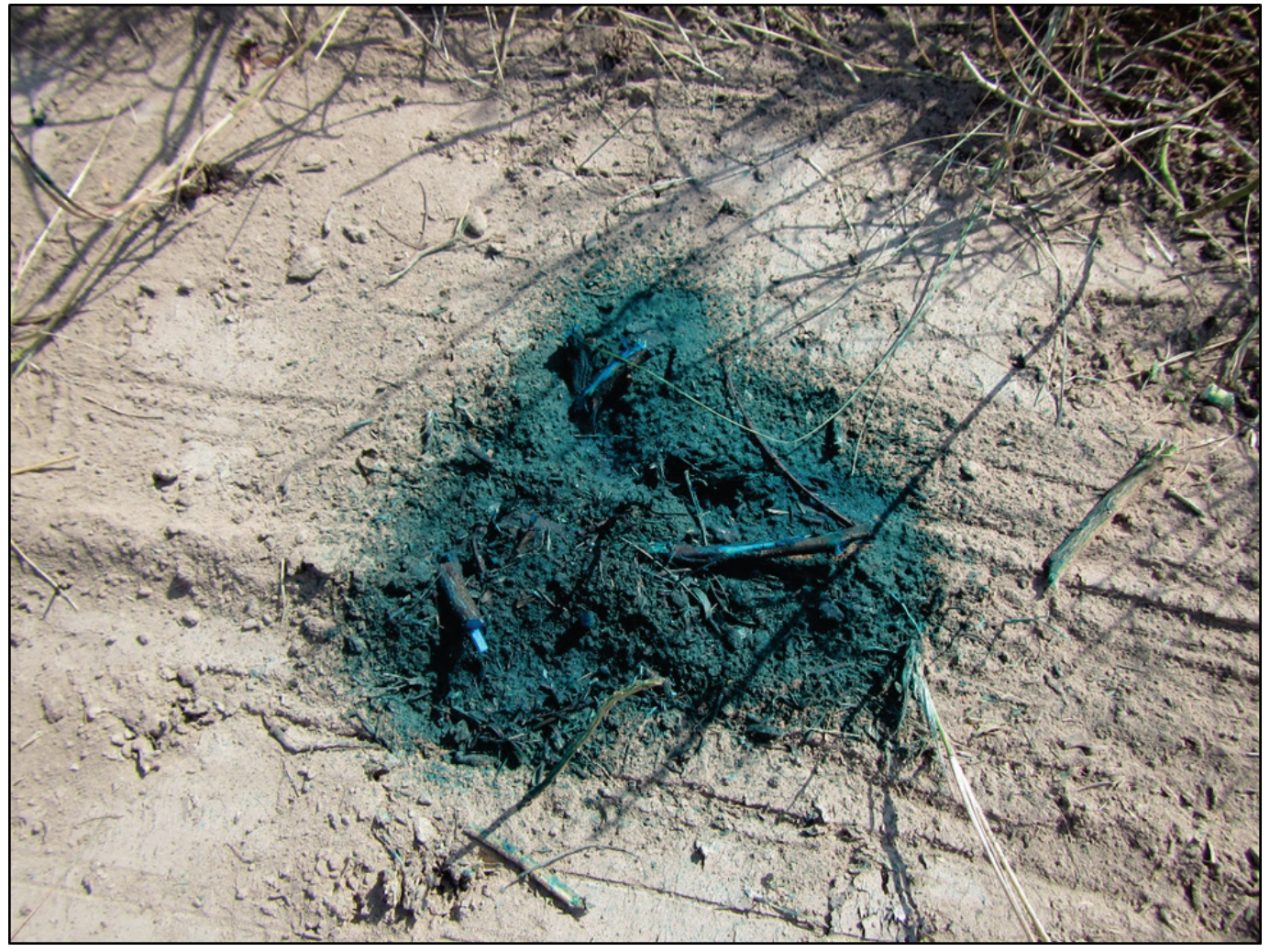




\subsubsection{Soil sampling}

In order to evaluate the potential fate and transport of herbicides following cut stump application, five replicate 0.2 ha study plots were established in each soil series and treatment type for a total of 45 plots. Three plots within each treatment type were assessed prior to tree cutting and herbicide application to establish background TBEE, triclopyr, and TCP concentrations in June 2015. The same plots were repeatedly assessed over time to evaluate soil and water herbicide concentrations and provide insight into potential herbicide fate and transport under field conditions.

The concentration of herbicide and related compounds in soil was assessed over a seven month time period following herbicide application (Table B.1 and B.2). Soil was collected in the Cho series five times and in the Bosque and Nuff series four times. A total of 570 soil samples were collected over the study period (Table 8). During each sampling event, two previously identified cut stumps were located within the boundaries of the plot for soil collection (Figure 22, Figure 23, and Figure 24). Soil was sampled at $\mathrm{o} \mathrm{cm}, 30.5 \mathrm{~cm}$, and $61 \mathrm{~cm}$ distances from the edge of a herbicide-treated stump (Figure 25 and Figure 26). At the control treatment locations, soil was only sampled directly adjacent to the cut stump (Figure 27). The upper portion of the soil profile was sampled using a $5 \mathrm{~cm}$ tall, $5 \mathrm{~cm}$ diameter soil core. Soil samples were maintained at $<4^{\circ}$ $\mathrm{C}$ prior to laboratory analysis. 
Figure 22. Soil sampling locations in the Bosque soil. Center of plot is represented as $\mathrm{X}$; soil sampling locations at identified cut stumps are represented as bull's eye.

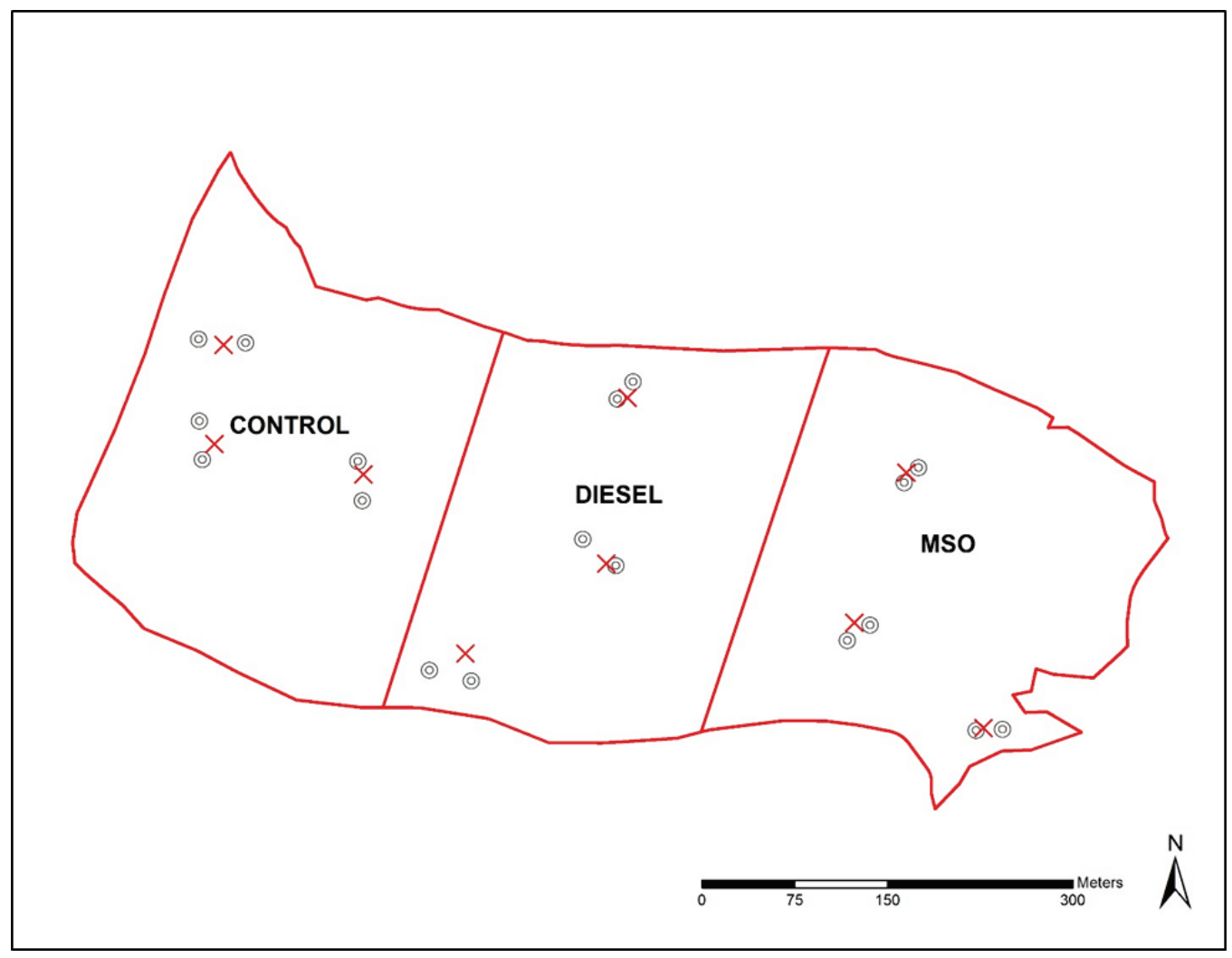


Figure 23. Soil sampling locations in the Cho soil. Center of plot is represented as X; soil sampling locations at identified cut stumps are represented as bull's eye.

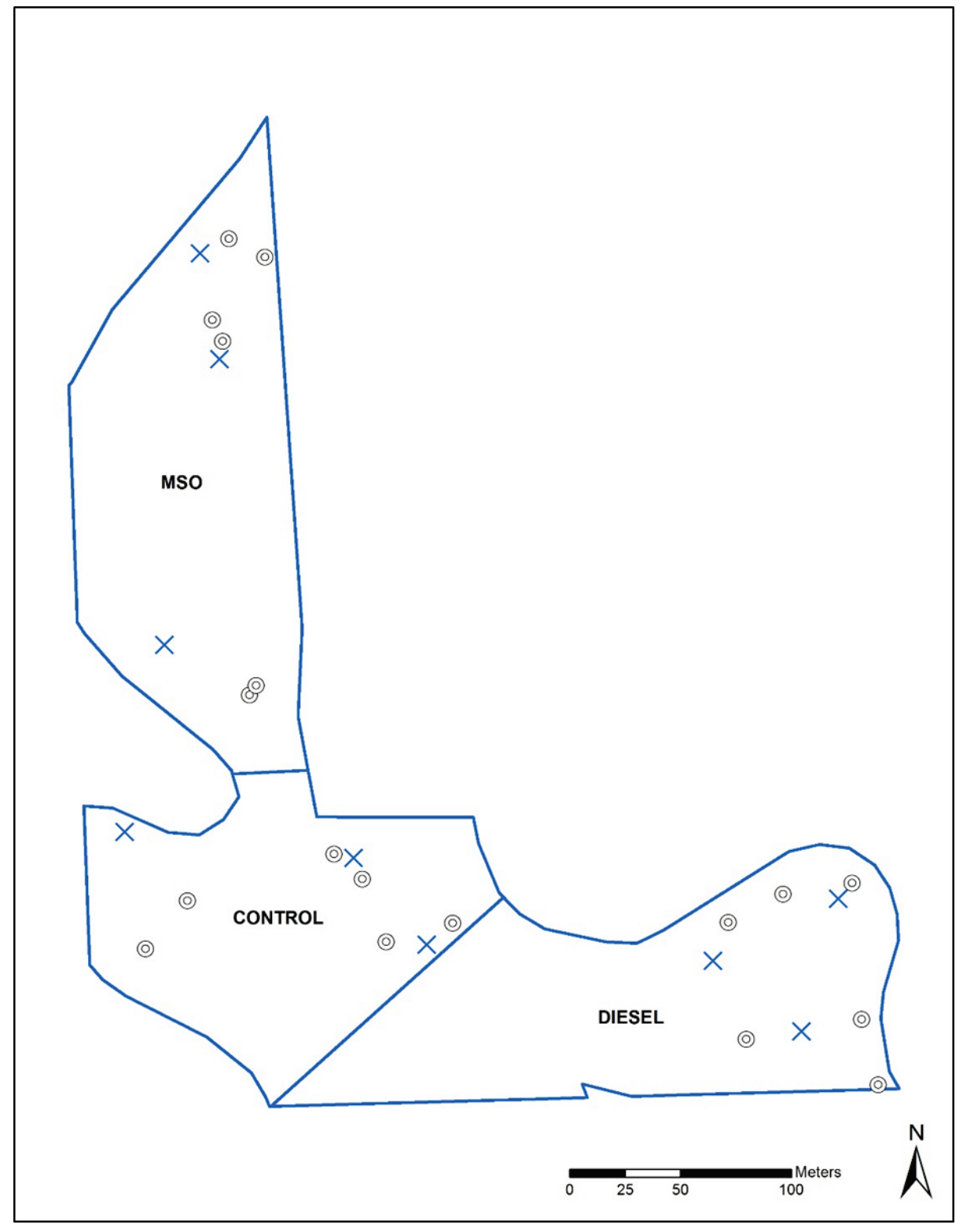


Figure 24. Soil sampling locations in the Nuff soil. Center of plot is represented as X; soil sampling locations at identified cut stumps are represented as bull's eye.

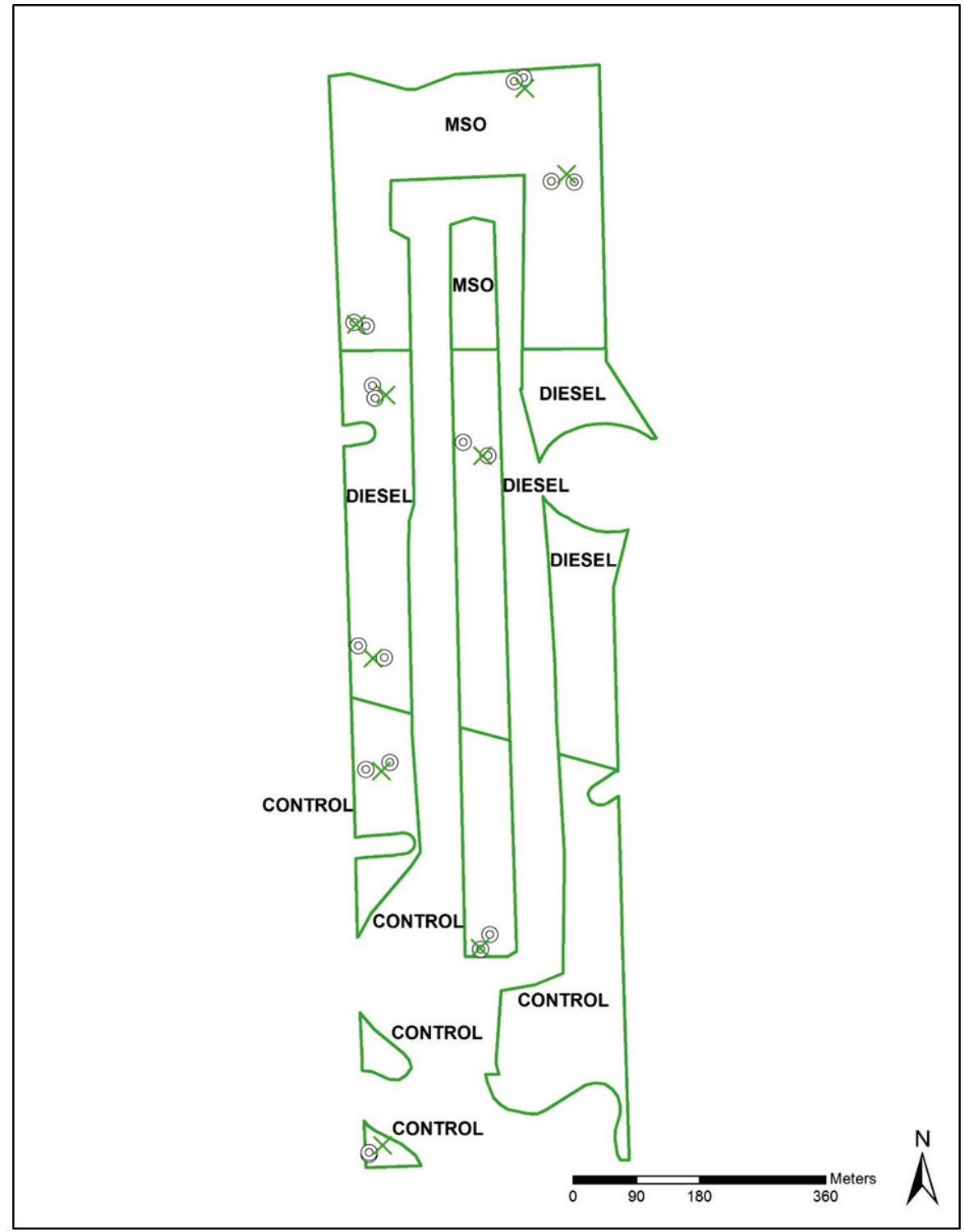


Figure 25. Example of soil sampling design for herbicide-treated stumps. Soil was sampled at $0 \mathrm{~cm}, 30.5 \mathrm{~cm}$, and $61 \mathrm{~cm}$ away from the edge of a treated stump.

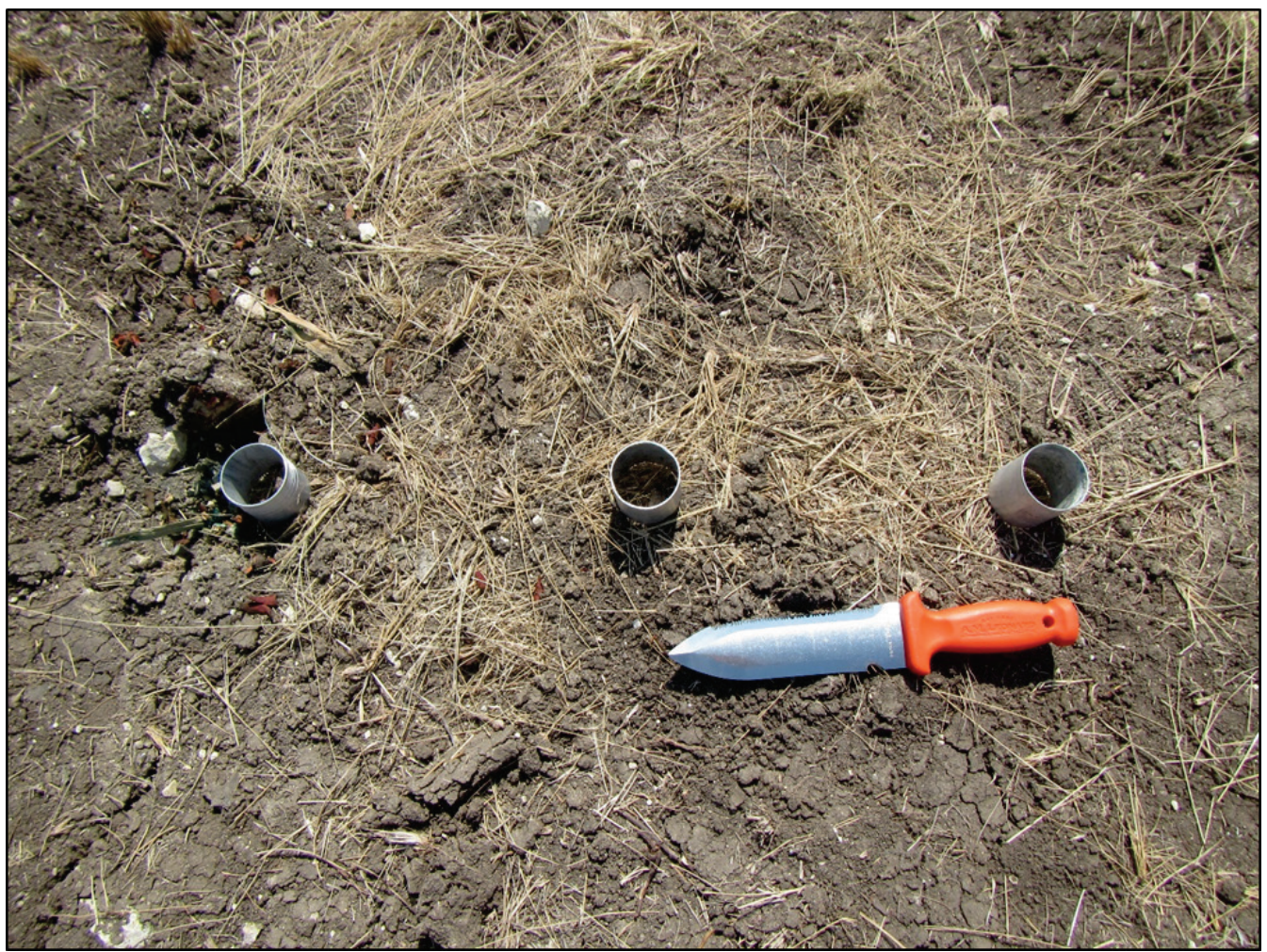

Figure 26. Soil was sampled $61 \mathrm{~cm}, 30.5 \mathrm{~cm}$, and $0 \mathrm{~cm}$ from an herbicide-treated stump.

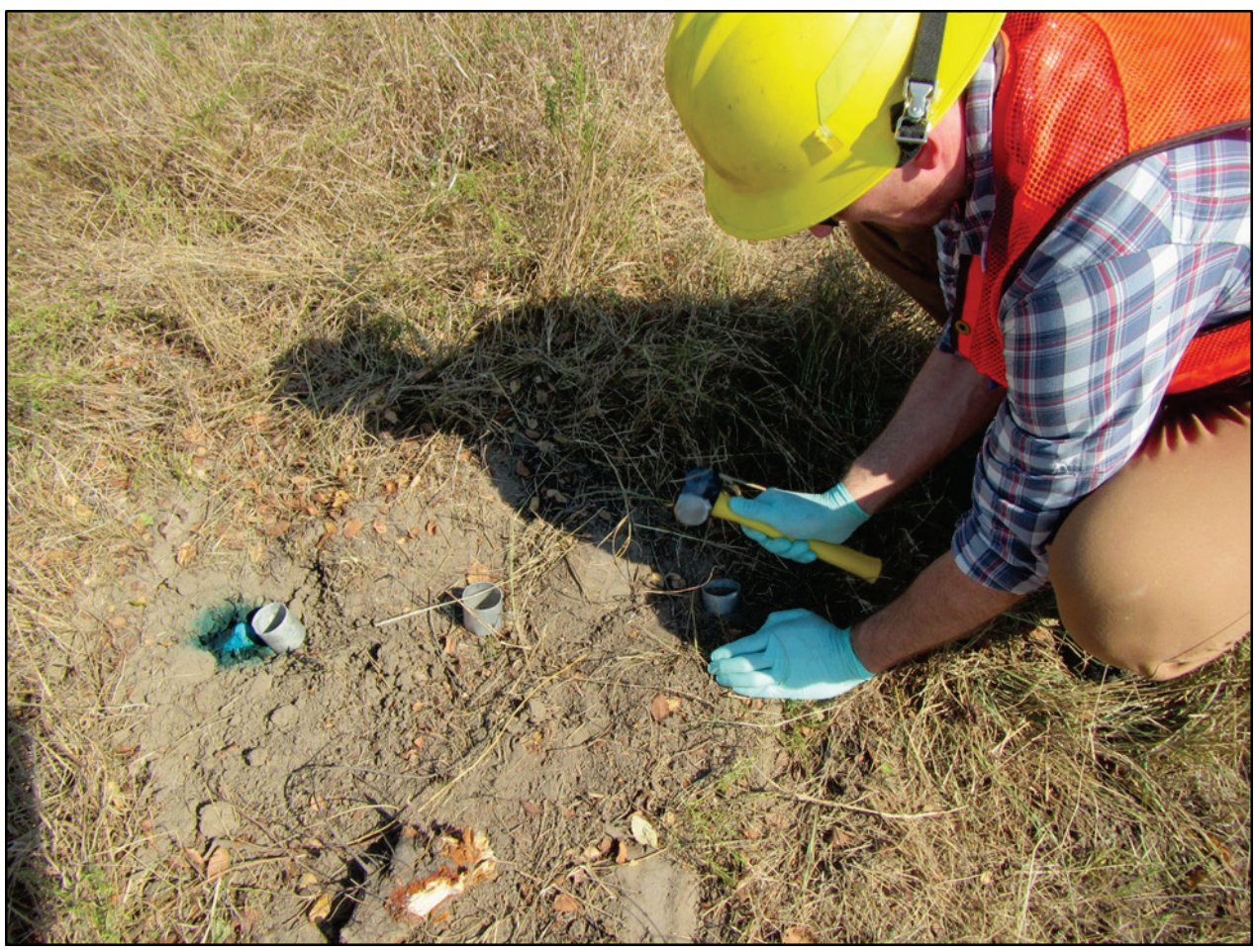


Figure 27. Example of soil sampling design for cut stumps in the control treatment.

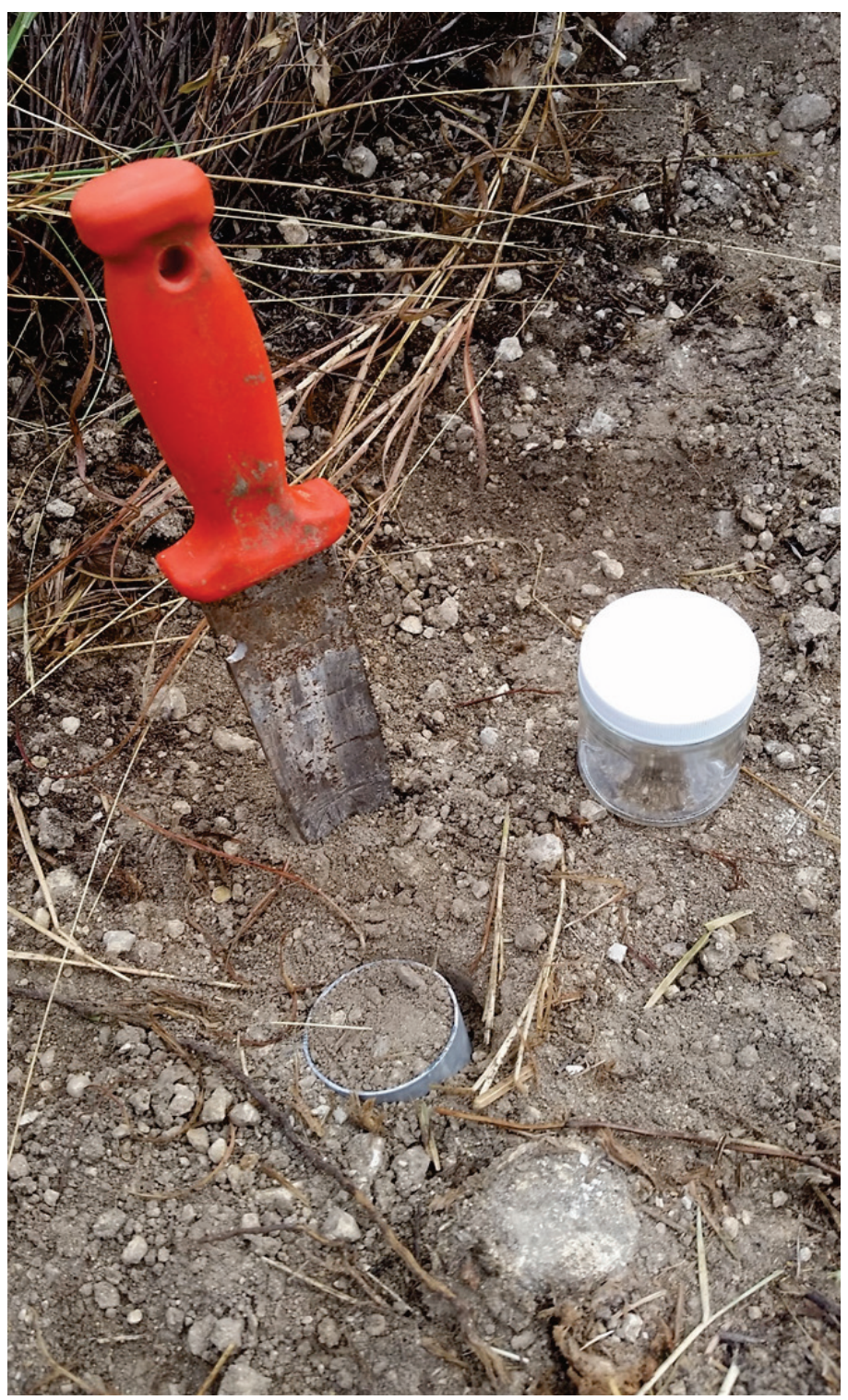

Table 8. Number of soil samples collected for each sampling date.

\begin{tabular}{|c|c|}
\hline Sampling Dates & Number of Soil Samples \\
\hline 14-19 June 2015 & 27 \\
\hline 9-11 September2015 & 42 \\
\hline 20-23 September 2015 & 126 \\
\hline 26-30 October 2015 & 123 \\
\hline 30 November-4 December 2015 & 126 \\
\hline 25-28 April 2016 & 126 \\
\hline Total & 570 \\
\hline
\end{tabular}




\subsubsection{Water sampling}

Water samples were collected in glass amber containers, rinsed once with site water and maintained at $<4{ }^{\circ} \mathrm{C}$ prior to laboratory analysis (Figure 28). Water samples were collected upstream of Bosque soil in Cowhouse Creek and from the large pond located in the Nuff soil to establish background concentrations of triclopyr, TBEE, and TCP in June 2015 (Figure 29 and Figure 30). Water samples were collected at Cowhouse Creek, drainage pond, and shallow standing water when present following tree cutting and herbicide application. A total of 32 water samples were collected over the study period (Table 9).

Figure 28. Example of water collection at Cowhouse Creek located next to Bosque soil.

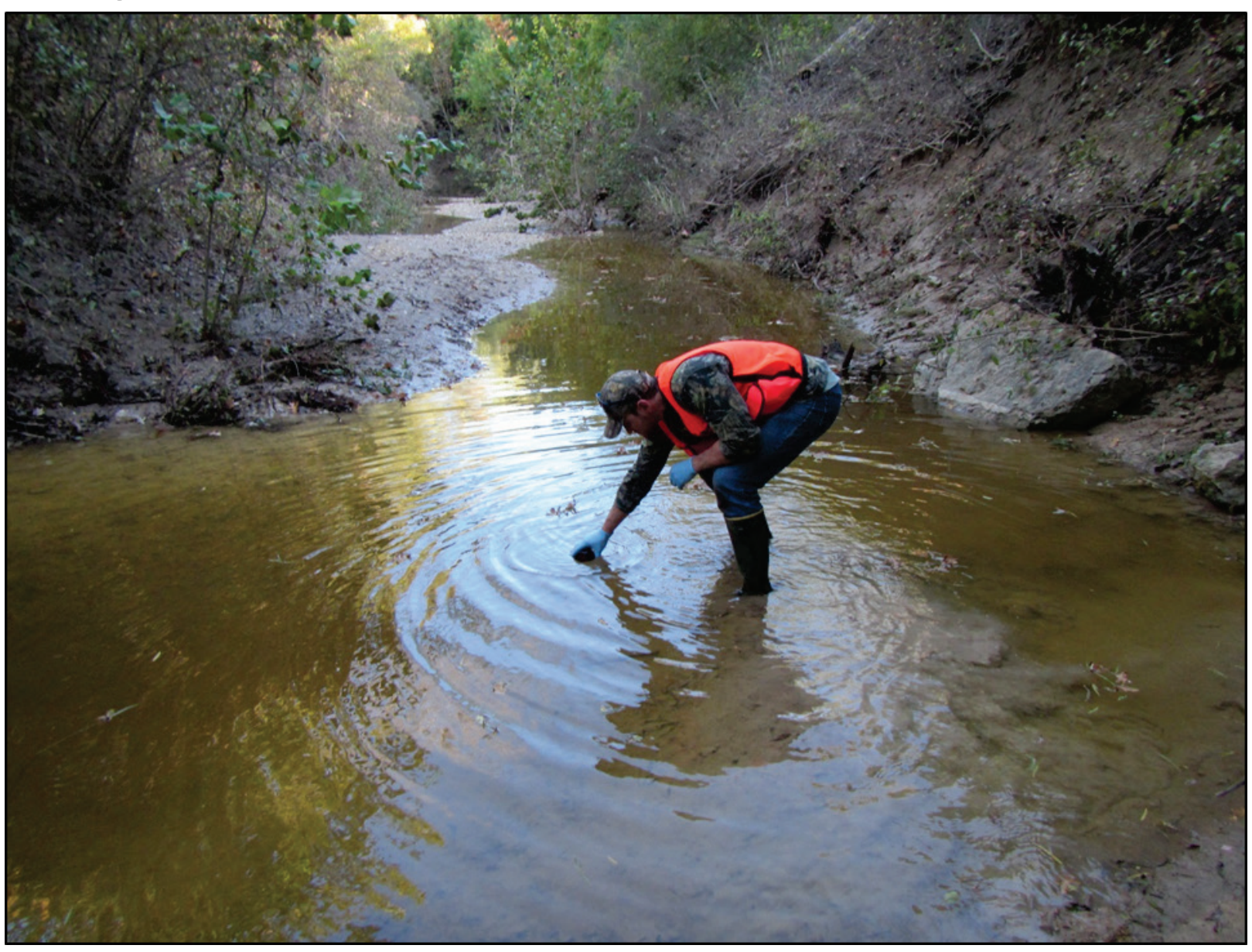


Figure 29. Water collection locations to establish concentrations of herbicide and related compounds pre- and post- treatment at the Bosque site.

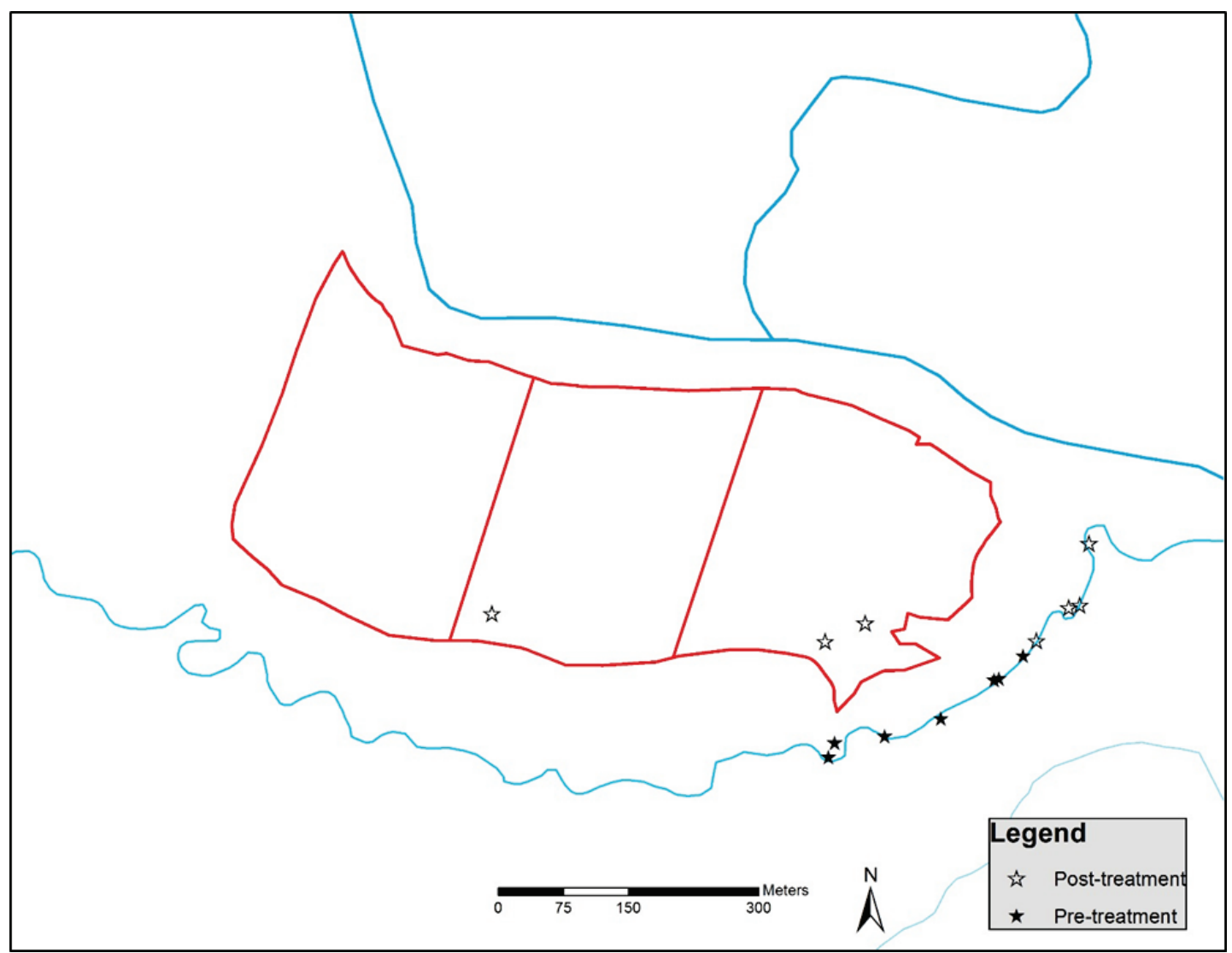


Figure 30. Water collection locations to establish concentrations of herbicide and related compounds pre- and post- treatment at the Cho and Nuff sites.

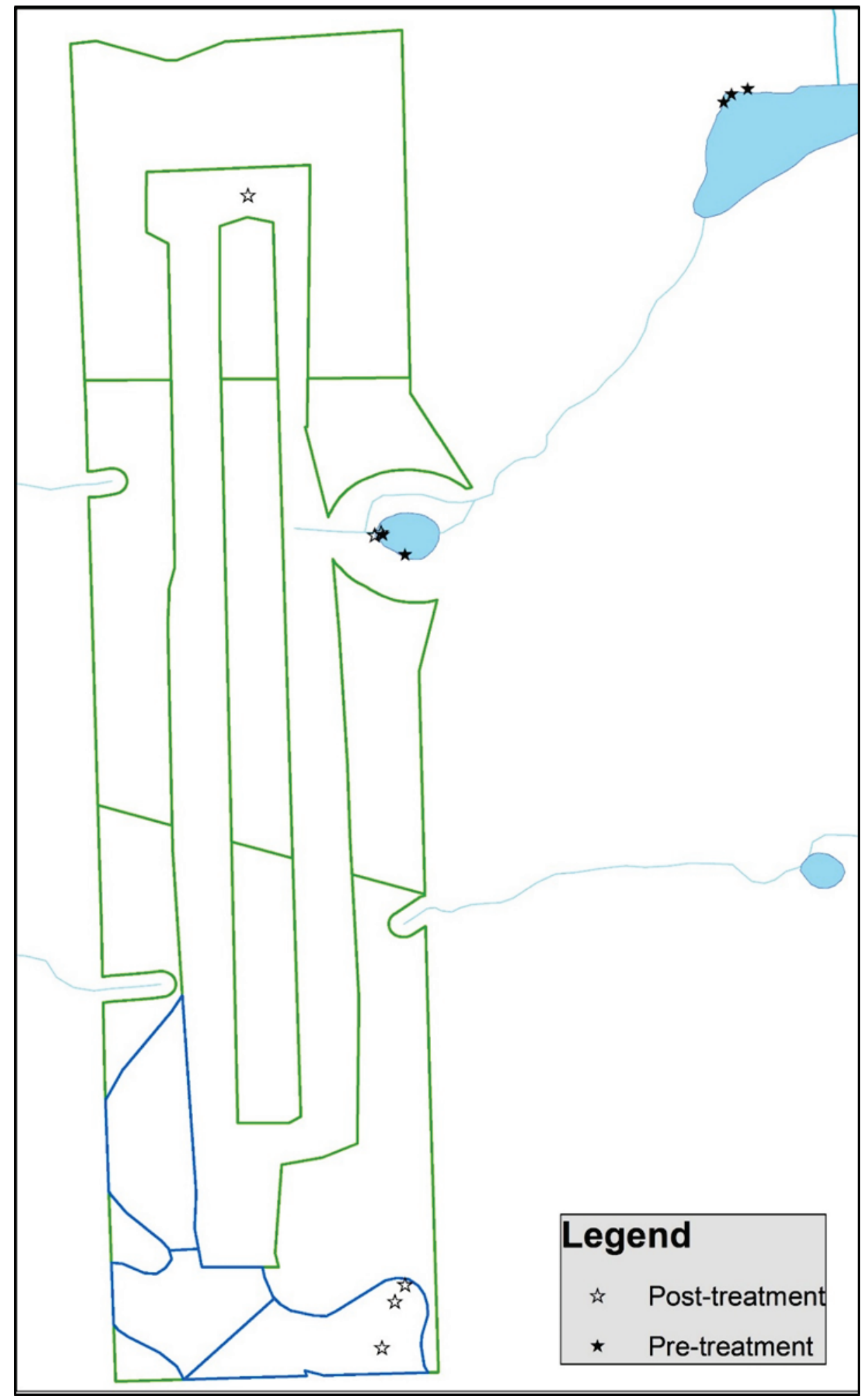


Table 9. Number of water samples collected for each sampling date.

\begin{tabular}{|c|c|}
\hline Sampling Dates & Number of Water Samples \\
\hline 14-19 June 2015 & 14 \\
\hline 9-11 Sept 2015 & 0 \\
\hline $20-23$ Sept 2015 & 2 \\
\hline 26-30 Oct 2015 & 7 \\
\hline 30 Nov-4 Dec 2015 & 6 \\
\hline $25-28$ April 2016 & 3 \\
\hline Total & 32 \\
\hline
\end{tabular}

\subsubsection{Soil and water laboratory analysis}

The analysis of TBEE, trichlopyr, and TCP was accomplished using reversed phase HPLC with UV detection after extraction from water and soil matrices. Specifically, an Agilent 1200 HPLC with a UV/Vis detector at $230 \mathrm{~nm}$ was used for all analyses. A Phenonmenex Synergi HydroPro (4 $\mathrm{uM}, 80 \mathrm{~A}, 250 \times 4.6 \mathrm{~mm}$ ) column was used for the chromatographic separation with a mobile phase flow rate of $1 \mathrm{~mL}$ min-1. A sample of $50 \mu \mathrm{L}$ was injected and the separation achieved using a gradient elution program that increases in acetonitrile concentration from 30 to $80 \%$ over a 10 minute time period (Fischer et al. 2008).

Soil samples were analyzed using a $5 \mathrm{~g}$ aliquot of soil shaken for 12-hours with $40 \mathrm{~mL}$ of a $90 \%$ Acetone / $10 \% 1 \mathrm{M} \mathrm{HCl}$ mixture. The extracts were then concentrated to $2 \mathrm{~mL}$ using a nitrogen manifold in a fume hood. After concentration, the extracts were diluted to $20 \mathrm{~mL}$ with $0.5 \mathrm{M} \mathrm{HCl}$. The diluted samples were placed on a Supelco ENVI-18 (6 mL) SPE cartridge that is conditioned with $5 \mathrm{~mL}$ of acetonitrile followed by $5 \mathrm{~mL}$ of $0.1 \mathrm{M}$ $\mathrm{HCl}$. After passing the sample through the cartridge, the SPE cartridge was rinsed with a $3 \mathrm{~mL}$ mixture of $40 \%$ acetonitrile / 59\% water / 1\% 1 M HCL. The final extract is eluted with a $3 \mathrm{~mL}$ mixture of $80 \%$ acetonitrile / $19 \%$ water / 1\% $1 \mathrm{M}$ HCL. The soil sample extracts are adjusted to a 1:1 acetonitrile/water ratio and placed in $2 \mathrm{~mL}$ autosampler vials for HPLC analysis.

Water Samples were analyzed by first conditioning a Supelco ENVI-18 (6 $\mathrm{mL}) \mathrm{SPE}$ cartridge with the addition of $5 \mathrm{~mL}$ methanol and $10 \mathrm{~mL}$ of water at $\mathrm{pH} 2(\mathrm{HCl}) . \mathrm{A} 100 \mathrm{~mL}$ aliquot of sample water was acidified to $\mathrm{pH} 2$ with $1 \mathrm{M} \mathrm{HCl}$ and passed through the SPE cartridge. The cartridge was 
rinsed with $\mathrm{pH} 2$ water and the analytes are eluted with $5 \mathrm{~mL}$ of a $96 \%$ methanol / $4 \%$ of a $0.1 \%$ aqueous TFA solution. The water extracts are adjusted to a 1:1 methanol/water ratio and placed in $2 \mathrm{~mL}$ autosampler vials for HPLC analysis.

\subsubsection{Data analysis}

Statistical relationships were examined between time and distance using JMP 13.0 (SAS Institute Inc., Cary, NC) univariate split plot approach to perform a repeated measures analysis of variance $(\alpha=0.05)$ with Tukey's post hoc analysis. Outliers were determined using box and whisker plots and were excluded if the data point fell outside of the 1st or 3rd quarter \pm 1.5 times the interquartile range (Quinn and Keough 2002).

Concentrations of TBEE, triclopyr, and TCP that were under the reporting limit (soil, $100 \mathrm{ug} \mathrm{kg-1;} \mathrm{water,} 0.02 \mathrm{mg} \mathrm{L}-1$ ) were excluded from the analysis due to uncertainty of error at low concentrations.

\subsection{Results}

\subsubsection{Soil physicochemical parameters}

The Bosque, Cho, and Nuff soils are characterized as Mollisols. The CEC for Cho was higher than was for the Nuff and Bosque soils (Figure 31; Table 10). The Bosque soil has a higher percentage of sand than the Cho and the Nuff soils. All measured carbon values (TC, TOC, TIC) were higher in the Bosque soil than the Cho and Nuff soils. The $\mathrm{pH}$ was not significantly different across the soil types. 
Table 10. Physicochemical properties of each soil series (mean $\pm \mathrm{SE}$ ). All measurements were completed in triplicate except for moisture measurements. CEC, cation exchange capacity; POM, particulate organic matter; TC, total carbon; TIC, total inorganic carbon; TOC, total organic carbon; $\mathrm{KCl}$, potassium chloride; $\mathrm{CaCl}_{2}$ calcium chloride; $\mathrm{EC}$, electrical conductivity; $\mathrm{FC}$, soil moisture at Field Capacity; PWP, soil moisture at permanent wilting point.

\begin{tabular}{|c|c|c|c|c|c|c|c|}
\hline Series & CEC & POM & Silt & Sand & Clay & TC & TIC \\
\hline & cmolc kg-1 $^{-1}$ & $\%$ & $\%$ & $\%$ & $\%$ & mg kg-1 & mg kg-1 \\
\hline Bosque $B$ & $978.12 \pm 5.66$ & $0.09 \pm 0$ & $44.95 \pm 1.73$ & $18.42 \pm 0.43$ & $36.63 \pm 1.32$ & $25.93 \pm 5.27$ & $4.28 \pm 0.6$ \\
\hline Bosque A3 & $659.14 \pm 5.31$ & $0.1 \pm 0$ & $37.48 \pm 0.5$ & $34.17 \pm 0.08$ & $28.35 \pm 0.42$ & $19.42 \pm 0.97$ & $3.48 \pm 0.11$ \\
\hline Bosque C5 & $689.69 \pm 4.53$ & $0.15 \pm 0$ & $40.53 \pm 0.58$ & $26.32 \pm 0.13$ & $33.15 \pm 0.54$ & $27.59 \pm 4.11$ & $4.26 \pm 0.61$ \\
\hline Cho A1 & $1687.86 \pm 6.92$ & $0.13 \pm 0$ & $48.45 \pm 0.33$ & $13.65 \pm 0.07$ & $37.9 \pm 0.28$ & $18.46 \pm 0.49$ & $3.51 \pm 0.19$ \\
\hline Cho C5 & $1386.34 \pm 74.8$ & $0.1 \pm 0.01$ & $55.31 \pm 0.49$ & $13.55 \pm 0.21$ & $31.14 \pm 0.69$ & $15.39 \pm 0.09$ & $3.58 \pm 0.04$ \\
\hline Cho B3 & $1401.81 \pm 27.91$ & $0.2 \pm 0.01$ & $47.24 \pm 0.45$ & $15.85 \pm 0.33$ & $36.91 \pm 0.35$ & $18.39 \pm 2.94$ & $3.14 \pm 0.43$ \\
\hline Nuff B1 & $913.64 \pm 10.29$ & $0.15 \pm 0.01$ & $44.66 \pm 0.79$ & $12.87 \pm 0.04$ & $42.47 \pm 0.76$ & $17.18 \pm 0.48$ & $2.92 \pm 0.39$ \\
\hline Nuff B3 & $776.49 \pm 1.46$ & $0.21 \pm 0$ & $46.62 \pm 0.85$ & $12.14 \pm 0.04$ & $41.24 \pm 0.81$ & $17.69 \pm 0.55$ & $3.06 \pm 0.2$ \\
\hline Nuff C5 & $788.07 \pm 1.05$ & $0.17 \pm 0.01$ & $45.98 \pm 0.42$ & $15.79 \pm 0.25$ & $38.23 \pm 0.33$ & $18.68 \pm 0.45$ & $3.05 \pm 0.23$ \\
\hline \multirow[t]{2}{*}{ Series } & TOC & pH-water & $\mathrm{pH}-\mathrm{KCl}$ & $\mathrm{pH}-\mathrm{CaCl}_{2}$ & EC & FC & PWP \\
\hline & $\mathrm{mg} \mathrm{kg}^{-1}$ & - & - & - & uS $\mathrm{cm}^{-1}$ & $\%$ & $\%$ \\
\hline Bosque $B$ & $21.64 \pm 4.69$ & $7.59 \pm 0.1$ & $7.5 \pm 0.05$ & $7.56 \pm 0.02$ & $260.67 \pm 21.47$ & & \\
\hline Bosque A3 & $15.94 \pm 0.87$ & $7.59 \pm 0.02$ & $7.27 \pm 0.12$ & $7.54 \pm 0.01$ & $320.07 \pm 9.79$ & $17 \pm 0$ & $12 \pm 0$ \\
\hline Bosque C5 & $23.33 \pm 3.52$ & $7.59 \pm 0.05$ & $7.58 \pm 0.06$ & $7.52 \pm 0.05$ & $265.13 \pm 18.68$ & & \\
\hline Cho A1 & $14.95 \pm 0.49$ & $7.6 \pm 0.09$ & $7.56 \pm 0.08$ & $7.8 \pm 0.03$ & $287.97 \pm 18.94$ & & \\
\hline Cho C5 & $11.81 \pm 0.1$ & $7.72 \pm 0.01$ & $7.64 \pm 0.04$ & $7.35 \pm 0.33$ & $265.4 \pm 1.4$ & $18 \pm 0$ & $13 \pm 0$ \\
\hline Cho B3 & $15.25 \pm 2.54$ & $7.69 \pm 0.01$ & $7.39 \pm 0.01$ & $7.76 \pm 0.02$ & $296.97 \pm 8.91$ & & \\
\hline Nuff B1 & $14.26 \pm 0.11$ & $7.59 \pm 0.01$ & $7.46 \pm 0.02$ & $7.69 \pm 0.03$ & $329.27 \pm 5.52$ & & \\
\hline Nuff B3 & $14.63 \pm 0.67$ & $7.62 \pm 0.01$ & & & $362.27 \pm 6.52$ & $26 \pm 0$ & $18 \pm 0$ \\
\hline Nuff C5 & $15.63 \pm 0.22$ & $7.7 \pm 0.02$ & $7.46 \pm 0.02$ & $7.64 \pm 0.03$ & $339.77 \pm 2.23$ & & \\
\hline
\end{tabular}




\subsubsection{Herbicide concentration in soil}

Due to the rapid conversion between triclopyr and TBEE, the following sections report herbicide concentrations as the sum of those compounds (i.e., triclopyr + TBEE). The concentrations of the main herbicide degradation product (TCP) are reported separately. Background concentrations of triclopyr + TBEE and TCP were assessed in each soil series prior to herbicide application. Triclopyr + TBEE and TCP were not detected in any of the three soil series prior to the 2015 herbicide application. Following herbicide application, a total of 543 soil samples were analyzed for triclopyr + TBEE and TCP (Table 11). Triclopyr + TBEE was detected in 353. The TCP was detected in 216. The triclopyr + TBEE was identified in 140 soil samples located directly adjacent to treated stump (o cm), 101 soil samples located $30.5 \mathrm{~cm}$ from the treated stump, and 96 soil samples located $61 \mathrm{~cm}$ from the treated stump. There were 17 soil samples in control areas that had triclopyr + TBEE. The breakdown product of triclopyr, TCP was in 115 soil samples located adjacent to treated stump, 56 soil samples a $30.5 \mathrm{~cm}$ from the treated stump, and 43 soil samples located $61 \mathrm{~cm}$ from the treated stump. There were 2 soil samples in control areas that contained TCP. The presence of herbicide and related compounds within control areas is not unexpected due to the potential for cross contamination by equipment during tree cutting and mulching activities. Throughout the study, observed herbicide concentrations in control area soils remained low $\left(<1000 \mu \mathrm{g} \mathrm{kg}^{-1}\right)$ near the $100 \mu \mathrm{g} \mathrm{kg}^{-1}$ reporting limit. These values remains several orders of magnitude below the $1000000 \mu \mathrm{g} \mathrm{kg}^{-1}$ concentrations observed within the RU-MSO and RU-diesel treatment areas. 
Table 11. Number of samples containing triclopyr + TBEE or TCP in each soil series, treatment, and distance from treated stump (cm). TBEE, triclopyr-2-butoxy-ethylester; TCP, 3,5,6-Trichloro-2-pyridinol.

\begin{tabular}{|c|c|c|c|c|c|}
\hline Soil Series & Treatment & $\begin{array}{c}\text { Distance } \\
\text { from Stump } \\
(\mathrm{cm})\end{array}$ & $\begin{array}{c}\text { Number of } \\
\text { samples }\end{array}$ & $\begin{array}{c}\text { Number of } \\
\text { samples } \\
\text { containing triclopyr } \\
+ \text { TBEE }\end{array}$ & $\begin{array}{c}\text { Number of } \\
\text { samples } \\
\text { containing TCP }\end{array}$ \\
\hline \multirow[t]{7}{*}{ Bosque } & RU-diesel & 0 & 23 & 17 & 12 \\
\hline & & 30.5 & 23 & 11 & 6 \\
\hline & & 61 & 23 & 12 & 3 \\
\hline & RU-MSO & 0 & 24 & 22 & 17 \\
\hline & & 30.5 & 24 & 15 & 9 \\
\hline & & 61 & 24 & 16 & 6 \\
\hline & Control & 0 & 24 & 4 & 1 \\
\hline \multirow[t]{7}{*}{ Cho } & RU-diesel & 0 & 30 & 29 & 22 \\
\hline & & 30.5 & 30 & 14 & 6 \\
\hline & & 61 & 30 & 12 & 3 \\
\hline & RU-MSO & 0 & 30 & 28 & 23 \\
\hline & & 30.5 & 30 & 19 & 10 \\
\hline & & 61 & 30 & 17 & 5 \\
\hline & Control & 0 & 30 & 7 & 0 \\
\hline \multirow[t]{7}{*}{ Nuff } & RU-diesel & 0 & 24 & 22 & 20 \\
\hline & & 30.5 & 24 & 21 & 16 \\
\hline & & 61 & 24 & 19 & 15 \\
\hline & RU-MSO & 0 & 24 & 22 & 21 \\
\hline & & 30.5 & 24 & 21 & 9 \\
\hline & & 61 & 24 & 19 & 11 \\
\hline & Control & 0 & 24 & 6 & 1 \\
\hline Total & & & 543 & 353 & 216 \\
\hline
\end{tabular}

\subsubsection{Herbicide concentration reduction over time}

The concentration of triclopyr + TBEE decreased rapidly following application. For example, a $72 \%$ reduction in triclopyr + TBEE concentration occurred over one month following herbicide application, representing a statistically significantly decrease $(\mathrm{p}<0.0001)$ (Figure 31 and Table 12). After two months, the average concentration of triclopyr + TBEE was $82 \%$ lower than the initial concentration. An average $98 \%$ reduction of triclopyr + TBEE occurred seven months after herbicide 
application. The reduction in triclopyr + TBEE concentration was most pronounced in soils directly adjacent to treated stumps, which showed $88 \%$ herbicide reduction in the first month, followed by a $99 \%$ decrease within three months. Based upon the field data, the half-life for triclopyr + TBEE in soil adjacent to treated stumps across surfactant treatment ranged from 7.6-57 days (average 25 days). These values agree with other published studies (Ganapathy 1997; Tu et al. 2001).

Table 12. Average percent reduction of triclopyr + TBEE over the seven month study period. TBEE, triclopyr 2-butoxyethyl ester.

\begin{tabular}{|c|c|c|c|}
\hline \multirow{2}{*}{$\begin{array}{c}\text { Distance from } \\
\text { treated stump (cm) }\end{array}$} & One Month & Three Months & Seven Months \\
\cline { 2 - 4 } & \multicolumn{3}{|c|}{ \% reduction triclopyr + TBEE } \\
\hline 0 & 88 & 99 & 100 \\
\hline 30.5 & 61 & 86 & 97 \\
\hline 61 & 67 & 62 & 96 \\
\hline Average & 72 & 82 & 98 \\
\hline
\end{tabular}

\subsubsection{Herbicide concentration within each soil series}

The relationship between each surfactant type and soil series was examined at three distances for triclopyr + TBEE and TCP (Figure 31). Note that following herbicide application, the concentration of triclopyr + TBEE decreases while the concentration of the degradation byproduct TCP displays an initial increase. This relationship is expected and demonstrates that herbicide degradation is occurring under field conditions. The degradation continues throughout the study period; however, the rate of degradation slows as the total amount of herbicide within the soil is reduced over time. Soil adjacent to treated stumps had significantly higher concentrations of triclopyr + TBEE $(\mathrm{p}<0.0001)$ and TCP $(\mathrm{p}<0.0001)$ across each soil series examined (Figure 31). The control sites had significantly lower concentrations of triclopyr + TBEE ( $p=0.0037$; Figure 32 ) and TCP ( $p=0.0039$; Figure 33) across soil series. There was no significant difference between the concentration of triclopyr + TBEE or TCP in RU-MSO and RU-diesel treatments at $30.5 \mathrm{~cm}$ from treated stump (Figure 34 and Figure 35 respectively). Similarly, there was no significant difference in triclopyr + TBEE or TCP concentrations $n$ RU-MSO and RUdiesel treatments at $61 \mathrm{~cm}$ from treated stump (Figure 36 and Figure 37 respectively). There was no significant difference across soil series between either triclopyr + TBEE $(\mathrm{p}=0.5420)$ or TCP $(\mathrm{p}=0.1843)$ with time after herbicide application. 
Figure 31. Mean ( \pm SE) concentration of triclopyr + TBEE (upper) and TCP (lower) across all soils by treatment and distance from the cut stump.

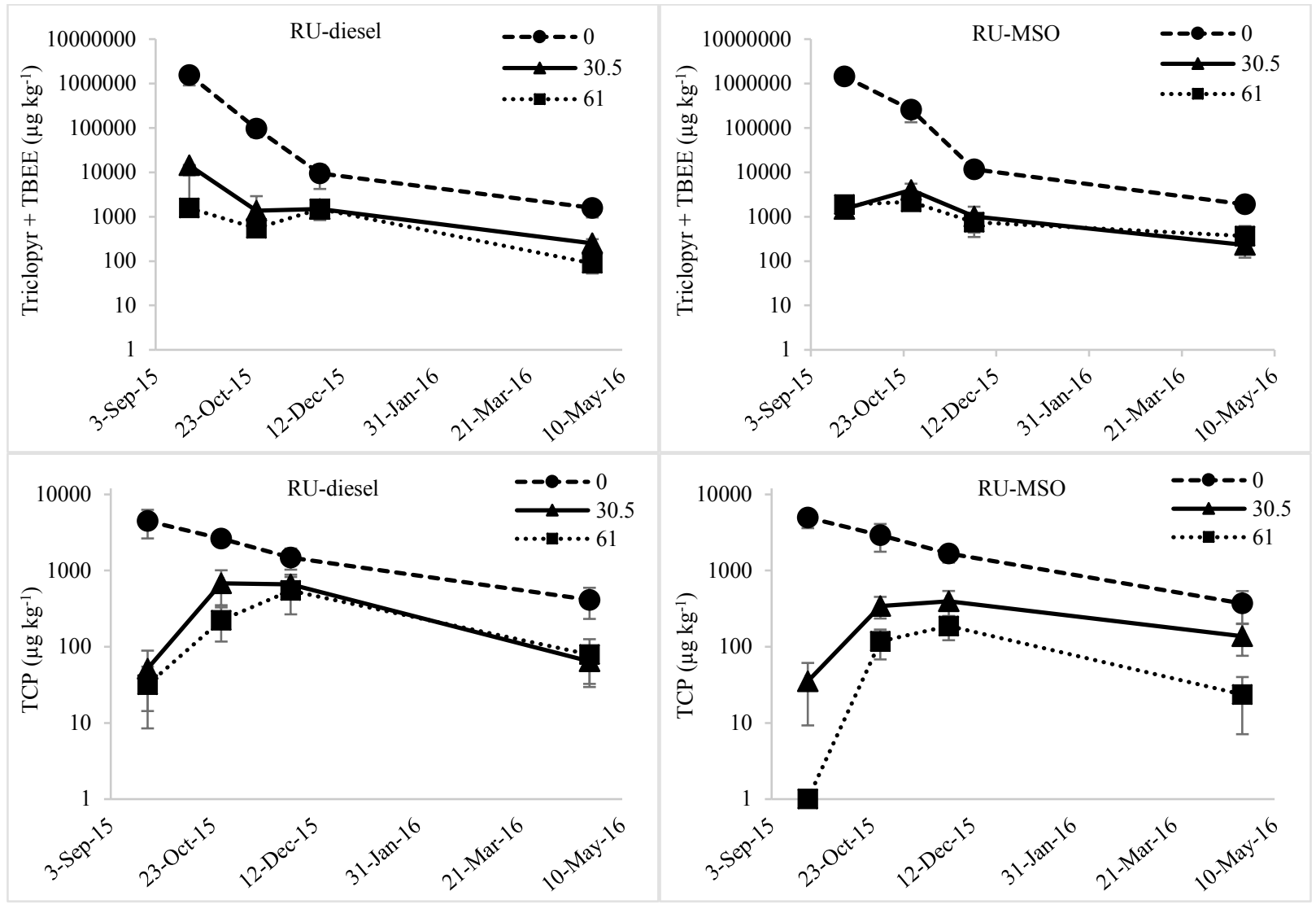


Figure 32. Mean ( \pm SE) concentration of triclopyr + TBEE in soils located adjacent to treated stumps $(0 \mathrm{~cm})$ by treatment in each soil series and across all soil series.

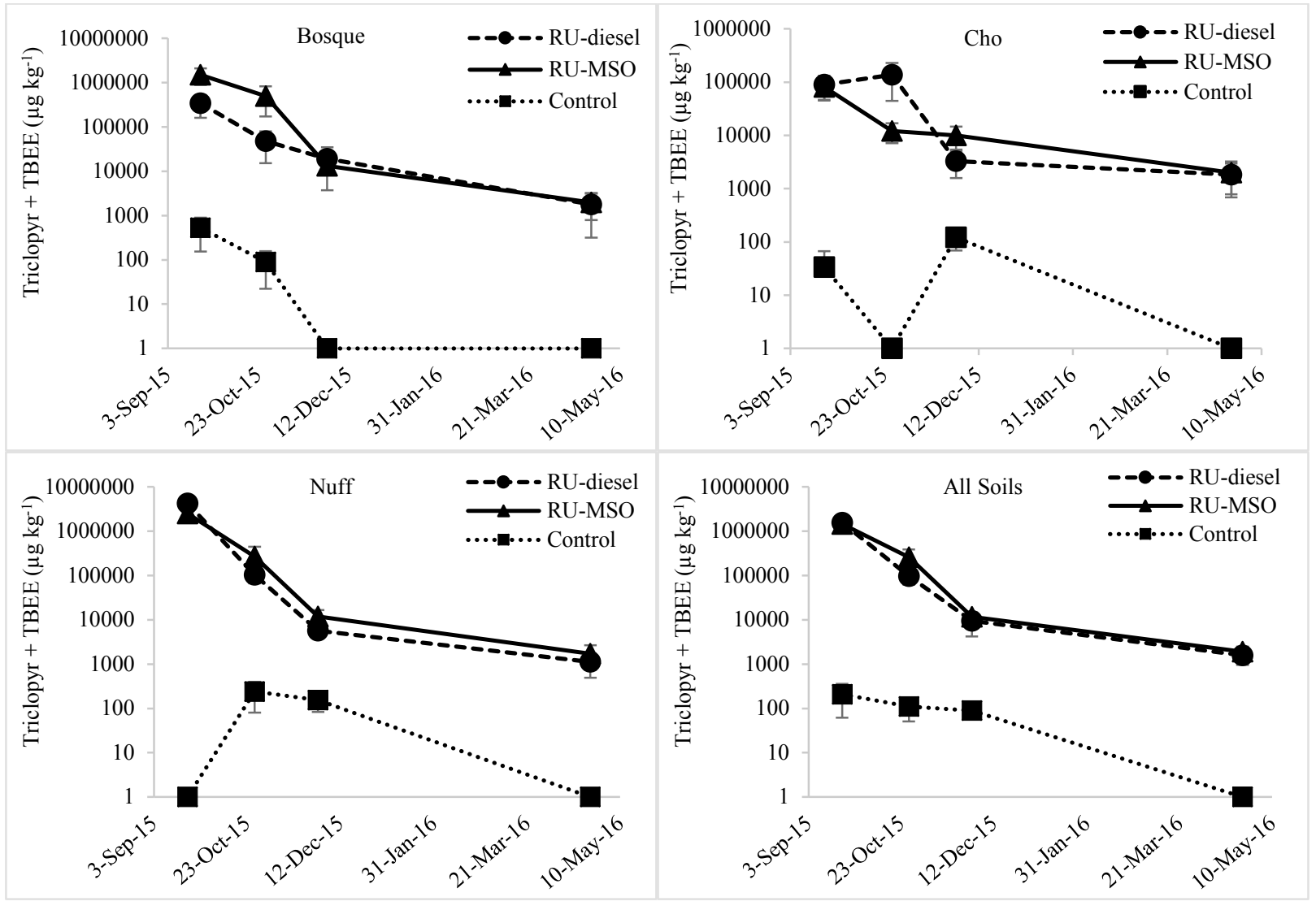


Figure 33. Mean ( \pm SE) concentration of triclopyr + TBEE in soils located $30.5 \mathrm{~cm}$ from treated stumps by treatment in each soil series and across all soil series.

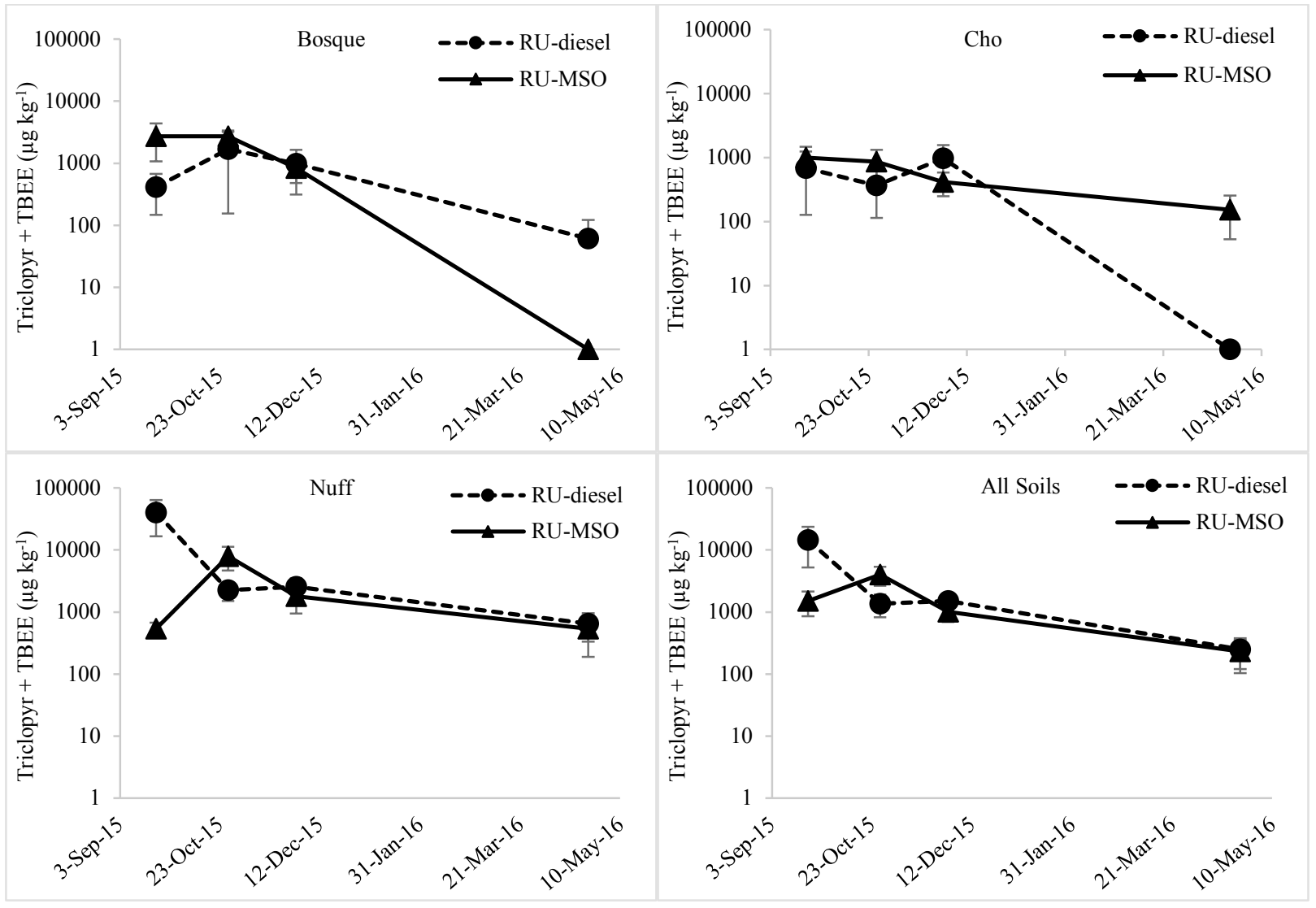


Figure 34. Mean ( \pm SE) concentration of TCP in soils located $30.5 \mathrm{~cm}$ from treated stumps by treatment in each soil series and across all soil series.

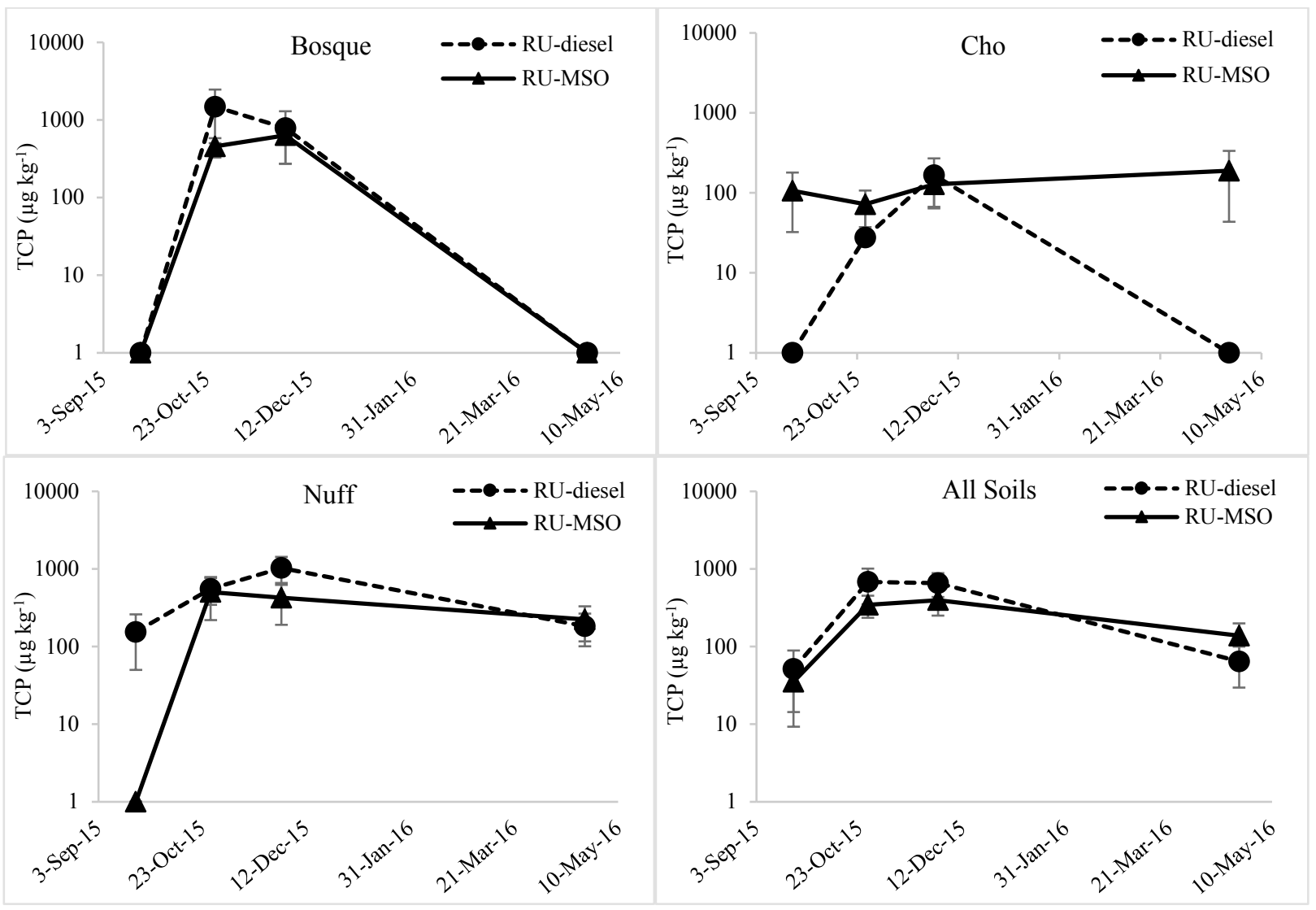


Figure 35. Mean ( \pm SE) concentration of triclopyr + TBEE in soils located $61 \mathrm{~cm}$ from treated stumps by treatment in each soil series and across all soil series.

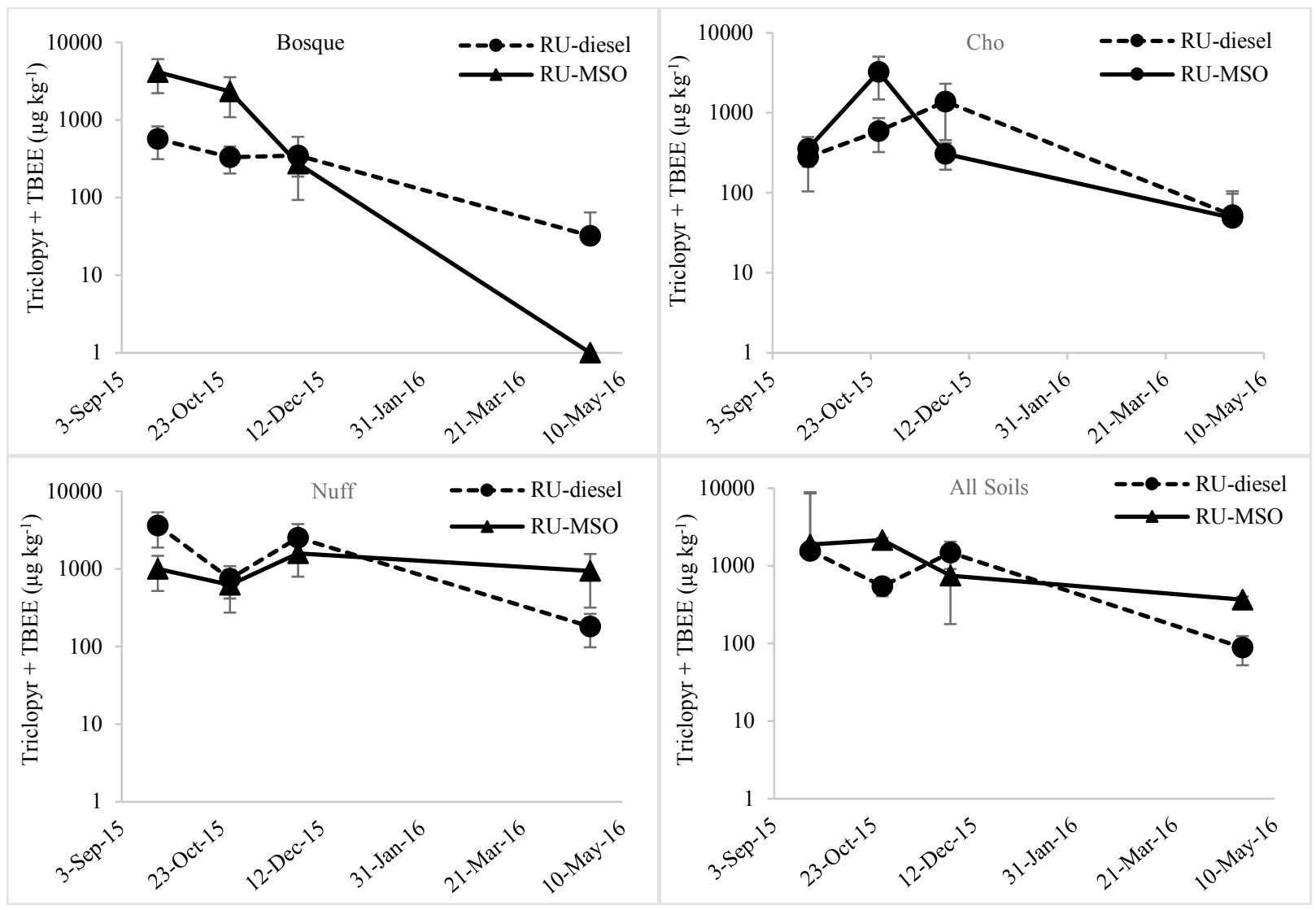


Figure 36. Mean ( \pm SE) concentration of TCP in soils located $61 \mathrm{~cm}$ from treated stumps by treatment in each soil series and across all soil series.

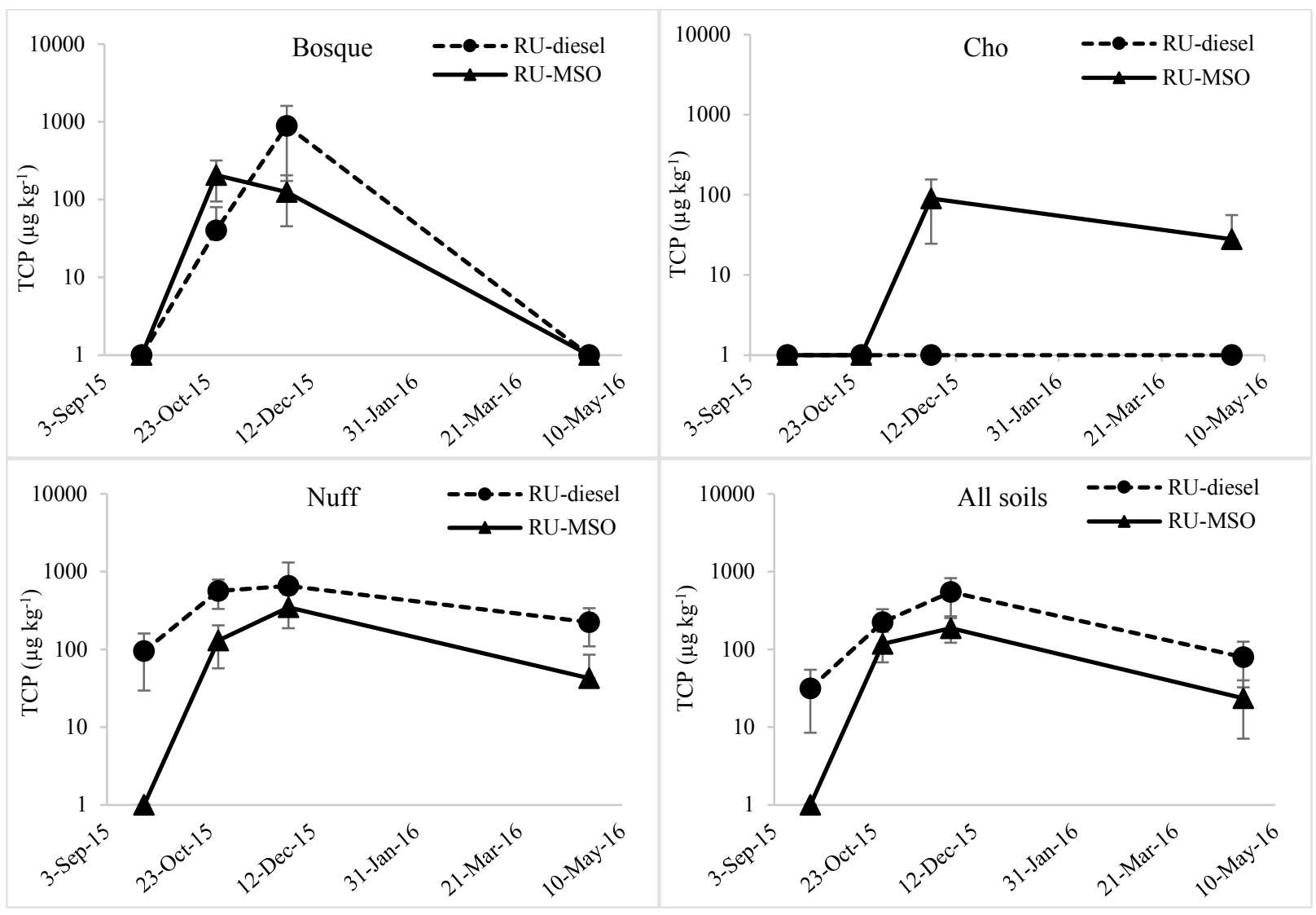

\subsubsection{Treatment effect on herbicide concentrations in soils}

The relationship between treatments within a soil series was examined across distance from the cut stump application area and time. The concentration of triclopyr + TBEE was significantly lower in October than in September at herbicide treated stumps ( $\mathrm{p}<0.0001)$ (Figure 38). There was no significant difference between the concentration of triclopyr + TBEE between RU-MSO and RU-diesel treatments when compared with distance from treated stump $(\mathrm{p}=0.5339)$ or time after herbicide application ( $\mathrm{p}=0.0743)$ within each soil series examined (Figure 38 ). There was also no significant difference between the concentration of TCP between RU-MSO and RU-diesel treatments when compared with distance from treated stump $(\mathrm{p}=0.7727)$ or time after herbicide application ( $p=0.2649$; Figure 39). Within each soil series, soils directly adjacent to RU-MSO and RU-diesel treated stumps had significantly higher concentrations of triclopyr + TBEE ( $\mathrm{p}=0.0001$; Figure 38$)$ and TCP $(p<0.0001$; Figure 39) than soils collected further from the point of application. 
Figure 37. Mean concentration of triclopyr + TBEE ( \pm SE) by treatment, RU-diesel (left) RU-MSO (right) over time and distance $(\mathrm{cm})$ within each soil series examined.

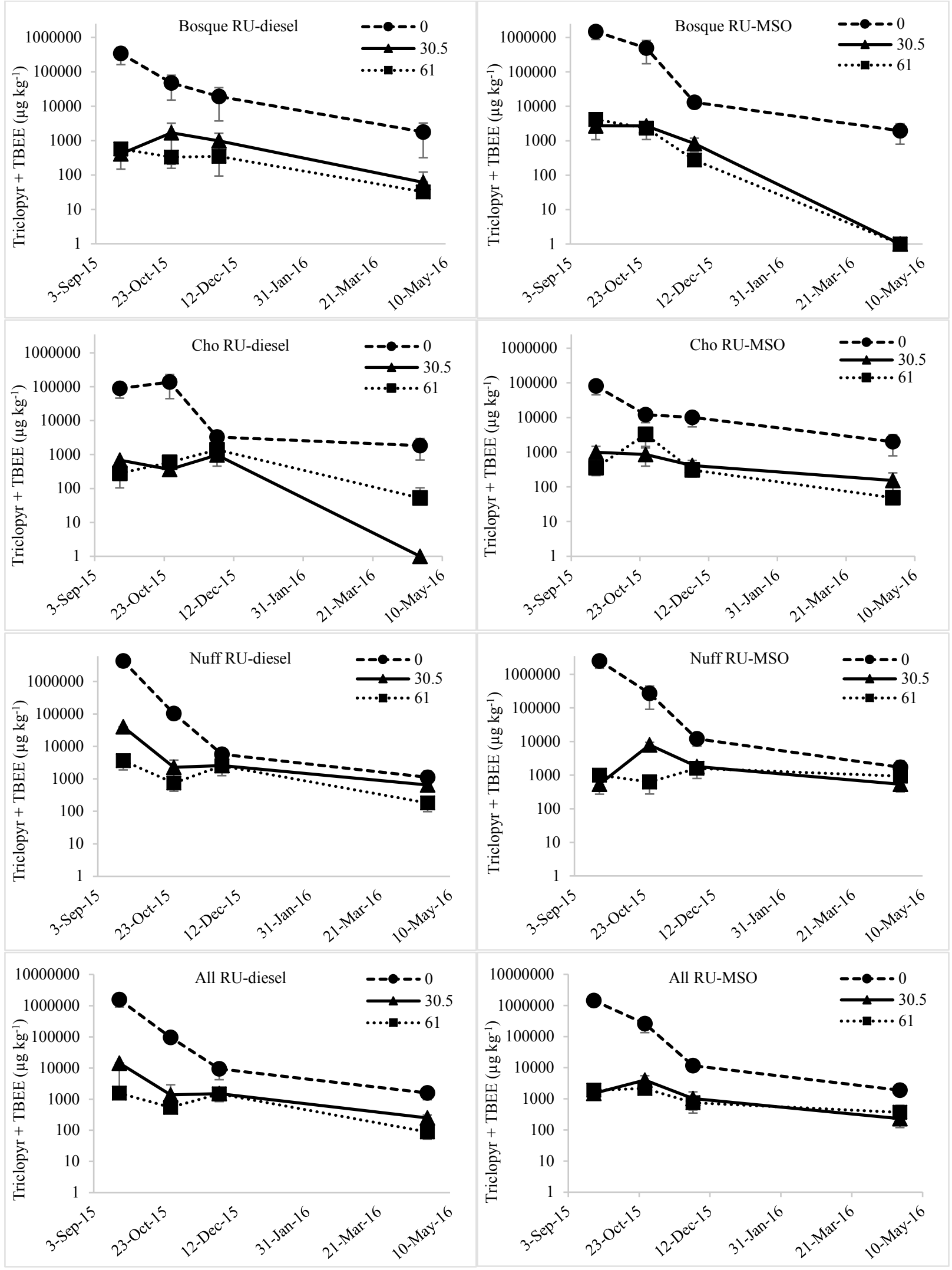


Figure 38. Mean concentration of TCP ( \pm SE) by treatment RU-diesel (left), RU-MSO

(right) over time and distance $(\mathrm{cm})$ by soil series and over all soil series.

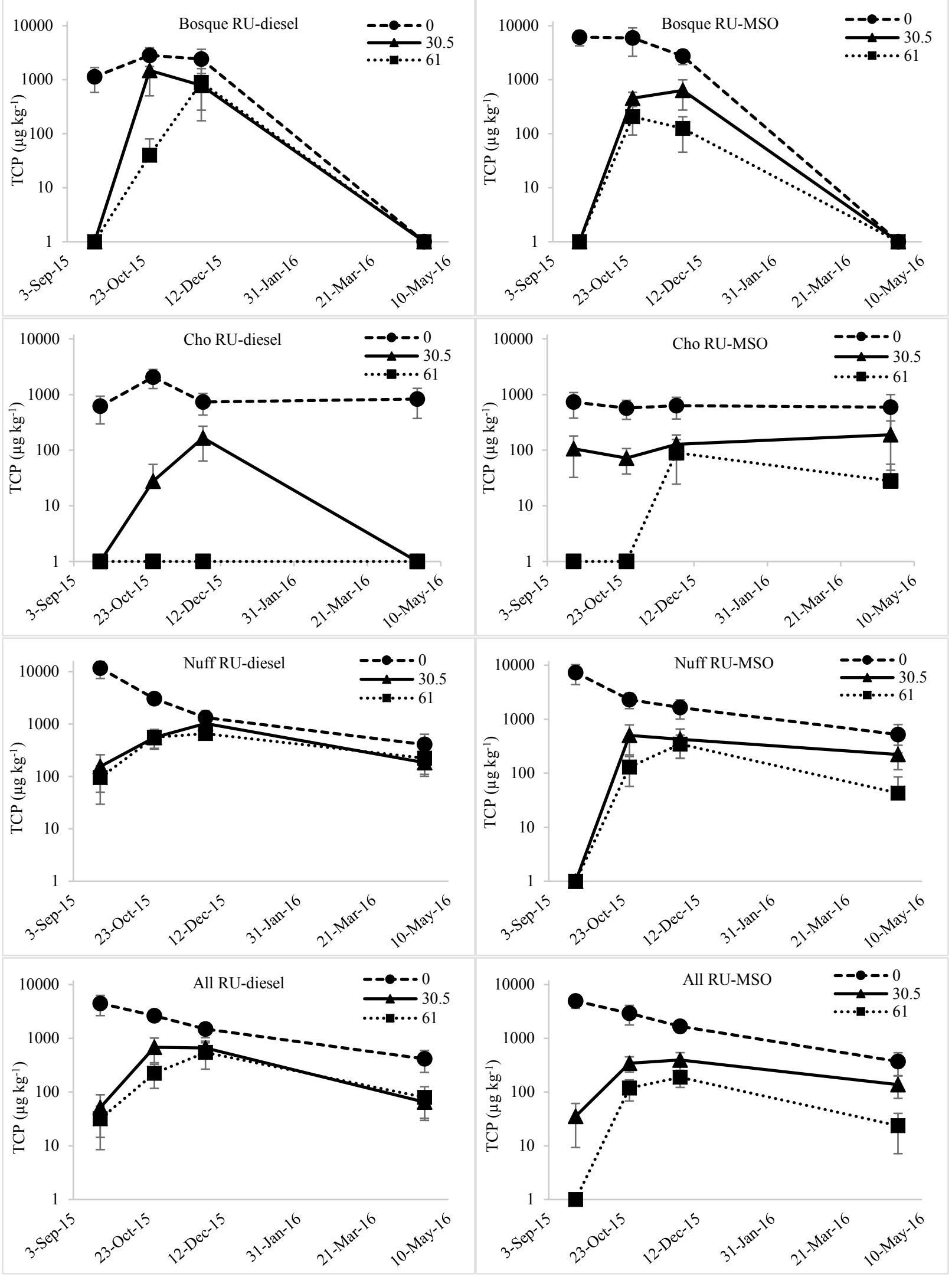




\subsubsection{Water analysis}

Two aquatic resources, Cowhouse Creek (Bosque study area) and a large pond located adjacent to the Nuff study area, were sampled throughout the study period following herbicide application. Triclopyr, TBEE, and TCP were not detected prior to herbicide application in Cowhouse Creek or the pond. When present, standing water on the soil surface was collected within the study areas. This occurred at the Bosque and Cho locations in October 2015, November 2015, and April 2016; and at the Nuff location in April 2016. Triclopyr, TBEE, or TCP were not detected in Cowhouse Creek or the large pond adjacent to the Nuff study area at any point following herbicide application. Triclopyr was detected at a low concentration, $0.0267 \mathrm{mg}$ L-1 in standing water located in the Bosque soil in October 2015. This standing water sample was the only water collected during the study to have a trace amount of triclopyr present. However, the concentration remained near the reporting concentration of $0.2 \mathrm{mg} \mathrm{L}^{-1}$. Triclopyr, TBEE, and TCP were not detected in standing water in the Cho or Nuff soils.

\subsection{Discussion}

Fort Hood and other military installations require management to maintain open grassland habitats to accomplish the training mission. Grassland habitat areas are maintained by a variety of techniques, including the removal and control of woody species encroachment using the herbicides such as RU. The active ingredient in RU, triclopyr as well as related compounds were assessed in soil and water under field conditions to evaluate potential fate and transport (Ganapathy 1997).

The concentration of triclopyr + TBEE in soil declined over time, particularly within the first month following application. The half-life for triclopyr + TBEE in soil adjacent to treated stumps ranged from 7.6-57 days (average 25 days), which is similar to previously published average halflives (30 days) for triclopyr (Tu et al. 2001). Triclopyr is degraded through several pathways to TCP. The major pathway for triclopyr degradation and TCP production in soil is through microbial metabolism, especially under warm, moist conditions (Tu et al. 2001). Photolysis and hydrolysis are minor triclopyr degradation pathways in soil, but play a larger role in compound degradation in aquatic environments. Microbial activity and degradation of triclopyr is enhanced with increases in temperature and moisture (Newton, 1990; Ganapathy 1997). Both warm and unusually wet 
conditions at Fort Hood in 2015 supported favorable conditions for herbicide degradation via the microbial metabolic pathway (Figure 40).

Figure 39. Daily measured precipitation events with soil sampling events (black arrows) at Stillhouse Hollow Dam (Bell County, TX) weather station for 2015. The black line is the normal precipitation and the dashed lines are $\pm 30 \%$.

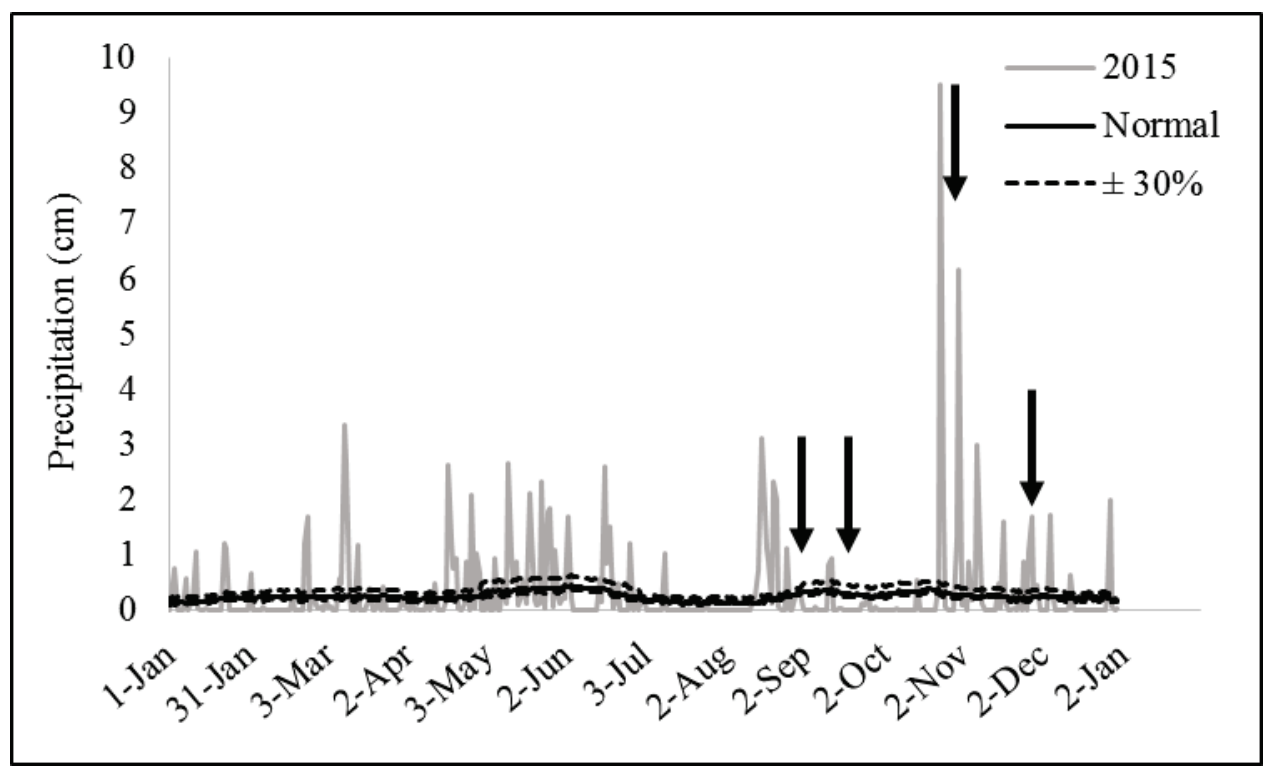

Soil properties that govern the potential extent of triclopyr movement and degradation, such as organic matter and CEC, are routinely recorded in soil series descriptions (Soil Survey Staff, 1999). All soils were characterized as Mollisols, which exhibit dark colored surface horizons and high levels of base saturation on the soil CEC. Mollisols commonly display mollic or humic rich layer, and/or argillic (high $\mathrm{Si}$ ), natric (mineral horizon) or calcic (high $\mathrm{Ca}$ ) horizons. It is also possible to have a petrocalcic horizon in these soils (USDA 2017). The Bosque soil has more humic material than the other soil types examined. The Cho and Nuff series contained very high levels of calcium, especially the Cho which is characterized by the presence of a shallow petrocalcic horizon.

There were inherent physical and chemical differences in these soil types that may impact the potential fate and transport of herbicides in these systems. In general, the Cho and Nuff soils are physicochemically very similar with an exception of a few properties. The CEC of Cho soils is higher than it is for the Nuff and Bosque soils. High CEC indicates that the Cho soils may exhibit higher retention of certain compounds and soil nutrients than Nuff or the Bosque soil. The Bosque soil has a higher percentage of sand than the Cho and the Nuff soils which may increase its 
ability to leach soil solution. However, the Bosque soil contained higher carbon values (TC, TOC, TIC) than the Cho and Nuff soils. High carbon contents are associated with higher retention of compounds, including many herbicides. The $\mathrm{pH}$ does not appear to be significantly different across the soil types, thus is not likely to be an important driver of herbicide retention in these soils. Previous soil sorption studies indicted sorption of triclopyr to soil increases with time (Buttler et al. 1993), organic matter (Ghassemi et al. 1981), and CEC (Pusino et al. 1994). Other studies link higher CEC and organic matter with high triclopyr adsorption to soil (Pusino et al. 1994), potentially explaining the significantly higher triclopyr + TBEE seen in soils located adjacent to treated stumps. In summary, Bosque, Nuff, and Cho soils each exhibit soil properties associated with high compound retention capacity. The soil physicochemical properties suggest limited potential for herbicide transport, which agrees with the soil and water concentrations observed throughout the study period.

The current study examined two herbicide-surfactant treatments, RUMSO and RU-diesel. Soil concentrations remained similar under both treatments (i.e., no statistically significant differences) and across the three soil series examined. These findings suggest that both RU-MSO and RU-diesel treatment remained bound to the soils adjacent to treated stumps with limited potential transport. The concentration of triclopyr + TBEE declined on average $72 \%$ over the first month following application in both RU-MSO and RU-diesel treatments, followed by $98 \%$ reduction in concentration during the study period, further supporting the microbial degradation pathway.

Available literature suggests that triclopyr displays a low potential for lateral movement (Newton et al. 1990; Stephenson et al. 1990). Neither Triclopyr + TBEE nor TCP were detected in a nearby aquatic resources during the study period, supporting previous studies. Other studies failed to identify triclopyr in downstream water, suggesting limited risk for triclopyr leaching to surface or subsurface water (Norris et al., 1987). Triclopyr was detected at a low level, $0.0267 \mathrm{mg} \mathrm{L}^{-1}$ (reporting limit 0.02 $\mathrm{mg} \mathrm{L}^{-1}$ ) in standing water located in the Bosque series the day after an unusually large rain event in October 2015 ( $\sim 9 \mathrm{~cm}$; Figure 39). This was the only detection of triclopyr in any standing, creek, or drainage pond water during the study period. 
Based upon the data collected under field conditions, triclopyr, TBEE, and TCP were largely retained on the soil surface, where degradation occurred. These findings are supported by the steady decline in herbicide concentration over time. If lateral transport occurred, herbicide concentrations would have increased with distance from the treated stump over time. This was not observed. Similarly, if substantial vertical transport occurred, herbicide concentrations would decrease irregularly following substantial rain events. This was also not observed.

Additionally, herbicides were absent from surface water bodies adjacent to the treatment areas, further supporting a limited transport-microbial degradation model. These observations, along with the results of previously published literature, support limited transport of triclopyr and related compounds within the soil matrix.

\subsection{Summary}

Herbicide concentrations in soil and water were assessed under field conditions for potential fate and transport. The soil series displayed similar responses to herbicide application. Also, the surfactants treatments (RU-MSO and RU-diesel) yielded similar results. The concentration of triclopyr + TBEE was significantly higher in soil adjacent to treated stumps and decreased markedly within the first month. The average halflife was 25 days across treatment and soil series. Neither triclopyr + TBEE nor TCP were detected in a nearby aquatic resources during the study period and only one low concentration sample occurred in standing water following a large rain event. Soil properties that govern the potential extent of triclopyr movement and degradation were assessed by examining triclopyr application in the three soil series. Bosque, Cho, and Nuff soils each display physicochemical parameters associated with high potential for compound retention. These soil properties, coupled with the observed patterns of soil concentration and reduction, support a limited transportmicrobial degradation model for herbicide application within the study area. 


\section{Laboratory Investigation of Herbicide Soil Affinity and Degradation}

\subsection{Introduction}

Natural resource managers frequently need to control the growth of woody vegetation in order to maintain open grassland habitats. Management activities associated with woody vegetation control often apply herbicides to cut stumps. This approach minimizes herbicide use compared to other applications methods (e.g., aerial spraying). However, treatment application parameters must be optimized to diminish potential transport and persistence in the environment.

When examining the potential for herbicide transport, studies often examine the degree to which compounds are attracted to, and held within the soil matrix, most commonly referred to as soil sorption. Sorption studies utilize techniques in which a known concentration of herbicide is mixed with soil under laboratory conditions. Once the soil-herbicide mixture reaches equilibrium, the distribution of herbicide in solution and in the soil is determined. The distribution of herbicide between aqueous and solid phases is described by a soil adsorption coefficient $(\mathrm{k} \neg d)$ or a soil-organic matter partitioning coefficient (koc). Herbicides that bind tightly to the soil (e.g., high sorption, high $\mathrm{k}_{d}$ ) display limited mobility and pose little threat to off-site resources. Conversely, herbicides with low sorption have the capacity for rapid transport via ground and surface waters, increase the risk of environmental impact to aquatic resources.

The herbicide treatment at Fort Hood utilized Remedy Ultra (RU), with the active ingredient triclopyr butoxyethyl ester (TBEE) (Dow AgroSciences 2008). As shown in Figure40, TBEE rapidly undergoes hydrolysis in water, converting to triclopyr, the compound exhibiting phytotoxicity (Ganapathy 1997). When RU is added to water it forms a cloudy white suspension (Figure 41). This reaction with water is likely the result of adjuvants; a proprietary chemical mixture added to the herbicide formulation to increase plant control efficacy. Formation of the white suspension may also result from the low solubility of TBEE $\left(6.81 \mathrm{mg} \mathrm{L}^{-1}\right)$ before it rapidly converts to triclopyr, which has a reported solubility of $440 \mathrm{mg} \mathrm{L}^{-1}$ (Ganapathy 1997). However, when the herbicide was applied in the field, it was mixed with surfactants as described in Section 3.2.1 (RUMSO and RU-diesel treatments). The adjuvants and wetting agents likely 
influence the solubility of both TBEE and triclopyr. Additionally, suspension formation coupled with the unknown influence of wetting agents on solubility increases the complexity of sorption experiments. As a result, the current study utilizes the term affinity in place of the term sorption to describe the partitioning of herbicide compounds between soil and water. The symbol $\mathrm{k}^{\prime}$ is applied to describe the affinity of herbicide compounds for the soils examined.

Previous studies have found that TBEE has a KOC value of 6,000, indicating a strong affinity to soil, resulting in low mobility (McCall and Gavit 1986). However, TBEE rapidly hydrolyzes to triclopyr, which has a much lower KoC of 27 (McCall and Gavit 1986). Therefore, triclopyr should be considered relatively mobile compared with TBEE. However, the application of surfactants (RU-MSO and RU-diesel) likely alter herbicide solubility. Regarding compound persistence, triclopyr's major degradation pathway in water is photolysis, resulting in a half-life of 1.3 days (Linders et al. 1994). In soil, microbial degradation dominates, with a reported halflife of 12-27 days (Linders et al. 1994). These half-lives are relatively short, indicating low environmental persistence of the phytotoxic chemical in RU. The manufacturer-recommended application mixture with wetting agents may change the persistence of triclopyr in the environment.

Figure 40. Triclopyr butoxyethyl ester (TBEE) as found in Remedy Ultra (RU), the precursor to the active ingredient triclopyr and its degradation pathways in soil and water. Adapted from Ganapathy 1997.

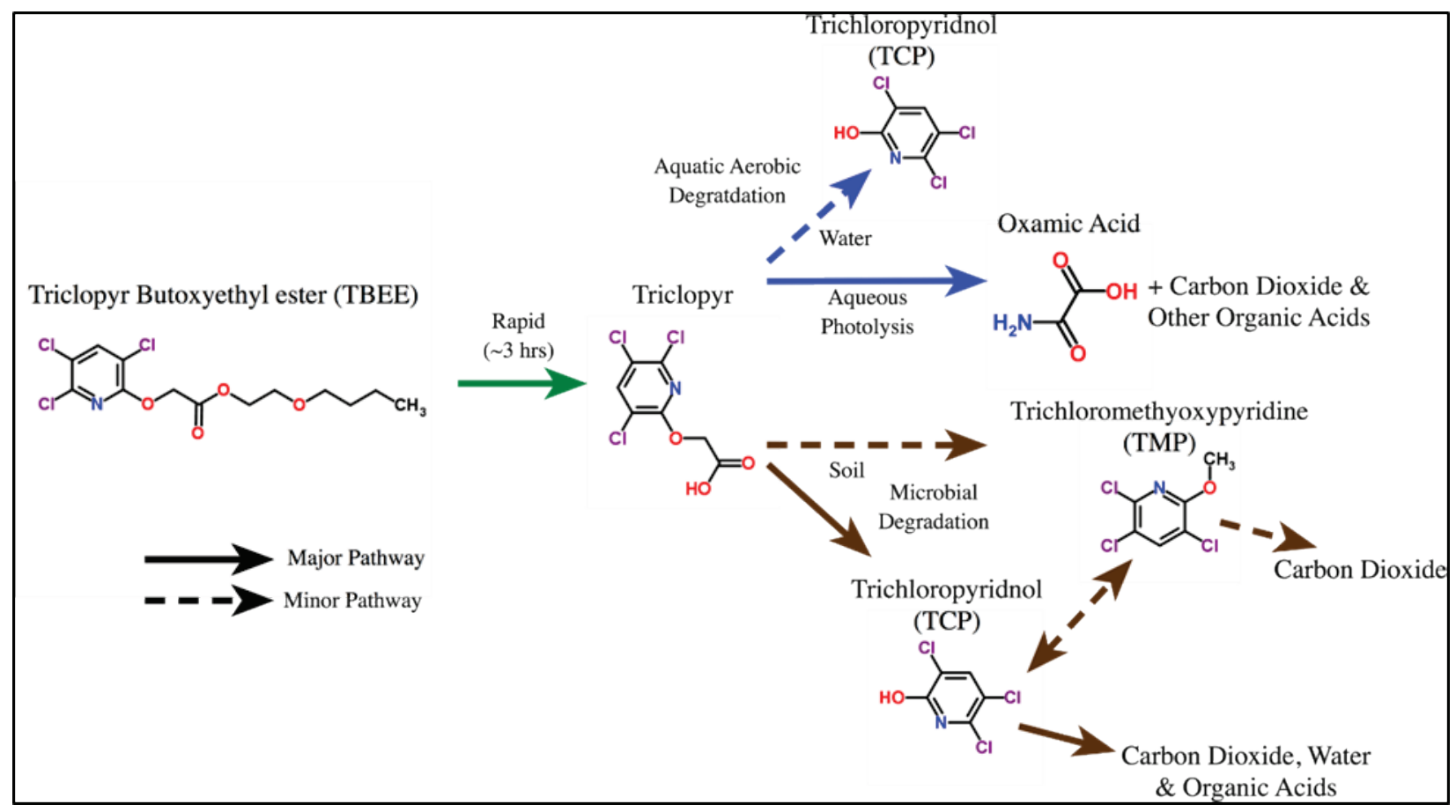


Figure 41. The white suspension formed when mixing Remedy Ultra (RU) with water.

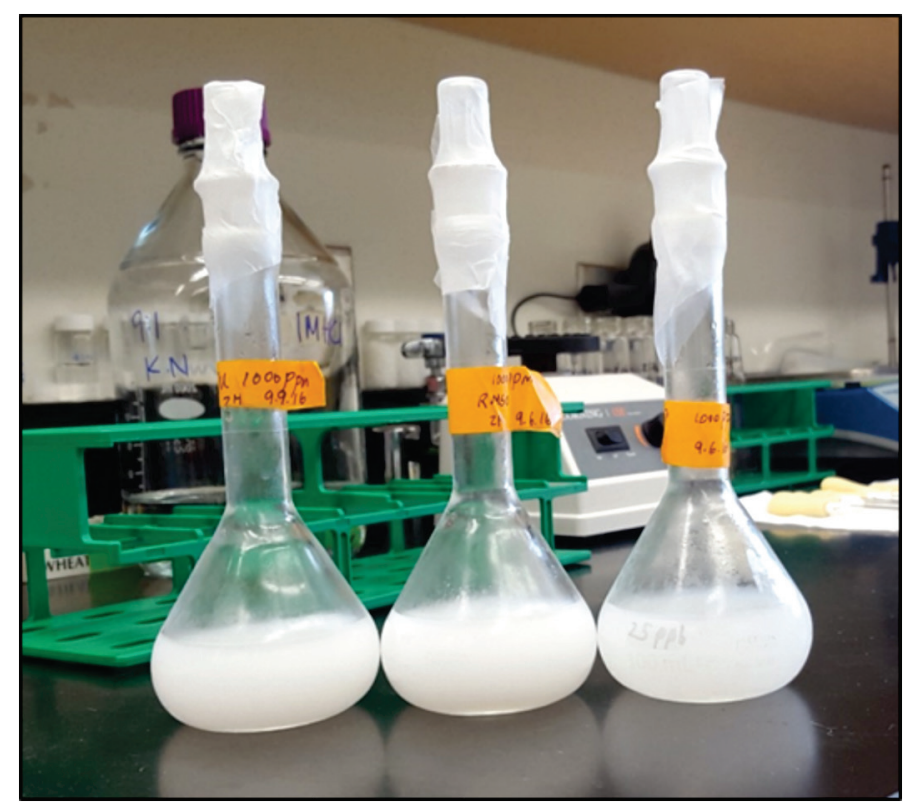

While there is some published data that provides insight into how the active ingredients in RU (TBEE and triclopyr) might behave in the environment, transport and fate of the herbicide at Fort Hood could vary based on the manufacturer-recommended application mixture and specific soil properties. Therefore, in this study, the affinity and degradation of TBEE and triclopyr were examined in three soils from Fort Hood when the herbicide was applied per manufacturer recommendation.

\subsection{Objective of laboratory soil affinity and degradation studies}

Affinity and degradation studies generate data that helps to understand compound behavior once released to the environment. This includes insight into a compound's transformation, potential organismal uptake, and environmental transport (OECD 2000). As a result the Section 4.3 provides data and analysis to improve our understanding of potential herbicide transport and persistence by utilizing laboratory microcosm studies examining the affinity and degradation of herbicides to three soils from Fort Hood. 


\subsection{Methods}

\subsubsection{Soils}

Bosque, Nuff, and Cho soils were collected at the Fort Hood Army Installation in June 2015. The soils were sieved to $2 \mathrm{~mm}$ to remove large debris and homogenize soils prior to microcosm studies. The total organic carbon (TOC) for Bosque (clay loam), Nuff (very stony silty clay loam) and Cho (clay loam) was $20.3 \pm 6.1,14.0 \pm 2.8$ and $14.8 \pm 0.9 \mathrm{mg} \mathrm{C} \mathrm{kg}^{-1}$ respectively. Additional soil properties can be found in Appendix A.

\subsubsection{Soil affinity, concentration effects, and desorption}

To understand soil partitioning of herbicides, a sorption coefficient ( $\mathrm{K}_{d}$, $\mathrm{cm}^{3} \mathrm{~g}^{-1}$ ) is determined. However, due to the formation of a suspension when RU is mixed in water (as described in Section 4.1), the term affinity $\left(\mathrm{K}_{d^{\prime}}, \mathrm{cm}_{3} \mathrm{~g}^{-1}\right)$ is used in this study. To determine partitioning coefficients of triclopyr in three soils, batch equilibrium studies were conducted using OECD (Organization for Economic Cooperation and Development) method 106 (OECD 2000). These benchtop studies involve adding a predetermined mass of soil ( $2 \mathrm{~g}$ ) to a glass vial, followed by $10 \mathrm{ml}$ of a 0.01 $\mathrm{M} \mathrm{CaCl}_{2}$ aqueous solution. The solution also contained $100 \mathrm{mg} \mathrm{L}^{-1} \mathrm{NaN}_{3}$ to prevent biotic degradation. Next, samples were spiked with one of three treatments (Table 13) and incubated in the dark on a shaker for 72 hours. All treatments were prepared in quadruplicate.

Table 13. Soil treatments used during the sorption, desorption and degradation microcosm studies. The RU-MSO and RU-diesel treatments with wetting agents were mixed at a $75: 25$ ratio.

\begin{tabular}{|c|c|c|}
\hline Soil & Target analyte concentration & Treatment \\
\hline Bosque & $25 \mathrm{mg} \mathrm{L}^{-1}$ TBEE & RU-control \\
\hline Bosque & $25 \mathrm{mg} \mathrm{L}^{-1}$ TBEE & RU-MSO \\
\hline Bosque & $25 \mathrm{mg} \mathrm{L}^{-1}$ TBEE & RU-diesel \\
\hline Nuff & $25 \mathrm{mg} \mathrm{L}^{-1}$ TBEE & RU-control \\
\hline Nuff & $25 \mathrm{mg} \mathrm{L}^{-1}$ TBEE & RU-MSO \\
\hline Nuff & $25 \mathrm{mg} \mathrm{L}^{-1}$ TBEE & RU-diesel \\
\hline Cho & $25 \mathrm{mg} \mathrm{L}^{-1}$ TBEE & RU-control \\
\hline Cho & $25 \mathrm{mg} \mathrm{L}^{-1}$ TBEE & RU-MSO \\
\hline Cho & $25 \mathrm{mg} \mathrm{L}^{-1}$ TBEE & RU-diesel \\
\hline
\end{tabular}


After incubation, samples were removed from the shaker, centrifuged at 2500 rpm for six minutes, the aqueous phase was removed and then acidified to $\mathrm{pH} 2$ with $1 \mathrm{~N} \mathrm{HCl}$. Prior to analysis, acetone (10\% for RU and RU-MSO treatments and 30\% for the RU-diesel treatment) was added to each sample to improve recoveries of the target analytes.

The combined concentration of TBEE and triclopyr measured in each samples solution was used to calculate the sorption potential $\left(\mathrm{K}_{d^{\prime}}, \mathrm{cm}^{3} \mathrm{~g}^{-1}\right)$ of the active ingredient in RU.

$$
K_{d}{ }^{\prime}\left(\mathrm{cm}^{3} \mathrm{~g}^{-1}\right)=\frac{C_{s}^{a d s}(e q)}{C_{a q}^{a d s}(e q)}
$$

Equation 1

In Equation 1, the equilibrium (eq) concentration in soil $\left(C_{s}^{a d s}\right)$ is divided by the concentration in water $\left(C_{a q}^{a d s}\right)$.Soil treatments were designed to mimic field conditions. As a result, laboratory studies utilized $25 \mathrm{mg} \mathrm{L}^{-1}$ treatment concentrations, which closely matched the $17 \mathrm{mg} \mathrm{kg}^{-1}$ concentration observed in field data one month after initial herbicide application. For all samples, $25 \mathrm{mg} \mathrm{L}^{-1}$ refers to the concentration of TBEE added. For RU only treatments, $25 \mathrm{mg} \mathrm{L}^{-1}$ of TBEE in the RU formulation was added to each vial.

To test the effect of concentration on affinity, batch equilibrium microcosms were conducted using the Bosque soil at a variety of TBEE concentrations (e.g., 25, 50, 100 and $200 \mathrm{mg} \mathrm{L}^{-1}$ ). In addition to $\mathrm{K}_{d^{\prime}}$ values, Freundlich isotherms $\left(\mathrm{K}_{F}{ }^{\prime}\right)$ were determined to assess chemical affinity over a range of concentrations. The isotherms are determined by graphing the log-transformed values of concentrations in solution at equilibrium with the log-transformed concentration of the compound sorbed to soil at equilibrium.

Desorption studies follow similar protocols as the affinity analysis described above, where samples were spiked, incubated and the aqueous fraction is separated and analyzed. The target analytes and water content remaining in the soil fraction was then calculated using a mass balance approach. Next, fresh $\mathrm{CaCl}_{2}$ solution was added to the vials and incubated for 72 hours. The vials were then centrifuged and the solution separated and analyzed for target analytes. The desorption coefficient $\left(\mathrm{K}_{\mathrm{des}}{ }^{\prime}\right)$ was then determined using the following calculations: 


$$
\mathrm{K}_{\mathrm{des}}{ }^{\prime}\left(\mathrm{cm}^{3} \mathrm{~g}^{-1}\right)=\frac{\mathrm{m}_{\mathrm{s}}^{\mathrm{ads}}(\mathrm{eq})-\mathrm{m}_{\mathrm{ad}}^{\mathrm{des}}(\mathrm{eq})}{\mathrm{m}_{\mathrm{aq}}^{\mathrm{des}}(\mathrm{eq})} \times \frac{\mathrm{V}_{\mathrm{T}}}{\mathrm{m}} \quad \text { Equation } 2
$$

In Equation 2, the mass of analyte in the soil after desorption $\left(\mathrm{m}_{\mathrm{ad}}^{\mathrm{des}}\right)$ is subtracted by the mass in soil after affinity equilibrium $\left(\mathrm{m}_{\mathrm{s}}^{\text {ads }}\right)$, which is then divided by $\mathrm{m}_{\mathrm{ad}}^{\mathrm{des}}$. This is then multiplied by the total aqueous soil volume during desorption $\left(\mathrm{V}_{T}, L\right)$ divided by total soil mass ( $\left.\mathrm{m}_{\text {soil }}, \mathrm{g}\right)$.

\subsubsection{Degradation}

To investigate herbicide degradation, all samples were prepared as described above for affinity studies, but without $\mathrm{NaN}_{3}$ application. This allows for biotic degradation to occur. Samples of treatment were prepared so that quadruplicates of vials could be extracted after 1, 7, 14, and 30 days in the three soils examined. An additional incubation period of 60 days was included for the Cho soil. The experiment length was determined based on published data by the California Department of Pesticide Regulation (Ganapathy 1997). After each period, vials were weighed, centrifuged at $2500 \mathrm{rpm}$ for six minutes and the aqueous solution transferred to a separate container. The mass of water remaining in the vial with soil was determined by mass balance. The aqueous fraction was then processed and analyzed per methods described in the affinity section above. The soil fraction was acidified to $\mathrm{pH} 2$ with $8-12 \mathrm{~mL}$ of concentrated $\mathrm{HCl}$ depending on soil type. Next, soils were extracted with $25 \mathrm{~mL}$ of a 9:1 acetonitrile to $1 \mathrm{~N} \mathrm{HCl}$ solution, sonicated for five minutes and shaken for at least two hours. Samples were then centrifuged and the liquid phase was transferred to a collection vial. Another $15 \mathrm{~mL}$ of the 9:1 acetonitrile, $1 \mathrm{~N} \mathrm{HCl}$ solution was added to the soil, sonicated for five minutes and then shaken for 30 minutes. The samples were then centrifuged and the solution combined with previous extracts. The extracts were then condensed under a stream of nitrogen gas until the acetone was evaporated leaving $12-16 \mathrm{~mL}$ of water. The remaining extracts were then diluted to $30 \mathrm{~mL}$ with $0.1 \mathrm{~N} \mathrm{HCl}$ ( $\mathrm{pH} 2$ water) before sample clean up with solid phase extraction (SPE).

Extract processing was performed using an AutoTrace 280 (Thermo Scientific) using Supelco Supelclean ENVI-18 SPE Tubes, $6 \mathrm{~mL}$ (1 g). The cartridges were conditioned with $5 \mathrm{~mL}$ acetonitrile, followed by $5 \mathrm{~mL}$ of $\mathrm{pH} 2$ water. Next, samples were sonicated for $\sim 30$ seconds, loaded onto the SPE cartridges, and then dried with nitrogen gas for two minutes. After drying, cartridges were rinsed with $4 \mathrm{~mL}$ of a $40 \%$ acetonitrile, $39 \%$ water 
and $1 \% 1.0 \mathrm{~N} \mathrm{HCl}$ solution and then eluted with a $3 \mathrm{~mL}$ solution of $80 \%$ acetonitrile, $19 \%$ water and $1 \% 1.0 \mathrm{~N} \mathrm{HCl}$. The final extracts were dried to $\sim 0.5 \mathrm{~mL}$ under a gentle stream of nitrogen, transferred to an HPLC vial and reconstituted to $1 \mathrm{~mL}$ with acetone and $0.1 \mathrm{~N} \mathrm{HCl}$. The half-life of the active ingredient in RU was calculated for each of the three treatments by determining the combined amount of triclopyr and TBEE remaining in both the water and sediment at each time interval and fitting that data with an exponential decay model. From the model, the first-order degradation rate constant $\mathrm{k}\left(\mathrm{d}^{-1}\right)$ was determined and used to calculate half-life $\left(\mathrm{t}_{1 / 2}\right)$.

\subsubsection{Analytical methods}

Analysis was performed using an Agilent 1100 series HPLC with UV detector fitted with a Phenomenex guard cartridge kit and Synergi $4 \mathrm{~mm}$ Hydro-RP 80A LC column (250 x $4.6 \mathrm{~mm}$ ). The UV analysis was conducted at $230 \mathrm{~nm}$ for all compounds. The mobile phase used during analysis was (A) $0.1 \%$ aqueous phosphoric acid and (B) acetonitrile. The following ramp was used: $\mathrm{o}$ to $2.5 \mathrm{~min} 70 \% \mathrm{~A}$ and $30 \% \mathrm{~B}$, from 2.5 to 22 min transition to $20 \%$ A and $80 \% \mathrm{~B}$, hold until $28.50,28.50$ to $30 \mathrm{~min}$ $70 \%$ and $30 \% \mathrm{~B}$.

A six-point standard curve $\left(1,5,25,50,100,200 \mathrm{mg} \mathrm{L}^{-1}\right)$ for TBEE, triclopyr, and TCP was run before each analysis and check standards were run every 20 samples. During quantification of analytes from each sample, the lowest point on the standard curve was used as the limit of quantification. To assess recoveries, spikes (10 $\mathrm{mg} \mathrm{L}^{-1} \mathrm{or} \mathrm{mg} \mathrm{kg-1}^{-1}$ ) were added to a pair of replicate samples every 12 samples, with an acceptable range of 75 to $120 \%$.

\subsubsection{Statistical methods}

All samples were prepared, incubated and analyzed in quadruplicate to enable statistical comparisons. Data was analyzed in SAS 9.4 (SAS Institute Inc., Cary, NC). For sorption studies, analysis of variance (ANOVA) with Tukey-Kramer post-hoc tests were used to determine significant differences between mean $\mathrm{K}_{d}{ }^{\prime}$ and $\mathrm{K}_{d e s}{ }^{\prime}$ values. When the assumption of normality was not met, the data was log transformed. 


\subsection{Results}

\subsubsection{Soil affinity, concentration effects and desorption}

Three herbicide treatments, at $25 \mathrm{mg} \mathrm{L}^{-1} \mathrm{TBEE}$, were tested across each of the three soil types. Comparisons of $\mathrm{Kd}^{\prime}$ values shown in Figure 42 and Figure 43 are for the combined concentrations of TBEE and triclopyr. When comparing each of the three herbicide treatments within each soil type, RU-diesel has significantly higher affinity potential in the Cho (RU $p$ $<0.01$; RU-MSO p = 0.02) and Nuff (RU p = 0.02; RU-MSO p = 0.03) soils, roughly double the other two treatments in those soils (Figure 43). For herbicide treatments across soil types, the Bosque soil resulted in significantly higher affinity when treated with RU (Cho $\mathrm{p}=0.3)$ and RUMSO (Cho $p=0.01$; Nuff $p=0.01$ ) in a few instances (Figure 44). There were no significant differences when comparing RU-diesel across the soil types, but there was an increasing trend: Cho $>$ Nuff $>$ Bosque (Figure 44).

Figure 42. Triclopyr + TBEE affinity for each treatment within soil type. Capital letters represent significant differences and error bars are standard error. Control: Remedy Ultra (RU); RU-MSO: RU with Methylated Seed Oil; RU-diesel: RU with Diesel Fuel.

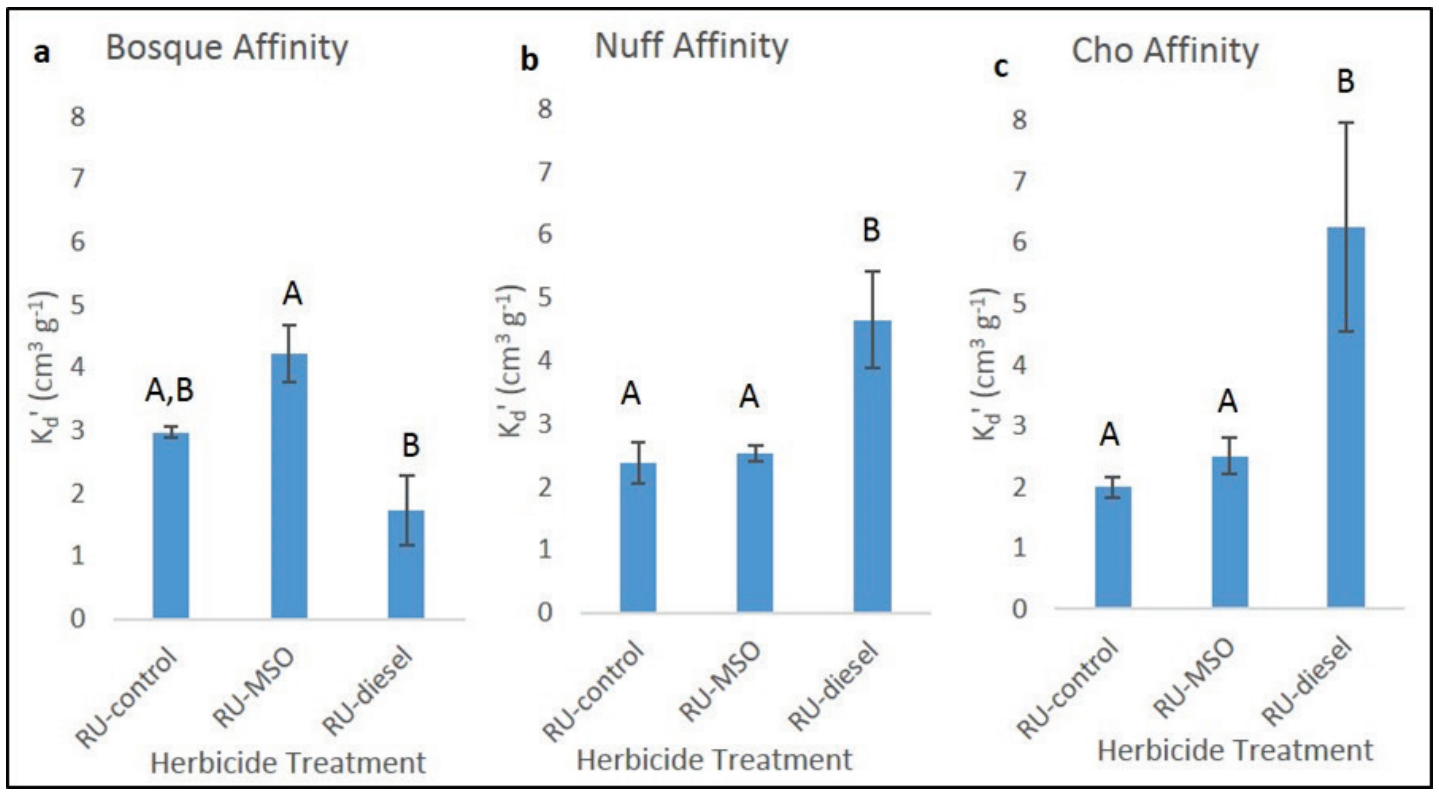


Figure 43. Triclopyr + TBEE affinity for each treatment across soil type. Capital letters represent significant differences and error bars are standard error. Control: Remedy Ultra (RU); RU-MSO: RU with Methylated Seed Oil; RU-diesel: RU with Diesel Fuel.

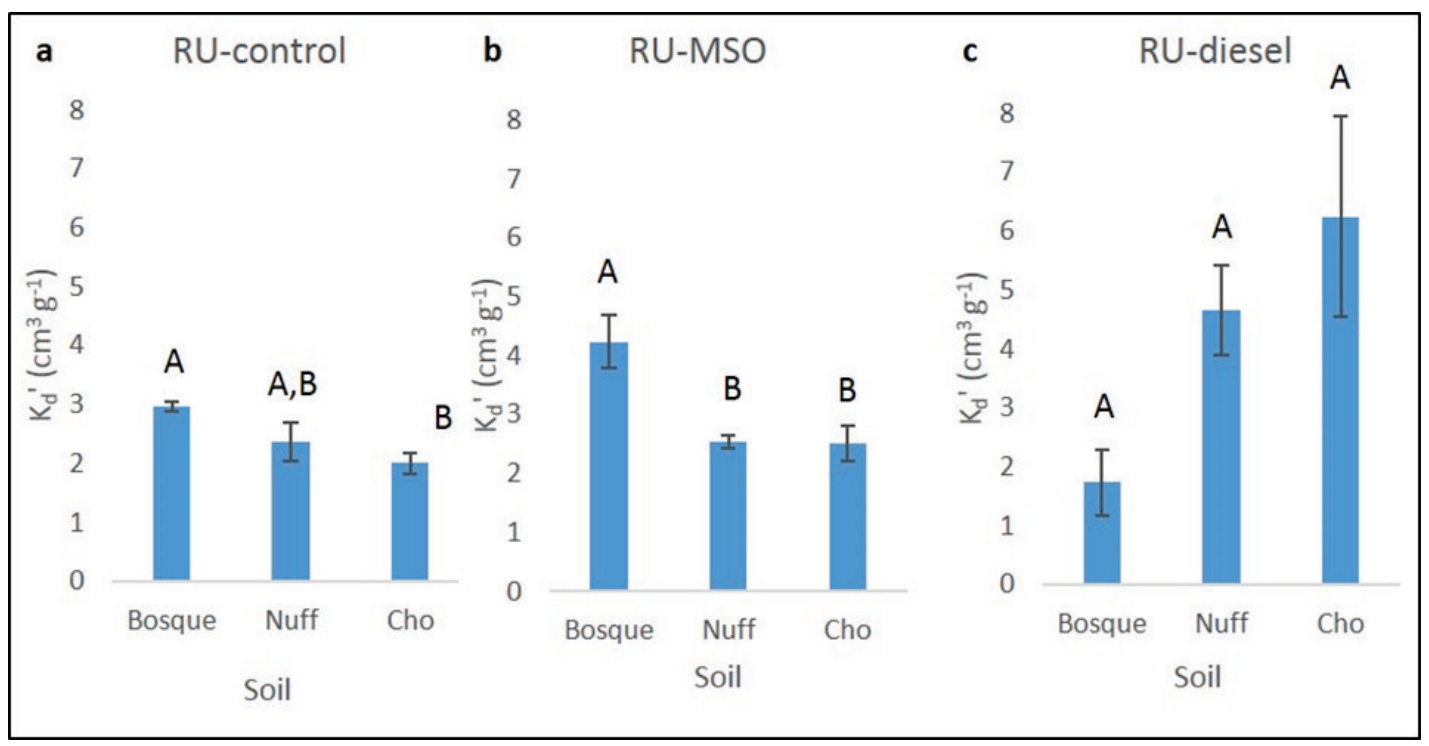

The influence of concentration on affinity was examined using affinity isotherms with the herbicide and wetting agent at four concentrations (25, 50, 100, and $200 \mathrm{mg} \mathrm{L}^{-1}$ ) in the Bosque soil. There were no significant differences associated with increasing concentrations for the RU and RUdiesel treatments (Figure 45). However, there was an apparent increase in affinity for RU-diesel with concentration, but the difference was not statistically significant (Figure 45). For RU-MSO, there is also an increasing trend observed, but only the $25 \mathrm{mg} \mathrm{L}^{-1}$ treatment was significantly lower than the other $50(\mathrm{p}<0.01), 100(\mathrm{p}<0.01)$ and $200(\mathrm{p}$ $<0.01) \mathrm{mg} \mathrm{L}^{-1}$ concentrations (Figure 45). When comparing affinity at each concentration across the three treatments, RU-MSO has significantly higher values than $\mathrm{RU}$ at $50(\mathrm{p}<0.01), 100(\mathrm{p}=0.03)$ and $200(\mathrm{p}<0.01)$ $\mathrm{mg} \mathrm{L}^{-1}$ (Figure 46). The RU-MSO affinity is also significantly higher than RU-diesel at $50(\mathrm{p}<0.01)$ and $200(\mathrm{p}<0.01) \mathrm{mg} \mathrm{L}^{-1}$. Results indicate that in general the RU-MSO treatment displayed a stronger affinity for soil than other treatments, especially at higher herbicide concentrations. 
Figure 44. The effect of concentration on affinity for each of the three treatments in Bosque soil. Capital letters represent significant differences and error bars are standard error. Control: Remedy Ultra (RU); RU-MSO: RU with Methylated Seed Oil; RU-diesel: RU with Diesel Fuel.

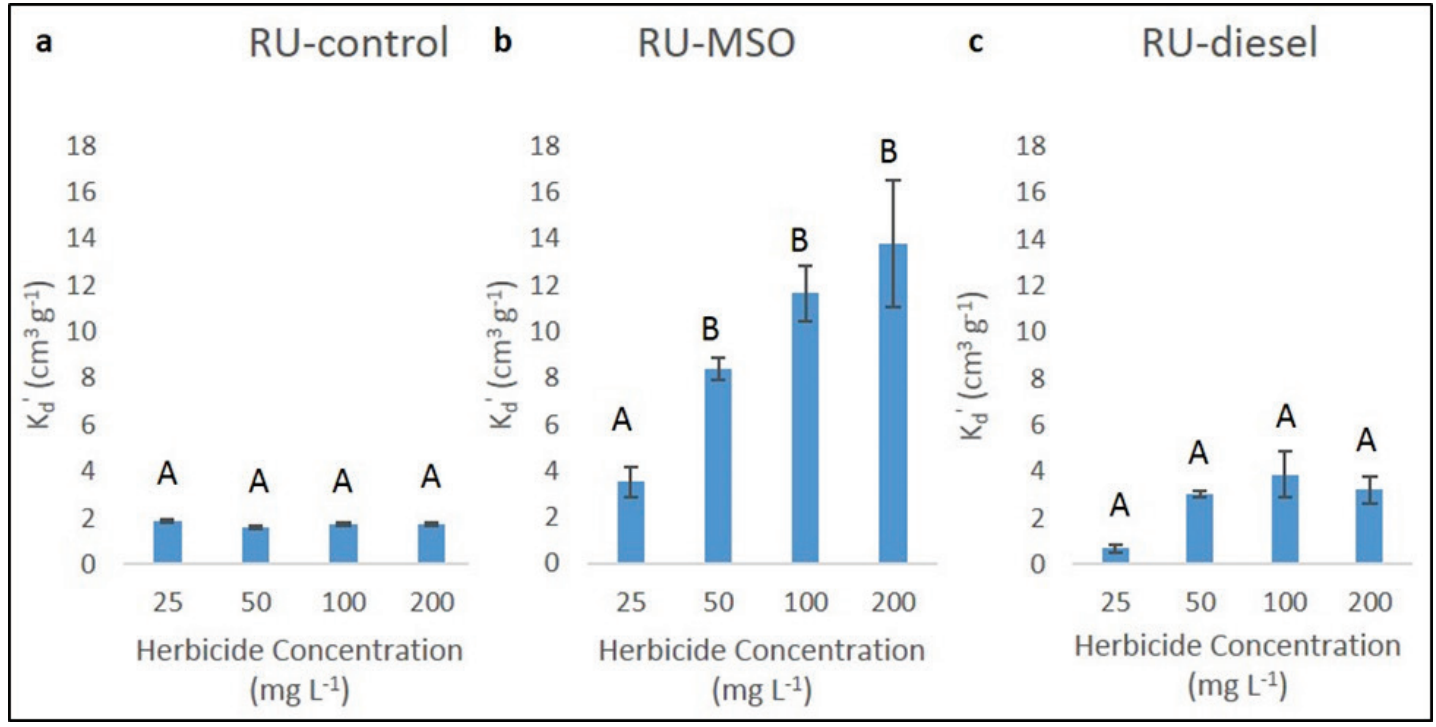

Figure 45. The effect of concentration on affinity across the three treatments. Capital letters represent significant differences and error bars are standard error. Control: Remedy Ultra (RU); RU-MSO: RU with Methylated Seed Oil; RU-diesel: RU with Diesel Fuel.

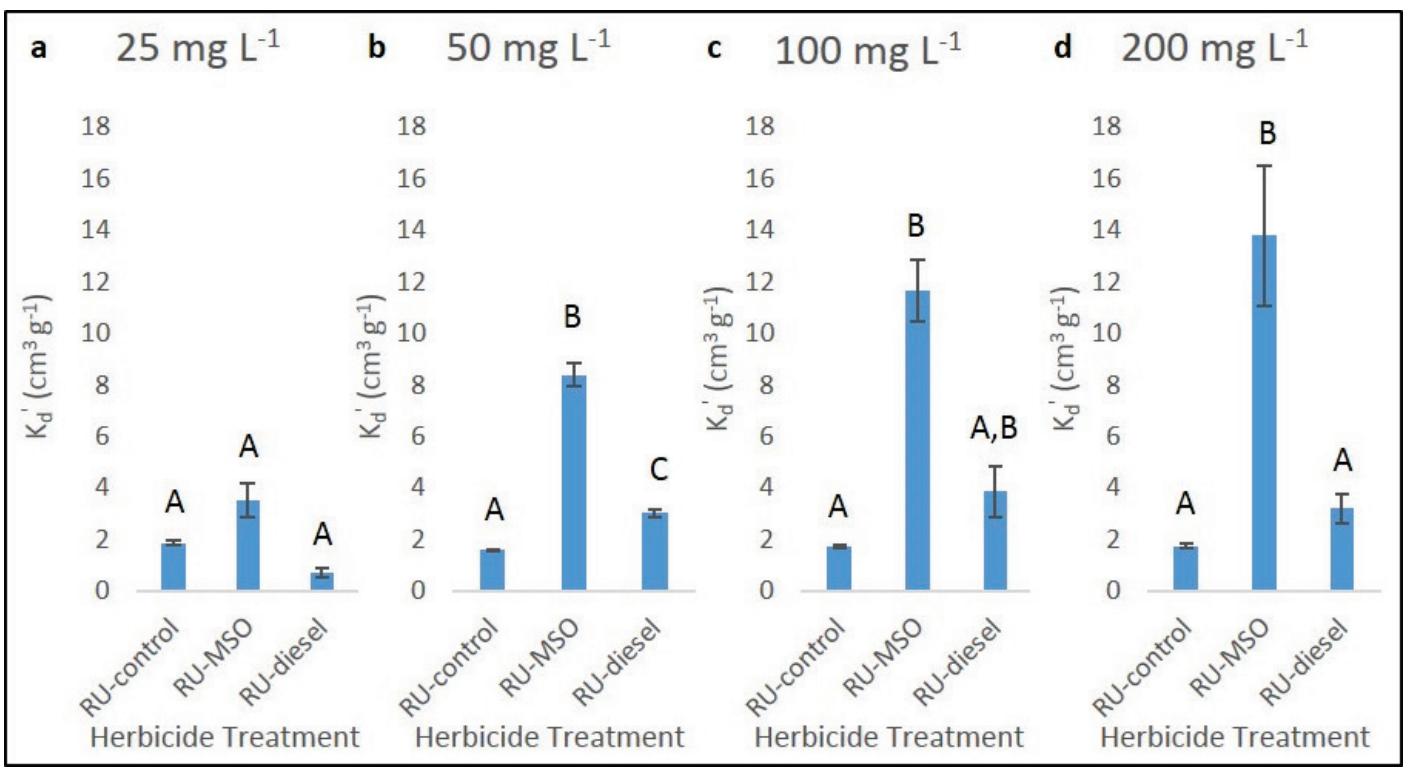

Freundlich isotherms produced the $\mathrm{K}_{\mathrm{F}}{ }^{\prime}$ and $n$ values, which indicate the target analytes affinity for the soil and the linearity of the soil sorption. The $\mathrm{KF}_{\mathrm{F}}$ 'values for the Bosque soil are: RU (0.26) > RU-MSO (-0.05) > RUdiesel (-0.74). These low values indicate a low affinity of the target analyte to soil when tested under these experimental conditions. The $n$ values 
presented in Figure 47 is 1.02 for the Control, indicating that soil sorption is linear, meaning that as concentration increase affinity increases proportionally. This behavior is also reflected in Figure 45, where the $\mathrm{Kd}^{\prime}$ for RU-diesel does not significantly change with increasing concentrations. For RU-MSO and RU-diesel, $\mathrm{n}<1$, implying affinity to soil increases as concentrations increase. This is also reflected in Figure 45 where, although not always significant, the herbicide affinity for soil increases with increasing concentration.

For desorption, soils were tested at $25 \mathrm{mg} \mathrm{L}^{-1}$ in the Bosque soil. The $\mathrm{K}_{\mathrm{des}}{ }^{\prime}$ values were significantly higher for RU and RU-MSO compared to their $\mathrm{K}_{\mathrm{d}}{ }^{\prime}$ values (Figure 48). Higher $\mathrm{K}_{\mathrm{des}}$ ' indicates that once partitioned to the soil, the active ingredient in RU and RU-MSO treatments is tightly held to the soil and desorption is limited. These findings also indicate a low potential for herbicide transport to aquatic resources. For the RU-diesel treatment, no Kdes' values are reported, as the small amount of active ingredient that partitioned to the soil during this treatment desorbed from the soil.

Figure 46. Freundlich isotherms for each treatment in the Bosque soil. Control: Remedy Ultra (RU); RU-MSO: RU with Methylated Seed Oil; RU-diesel: RU with Diesel Fuel.

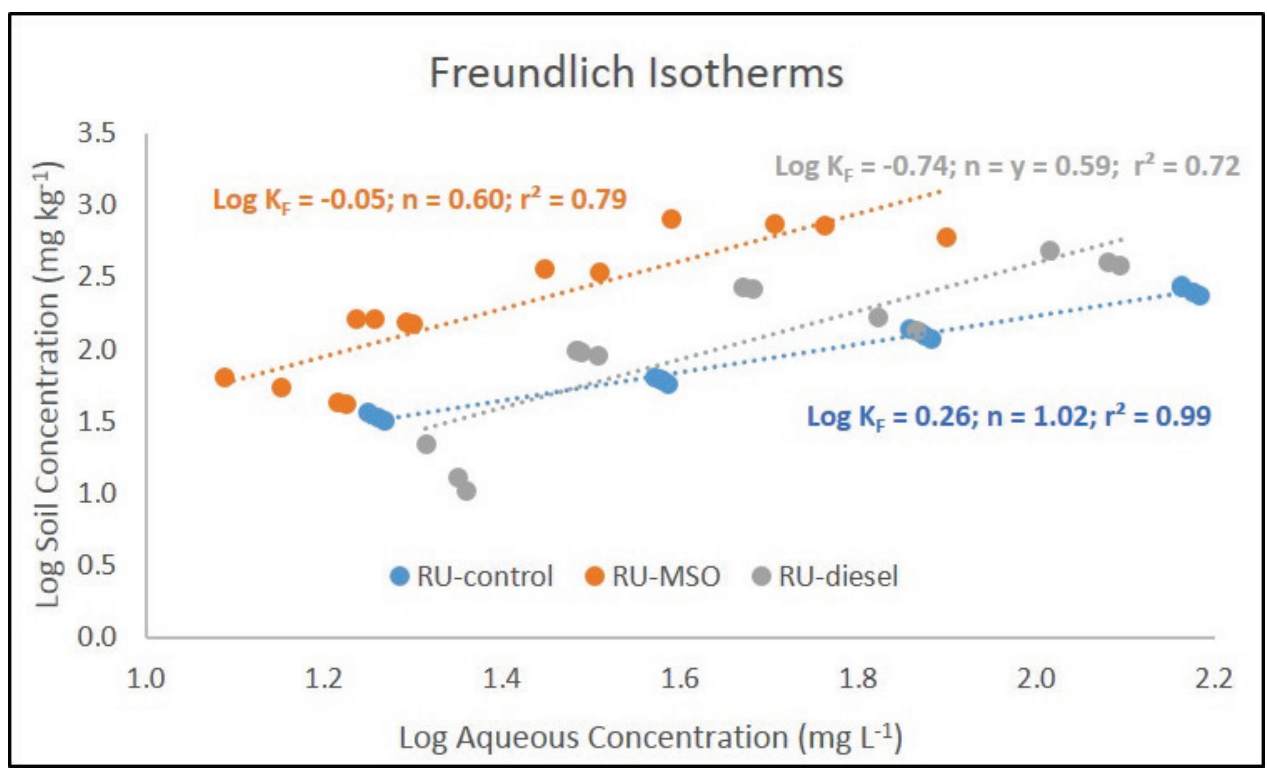


Figure 47. Partitioning values for affinity and desorption in the Bosque soils. No values are provided for RU D as the amount that partitioned to the soil all desorbed. Control: Remedy Ultra (RU); RU-MSO: RU with Methylated Seed Oil; RU-diesel: RU with Diesel Fuel

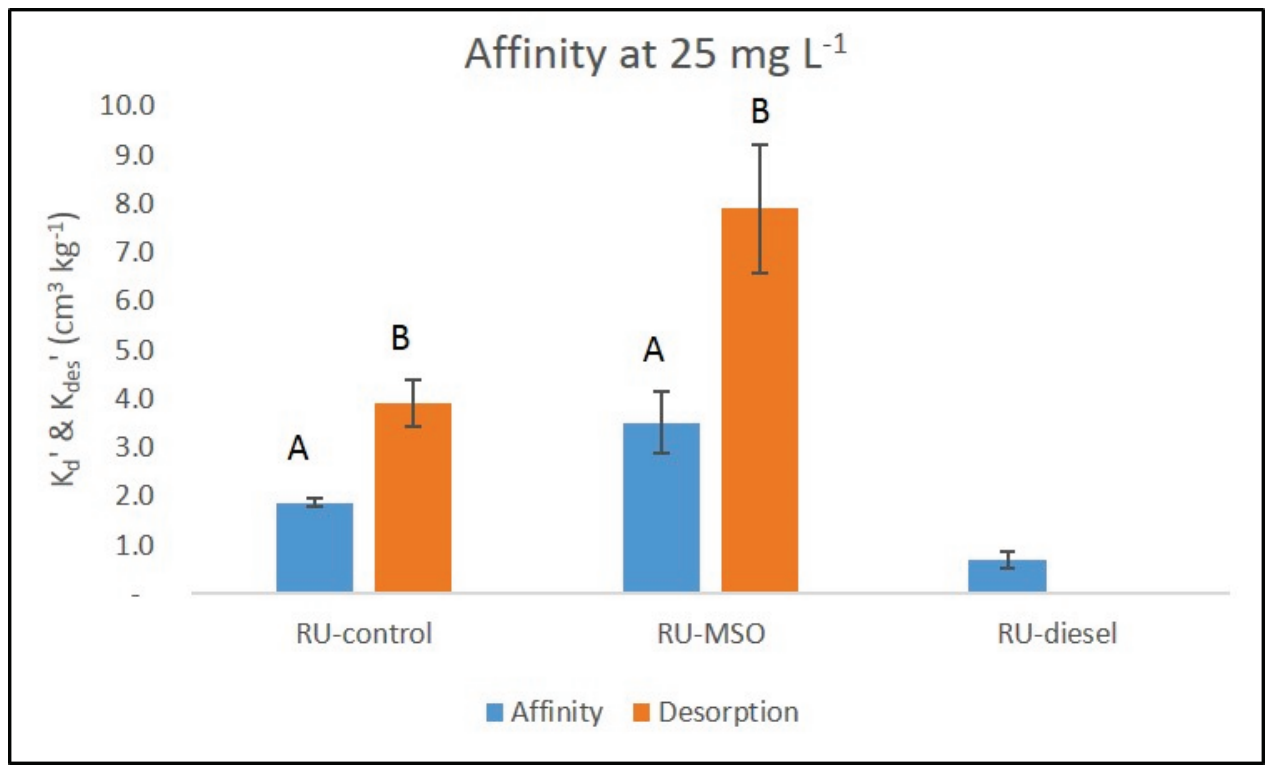

\subsubsection{Degradation}

The degradation of herbicides within the three treatments was examined in each soil (Figure 49). The three treatments resulted in an average loss of $\sim 17 \%$ of the active ingredients in the Bosque and Nuff soil over 30 days, while the Cho resulted in resulted in a $\sim 27 \%$ decline over 60 days (Figure 49). In the Bosque soil, variations in data from day $0-7$ followed by little degradation for the remainder of the study prevent the use of the exponential decay model to quantify half-life of these three treatments (Table 14). In the Nuff soil, half-lives were calculated for RU (67 d), RUMSO (231 d) and RU-diesel (117 d) (Table 14). These values are within the range reported by Tu et al. (2001), but remain well above the half-lives observed within the field study. Potential differences may result from the higher temperatures and wetting-drying cycles associated with field conditions. It is important to note that their $\mathrm{r}^{2}$ values determined based upon laboratory studies indicate a weak fit for exponential decay model and that each half-life value falls outside of the length of the study. Therefore, half-life values for treatments in the Nuff soil should be considered rough estimates. For the Cho soil, degradation was monitored over 60 days. While this was twice as long as RU and RU-MSO treatments, the target analyte concentrations only dropped an additional $10 \%$, to $\sim 73 \%$ remaining. The extra 30 days of degradation time did improve the fit of the RU and RUMSO data to the exponential decay model, producing r2 values of 0.58 and 
0.51 (Table 14). However, the RU-diesel was still a poor fit $(\mathrm{r} 2=0.01)$. While this data better fit the model, the half-life values for RU (158 d) and RU-MSO (231 d) were also outside of the $60 \mathrm{~d}$ study period, indicating that caution should be taken when using this data.

Table 14. First order rate constants $(k)$ and half-life values for the three treatment across all soil types. Bosque and Nuff soils were tested over 30 days, while Cho was tested for 60 days. RU-control: Remedy Ultra (RU); RU-MSO: RU with Methylated Seed Oil; RU-diesel: RU with Diesel Fuel

\begin{tabular}{|c|c|c|c|c|c|c|c|c|c|c|c|}
\hline & \multicolumn{3}{|c|}{ Bosque } & & Nuff & & & & Cho & & \\
\hline & $\begin{array}{c}k \\
\left(d^{-1}\right)\end{array}$ & $\begin{array}{c}\mathrm{t}_{1 / 2} \\
(\mathrm{~d})\end{array}$ & $\mathrm{r}^{2}$ & & $\begin{array}{c}\mathrm{k} \\
\left(\mathrm{d}^{-1}\right)\end{array}$ & $\begin{array}{c}\mathrm{t}_{1 / 2} \\
(\mathrm{~d})\end{array}$ & $\mathrm{r}^{2}$ & & $\begin{array}{c}\mathrm{k} \\
\left(\mathrm{d}^{-1}\right)\end{array}$ & $\begin{array}{c}\mathrm{t}_{1 / 2} \\
(\mathrm{~d})\end{array}$ & $\mathrm{r}^{2}$ \\
\hline RU-control & $-\mathrm{a}$ & $\mathrm{S}^{\mathrm{b}}$ & - & & 0.01 & 67 & 0.09 & & 0.004 & 158 & 0.58 \\
\hline RU-MSO & - & $\mathrm{S}$ & - & & 0.003 & 231 & 0.16 & & 0.003 & 231 & 0.51 \\
\hline RU-diesel & - & $\mathrm{S}$ & - & & 0.006 & 117 & 0.14 & & 0.001 & 578 & 0.01 \\
\hline
\end{tabular}

a Values were not determined due to low degradation over the test period b Indicates that concentrations were static throughout the incubation.

\subsection{Discussion}

The microcosm studies involved the dilution of RU in water, which resulted in a white suspension (Figure 41). This likely creates a multiphase solution comprised of water and fine particulate matter that occurs independent of the surfactants. This reaction would likely occur in the environment if the herbicide is applied directly or drifts into surface waters (i.e., rivers, streams or pool/puddles) and will likely influence the fate and transport of the herbicide compounds. Due to standard sorption, desorption and degradation testing methods used, it is not possible to know the influence the suspension played in the current study. Therefore, all sorption results are referred to as "affinity," a broader term that would include sorption to soil, but also potential precipitation of the target analytes.

The affinity of herbicide compounds were examined in three soils and three treatments. Affinity experiments demonstrate that each of the soils examined has the capacity to sequester herbicide compounds at the concentrations observed during field monitoring under the laboratory conditions. Additionally, compound desorption from soil the RU and RUMSO treatments displayed high desorption values, indicating strong partitioning or at least slow desorption. When examining partitioning of the herbicide across a broader concentration range (25 to $200 \mathrm{mg} \mathrm{L}^{-1}$ ) in 
the Bosque soil the affinity was RU-MSO $>>$ RU-diesel $>$ RU. The RUMSO treatments had a significantly higher affinity to the Bosque soil than the other treatments at higher concentrations $\left(50,100\right.$ and $\left.200 \mathrm{mg} \mathrm{L}^{-1}\right)$. This indicates that at higher concentrations ( $>25 \mathrm{mg} \mathrm{L}^{-1}$ ), which were frequently measured in soils during on-site monitoring, RU-MSO would be the least mobile in the soil.

The active herbicide ingredients (TBEE and triclopyr) degraded by $\sim 17 \%$ over 30 days in Bosque and Nuff soils and $27 \%$ in the Cho soil which ran for 60 days. Unfortunately, due to low degradation, accurate half-life values were not determined for the Bosque soil. The half-life of the active ingredients were determined in the Nuff soil for each of the three treatments (67-231 days), but due to a poor fit to the exponential decay model and that they were outside of the 30-day study window, these numbers should be considered estimates only. Degradation data in the Cho soil displayed half-life values of 158-578 days; however, these were also beyond the 60 day study duration. While these half-life values can only be considered estimates, they do align with the data show in Figure 48 , demonstrating that degradation of the active ingredient is slower under the test conditions than observed within field studies. Previous studies found that the half-life of triclopyr in water with light (natural and artificial) was 1.3 days (Woodburn et al. 1993). However, when studied in darkness the half-life was $>270$ days (Linders et al. 1994). Therefore, aqueous degradation of triclopyr is driven by photolysis. In soil, the halflife in a previous study was 20 days (Linders et al. 1994) and driven by microbes (Ganapathy 1997). The samples analyzed in this study were not processed in complete darkness, so half-lives from 1.3-20 days, as reported in previous studies was expected based upon field observations. However, the results indicate much longer half-lives than the 30 or 60 day timeframes tested. At least part of this longer than expected persistence may be due to the suspension formed when directly adding RU to water, whereas in typical degradation experiment, active ingredients are tested without the influence of adjuvants. 
Figure 48. Change in the total concentrations (sum of soil and water concentrations) of triclopyr normalized to the initial value for each of the treatments in Bosque, Nuff, and Cho soils. Error bars represent standard error.

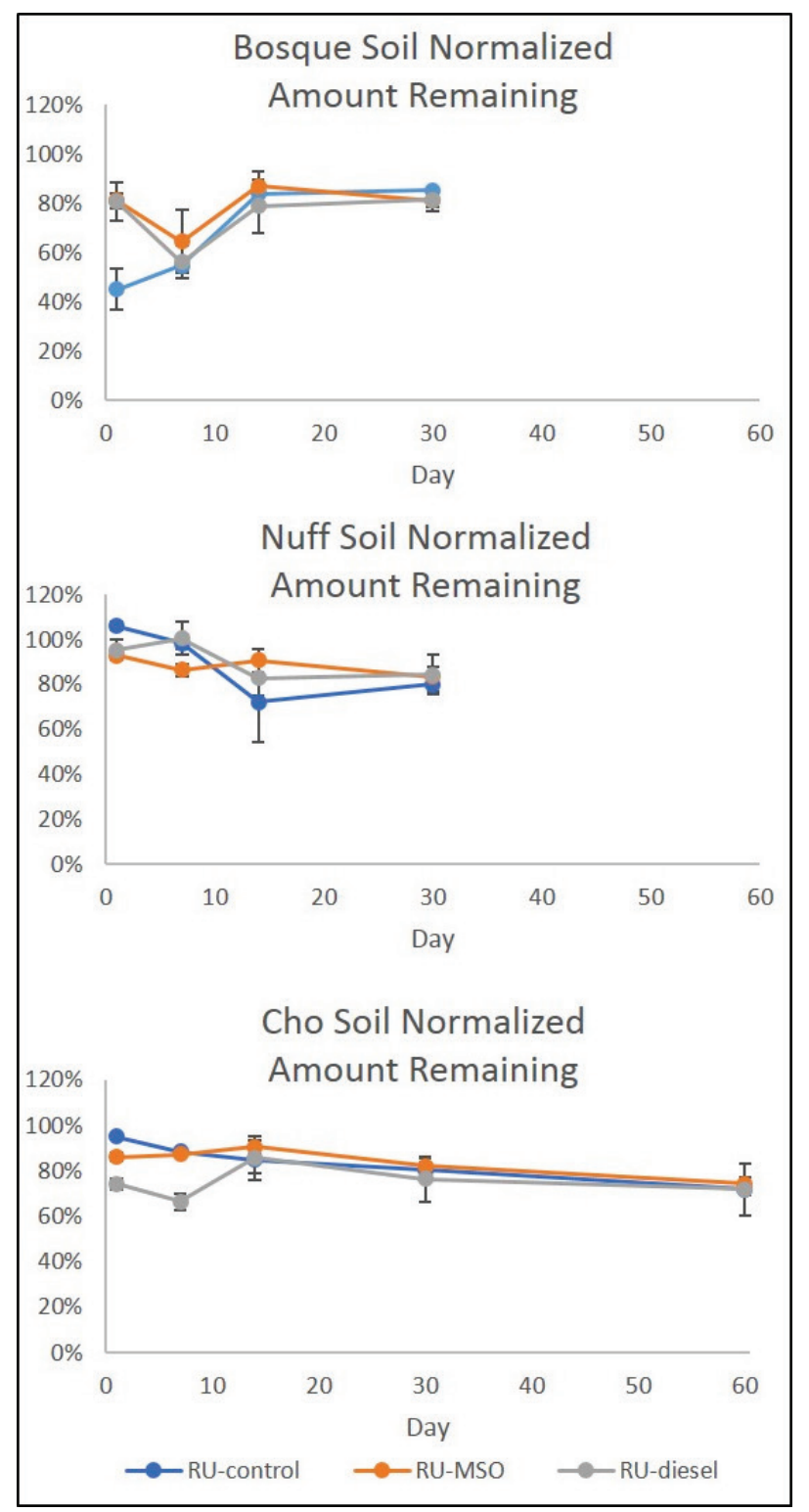

\subsection{Summary}

The results of this study show that there is some variation in the effect of herbicide treatment across the three soil types on soil partitioning and compound degradation. First, at concentrations near the mean observed at Fort Hood shortly after application, the RU-diesel treatment generally had higher partitioning to the soils. However, desorption demonstrated that it had the ability to leach from soil more easily than the other treatments. 
Therefore, RU-MSO, which exhibited higher affinity to the soil at higher concentrations and a reduced ability to leach from the soil exhibits a lower potential for offsite transport than the other treatments examined.

Regarding degradation, all three of the treatments tested demonstrated that they would likely persist longer than the 30-60 day window for which the chemicals were tested, implying that degradation could be slow. However, degradation would be expected to increase under field conditions at Fort Hood, which exhibits high temperatures and moist conditions during the growing season, when herbicide applications are conducted. 


\section{Column Experiments to Assess Herbicide Mobility in Soils}

\subsection{Introduction}

Studies were designed to assess the fate of RU and commonly used surfactants (RU-MSO and RU-diesel) in soil collected at Fort Hood, TX. Soil column studies were used to illustrate the potential transport of the RU compounds in the field. Soil column studies are used to more accurately represent field conditions and demonstrate herbicide movement through the soil profile. Field monitoring, conducted in conjunction with column studies provide the best available method to quantify potential herbicide transport. Saturated soil column studies were performed to illustrate herbicide transport when the soil column is fully saturated with water. Since the soils in the Fort Hood area are rarely fully saturated, these studies represent a worst case scenario for potential herbicide transport. Unsaturated soil columns were attempted in order to demonstrate herbicide transport under normal conditions. However, herbicide breakthrough was not achieved under a variety of laboratory conditions. In addition, solution studies were conducted to understand the reaction between RU and water. Since water is present in all natural systems, this reaction may dictate the fate of triclopyr-containing herbicides in soils.

\subsection{Objective of herbicide mobility column experiments}

The following section illustrates herbicide movement in soil and the impact that surfactants have on its mobility. The data were generated through laboratory soil column studies to mimic field conditions at Fort Hood.

\subsection{Methods}

\subsubsection{Saturated column studies}

The general procedure for column mobility experiments is to perform column leaching studies by applying water containing the dissolved compound(s) of interest to vertically placed columns. The dilution of RU with aqueous solutions results in a cloudy precipitate which would lead to delivery of a heterogeneous solution with a mix of particulate and aqueous compounds to the soil columns. To simulate delivery of RU in the field, a 
small amount of the total soil in each column was spiked with herbicide and leached with a dilute salt solution.

Flow rates for columns studies are often dependent on both the compound of interest and the physical characteristics of the soil being investigated. For saturated column investigations, a leachate flow delivery rate of 0.5 $\mathrm{mL} / \mathrm{min}$ is generally used to ensure a stable flow rate through the length of the column. The Bosque soil was packed to a density of $\sim 1.1 \mathrm{gm} / \mathrm{cm} 3$ and a flow rate of $0.5 \mathrm{~mL} / \mathrm{min}$ into and out of the columns was established. Cho and Nuff soils were packed to approximately the same density, but the same flow rate could not be achieved due to low soil permeability. Additional lower flow rates were investigated resulting in no, very little, or reduced flow through the soils. The soils were then diluted with sand (Sigma Aldrich 50/70 mesh) to varying ratios of soil to sand (75:25, 50:50, and $25: 75$ ). Utilizing a mixture of $25 \%$ soil to $75 \%$ sand, a consistent flow of $0.10 \mathrm{~mL} / \mathrm{min}$ through both Cho and Nuff soil columns was established. Column experiments were performed by dry packing soils and soil/sand mixtures to a bulk density of $\sim 1.2 \mathrm{~g} \mathrm{~cm}-3$ in duplicate $10 \mathrm{~cm}$ by $1 \mathrm{~cm}$ (diameter) glass chromatography columns (Figure 49).

Figure 49. Packed chromatography column.

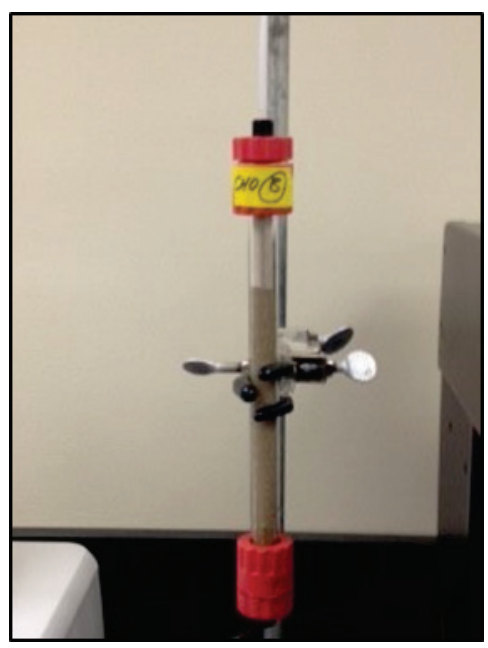

Bosque soil and 25:75 Cho and Nuff soil/sand mixtures were spiked with a 25\%:75\% RU-MSO or 25\%:75\% RU-diesel mixture to simulate field delivery of the herbicide. Each column was packed with an initial layer of 0.5 grams of sand (to promote even flow into the column) followed by two, 1.0 gram increments of spiked soil and soil/sand mixtures. The remainder of the columns were packed with 1.0 gram increments (to promote 
uniform soil packing) of clean soil and soil/sand mixtures. The final layer of each column consisted of another 0.5 gram increment of sand to prevent clogging of the outflow screen. Each column contained approximately 19 grams of materials.

For saturated flow experiments, two replicate columns were prepared for each soil type and treatment evaluated. During the saturated flow study, the soil remains saturated during the entire course of the experiment. This is best accomplished by pumping solution upward through the column (Figure 50). Columns containing Bosque soil were continuously leached with a dilute (0.3 $\mathrm{mM}) \mathrm{CaCl} 2$ background solution at a flow rate of 0.5 $\mathrm{mL} / \mathrm{min}$. The Cho and Nuff experimental set-ups were identical, with flow rate through the columns being reduced to $0.12 \mathrm{~mL} / \mathrm{min}$ due to limited flow through these soils. Volume of individual samples collected was based on the pore volume of each packed soil. Pore volume is defined as the volume of water per unit area held in wetted soil pores of the column. It requires approximately one pore volume of water to move a mobile solute the entire length of the soil column. For the Bosque tests, samples were collected every 15 minutes to give individual sample volumes of $6 \mathrm{~mL}$. Samples for the Cho and Nuff tests were collected every 47 minutes to produce the same sample volume. At the conclusion of each experiment the aqueous samples were analyzed for triclopyr, triclopyr-2-butoxyethylester (TBEE), and 3,5,6-Trichloro-2-pyridinol (TCP). Aqueous solution $\mathrm{pH}$ and electrical conductivity (EC) values were also collected for each sample. The columns were sub-sectioned into $5 \mathrm{~cm}$ increments providing seven or eight soil samples per column. Columns were sectioned from the top down to prevent cross-contamination between layers. 
Figure 50. Column set-up.

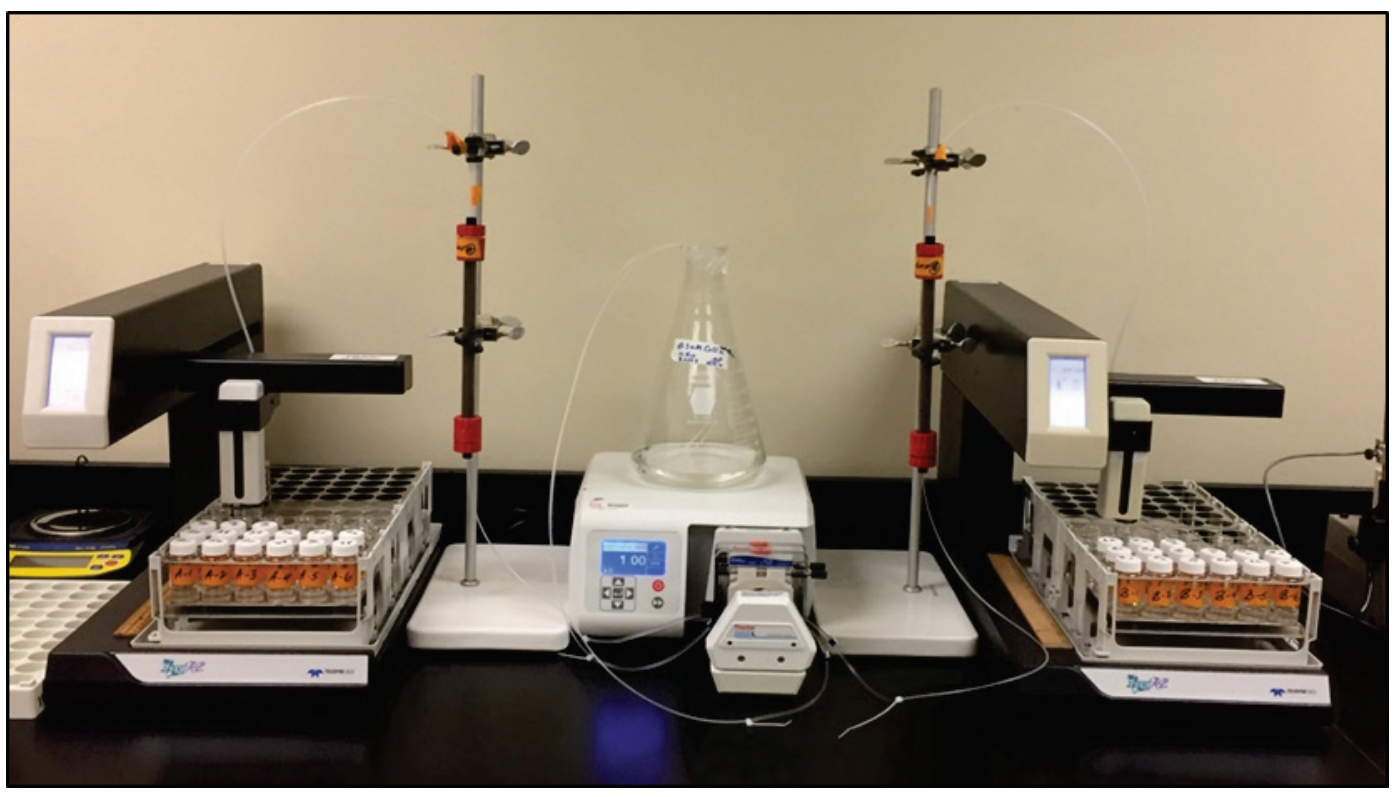

\subsubsection{Unsaturated column studies}

Unsaturated column studies were initially investigated. The experimental design of this type of column set-up involves applying positive pressure to the column to promote uniform pressure along the length of the column giving uniform water volumetric content throughout the column. These experiments were attempted with the predominant soil (Nuff) present within the study area (Figure 51). However, preliminary experiments were unable to establish any flow through the soils. The difficulty encountered suggests that vertical and horizontal transport of materials present in soil water remains limited within the Nuff soil. As a result, additional studies focused on saturated column experiments, which represent a worst case scenario for potential herbicide transport. 
Figure 51. Unsaturated columns.

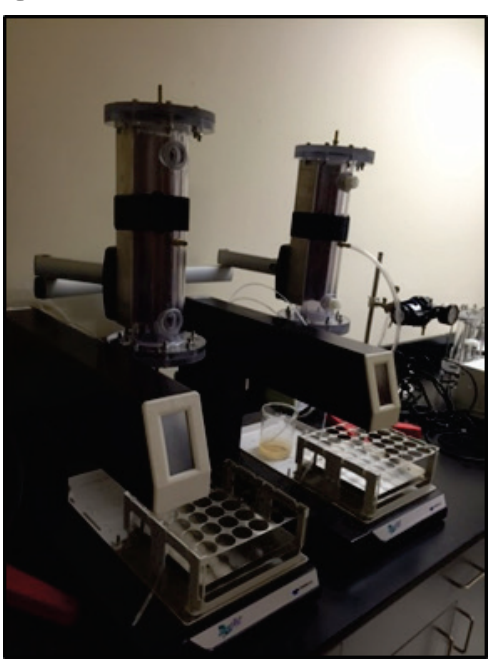

\subsubsection{Remedy Ultra (RU) experiments}

During initial study design, staff visually observed particulate matter exiting the packed soil columns. To investigate the separation of RU in aqueous solution, representative spike solutions were prepared as described above in Section 4.0. Duplicate solutions were centrifuged at 100,000 rpm for one hour resulting in a separation of two layers (Figure 52). The top "lipid" layer was pipetted off and the samples were centrifuged at the same rate and time two additional times, removing the overlying layer after each repetition for analytical analysis. Additionally, the pure RU material was sent for analysis to determine the concentration and speciation of herbicide compounds in the initial starting material.

Figure 52. Remedy Ultra (RU)

in $10 \mathrm{mM} \mathrm{CaCl} 2$

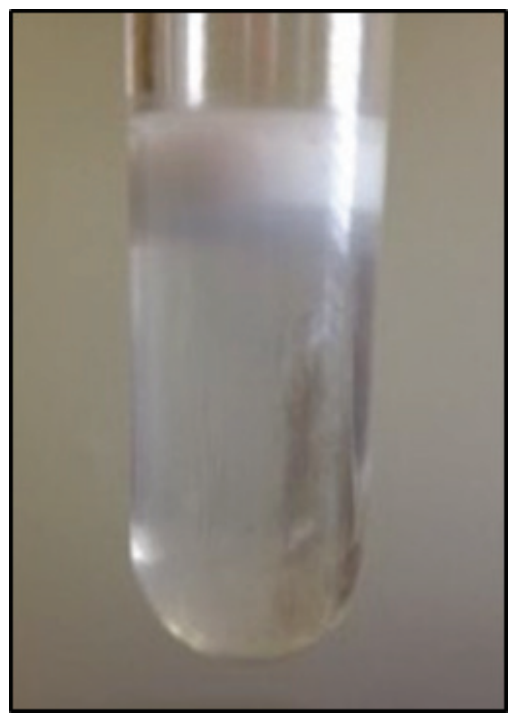




\subsection{Column experiment results}

\subsubsection{Saturated column leaching experiment results}

During column experiments, the Bosque soil did not expand and did not require dilution with sand in order to conduct the saturated column leaching experiment. Figure 53 shows the results of the column leaching experiment for the Bosque soil spiked with RU-MSO. Data within this section is presented in terms of pore volume, which is defined as the volume of water/solution needed to flush the soil in the column once. Examining the data collected during replicate 1, approximately $25 \%$ of the spiked concentration of triclopyr was released within the $1^{\text {st }}$ pore volume. After the initial release, the concentration of triclopyr decreased rapidly in pore volumes two-four. After five pore volumes had flowed through the soil column, the concentration of triclopyr being released decreased to less than $1 \%$ of the initial spiked concentration of triclopyr. Similarly, replicate two released less than $1 \%$ of the initial spiked concentration of triclopyr after six pore volumes had flowed through the soil column. The cumulative volume leached from both soil columns was 20.5 and 19.2 pore volumes for replicates one and two, respectively. Results indicate that $43 \%$ and $54 \%$ of the initial spiking concentration of triclopyr was leached during the entire column experiment for replicates one and two, respectively.

Figure 53. Column leaching results for the Bosque soil with RU-MSO treatment. $\mathrm{C} / \mathrm{C}_{0}$ is the concentration of analyte measured in the leachate solution (C) divided by the initial spiking concentration $\left(\mathrm{C}_{0}\right)$ and is unitless. Pore volumes are expressed as the volume of leachate collected (V) divided by the maximum pore volume in the column $\left(V_{0}\right)$ and is unitless.

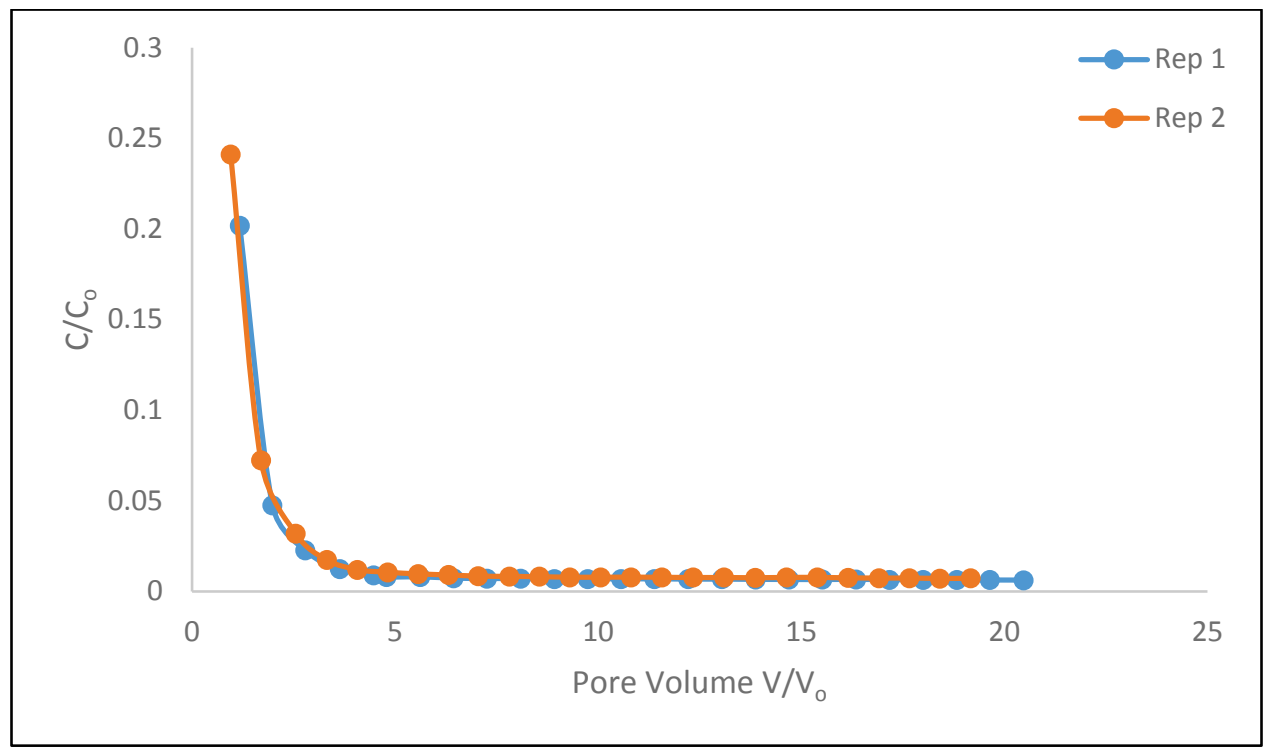


Figure 54 shows the results of the column leaching experiment for the Bosque soil spiked with RU-diesel. During the $1^{\text {st }}$ pore volume, which was complete saturation of the soil an initial concentration of approximately $10 \%$ of the spiked triclopyr concentration was released. After the initial release, the concentration of triclopyr continued to decrease through pore volumes two and three to less than $2 \%$ of the initial spiked triclopyr concentration. During pore volume four, the concentration of triclopyr being released increased to $2 \%$. After four pore volumes had flowed through the soil column, the concentration of triclopyr being leached from the column increased to $5 \%$ for replicate two. After approximately six pore volumes, the concentration of triclopyr decreased to less than $1 \%$ and $1.5 \%$ for replicates one and two respectively. The cumulative volume leached from both soil columns was 11.4 and 10.1 pore volumes for replicates one and two, respectively. Results indicate that $29 \%$ and $40 \%$ of the initial spiking concentration was leached during the entire column experiment for replicates one and two, respectively. No degradation products were seen in the column leachate from the Bosque soil for either the RU-MSO or the RU-diesel treatments.

Figure 54. Column leaching results for the Bosque soil with RU-diesel treatment. $\mathrm{C} / \mathrm{C}_{0}$ is the concentration of analyte measured in the leachate solution (C) divided by the initial spiking concentration $\left(\mathrm{C}_{0}\right)$ and is unitless. Pore volumes are expressed as the volume of leachate collected (V) divided by the maximum pore volume in the column $\left(\mathrm{V}_{0}\right)$ and is unitless.

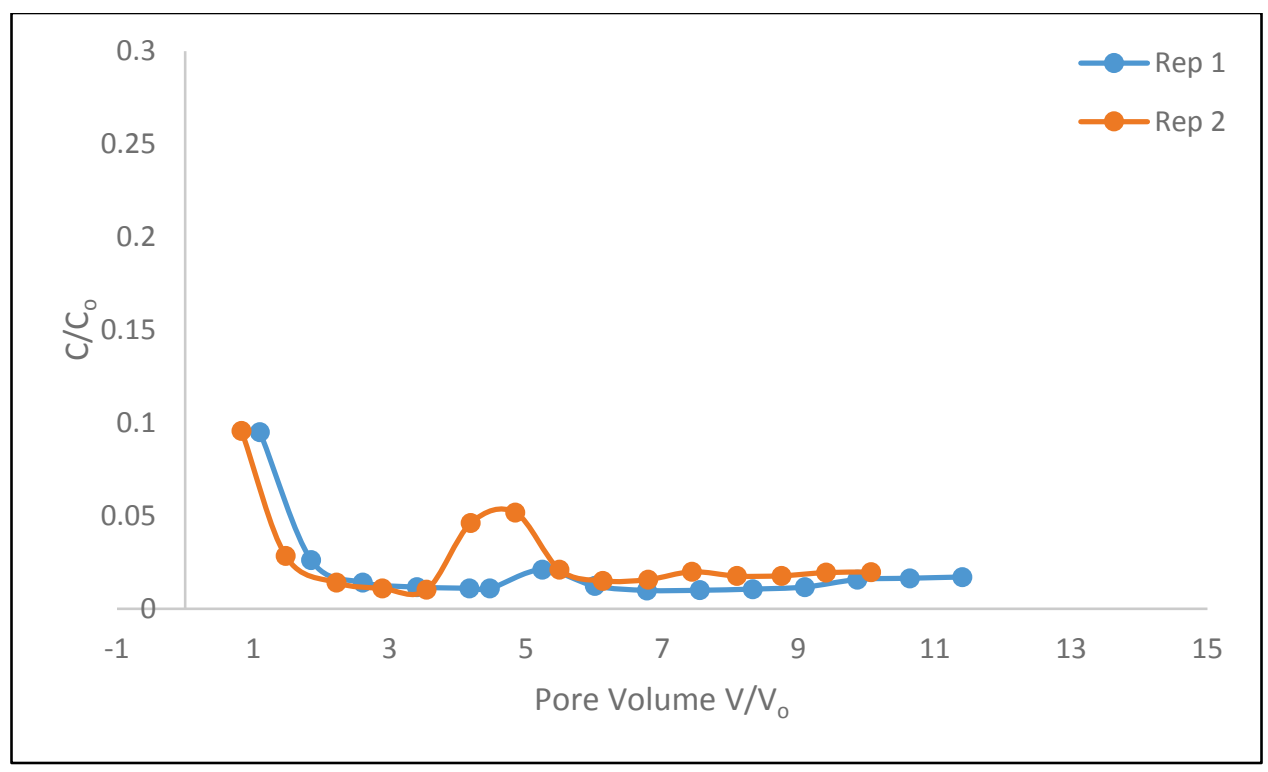

During column experiments the Cho soil expanded and restricted water flow, when it was the only material within the columns. Therefore, the soil was diluted with sand to achieve adequate solution flow. The final mixture 
in the column was $75 \%$ sand and $25 \%$ Cho soil. Figure 55 shows the results of the column leaching experiment for the sand diluted Cho soil spiked with the RU-MSO treatment. During the $1^{\text {st }}$ pore volume, which was complete saturation of the soil, an initial concentration of approximately $2 \%$ of the spiked concentration was released. After the initial release, the concentration of triclopyr decreased in pore volume two and throughout the rest of the column leaching experiment. After the initial pulse, the concentration of triclopyr was less than $1 \%$ of the spiked triclopyr concentration for both replicates one and two. The cumulative volume leached from both soil columns was 11.4 and 11.9 pore volumes for replicates one and two, respectively. Less than $1 \%$ of the initial spiking concentration was leached during the entire column experiment for both replicates one and two. Degradation of the triclopyr to TCP occurred. The TCP results displayed the same general trend observed for triclopyr in which the concentration leached remained less than $1 \%$ throughout the column leaching experiment.

Figure 55. Column leaching results for the $75 \%$ Sand and $25 \%$ Cho soil with RU-MSO treatment. $\mathrm{C} / \mathrm{C}_{0}$ is the concentration of analyte measured in the leachate solution $(C)$ divided by the initial spiking concentration $\left(\mathrm{C}_{0}\right)$ and is unitless. Pore volumes are expressed as the volume of leachate collected (V) divided by the maximum pore volume in the column ( $\left.V_{0}\right)$ and is unitless.

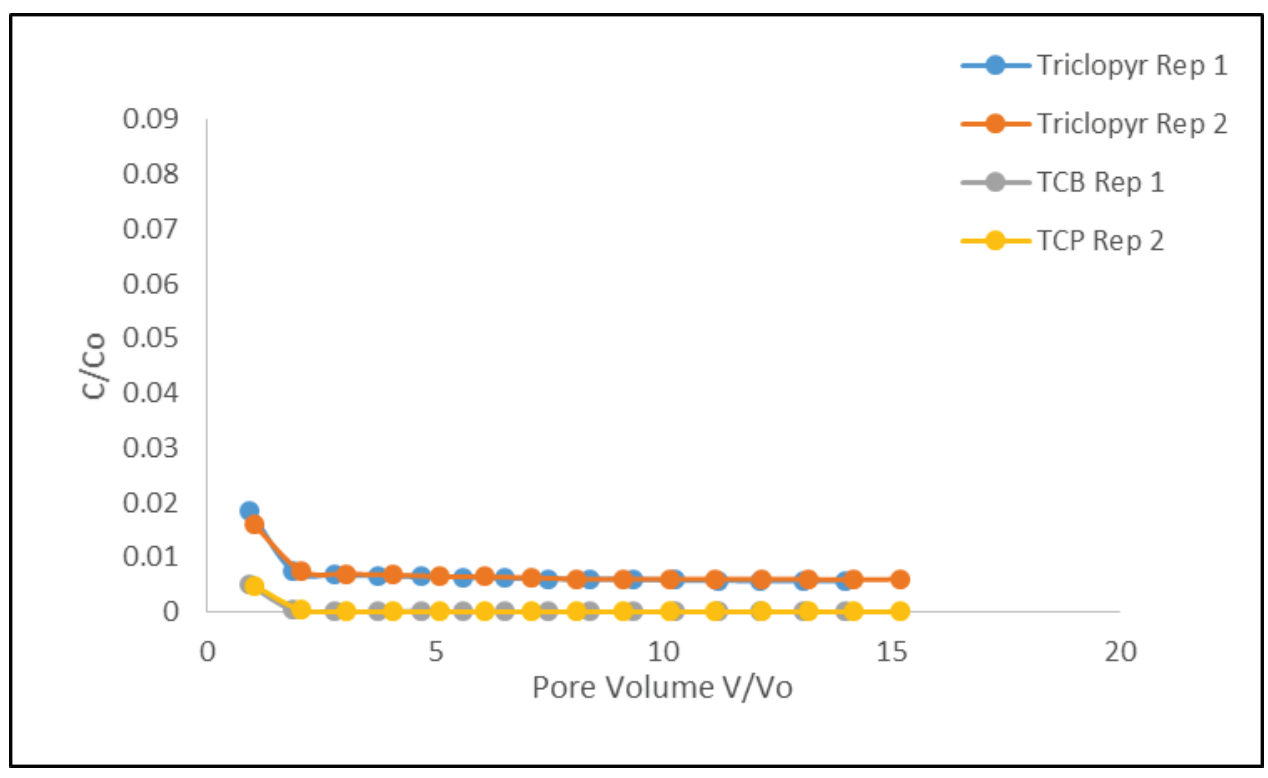

During column experiments, the Cho soil expanded and restricted water flow when it was the only material within the columns. Therefore, the soil was diluted with sand to achieve adequate solution flow. The final mixture in the column was $75 \%$ sand and $25 \%$ Cho soil. Figure 56 shows the results of the column leaching experiment for the sand diluted Cho soil RU-diesel 
treatment. During the $1^{\text {st }}$ pore volume, approximately $8 \%$ of the spiked triclopyr concentration was released. After the initial release, the concentration of triclopyr decreased in pore volumes two and three and leveled off after pore volume four. After the initial pulse, the concentration of triclopyr was less than $1 \%$ of the initial spiked concentration for both replicates one and two.The cumulative volume leached from both soil columns was 16.9 and 16.4 pore volumes for replicates one and two, respectively. Less than $1 \%$ of the initial triclopyr spiking concentration was leached during the entire column experiment for both replicates one and two. Degradation of the triclopyr to TCP occurred. The TCP results displayed the same general trend observed for triclopyr in which the concentration leached remained less than $1 \%$ throughout the column leaching experiment.

Figure 56. Column leaching results for the $75 \%$ Sand and $25 \%$ Cho soil with RUdiesel treatment. $\mathrm{C} / \mathrm{C}_{0}$ is the concentration of analyte measured in the leachate solution (C) divided by the initial spiking concentration $\left(\mathrm{C}_{0}\right)$ and is unitless. Pore volumes are expressed as the volume of leachate collected (V) divided by the maximum pore volume in the column $\left(V_{0}\right)$ and is unitless.

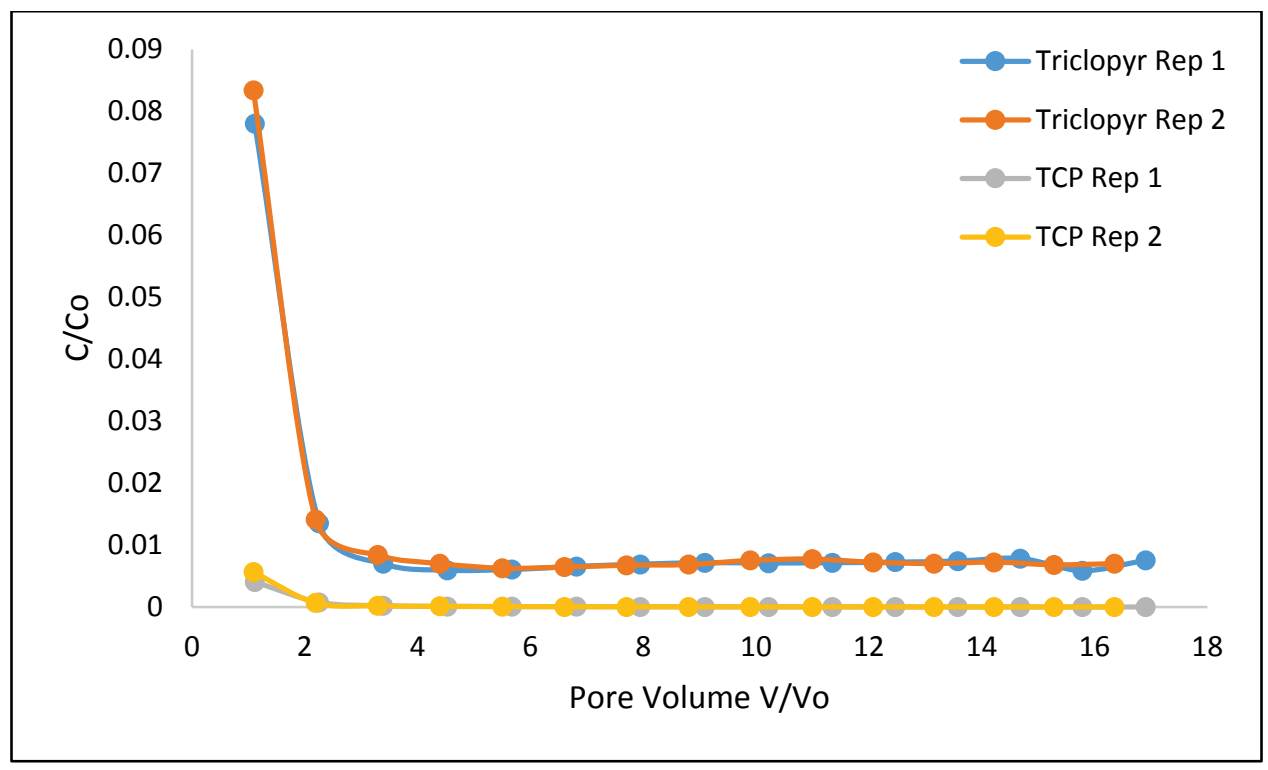

During column experiments, the Nuff soil expanded and restricted water flow when it was the only material within the columns. Therefore, the soil was diluted with sand to achieve adequate solution flow. The final mixture in the column was $75 \%$ sand and $25 \%$ Nuff soil. Figure 57 shows the results of the column leaching experiment for the sand diluted Nuff soil RU-MSO treatment. During the $1^{\text {st }}$ pore volume, which was complete saturation of the soil an initial concentration of approximately $1.75 \%$ of the spiked triclopyr concentration was released. After the initial release, the 
concentration of triclopyr decreased in pore volume two and throughout the rest of the column leaching experiment. After the initial pulse the concentration of triclopyr was less than $1 \%$ of the initial spiked triclopyr concentration for both replicates one and two.The cumulative volume leached from both soil columns was 14.5 and 14.6 pore volumes for replicates one and two, respectively. Less than $1 \%$ of the initial spiked triclopyr concentration was leached during the entire column experiment for both replicates one and two. Degradation of the triclopyr to TCP occurred. The TCP results displayed the same general trend observed for triclopyr in which the concentration leached remained less than $1 \%$ throughout the column leaching experiment.

Figure 57. Column leaching results for the $75 \%$ Sand and $25 \%$ Nuff soil with RU-MSO treatment. $\mathrm{C} / \mathrm{C}_{0}$ is the concentration of analyte measured in the leachate solution (C) divided by the initial spiking concentration $\left(\mathrm{C}_{0}\right)$ and is unitless. Pore volumes are expressed as the volume of leachate collected (V) divided by the maximum pore volume in the column $\left(\mathrm{V}_{0}\right)$ and is unitless.

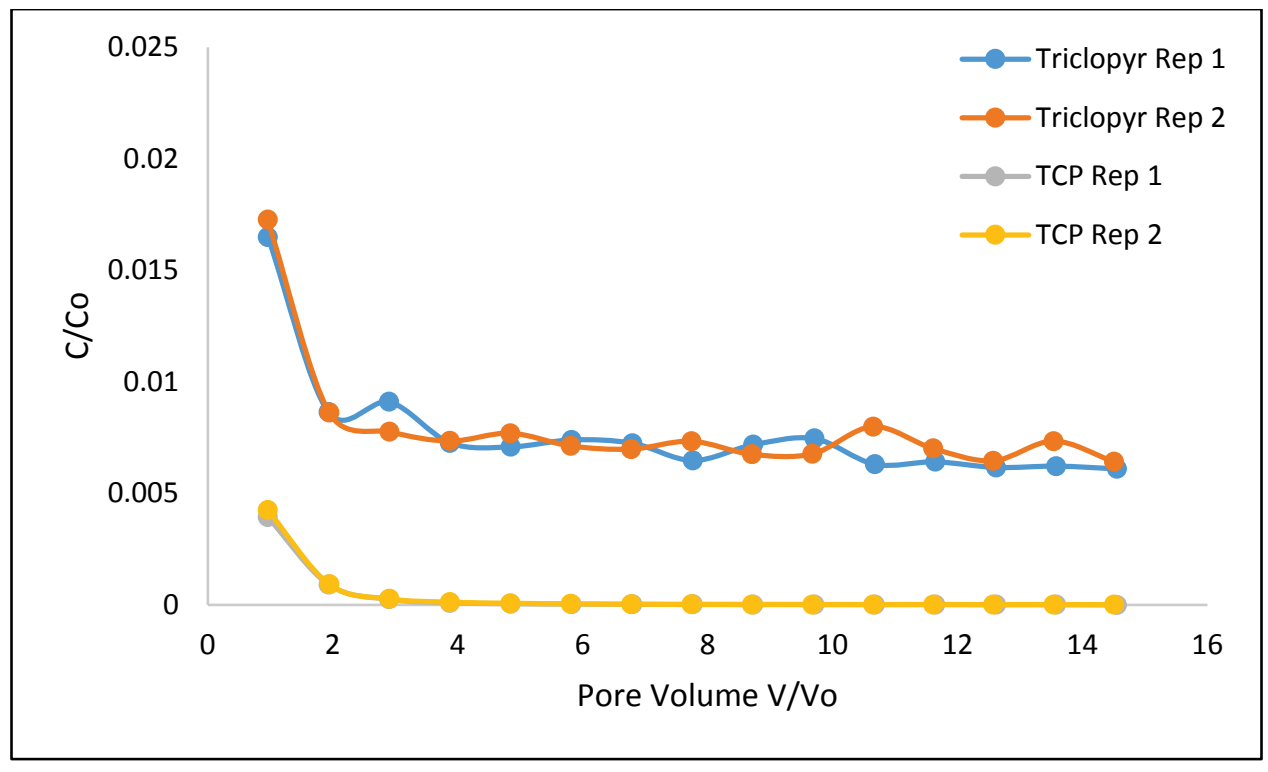

During column experiments, the Nuff soil expanded and restricted water flow when it was the only material within the columns. Therefore, the soil was diluted with sand to achieve adequate solution flow. The final mixture in the column was $75 \%$ sand and $25 \%$ Nuff soil. Figure 58 shows the results of the column leaching experiment for the sand diluted Nuff soil RU-diesel. During the $1^{\text {st }}$ pore volume, which was complete saturation of the soil an initial concentration of approximately $2 \%$ of the spiked triclopyr concentration was released for both replicates one and two. After the initial release, the concentration of triclopyr decreased in pore volume two and throughout the rest of the column leaching experiment. After the initial pulse the 
concentration of triclopyr was less than $1 \%$ of the initial spiked triclopyr concentration for both replicates one and .The cumulative volume leached from both soil columns was 17.3 and 17.9 pore volumes for replicates one and two, respectively. Less than $1 \%$ of the initial spiked triclopyr concentration was leached during the entire column experiment for both replicates one and two. Degradation of the triclopyr to TCP occurred. In general, the same trends that were present for triclopyr were present for the TCP. The initial concentration after one pore volume was less than $0.5 \%$ and continued to decrease during the column leaching experiment.

Figure 58. Column leaching results for the $75 \%$ Sand and $25 \%$ Nuff soil with RUdiesel treatment. $\mathrm{C} / \mathrm{C}_{0}$ is the concentration of analyte measured in the leachate solution (C) divided by the initial spiking concentration $\left(\mathrm{C}_{0}\right)$ and is unitless. Pore volumes are expressed as the volume of leachate collected (V) divided by the maximum pore volume in the column $\left(V_{0}\right)$ and is unitless.

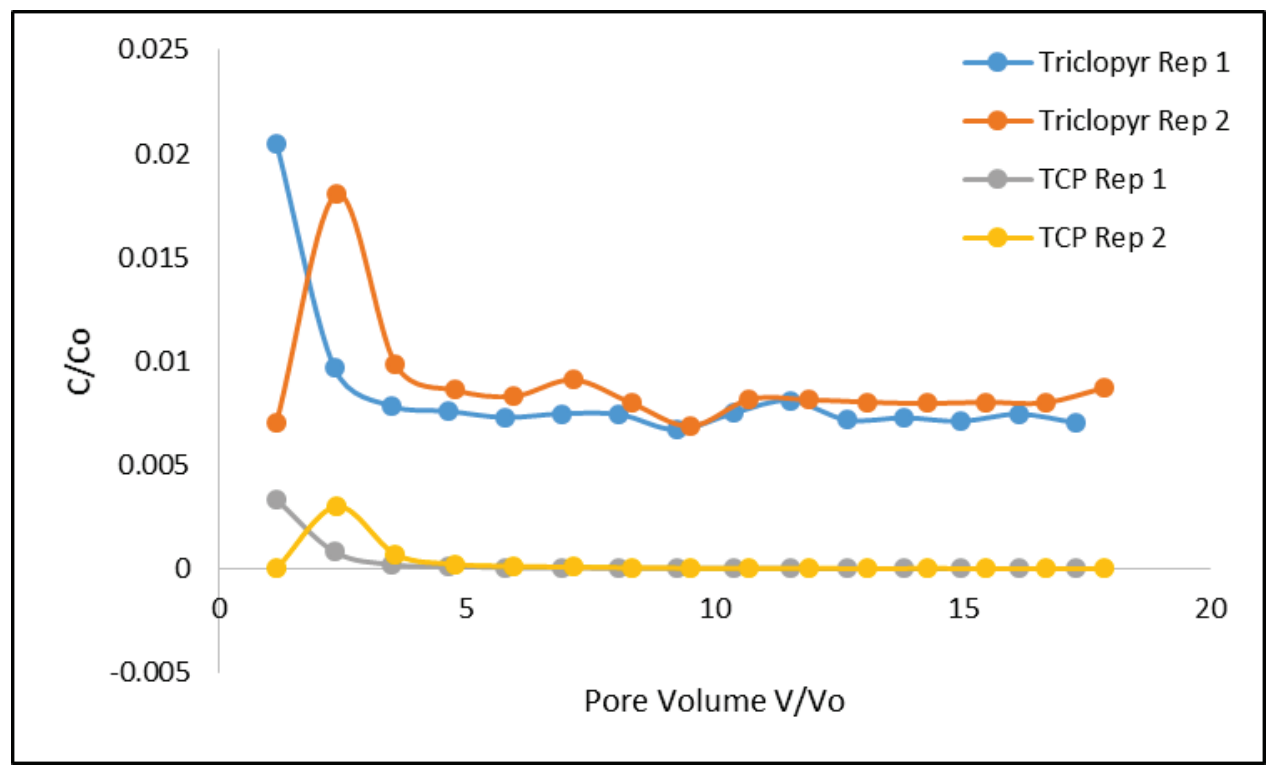

\subsubsection{Unsaturated column results}

As previously discussed, the unsaturated soil column studies were attempted under multiple laboratory conditions. However, attempts to establish flow through the soils in an unsaturated stated were unsuccessful. This is a significant indicator that soil solutions containing triclopyr will not readily flow through these soils due to the physicochemical properties of these soils, thus limiting transport. Additionally, limited transport was observed in saturated column studies further supporting limited transport potentials. 


\subsubsection{Column soils herbicide concentration results}

This section demonstrates how herbicide compounds are distributed with the soil column. The distribution of herbicide compounds provides additional insight into the potential transport or retention within the soils examined. Results show the majority of triclopyr and TBEE remained within the upper $5 \mathrm{~cm}$ of the Bosque, Cho, and Nuff column experiments under both RU-MSO and RU-diesel treatments. Figure 59 through Figure 64 display the distribution of compounds within the packed columns. The $y$-axis (Sample) indicates the depth within the soil column, with sample 7 or 8 collected where triclopyr was introduced into the soil column and sample 1 located at the end of the column. 
Figure 59. Soil concentrations of triclopyr, TBEE, and TCP in Bosque column soils spiked with RU-MSO. Soils were sampled in one inch increments.

Sample 1 is from the beginning of the column or the spiked triclopyr plug, while sample 7 is at the end of the column.

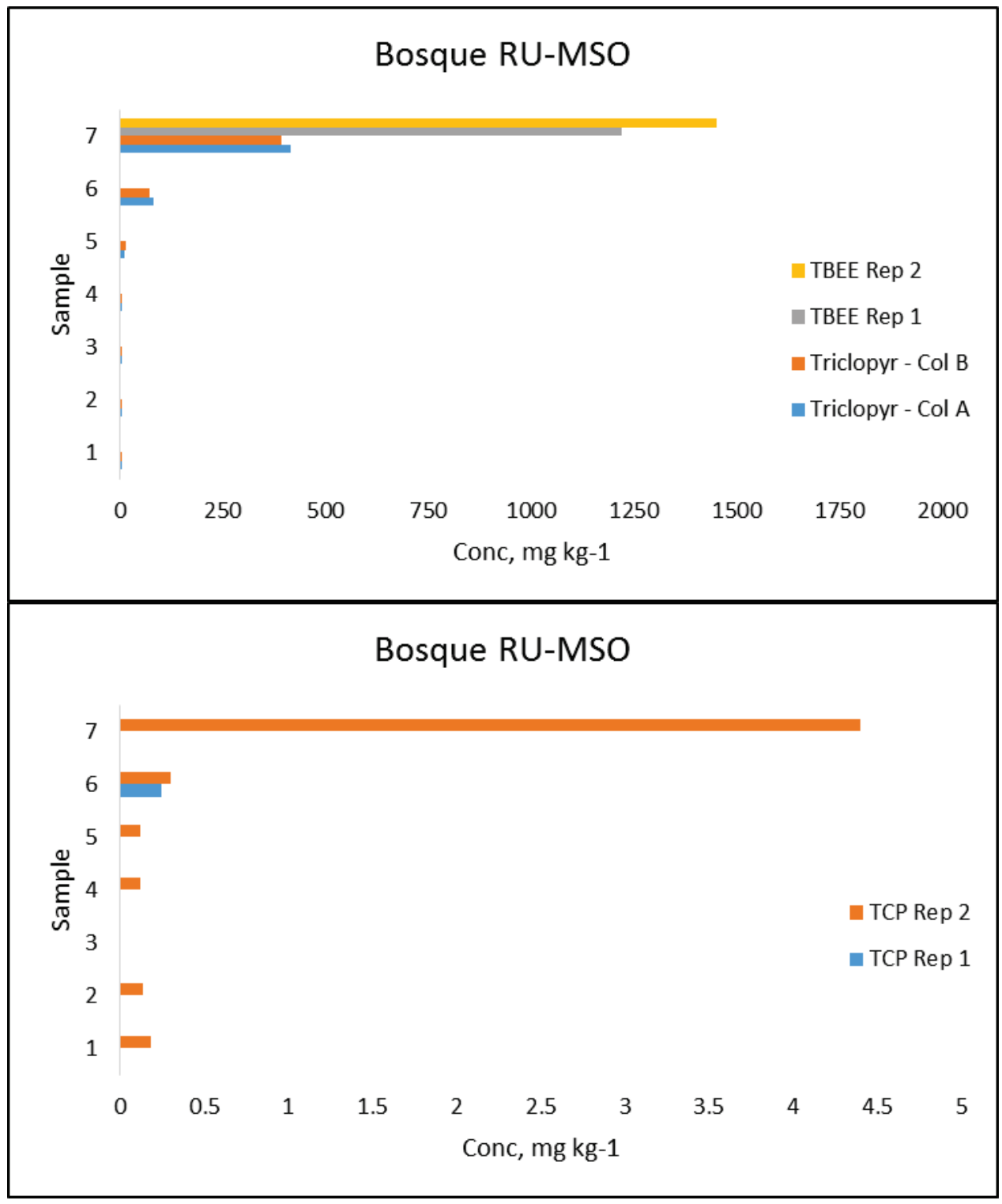


Figure 60. Soil concentrations of triclopyr and TBEE (upper) and TCP (lower) in Bosque column soils spiked with RU-diesel. Soils were sampled in one inch increments. Sample 1 is from the beginning of the column or the spiked triclopyr plug, while sample 7 is at the end of the column.

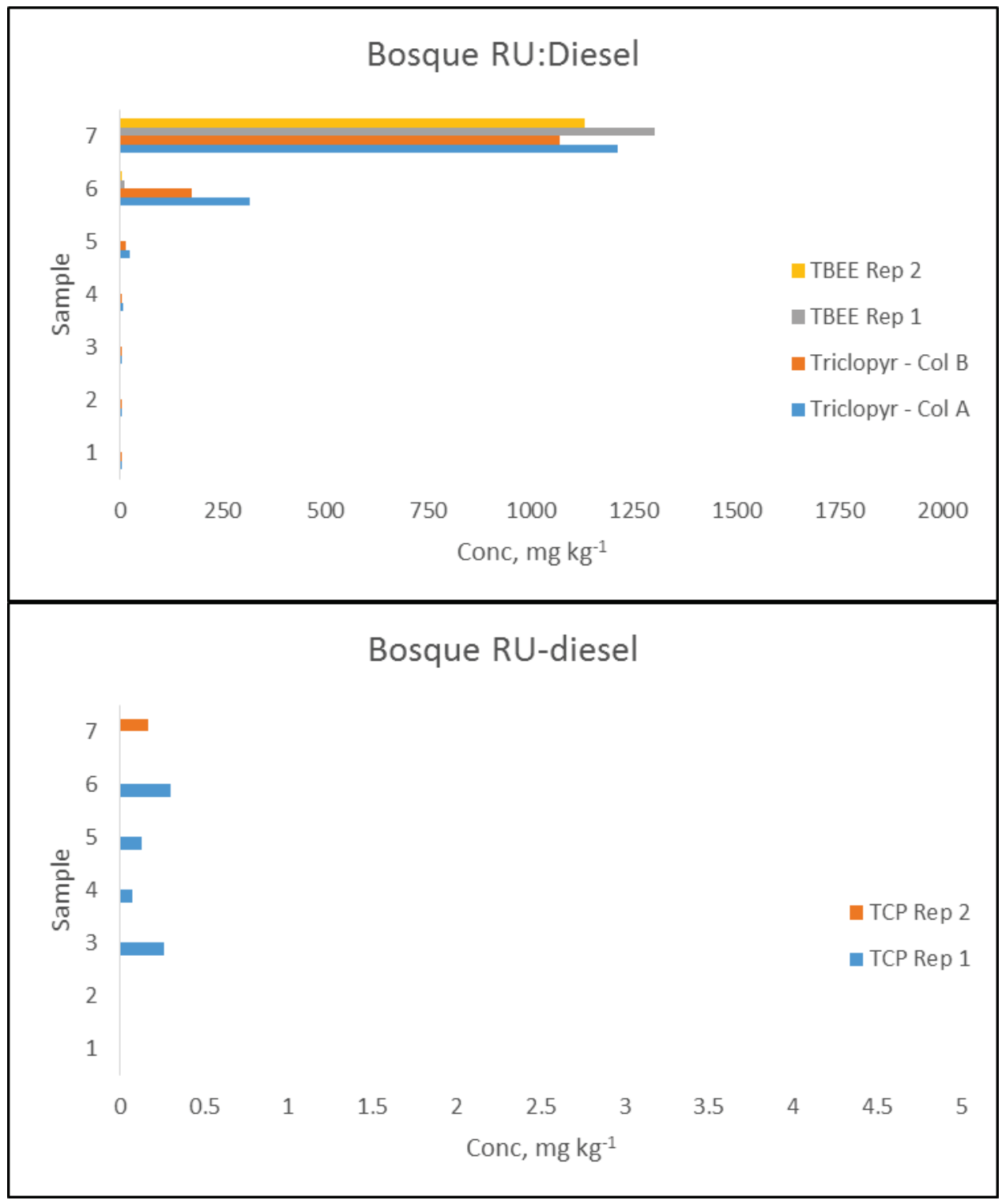


Figure 61. Soil concentrations of triclopyr and TBEE (upper) and TCP (lower) in Cho column soils spiked with RU-MSO. Soils were sampled in one inch increments. Sample 1 is from the beginning of the column or the spiked triclopyr plug, while sample 7 is at the end of the column.

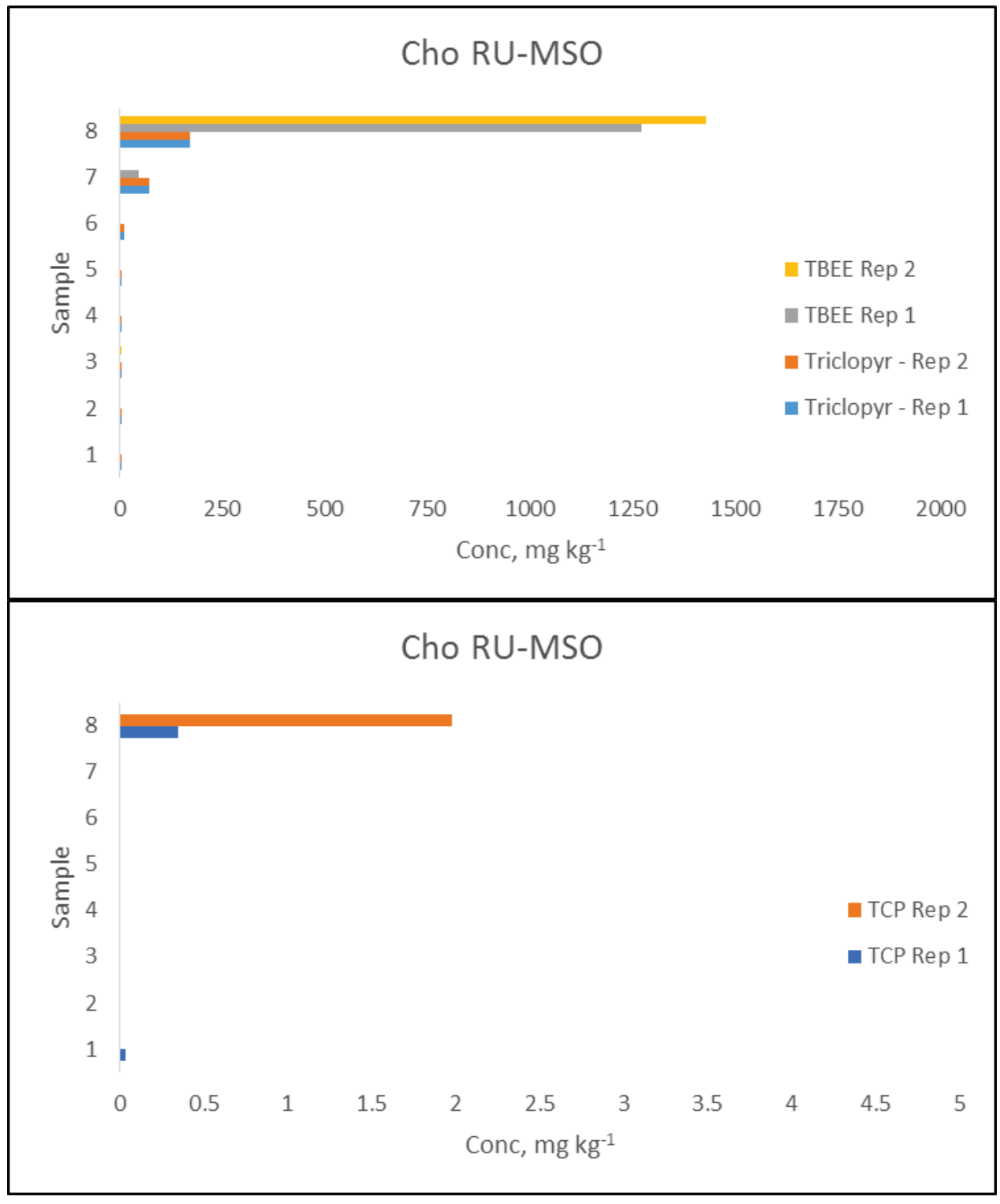


Figure 62.Soil concentrations of triclopyr and TBEE (upper) and TCP (lower) in Cho column soils spiked with RU-diesel. Soils were sampled in one inch increments. Sample 1 is from the beginning of the column or the spiked triclopyr plug, while sample 7 is at the end of the column.
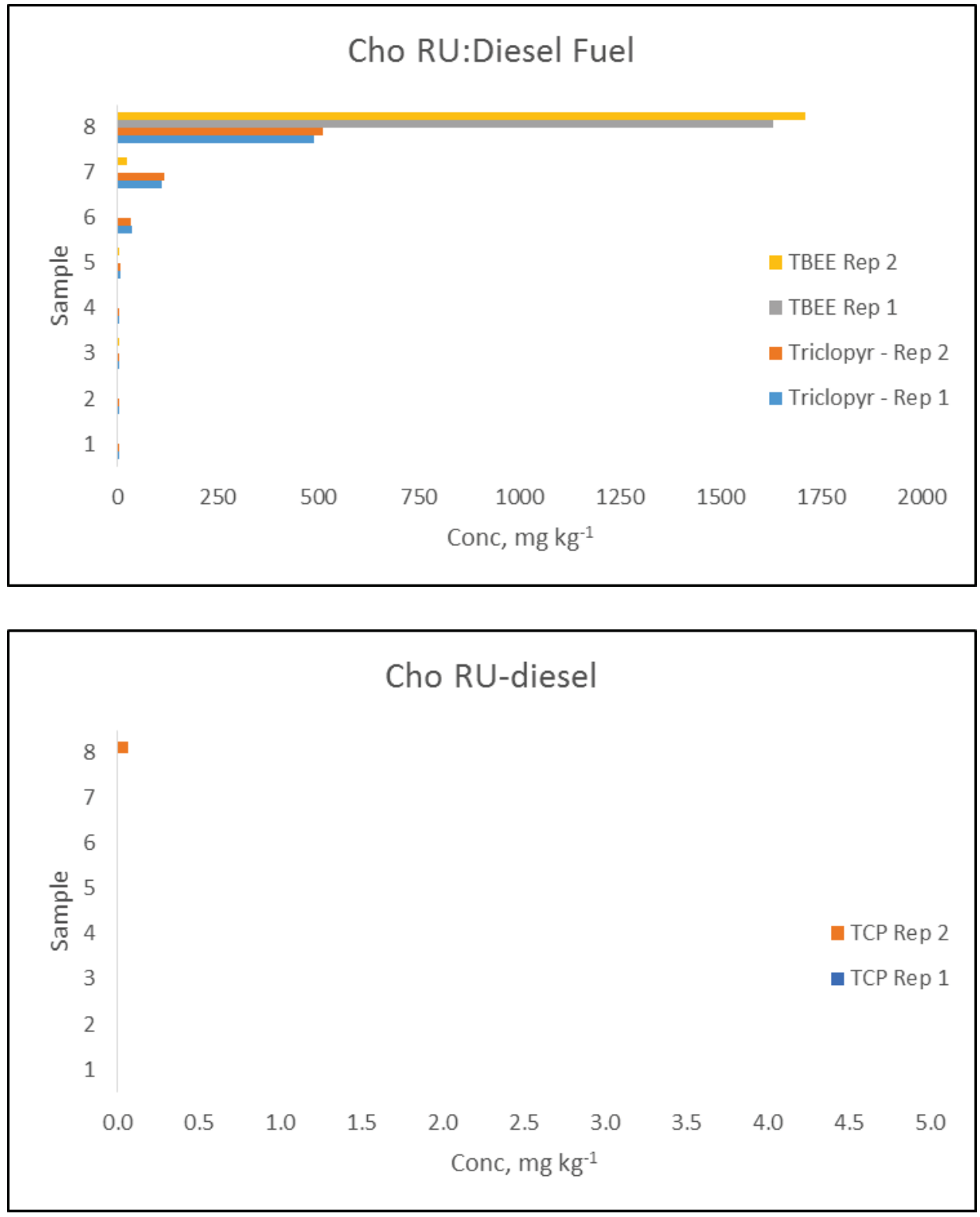
Figure 63. Soil concentrations of triclopyr and TBEE (upper) and TCP (lower) in Nuff column soils spiked with RU-MSO. Soils were sampled in one inch increments. Sample 1 is from the beginning of the column or the spiked triclopyr plug, while sample 7 is at the end of the column. Pyridinol was not seen in the soil in these treatments.

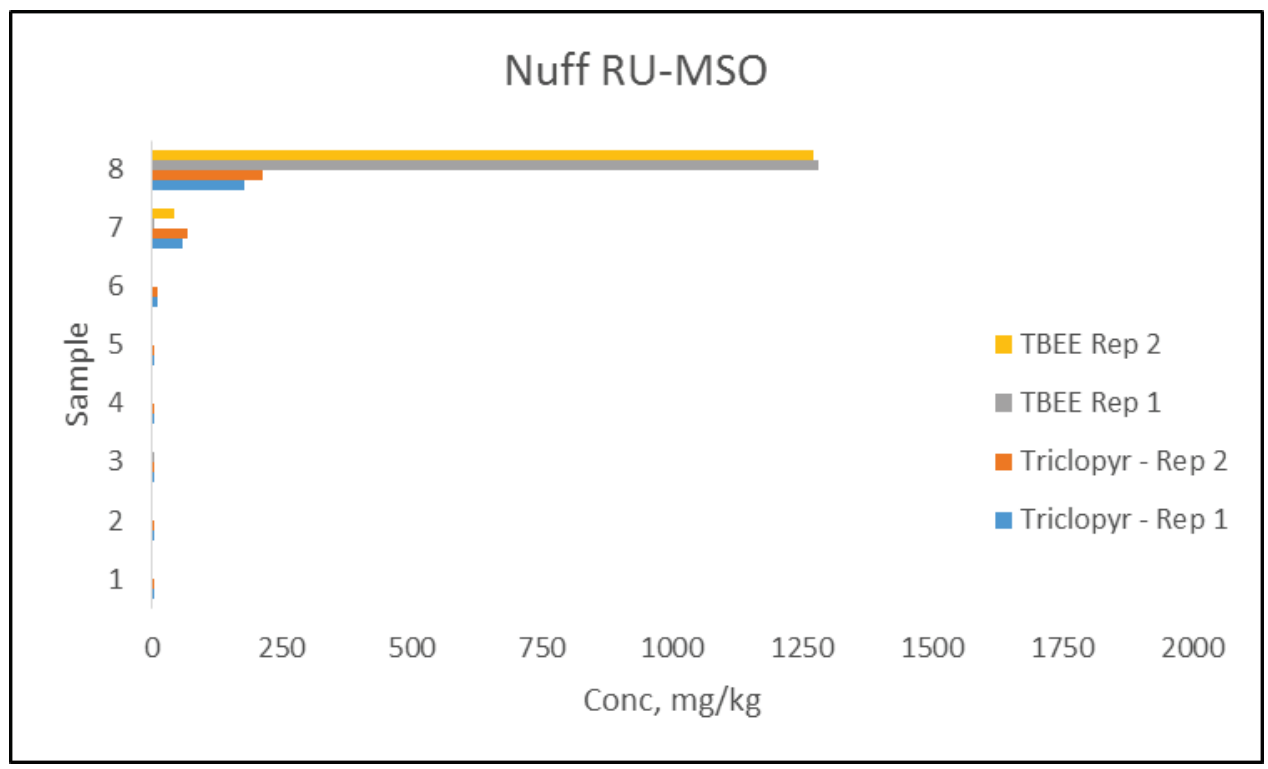


Figure 64. Soil concentrations of triclopyr and TBEE (upper) and TCP (lower) in Nuff column soils spiked with RU-diesel. Soils were sampled in one inch increments. Sample 1 is from the beginning of the column or the spiked triclopyr plug, while sample 7 is at the end of the column.

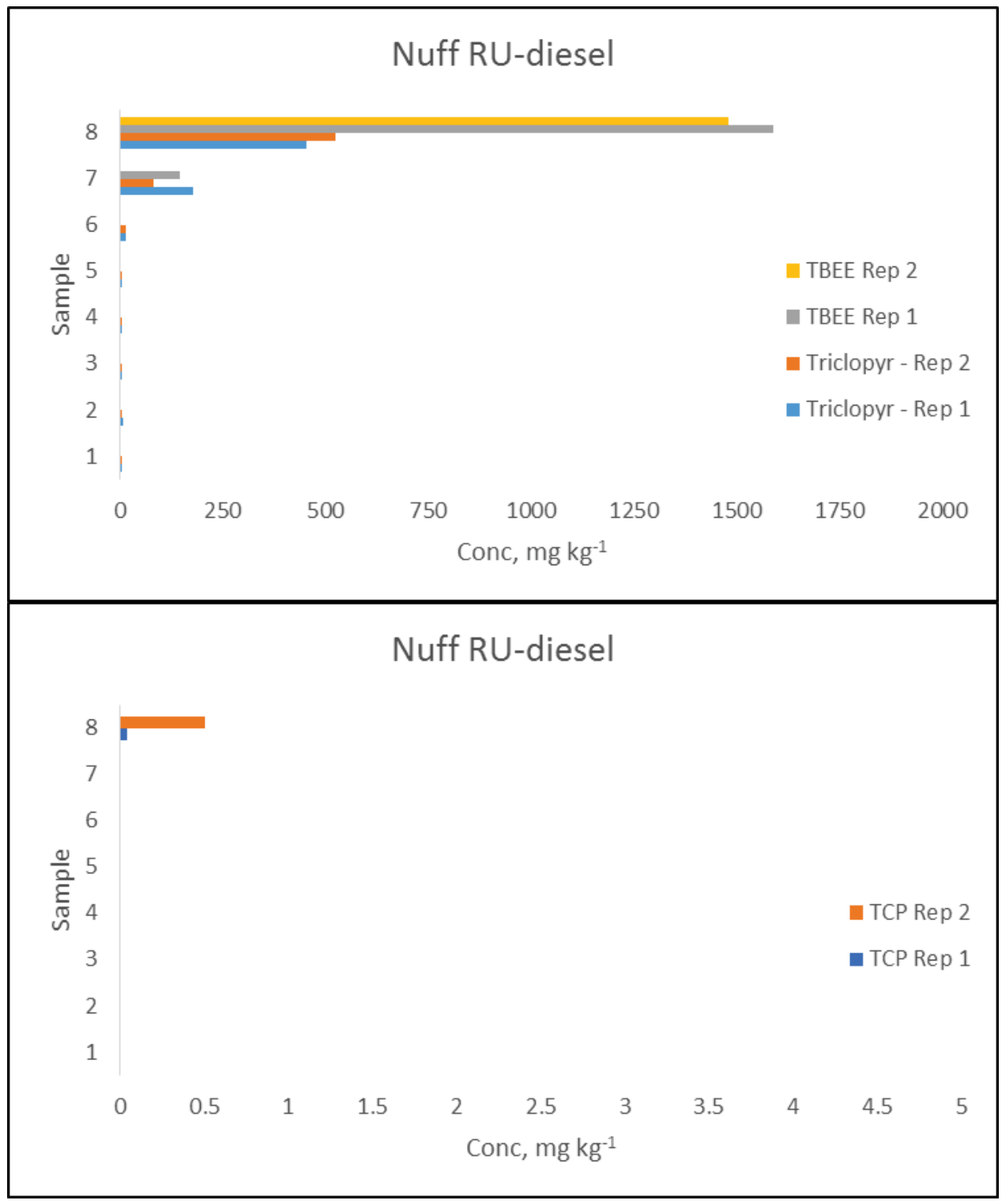

\subsubsection{Soil pH and electrical conductivity results}

The electrical conductivity and $\mathrm{pH}$ were measured in all column leachate solutions. For all soils and all treatments, the electrical conductivity was highest in the first sample/pore volume. This coincides with the higher triclopyr concentration in the solution. In most cases, the EC levels off after the first sample which reflects the decrease in salt or herbicide concentration. The Bosque soil experienced more heterogeneity in the EC values across the soil column collection period. This indicates that this soil 
may have experienced some intermittent flow periods. The Cho and Nuff leachates had very similar $\mathrm{EC}$ and $\mathrm{pH}$ values. Overall, the $\mathrm{pH}$ of all of the soil leachate remain fairly consistent across the duration of the study (within about $1 \mathrm{pH}$ unit). In general, the soil leachate solutions were about 0.5 to $1 \mathrm{pH}$ unit higher in $\mathrm{pH}$ than the measured soil $\mathrm{pH}$ on average. These data indicate that the $\mathrm{RU}$ and surfactant treatments may not significantly alter soil $\mathrm{pH}$. The EC and $\mathrm{pH}$ data for the column studies can be found in Table 10.

\subsubsection{Remedy Ultra (RU) solution experiment results}

Results indicate that $98.7 \%$ of the triclopyr compounds were in the lipid/cloudy layer represented by the white precipitate discussed above (Table 15). Only approximately $1 \%$ remained in the aqueous bottom layer. The initial RU solution predominantly contained the TBEE compound, which was to be expected, followed by triclopyr and TCP, respectively (Table 16).

Table 15. Percent herbicide species in the separation experiment.

\begin{tabular}{|c|c|c|}
\hline Compound & Lipid Phase (\%) & Aqueous Phase (\%) \\
\hline Triclopyr & 0.15 & 0.03 \\
\hline TBEE & 98.7 & 1.05 \\
\hline TCP & 0.05 & 0.015 \\
\hline
\end{tabular}

Table 16. Concentration of triclopyr compounds in pure Remedy Ultra (RU).

\begin{tabular}{|c|c|}
\hline Compound & Concentration $\left(\mathrm{mg} \mathrm{L}^{-1}\right)$ \\
\hline Triclopyr & 1291 \\
\hline TBEE & 250256 \\
\hline TCP & 231 \\
\hline
\end{tabular}

\subsection{Discussion}

Overall, the reproducibility of the column experiments displayed good agreement between replicates and similar results were found across all three soil types. The herbicide compounds were not very mobile and the vast majority of compounds were retained within the soils examined. When comparing the RU-MSO and RU-diesel treatments as potential surfactants in the Bosque soil, the RU-diesel resulted in less triclopyr 
leaching over time with $34.5 \%$ of the initially spiked triclopyr compared to $48.5 \%$ of the initially spiked triclopyr with MSO. When comparing the RUMSO and RU-diesel treatments in the Cho soil, the diesel results in more leaching over time. However, less than $1 \%$ of the spiked triclopyr was leached with either treatment in the Cho soil. The Nuff soil behaved similarly, with less than $1 \%$ of the total triclopyr being leached under either RU-MSO or RU-diesel treatments. In addition, after approximately five pore volumes of leachate the concentration of triclopyr leached levels off to $1 \%$ of the initial concentration of triclopyr that was introduced to the soil across all three soil types.

The column leaching experiments for the Cho and Nuff soils only contained $25 \%$ of the natural soil. Therefore, it is expected that even less triclopyr would be transported off-site or vertically through the soil profile under natural field conditions. The results described strongly suggest that the amount of triclopyr and related compounds leached at a field site where sand is not present will be less than what is reported here. The saturated column leaching studies represent a worst case scenario because the sand allows for greater mobility of the leaching fluid and any compounds within the fluid. In addition, the sand that was used in the column leaching experiments does not have physical and chemical properties similar to soil. The absorptive surfaces that are present in soils would further decrease the mobility of triclopyr.

The soil column studies represent potential triclopyr transport in fully saturated soils. A fully saturated soil is described as a soil where all of the soil pores are full of water. Potential herbicide transport is maximized under these conditions. Therefore, these results suggest that minimal triclopyr and its degradation products will be transported in the Bosque soil, and extremely limited in the Nuff and Cho soils. A large majority of the soils in this area at Fort Hood are composed of Nuff soil which exhibited less triclopyr mobility compared to the Bosque soil which is only present in select areas. The Bosque soil does have a slightly greater potential to leach triclopyr, but it is still expected to be minimal under natural conditions when the soil is not fully saturated and under normal flow conditions.

In addition, the column studies show that a vast majority of the triclopyr is retained in the upper portion $(5 \mathrm{~cm})$ of all of the soils with very little found in the subsurface. The Bosque soil from the column study retained some of 
the TBEE and the TCP degradation compound in addition to the triclopyr. This is interesting to note because neither the TBEE nor the TCP was transported through the soil column and into the leached solution. This indicates that these compounds may be less mobile than the triclopyr and have a higher affinity for the Bosque soil surfaces. A small amount of TCP did leach through the Nuff and Cho soils and a small amount $\left(<2 \mathrm{mg} \mathrm{kg}^{-1}\right)$ was retained in the upper $5 \mathrm{~cm}$ of the soil profile. The TBEE compound is found in all three soils after leaching, yet no TBEE compound was found in the soil leaching solution. This indicates that the TBEE is likely retained by the soil or experiences degradation in the soil. In the cases where degradation of the triclopyr occurred, the TCP behaved similarly in both the RU-MSO and RU-diesel treatments for the Cho and Nuff soils. The low concentration of TCP in all soils and leachate suggests that if degradation does occur in the field sites it will not happen readily and will represent a small proportion of the herbicide form in the soil.

Surfactant type does not appear to significantly impact herbicide mobility in the Cho and Nuff soils. The RU-diesel treatment did result in less triclopyr transport in the Bosque soil when compared to the RU-MSO treatment. More TBEE and triclopyr were retained in the Bosque soil with the RU-diesel treatment than with the RU-MSO treatment.

In general, the Cho and Nuff soils behaved differently from the Bosque soil. The Cho and the Nuff retained more triclopyr than the Bosque soil in the column studies. The Bosque soil has a higher percentage of organic material which does not appear to influence triclopyr retention. Data suggests that the finer texture, higher silt and clay, found in the Cho and Nuff soils appear to impact herbicide/triclopyr fate in these soils.

The experiments examining the reaction of $\mathrm{RU}$ and associated formation of a lipid phase proved valuable. They demonstrated the impact that water has on the solubility of RU solution. This relationship is vital to understanding triclopyr transport in natural systems where water is present. When mixed with water or a solution with a background electrolyte, the RU which contains the triclopyr forms a cloudy solution or "emulsion". These experiments were designed to determine if the triclopyr was found in the cloudy or suspension portion of the mixture or if it was solubilized in the aqueous portion. 
Triclopyr was overwhelmingly (98.7\%) found in the cloudy or fine particulate suspension portion of the RU-aqueous solution. This indicates that in natural systems when water is present that the triclopyr found in the RU, even in the presence of surfactants, will form a suspension which could limit its direct sorptive capabilities. Triclopyr found in this particulate/suspension form will most likely not form traditional sorption complexes on soil surfaces as would be expected of a soluble compound in an aqueous solution. Therefore, the triclopyr retention phenomenon is "sorption", but referred to as affinity as described above.

\subsection{Summary}

Saturated column studies documented the potential transport of herbicide compounds within three soil series. In general, the potential for transport remains limited, especially in the Nuff and Cho soils, which released less than $1 \%$ of the applied herbicide. The Bosque soil displayed more potential herbicide release, but based on results conducted under a worst case scenario, potential transport under field conditions is expected to remain low. Additionally, the distribution of herbicides with soil columns demonstrates that the majority of herbicide compounds remained near the column inflow, suggesting that potential transport of TBEE and TCP are also limited. The behavior of RU in water was investigated, suggesting that herbicide compounds largely occupy a lipid or emulsion phase, with potential implications for material fate and transport. 


\section{Data Synthesis and Management Recommendations}

Although many studies evaluate herbicide effectiveness, fate, transport, and potential environmental impacts, few assessments fully integrate vegetation surveys with field monitoring and comprehensive laboratory testing. As a result, the sections above evaluate vegetation effectiveness and herbicide potential fate and transport under field and laboratory conditions. Results suggest that following application, herbicides were largely held within the soil matrix, with limited transport and substantial degradation in both field and laboratory approaches. Notably, the RUMSO treatment appeared most effective for vegetation control. Additionally RU-MSO was strongly held within the soil based upon desorption results and showed low transport potential in column studies. As a result, RU-MSO treatments are preferable to control and RU-diesel treatments to maximize woody vegetation control while minimizing transport and potential impacts to environmental resources (e.g., surface and ground waters).

Several observations made during data collection may further improve woody vegetation management while promoting best management practices in herbicide application. First, limiting excessive ground disturbance provides several potential benefits. As noted above, extensive ground disturbance may decrease herbicide effectiveness if cut stumps are sheared from the larger root system prior to incorporation of phytotoxic compounds. Additionally, extensive disturbance can favor establishment of aggressive undesirable woody species. Finally, extensive disturbance prior to large rain events may increase erosion, leading to potential herbicide transport in particulate and/or dissolved forms. Scheduling herbicide applications during periods with low rainfall predictions also promotes the maximum herbicide retention and effectiveness, while minimizing risks to aquatic resources. Further, ensuring that each stump is sprayed and overspray is avoided will result in effective herbicide use.

Incorporating herbicide applications into an integrated management plan will further enhance woody vegetation control. Resource managers commonly utilize herbicides in combination with other techniques such as chopping, prescribed burning and grazing to maintain open grassland habitats. For example, conducting herbicide applications one year 
followed by controlled burning in outset years could reduce woody vegetation density and promote growth of herbaceous species preferred by both wildlife and commercially grazed livestock. 


\section{Conclusions}

The current study examines the effectiveness of herbicide application to control woody vegetation within the Fort Hood installation. Results indicate that the application of herbicides improves treatment effectiveness, resulting in decreased sprouting rates one year after application compared to control treatments. Herbicide applications utilizing MSO as a surfactant proved most effective and is recommended for future woody vegetation control. A field investigation monitored soil herbicide concentrations over time, indicating that herbicide compounds were held within the soil matrix, limiting potential transport. Field studies suggest that herbicide compounds degraded on-site within an average half-life of 25 days. Laboratory studies support field observations, demonstrating that the three soils examined display the capacity to sequester herbicides within the soil matrix (i.e., affinity). Additionally, herbicide compounds were strongly bound to soils with limited desorption observed under RU-MSO treatments. Column studies further support limited potential herbicide transport, indicating $<50 \%$ herbicide release in Bosque soil and $<1 \%$ release in Nuff and Cho soils. Notably, column studies utilized a worst case scenario approach, lower potential transport rates are expected under field conditions. Available data suggests that herbicides provide a useful tool for woody vegetation management and pose limited risk for transport and potential environmental impacts if applied appropriately. Incorporating herbicide application into an integrated woody vegetation management plan will result in maintenance of open grassland habitats required for ongoing training activities. 


\section{References}

Berkowitz J. F., and C. V. Noble. 2015. Development of new hydric soil field indicators: Guidelines for data collection and submission. Soil Horizons 56(1).

Buttler, I. W., D. W. Roberts, L. E. Siders and R. C. Gardner. 1993. Non-crop right-of-way terrestrial dissipation of triclopyr in California. DowElanco. Data package Report No. ABM-140265-E. DPR\# 51566-017.

Dow AgroSciences. 2008. Remedy Ultra Herbicide: Specimen Label. Indianapolis, IN.

Fischer, J. B., J. L. Michael, and H. L. Gibbs. 2008. Evaluation of HDPE water sample bottles and PVC sampler tubing used in herbicide dissipation studies. American Society of Agricultural and Biological Engineers 51: 1689-1695. doi: 10.13031/2013.25322.

Fort Hood Fact Sheet No. 0702. 2009. Fort Hood quick facts. Prepared by Fort Hood Public Affairs Office.

Fort Hood Fact Sheet No. 0703. 2009. Fort Hood Overview. Prepared by Fort Hood Public Affairs Office. http://www.hood.army.mil/facts/FS\%200702\%20\%20Fort\%20Hood\%20Quick\%20Facts.pdf.

Ganapathy, C. 1997. Environmental Fate of Triclopyr. In Environmental Monitoring \& Pesticide Management Branch. D. o. P. R., Ed. DPR: Sacaramento, CA,; p 18.

Ghassemi, M., L. Fargo, P. Painter, S. Quinlivan, R. Scofield and A. Takata., 1981. Environmental fates and impacts of major forest use pesticides. p. A-300-311. U.S. EPA. Office of Pesticides and Toxic Substances. Washington D.C.

Integrated Natural Resource Management Plan (INRMP). 2013. Fort Hood integrated natural resource management plan. FY2013-2017. Developed by: III Corps and Fort Hood, Texas in cooperation with the United States Department of the Interior, Fish and Wildlife Service, and the Texas Parks and Wildlife Department.

Kettler, T. A., J. W. Doran, and T. L. Gilbert. 2001. Simplified method for soil particle-size determination to accompany soil-quality analysis. Soil Science Society of America Journal 65:849-852. doi:10.2136/sssaj2001.653849x.

Klute A. 1986. Water retention: Laboratory methods. In Methods of soil analysis. Part 1: Physical and mineralogical methods. 2nd ed. Ed: Klute, A. Soil Science Society of America and American Society of Agronomy, Madison, Wisconsin.

Linders, J. B., J. W. Jansma, B. J. Mensink, and K. Oterman. 1994. Pesticides: Benefaction or Pandora's Box? A synopsis of the environmental aspects of 243 pesticides. National Institute of Public Health and Environmental Protection, Bilthoven, The Netherlands 1994, 679101014.

McCall, P. J., and P. D. Gavit. 1986. Aqueous photolysis of triclopyr and its butoxyethyl ester and calculated environmental photodecomposition rates. Environmental Toxicology and Chemistry 5(10): 879-885. doi: 10.1002/etc.5620051003. 
Newton, M., F. Roberts, A. Allen, B. Kelpsas, D. White, and P. Boyd. 1990. Deposition and dissipation of three herbicides in foliage, litter and soil of brushfields of southwest Oregon. Journal of Agriculture and Food Chemistry 38(2):574-583.

Norris, L., M. L. Montgomery, and L. E. Warren. 1987. Triclopyr persistence in western Oregon hill pastures. Bulletin of Environmental Contamination and Toxicoloogy 39:134-141. doi: 10.1007/BFo1691801.

Organization for Economic Cooperation and Development (OECD). 2000. Test No. 106: Adsorption-desorption using a batch equilibrium method. In OECD guideline for the testing of chemicals, Section 1, Ed. Paris. p 45.

Pusino, A., W. Liu, and C. Gessa. 1994. Adsorption of triclopyr on soil and some of its components. Journal of Agriculture and Food Chemistry 42:1026-1029.

Quinn, G. P., and M. J. Keough. 2002. Experimental design and data analysis for biologists. Cambridge University Press.

Reed, S. T., and D. C. Martens. 1996. Cooper and zinc. In Methods of soil analysis. Part 3: Chemical methods. 3rd ed. Ed: Sparks, D.L. Soil Science Society of America and American Society of Agronomy, Madison, Wisconsin.

Rhoades, J. D. 1996. Salinity: Electrical conductivity and total dissolved solids. In Methods of soil analysis. Part 3: Chemical methods. 3rd ed. Ed: Sparks, D.L. Soil Science Society of America and American Society of Agronomy, Madison, Wisconsin.

Sprecher, S. W., and A. G. Warne. 2000. Accessing and using meteorological data to evaluate wetland hydrology. ERDC/EL TR-WRAP-oo-1. Vicksburg, MS: U.S. Army Engineer Research and Development Center.

Sparks, D. L., and J. M. Bartels. 1996. Pt. 3: Chemical methods. No. 5-3. Madison WI: Soil Science Society of America.

Stephenson, G. R., K. R. Solomon, C. S. Bowhey and K. Liber. 1990. Persistence, leachability,and lateral movement of triclopyr (Garlon $®$ ) in selected Canadian forestry soils. Journal of Agriculture and Food Chemistry 38(2): 584-588. doi: 10.1021/jfooog2a053.

Sumner, M. E., and W. P. Miller. 1996. Cation exchange capacity and anion exchange. In Methods of soil analysis. Part 3: Chemical methods. 3rd ed. Ed: Sparks, D.L. Soil Science Society of America and American Society of Agronomy, Madison, Wisconsin.

Thomas, G. W. 1996. Soil pH and soil acidity. In Methods of soil analysis. Part 3: Chemical methods. 3rd ed. Ed: Sparks, D.L. Soil Science Society of America and American Society of Agronomy, Madison, Wisconsin.

Tu, M., C. Hurd, R. Robison, and J. M. Randall. 2001. Triclopyr. Weed Control Methods Handbook. The Nature Conservancy. 
U.S. Department of Agriculture, Natural Resources Conservation Service (USDA NRCS). 2006. Land Resource Regions and Major Land Resource Areas of the United States, the Caribbean, and the Pacific Basin. U.S. Department of Agriculture Handbook 296.

U.S. Department of Agriculture, Natural Resources Conservation Service (USDA NRCS). - Natural Resource Conservation Service (NRCS). Mollisols. (Accessed January 2017).

https://www.nrcs.usda.gov/wps/portal/nrcs/detail/soils/survey/class/maps/?ci d=nrcs142p2 053603 .

U.S. Department of Agriculture, Natural Resources Conservation Service (USDA NRCS).Soil Survey Staff. 1999. Soil taxonomy: A basic system of soil classification for making and interpreting soil surveys. $2^{\text {nd }}$ edition. Natural Resources Conservation Service. U.S. Department of Agriculture Handbook 436.

U.S. Department of Agriculture, Natural Resources Conservation Service (USDA NRCS).Soil Survey Staff. 2016. Natural Resources Conservation Service, United States Department of Agriculture. Web Soil Survey. Available online at http://websoilsurvey.sc.egov.usda.gov/. (Accessed December 2016).

Woodburn, K. B., F. R. Batzer, F. H. White, and M. R. Schultz. 1993. The aqueous photolysis of triclopyr. Environmental Toxicology and Chemistry 12 (1):43-55. 


\title{
Appendix A: Soil Series Examined
}

\author{
Bosque SERIES
}

The Bosque series consists of very deep, well drained, moderately permeable soils that formed in loamy, calcareous alluvial sediments. These are nearly level flood plain soils. Slopes range from o to 1 percent.

TAXONOMIC CLASS: Fine-loamy, mixed, superactive, thermic Cumulic Haplustolls

TYPICAL PEDON: Bosque loam-in a cultivated field (colors are for dry soil unless otherwise stated).

Ap-o to 5 inches; dark grayish brown (10YR 4/2) loam, very dark grayish brown (10YR 3/2) moist; weak very fine subangular blocky and fine granular structure; slightly hard, friable; strongly effervescent; moderately alkaline; abrupt smooth boundary. (o to 10 inches thick)

A1-5 to 20 inches; dark grayish brown (10YR 4/2) loam, very dark brown (10YR 3/2) moist; weak fine subangular blocky and fine granular structure; slightly hard, friable; many pores and wormcasts; common threads and films of calcium carbonate; strongly effervescent; moderately alkaline; gradual smooth boundary. (6 to 20 inches thick)

A2-20 to 38 inches; dark brown (10YR 3/3) clay loam, very dark brown (10YR 2/3) moist; weak subangular blocky structure; hard, firm; common threads and films of calcium carbonate; strongly effervescent; moderately alkaline; gradual smooth boundary. (6 to 30 inches thick)

Bw-38 to 50 inches; brown (10YR 5/3) clay loam, brown (10YR 4/3) moist; weak subangular blocky structure; very hard, firm; few fine faint dark yellowish brown streaks and spots; common threads and films of calcium carbonate; strongly effervescent; moderately alkaline; gradual smooth boundary. (o to 55 inches thick)

Akb-50 to 60 inches; dark grayish brown (10YR 4/2) clay, very dark grayish brown (10YR 3/2) moist; massive; very hard, firm; few fine faint brown mottles and streaks; many threads and films of calcium carbonate; violently effervescent; moderately alkaline. 
TYPE LOCATION: Erath County, Texas; from the intersection of Texas Highway 108 and Farm Road 8 in the north edge of Stephenville, Texas; 6.4 miles west-northwest of Farm Road 8; 0.3 mile east on a county road and 30 yards south of road in cultivated field.

RANGE IN CHARACTERISTICS: The texture of the control section is loam, sandy clay loam, or clay loam, with clay content ranging from 20 to 35 percent. Some pedons have thin, discontinuous fine sandy loam or silt loam strata. Siliceous or limestone pebbles range from none to about 10 percent by volume in some horizons. Most pedons have films and threads of calcium carbonate throughout the control section. Reaction is slightly alkaline or moderately alkaline and calcareous. Mean annual soil temperature ranges from 66 to 72 degrees $\mathrm{F}$.

The A horizon has hue of 7.5YR or 10YR, value of 3 to 5 , and chroma of 1 or 3. The mollic epipedon ranges from 20 to about 60 inches thick. Texture is loam, clay loam or sandy clay loam.

The Bw horizon is absent in some pedons. Where present, it has hue of 7.5YR or $10 Y R$, value of 4 to 6 , and chroma of 2 to 4 , with or without brownish streaks or mottles. Texture is loam, sandy clay loam or clay loam.

The Akb, Ab horizons, and Bwb horizon, where present, are typically below the 10 to 40 inch control section and are absent in some pedons. Texture is mainly clay or clay loam, but ranges to sandy clay loam, with color as described in the A horizon. Some pedons have brownish Bw or $\mathrm{C}$ horizons that range from fine sandy loam to clay.

COMPETING SERIES: These are Bippus (TX), Gageby (TX), Gowen (TX), Kaski (KS), and Whitesboro (TX) series. Similar soils are the Bergstrom, Frio, Oakalla, and Venus series. Bippus and Gageby soils are drier for longer periods of time and receive less than 28 inches of annual rainfall. Gowen, Kaski, and Whitesboro soils are noncalcareous. In addition, Kaski soils have mean annual soil temperature ranging from 59 to 66 degrees F. Bergstrom soils have fine-silty control sections. Frio soils have fine textured control sections. Oakalla soils have carbonatic mineralogy. Venus soils have mollic epipedons less than 20 inches thick and are on uplands. 
GEOGRAPHIC SETTING: Bosque soils occur along nearly level flood plains of streams in central Texas. They have formed in calcareous alluvial sediments. The mean annual temperature ranges from 64 to 70 degrees $F$. and mean annual precipitation ranges from 28 to 40 inches. Frost free days range from 220 to 275 days and elevation ranges from 20 to 1,400 feet. The Thornthwaite annual P-E indices from 42 to 64 .

GEOGRAPHICALLY ASSOCIATED SOILS: These include the competing Frio, Gowen, and Venus series. Also associated are Bunyan and Lewisville series. Bunyan soils lack mollic epipedons. Lewisville soils have mollic epipedons less than 20 inches thick and contain more than 35 percent clay in the 10 to 40 inch control section.

DRAINAGE AND PERMEABILITY: Well drained. Permeability is moderate. Runoff is negligible. The soil floods at 1 to 10 year intervals, except where protected by dikes or dams.

USE AND VEGETATION: Most areas are being farmed to sorghums, small grains, and pecan orchards. Some areas are used for bermudagrass pastures. Native trees are elm, hackberry, pecan, live oak, and cottonwood. Grasses include big and little bluestem, indiangrass, switchgrass, and sideoats grama.

DISTRIBUTION AND EXTENT: This soil occurs mainly in the North Central Prairies, Grand Prairie and Cross Timbers areas of north-central Texas. It is of large extent.

MLRA SOIL SURVEY REGIONAL OFFICE (MO) RESPONSIBLE: Temple, Texas

SERIES ESTABLISHED: Erath County, Texas; 1970.

REMARKS: Diagnostic horizons and features recognized in this pedon are:

Mollic epipedon - o to 38 inches. (A horizons)

Cambic horizon - 38 to 50 inches. (Bw horizon)

Other features - are calcareous to the surface and have an irregular decrease in organic matter through the solum. 


\section{Cho SERIES}

The Cho series consists of soils that are very shallow and shallow to a petrocalcic horizon. These well drained soils formed in loamy calcareous gravelly alluvium. These nearly level to moderately sloping soils are on stream terraces, alluvial fans and knolls on alluvial plain remnants on dissected plateaus. Slope ranges from o to 8 percent. Mean annual air temperature is about 19 degrees $\mathrm{C}$ ( 66 degrees $\mathrm{F}$ ), and mean annual precipitation is about $635 \mathrm{~mm}$ ( $25 \mathrm{in})$.

TAXONOMIC CLASS: Loamy, carbonatic, thermic, shallow Petrocalcic Calciustolls

TYPICAL PEDON: Cho loam--in rangeland. (Colors are for dry soil unless otherwise stated.)

A-o to $25 \mathrm{~cm}$ (o to $10 \mathrm{in}$ ); brown (10YR 4/3) loam, dark brown (10YR 3/3) moist; weak fine granular and weak medium subangular blocky structure; slightly hard, friable; many fine roots; common fine pores; 5 percent indurated caliche fragments on surface; 10 percent indurated caliche fragments; violently effervescent; moderately alkaline; abrupt wavy boundary. (Thickness of the A horizon is 18 to $51 \mathrm{~cm}$ [7 to $20 \mathrm{in}]$ )

Bkkm-25 to $36 \mathrm{~cm}$ (10 to 14 in); pinkish white (7.5YR 8/2) indurated caliche laminar petrocalcic; fractured at intervals of 150 to $460 \mathrm{~mm}$ (6 to 18 in) across by 25 to $51 \mathrm{~mm}$ ( 1 in to 2 in) thick; 5 percent brown (10YR 4/3) loam between plates and in solution channels; violently effervescent; moderately alkaline; clear wavy boundary. (Thickness of the Bkkm horizon is 5 to $30 \mathrm{~cm}$ [2 to $12 \mathrm{in}]$ )

Bkk-36 to $152 \mathrm{~cm}$ (14 to 60 in); pink (7.5YR 8/4) loam; massive; slightly hard, friable; 20 percent finely disseminated calcium carbonate; 20 to 30 percent weakly cemented to strongly cemented concretions and caliche fragments; violently effervescent; moderately alkaline.

TYPE LOCATION: McCulloch County, Texas; From the intersection U.S. Highway 87 and U.S. Highway 377 in Brady, 17.3 miles west-northwest on U.S. Highway 87, 15.9 miles north on Farm Road 503, (approximately 3.7 miles north of Doole), 0.4 mile northeast on ranch trail, and 200 feet northwest in rangeland. (Doole USGS topographic quadrangle; Latitude: 
31 degrees, 26 minutes, 56.4 seconds N; Longitude: 99 degrees, 35

minutes, 34.8 seconds W; NAD83)

\section{RANGE IN CHARACTERISTICS:}

Depth to petrocalcic contact: 18 to $50 \mathrm{~cm}$ (7 to 20 in)

Particle-size control section (weighted average):

Clay content: 15 to 35 percent total clay

A horizon

Hue: 7.5YR or $10 Y R$

Value: 3 to 5 dry

Chroma: 2 or 3 dry

Texture: Loam or clay loam, or their gravelly phases

Clay content: 15 to 35 percent total clay

Effervescence: Violently

Reaction: Slightly alkaline or moderately alkaline

Calcium carbonate equivalent: 40 to 65 percent by weight in the fine-earth fraction

Rock fragments: Amount-o to 34 percent, size-2 to $75 \mathrm{~mm}$, kind-caliche; and/or amount-o to 5 percent, size- 76 to $250 \mathrm{~mm}$, kind-limestone

Bkkm horizon

Hue: 5 YR to $10 Y R$

Value: 7 or 8 dry

Chroma: 1 to 4 dry

Cementation: Strongly cemented to indurated, laminar in upper 4 to $5 \mathrm{~cm}$ Effervescence: Violently

Reaction: Slightly alkaline or moderately alkaline

Bkk horizon

Hue: 5 YR to $10 Y R$

Value: 7 or 8 dry

Chroma: 1 to 4 dry

Texture: Loam, clay loam or silty clay loam; and their gravelly and very

gravelly phases

Effervescence: Violently

Reaction: Slightly alkaline or moderately alkaline

Calcium carbonate equivalent: 40 to 85 percent by weight 
Rock fragments: Amount-o to 50 percent by volume, size-2 to $75 \mathrm{~mm}$, kind- caliche, siliceous, and limestone

COMPETING SERIES: There are no other series in this family. Similar series are Eola (TX), Kavett (TX), Mailtrail (TX), Mereta (TX), Noelke (TX), Ozona (TX), Pitzer (TX), Valco (TX), and Valera (TX).

Eola and Mailtrail soils: Have more than 35 percent coarse fragments in the control section.

Kavett and Valera soils: Have a petrocalcic horizon that is underlain by hard limestone and Valera soils are moderately deep to a petrocalcic. Mereta soils: Are clayey and the mineralogy is mixed.

Noelke soils: Have a lithic contact within $50 \mathrm{~cm}$ of the surface.

Ozona and Pitzer soils: Have less than 40 percent by weight calcium carbonate equivalent in the control section.

Valco soils: Mean annual soil temperatures is 22 degrees $\mathrm{C}$ (72 degrees F) or higher.

\section{GEOGRAPHIC SETTING:}

Parent material: Loamy calcareous gravelly alluvium several feet thick or ancient alluvium derived from limestone and sandstone.

Landscape: Dissected plateaus

Landform: Stream terraces, alluvial fans and/or knolls on alluvial plain remnants

Slope: o to 8 percent

Climate: Dry subhumid

Soil moisture: Typic ustic moisture regime

Precipitation Pattern: The majority of the yearly amount occurs during the fall and spring months. The winter and summer months are normally drier.

Mean annual precipitation: 508 to $686 \mathrm{~mm}$ (20 to $27 \mathrm{in}$ )

Mean annual air temperature: 18 to 20 degrees C (64 to 68 degrees F)

Frost free days: 210 to 240

Elevation: 366 to $610 \mathrm{~m}(1,200$ to $2,000 \mathrm{ft})$

Thornthwaite P-E index: 25 to 50

GEOGRAPHICALLY ASSOCIATED SOILS: These are Kavett (TX), Mereta (TX), Nuvalde (TX), Rowena (TX) and Valera (TX) series.

Kavett and Valera soils: Occur on backslope and footslope positions.

Mereta soils: Occur on similar positions

Nuvalde and Rowena soils: Occur on lower positions on footslopes and are 
formed from more recent alluvial sediments.

DRAINAGE AND PERMEABILITY: Well drained. Permeability in the petrocalcic horizon is slow to very slow. Runoff is negligible on 0 to 1 percent slopes, very low on 1 to 3 percent slopes, low on 3 to 5 percent slopes, and medium on 5 to 8 percent slopes.

USE AND VEGETATION: Mainly used as rangeland. Some areas are used for growing small grains. The climax plant community is a mid grass prairie. The dominant grass is sideoats grama. Other grasses include little bluestem, Texas wintergrass, silver bluestem, Arizona cottontop, dropseeds, white tridens, hairy grama, little bluestem, slim tridens, buffalograss, Wright's threeawn, and curly mesquite. The woody plant is live oak. Forbs include bushsunflower, orange zexmenia, and gayfeather. With heavy stocking rates, the site could potentially deteriorate to a plant population of lotebush, prickly pear, Texas persimmon, tasajillo, agarito, threeawns, red grama, Texas grama, hairy tridens, prairie coneflower, and broomweed.

DISTRIBUTION AND EXTENT: West-Central Texas. Central Great Plains Winter Wheat and Range Region, LRR-H: MLRA 78A-Rolling Limestone Prairie; MLRA 78B-Central Rolling Red Plains, Western Part; and MLRA 8oB-Texas North-Central Prairies. Southwest Plateaus and Plains Range and Cotton Region, LLR-I: MLRA 81A-Edwards Plateau, Western Part; MLRA 81B-Edwards Plateau, Central Part; and MLRA 82A-Texas Central Basin. Southwestern Prairies Cotton and Forage Region, LRR-J: MLRA 85 -Grand Prairie. The series is extensive with over 500,000 acres.

MLRA SOIL SURVEY REGIONAL OFFICE (MO) RESPONSIBLE: Temple, Texas

SERIES ESTABLISHED: McCulloch County, Texas; 1970.

REMARKS: These soils were formerly included in the Kimbrough and Mereta series.

Although the series is classified as typic ustic at the series type location, the moisture subclass is aridic ustic in the western portion of the correlated range. A new series should be established for the the aridic ustic moisture regime. 
Diagnostic horizons and features recognized in this pedon are: Mollic epipedon: 0 to $25 \mathrm{~cm}$ (o to $10 \mathrm{in}$ ). (A horizon) Petrocalcic horizon: 25 to $36 \mathrm{~cm}$ (10 to 14 in) (Bkkm horizon) Calcic horizon: 36 to $152 \mathrm{~cm}$ (14 to $60 \mathrm{in}$ ) (Bkk horizon)

ADDITIONAL DATA: None

TAXONOMIC VERSION: Keys to Soil Taxonomy, 11th Edition, 2010.

\section{Nuff SERIES}

The Nuff series are moderately deep to shale. They are well drained, moderately slowly permeable soils. These soils formed in interbedded marl, limestone, and shale. They are gently sloping to moderately sloping soils on uplands. Slopes range from 1 to 6 percent.

TAXONOMIC CLASS: Fine-silty, carbonatic, thermic Udic Calciustolls

TYPICAL PEDON: Nuff silty clay loam, very stony, on a convex 2 percent slope in rangeland. (Colors are for dry soil unless otherwise stated.)

A1--o to 5 inches; dark gray (10YR 4/1) silty clay loam, very dark gray (10YR 3/1) moist; moderate medium subangular blocky structure parting to weak fine granular; very hard, friable; many very fine, fine and few medium roots; common wormcasts; few fine concretions of calcium carbonate; limestone fragments from 3 inches to 20 inches across and 1/2 inch to 1 inch thick cover about 20 percent of surface, and 5 percent by volume of layer; strongly effervescent; moderately alkaline; clear smooth boundary. (5 to 12 inches thick)

A2--5 to 11 inches; dark gray (10YR 4/1) silty clay loam, very dark gray (10YR 3/1) moist; moderate medium subangular blocky structure; very hard, friable; many very fine and fine roots; common wormcasts; few fine concretions of calcium carbonate; strongly effervescent; moderately alkaline; clear wavy boundary. (o to 8 inches thick)

Bk1--11 to 21 inches; brown (10YR 5/3) silty clay loam, dark brown (10YR 4/3) moist; moderate medium subangular blocky structure; very hard, friable; common very fine and fine roots; common wormcasts; common 
fine concretions of calcium carbonate; few cracks filled with soil from above; strongly effervescent; moderately alkaline; gradual smooth boundary. (5 to 15 inches thick)

Bk2--21 to 30 inches; grayish brown (2.5Y 5/2) silty clay loam, dark grayish brown (2.5Y 4/2) moist; weak medium subangular blocky structure; hard, friable; common very fine and fine roots; common fine and medium concretions and soft masses of calcium carbonate; strongly effervescent; moderately alkaline; clear smooth boundary. (8 to 18 inches thick)

Bk3--30 to 36 inches; light olive brown (2.5Y 5/4) silty clay loam, olive brown (2.5Y 4/4) moist; weak fine subangular blocky structure; hard, friable; few very fine and fine roots; common fine and medium concretions and soft masses of calcium carbonate; about 30 percent by volume limestone fragments 4 inches to 18 inches across and $1 / 2$ inch to $3 / 4$ inch thick; strongly effervescent; moderately alkaline; gradual wavy boundary. (o to 15 inches thick)

CB--36 to 58 inches; light gray ( $2.5 \mathrm{Y} 7 / 2)$, yellow (2.5Y 8/6), and yellow (10YR 7/8) interbedded layers of marl and shale with texture of silt loam, light brownish gray (2.5 $\mathrm{Y} 6 / 2)$, yellow $(2.5 \mathrm{Y} 7 / 6)$, and brownish yellow (10YR 6/8) moist; massive; few fine roots; few fossil shells $1 / 2$ inch to 1 $1 / 4$ inches across; strongly effervescent; moderately alkaline; gradual wavy boundary. (o to 36 inches thick)

C--58 to 80 inches; pale yellow (5Y 7/3) and yellow (10YR 7/8) interbedded compact layers of shale with texture of silty clay loam, pale olive (5Y 6/3) and brownish yellow (10YR 6/8) moist; massive; few fine roots; strongly effervescent; moderately alkaline.

TYPE LOCATION: Coryell County, Texas; from the intersection of U.S. Highway 84 and FM 116 west of Gatesville; 3.1 miles southwest on FM 116; 1.7 miles east on county road; 2.2 miles north on county road; 300 feet west in rangeland.

RANGE IN CHARACTERISTICS: The solum ranges from 20 to 40 inches thick. Limestone pebbles and fragments up to 48 inches across and 1/2 inch to 4 inches thick cover o to 15 percent of the surface layer. Most of the fragments are 6 to 24 inches across and 1/2 inch to 2 inches thick. Some 
fragments are tilted at an angle of 30 to 50 degrees. Pebbles, cobbles and stones make up o to 30 percent by volume of the surface layer. Calcium carbonate concretions are typically throughout and films, threads, or soft masses of calcium carbonate are within a depth of 15 to 24 inches of the soil surface.

The A horizon has hue of $10 \mathrm{YR}$ or $2.5 \mathrm{Y}$, value of 3 to 5 , and chroma of 1 or 2. It is silt loam, silty clay loam, or silty clay or their stony or very stony counterparts. Pebbles, cobbles, and stone sized limestone fragments range from 2 to 40 percent by volume but stones and cobbles typically make up 3 to 25 percent.

The B horizon has colors mainly in shades of brown with hue of 10YR or $2.5 \mathrm{Y}$, value of 4 to 7 , and chroma of 2 to 6 . Yellowish or brownish mottles range from none to a few. It is silty clay loam, silt loam, or their stony counterparts. Limestone fragments make up 5 to 35 percent by volume of some layers in this horizon. However, stony layers are thin, discontinuous, and are absent in some pedons.

The $\mathrm{C}$ horizon has yellowish, grayish, or brownish colors. It is interbedded marly and shaly silt loam, silty clay loam, or silty clay. Some pedons have limestone layers 2 to 4 inches thick randomly occurring at vertical intervals of 2 to 6 feet apart.

COMPETING SERIES: These include Brenham and Denton series in the same family and Bolar, Lewisville, Set and Topsey series in similar families. Brenham and Set soils have sola greater than 40 inches thick. Brenham soils formed in Tertiary Age materials. Set soils formed in Pennsylvania Age materials and are in drier climates. Denton soils have a lithic contact at 40 to 60 inches. Bolar and Topsey soils are fine loamy and in addition, Bolar soils are underlain by hard limestone. Lewisville soils have mixed mineralogy and do not have stony surfaces.

GEOGRAPHIC SETTING: Nuff soils are on erosional uplands. Surfaces are typically convex with slopes of 1 to 6 percent. These soils are on low hills, ridgetops, or narrow stream divides. Nuff soils formed in the Walnut Clay Geologic Formation of the Lower Cretaceous Period. Mean annual precipitation is 26 to 34 inches. Mean annual temperature is 64 to 68 degrees F. Frost free days range from 230 to 250 and elevation ranges 
form 1200 to 1600 feet above sea level. The Thornthwaite P-E indices range from 44 to 56 .

GEOGRAPHICALLY ASSOCIATED SOILS: These include Cho, Doss, Krum, Real, Slidell, and Wise series. Cho soils are shallow, loamy soils on ridgetops upslope from Nuff soils. Doss and Real soils are shallow, loamy soils on side slopes below Nuff soils. Krum and Slidell soils, which are deep, clayey soils, are along drains downslope from Nuff soils. The loamy Wise soils are on gentle slopes below the Nuff soils.

DRAINAGE AND PERMEABILITY: Well drained; medium runoff; moderately slow permeability.

USE AND VEGETATION: Mainly range. Native vegetation includes little bluestem, indiangrass, sideoats grama, and Texas wintergrass.

DISTRIBUTION AND EXTENT: Central Texas, in the southern part of the Grand Prairie. The series is of moderate extent.

MLRA SOIL SURVEY REGIONAL OFFICE (MO) RESPONSIBLE: Temple, Texas

SERIES ESTABLISHED: Coryell County, Texas; 1983.

REMARKS: This soil was previously included with the Sanger series. Areas that are nonstony usually have had the stones removed by man.

Classification was changed 11/89 from fine-silty, carbonatic, thermic Typic Calciustolls to fine-silty, carbonatic, thermic Udic Calciustolls.

Diagnostic horizons and features recognized in this pedon are:

Mollic epipedon - $\mathrm{o}$ to 11 inches.

Calcic horizon - 11 to 36 inches. 


\section{Appendix B: Soil Herbicide and \\ Physicochemical Parameters}


Table B.1. Mean soil triclopyr + TBEE concentrations ( \pm SE) over study period. TBEE, triclopyr-2-butoxy-ethylester.

\begin{tabular}{|c|c|c|c|c|c|c|c|}
\hline \multirow[b]{2}{*}{ Soil Series } & \multirow[b]{2}{*}{ Surfactant } & \multirow{2}{*}{$\begin{array}{c}\text { Distance from } \\
\text { Stump }(\mathrm{cm})\end{array}$} & \multicolumn{5}{|c|}{ Triclopyr + TBEE ( $\left.\mu \mathrm{g} \mathrm{kg}^{-1}\right)$} \\
\hline & & & $9 / 11 / 2015$ & $9 / 21 / 2015$ & $10 / 27 / 2015$ & $11 / 30 / 2015$ & $4 / 24 / 2016$ \\
\hline \multirow[t]{7}{*}{ Bosque } & Diesel & 0 & & $339681 \pm 178113$ & $47371 \pm 32286$ & $3962 \pm 3351$ & $353 \pm 275$ \\
\hline & & 30.5 & & $412 \pm 264$ & $1686 \pm 1530$ & $979 \pm 664$ & $61 \pm 61$ \\
\hline & & 61 & & $570 \pm 257$ & $330 \pm 126$ & $350 \pm 257$ & $37 \pm 32$ \\
\hline & MSO & 0 & & $1493083 \pm 613737$ & $497577 \pm 324124$ & $13133 \pm 4138$ & $1958 \pm 1162$ \\
\hline & & 30.5 & & $2726 \pm 1648$ & $2705 \pm 676$ & $835 \pm 355$ & $0 \pm 0$ \\
\hline & & 61 & & $4150 \pm 1935$ & $2322 \pm 1236$ & $274 \pm 87$ & $46 \pm 34$ \\
\hline & Control & 0 & & $528 \pm 373$ & $90 \pm 68$ & $0 \pm 0$ & $0 \pm 0$ \\
\hline \multirow[t]{7}{*}{ Cho } & Diesel & 0 & $292105 \pm 163007$ & $89068 \pm 42838$ & $137127 \pm 92487$ & $3296 \pm 1715$ & $710 \pm 255$ \\
\hline & & 30.5 & $568 \pm 393$ & $687 \pm 559$ & $366 \pm 251$ & $970 \pm 590$ & $30 \pm 30$ \\
\hline & & 61 & $0 \pm 0$ & $2573 \pm 2298$ & $592 \pm 269$ & $1402 \pm 924$ & $53 \pm 53$ \\
\hline & MSO & 0 & $96442 \pm 86704$ & $80976 \pm 35695$ & $12066 \pm 4925$ & $10051 \pm 4654$ & $2009 \pm 1221$ \\
\hline & & 30.5 & $64 \pm 53$ & $9882 \pm 8892$ & $862 \pm 464$ & $429 \pm 161$ & $154 \pm 101$ \\
\hline & & 61 & $0 \pm 0$ & $356 \pm 144$ & $3262 \pm 1789$ & $307 \pm 113$ & $49 \pm 49$ \\
\hline & Control & 0 & $0 \pm 0$ & $34 \pm 34$ & $0 \pm 0$ & $122 \pm 52$ & $0 \pm 0$ \\
\hline \multirow[t]{4}{*}{ Nuff } & Diesel & 0 & & $4255767 \pm 1466847$ & $103313 \pm 36423$ & $5672 \pm 1173$ & $1118 \pm 623$ \\
\hline & & 30.5 & & $40212 \pm 23599$ & $2257 \pm 742$ & $2554 \pm 925$ & $649 \pm 314$ \\
\hline & & 61 & & $3629 \pm 1743$ & $751 \pm 335$ & $2518 \pm 1263$ & $181 \pm 83$ \\
\hline & MSO & 0 & & $2506333 \pm 985672$ & $268432 \pm 177666$ & $11942 \pm 4663$ & $1706 \pm 967$ \\
\hline
\end{tabular}




\begin{tabular}{|c|c|c|c|c|c|c|c|}
\hline \multirow[b]{2}{*}{ Soil Series } & \multirow[b]{2}{*}{ Surfactant } & \multirow{2}{*}{$\begin{array}{c}\text { Distance from } \\
\text { Stump (cm) }\end{array}$} & \multicolumn{5}{|c|}{ Triclopyr + TBEE ( $\mu \mathrm{g} \mathrm{kg-1}$ ) } \\
\hline & & & $9 / 11 / 2015$ & $9 / 21 / 2015$ & $10 / 27 / 2015$ & $11 / 30 / 2015$ & $4 / 24 / 2016$ \\
\hline & & 30.5 & & $5042 \pm 4509$ & $7919 \pm 3261$ & $1787 \pm 838$ & $538 \pm 350$ \\
\hline & & 61 & & $18152 \pm 17158$ & $4003 \pm 3391$ & $1586 \pm 790$ & $950 \pm 617$ \\
\hline & Control & 0 & & $0 \pm 0$ & $241 \pm 160$ & $153 \pm 70$ & $0 \pm 0$ \\
\hline \multirow[t]{7}{*}{ Total } & Diesel & 0 & & $1561505 \pm 654486$ & $95937 \pm 33933$ & $4331 \pm 1170$ & $752 \pm 259$ \\
\hline & & 30.5 & & $13770 \pm 8672$ & $1369 \pm 541$ & $1501 \pm 440$ & $240 \pm 129$ \\
\hline & & 61 & & $2257 \pm 957$ & $546 \pm 141$ & $1486 \pm 568$ & $90 \pm 36$ \\
\hline & MSO & 0 & & $1435375 \pm 455949$ & $259358 \pm 125340$ & $11709 \pm 2455$ & $1891 \pm 609$ \\
\hline & & 30.5 & & $5883 \pm 3246$ & $4003 \pm 1340$ & $1017 \pm 321$ & $231 \pm 126$ \\
\hline & & 61 & & $7553 \pm 5716$ & $3196 \pm 1272$ & $747 \pm 308$ & $366 \pm 232$ \\
\hline & Control & 0 & & $208 \pm 147$ & $110 \pm 60$ & $90 \pm 32$ & $0 \pm 0$ \\
\hline
\end{tabular}


Table B.2. Mean soil TCP concentrations ( \pm SE) over study period. TCP, 3,5,6-Trichloro-2-pyridinol.

\begin{tabular}{|c|c|c|c|c|c|c|c|}
\hline \multirow[b]{2}{*}{ Soil Series } & \multirow[b]{2}{*}{ Surfactant } & \multirow{2}{*}{$\begin{array}{c}\text { Distance From } \\
\text { Stump }(\mathrm{cm})\end{array}$} & \multicolumn{5}{|c|}{ TCP ( $\left.\mu g^{k g}{ }^{-1}\right)$} \\
\hline & & & $9 / 11 / 2015$ & $9 / 21 / 2015$ & $10 / 27 / 2015$ & $11 / 30 / 2015$ & $4 / 24 / 2016$ \\
\hline \multirow[t]{7}{*}{ Bosque } & Diesel & 0 & & $1128 \pm 548$ & $2823 \pm 1066$ & $2397 \pm 1252$ & $0 \pm 0$ \\
\hline & & 30.5 & & $0 \pm 0$ & $1484 \pm 981$ & $795 \pm 509$ & $0 \pm 0$ \\
\hline & & 61 & & $0 \pm 0$ & $40 \pm 40$ & $889 \pm 715$ & $0 \pm 0$ \\
\hline & MSO & 0 & & $6131 \pm 1896$ & $5910 \pm 3199$ & $2740 \pm 833$ & $0 \pm 0$ \\
\hline & & 30.5 & & $0 \pm 0$ & $456 \pm 127$ & $303 \pm 108$ & $0 \pm 0$ \\
\hline & & 61 & & $0 \pm 0$ & $207 \pm 112$ & $132 \pm 78$ & $0 \pm 0$ \\
\hline & Control & 0 & & $0 \pm 0$ & $0 \pm 0$ & $0 \pm 0$ & $0 \pm 0$ \\
\hline \multirow[t]{7}{*}{ Cho } & Diesel & 0 & $1356 \pm 810$ & $615 \pm 319$ & $2054 \pm 770$ & $736 \pm 308$ & $833 \pm 461$ \\
\hline & & 30.5 & $0 \pm 0$ & $0 \pm 0$ & $163 \pm 130$ & $182 \pm 99$ & $0 \pm 0$ \\
\hline & & 61 & $0 \pm 0$ & $0 \pm 0$ & $60 \pm 60$ & $0 \pm 0$ & $0 \pm 0$ \\
\hline & MSO & 0 & $158 \pm 70$ & $731 \pm 355$ & $572 \pm 215$ & $653 \pm 253$ & $591 \pm 411$ \\
\hline & & 30.5 & $0 \pm 0$ & $106 \pm 74$ & $79 \pm 33$ & $128 \pm 61$ & $189 \pm 146$ \\
\hline & & 61 & $0 \pm 0$ & $0 \pm 0$ & $10 \pm 6$ & $90 \pm 66$ & $28 \pm 28$ \\
\hline & Control & 0 & $0 \pm 0$ & $0 \pm 0$ & $0 \pm 0$ & $0 \pm 0$ & $0 \pm 0$ \\
\hline \multirow[t]{6}{*}{ Nuff } & Diesel & 0 & & $11650 \pm 4222$ & $3050 \pm 680$ & $1335 \pm 466$ & $407 \pm 232$ \\
\hline & & 30.5 & & $155 \pm 105$ & $569 \pm 204$ & $1027 \pm 404$ & $183 \pm 83$ \\
\hline & & 61 & & $95 \pm 65$ & $570 \pm 226$ & $658 \pm 346$ & $224 \pm 115$ \\
\hline & MSO & 0 & & $7321 \pm 2925$ & $2311 \pm 737$ & $1649 \pm 640$ & $520 \pm 280$ \\
\hline & & 30.5 & & $0 \pm 0$ & $503 \pm 284$ & $446 \pm 227$ & $223 \pm 107$ \\
\hline & & 61 & & $85 \pm 85$ & $139 \pm 70$ & $348 \pm 160$ & $43 \pm 43$ \\
\hline
\end{tabular}




\begin{tabular}{|c|c|c|c|c|c|c|c|}
\hline \multirow[b]{2}{*}{ Soil Series } & \multirow[b]{2}{*}{ Surfactant } & \multirow{2}{*}{$\begin{array}{c}\text { Distance From } \\
\text { Stump }(\mathrm{cm})\end{array}$} & \multicolumn{5}{|c|}{ TCP ( $\left.\mu g^{k g}{ }^{-1}\right)$} \\
\hline & & & $9 / 11 / 2015$ & $9 / 21 / 2015$ & $10 / 27 / 2015$ & $11 / 30 / 2015$ & $4 / 24 / 2016$ \\
\hline & Control & 0 & & $0 \pm 0$ & $0 \pm 0$ & $0 \pm 0$ & $0 \pm 0$ \\
\hline \multirow[t]{7}{*}{ Total } & Diesel & 0 & & $4465 \pm 1819$ & $2632 \pm 460$ & $1489 \pm 460$ & $438 \pm 191$ \\
\hline & & 30.5 & & $52 \pm 37$ & $688 \pm 329$ & $668 \pm 223$ & $65 \pm 35$ \\
\hline & & 61 & & $32 \pm 23$ & $226 \pm 106$ & $546 \pm 279$ & $79 \pm 47$ \\
\hline & MSO & 0 & & $4963 \pm 1353$ & $2931 \pm 1163$ & $1681 \pm 396$ & $370 \pm 168$ \\
\hline & & 30.5 & & $35 \pm 26$ & $346 \pm 108$ & $292 \pm 90$ & $138 \pm 61$ \\
\hline & & 61 & & $28 \pm 28$ & $124 \pm 49$ & $190 \pm 65$ & $24 \pm 16$ \\
\hline & Control & 0 & & $0 \pm 0$ & $0 \pm 0$ & $0 \pm 0$ & $0 \pm 0$ \\
\hline
\end{tabular}


Table B.3. Water extractable metals concentrations reported in $\mathrm{mg} k \mathrm{~kg}-1$ for 3 locations for each soil series (mean $\pm \mathrm{SE}$ ). All measurements were completed in triplicate. BD indicates the element was below the instrument detection of $0.02 \mathrm{mg} \mathrm{kg-1}$ for all elements except for bromide $(\mathrm{Br})$ which has a detection limit of $0.01 \mathrm{mg} \mathrm{kg-1.}$

\begin{tabular}{|c|c|c|c|c|c|c|c|c|}
\hline Series & Aluminum (Al) & Antimony (Sb) & $\begin{array}{l}\text { Arsenic } \\
\text { (As) }\end{array}$ & $\begin{array}{l}\text { Barium } \\
\text { (Ba) }\end{array}$ & $\begin{array}{l}\text { Beryllium } \\
(\mathrm{Be})\end{array}$ & \begin{tabular}{|l} 
Boron \\
(B)
\end{tabular} & $\begin{array}{l}\text { Cadmium } \\
\text { (Cd) }\end{array}$ & $\begin{array}{l}\text { Calcium } \\
\text { (Ca) }\end{array}$ \\
\hline & \multicolumn{8}{|c|}{ mg kg-1 } \\
\hline Bosque B & $2.72 \pm 0.35$ & BD & $0.23 \pm 0.04$ & BD & $B D$ & $0.89 \pm 0.1$ & BD & $103.83 \pm 1.29$ \\
\hline Bosque A3 & $2.62 \pm 0.67$ & $B D$ & $0.23 \pm 0.03$ & $\mathrm{BD}$ & $\mathrm{BD}$ & $0.6 \pm 0.04$ & $B D$ & $93.12 \pm 4.94$ \\
\hline Bosque C5 & $2.36 \pm 0.06$ & $\mathrm{BD}$ & $\mathrm{BD}$ & $\mathrm{BD}$ & $\mathrm{BD}$ & $0.49 \pm 0.03$ & $B D$ & $101.21 \pm 1.3$ \\
\hline Cho A1 & $1.94 \pm 0.2$ & BD & BD & BD & BD & $0.33 \pm 0.02$ & $B D$ & $116.69 \pm 1.51$ \\
\hline Cho C5 & $1.6 \pm 0.06$ & $B D$ & BD & BD & BD & $0.26 \pm 0.02$ & BD & $112.63 \pm 0.58$ \\
\hline Cho B3 & $0.89 \pm 0.1$ & $B D$ & $0.21 \pm 0.01$ & $\mathrm{BD}$ & $\mathrm{BD}$ & $0.49 \pm 0.11$ & $B D$ & $86.71 \pm 7.76$ \\
\hline Nuff B1 & $0.6 \pm 0.03$ & $\mathrm{BD}$ & $0.23 \pm 0.03$ & $\mathrm{BD}$ & $\mathrm{BD}$ & $0.3 \pm 0.06$ & $B D$ & $97.68 \pm 1.38$ \\
\hline Nuff B3 & $0.59 \pm 0.01$ & $B D$ & $0.25 \pm 0.01$ & $\mathrm{BD}$ & $B D$ & $\mathrm{BD}$ & $B D$ & $97.52 \pm 1.74$ \\
\hline Nuff C5 & $0.7 \pm 0.04$ & BD & $0.17 \pm 0$ & BD & BD & BD & BD & $108.51 \pm 1.09$ \\
\hline \multirow[t]{2}{*}{ Series } & $\begin{array}{l}\text { Chromium } \\
(\mathrm{Cr})\end{array}$ & $\begin{array}{l}\text { Cobalt } \\
(\mathrm{Co})\end{array}$ & $\begin{array}{l}\text { Copper } \\
\text { (Cu) }\end{array}$ & $\begin{array}{l}\text { Iron } \\
(\mathrm{Fe})\end{array}$ & $\begin{array}{l}\text { Lead } \\
(\mathrm{Pb})\end{array}$ & $\begin{array}{l}\text { Lithium } \\
\text { (Li) }\end{array}$ & Magnesium (Mg) & $\begin{array}{l}\text { Manganese } \\
(\mathrm{Mn})\end{array}$ \\
\hline & \multicolumn{8}{|c|}{ mg kg-1 } \\
\hline Bosque B & BD & $B D$ & $0.22 \pm 0.03$ & $1.45 \pm 0.14$ & BD & BD & $7.63 \pm 0.02$ & BD \\
\hline Bosque A3 & BD & $B D$ & $\mathrm{BD}$ & $1.15 \pm 0.12$ & $B D$ & BD & $7.25 \pm 0.7$ & $B D$ \\
\hline Bosque C5 & BD & $B D$ & BD & $1.33 \pm 0.03$ & $B D$ & BD & $6.67 \pm 0.1$ & BD \\
\hline Cho A1 & $B D$ & $\mathrm{BD}$ & $\mathrm{BD}$ & $1.83 \pm 0.08$ & $\mathrm{BD}$ & $\mathrm{BD}$ & $5.04 \pm 0.18$ & $B D$ \\
\hline Cho C5 & BD & $B D$ & BD & $1.18 \pm 0.11$ & BD & BD & $4.41 \pm 0.02$ & BD \\
\hline Cho B3 & $\mathrm{BD}$ & $B D$ & $\mathrm{BD}$ & $0.69 \pm 0.2$ & $\mathrm{BD}$ & $B D$ & $3.76 \pm 0.59$ & $B D$ \\
\hline
\end{tabular}




\begin{tabular}{|c|c|c|c|c|c|c|c|c|}
\hline Nuff B1 & BD & BD & BD & $0.27 \pm 0.01$ & BD & BD & $1.95 \pm 0.08$ & BD \\
\hline Nuff B3 & BD & BD & BD & $0.26 \pm 0.01$ & BD & BD & $5.18 \pm 0.12$ & BD \\
\hline Nuff C5 & BD & $B D$ & BD & $0.32 \pm 0.02$ & BD & $B D$ & $3.06 \pm 0.07$ & $B D$ \\
\hline Series & $\begin{array}{l}\text { Nickel } \\
(\mathrm{Ni})\end{array}$ & $\begin{array}{l}\text { Phosphorus } \\
\text { (P) }\end{array}$ & Potassium (K) & Selenium (Se) & $\begin{array}{l}\text { Silicon } \\
(\mathrm{Si})\end{array}$ & $\begin{array}{l}\text { Silver } \\
\text { (Ag) }\end{array}$ & $\begin{array}{l}\text { Sodium } \\
(\mathrm{Na})\end{array}$ & $\begin{array}{l}\text { Strontium } \\
(\mathrm{Sr})\end{array}$ \\
\hline & \multicolumn{8}{|c|}{ mg kg-1 } \\
\hline Bosque B & BD & $2.5 \pm 0.14$ & $53.74 \pm 5.06$ & $B D$ & BD & BD & $2.67 \pm 0.46$ & $0.24 \pm 0$ \\
\hline Bosque A3 & BD & $2.28 \pm 0.18$ & $29.19 \pm 1.4$ & $0.19 \pm 0$ & BD & BD & $1.86 \pm 0.21$ & $0.25 \pm 0.02$ \\
\hline Bosque C5 & BD & $2.92 \pm 0.11$ & $49.69 \pm 0.85$ & BD & $B D$ & BD & $2.07 \pm 0.09$ & $0.2 \pm 0$ \\
\hline Cho A1 & BD & $1.44 \pm 0.07$ & $28.41 \pm 1.16$ & BD & $B D$ & BD & $2.85 \pm 0.51$ & BD \\
\hline Cho C5 & BD & $0.66 \pm 0.1$ & $11.12 \pm 0.41$ & $B D$ & $B D$ & $B D$ & $4.82 \pm 0.17$ & $0.28 \pm 0$ \\
\hline Cho B3 & BD & $0.9 \pm 0.21$ & $32.08 \pm 5.76$ & BD & $B D$ & BD & $0.86 \pm 0.2$ & $B D$ \\
\hline Nuff B1 & BD & $0.98 \pm 0.07$ & $9.8 \pm 0.5$ & $B D$ & BD & BD & $1.17 \pm 0.08$ & BD \\
\hline Nuff B3 & BD & $1.12 \pm 0.1$ & $16.92 \pm 0.64$ & $B D$ & BD & BD & $0.88 \pm 0.13$ & $B D$ \\
\hline Nuff C5 & BD & $1.35 \pm 0.15$ & $12.69 \pm 0.19$ & $B D$ & BD & BD & $1.28 \pm 0.08$ & BD \\
\hline Series & $\begin{array}{l}\text { Sulfur } \\
\text { (S) }\end{array}$ & $\begin{array}{l}\text { Thallium } \\
\text { (TI) }\end{array}$ & $\begin{array}{l}\text { Tin } \\
(\mathrm{Sn})\end{array}$ & $\begin{array}{l}\text { Titanium } \\
\text { (TI) }\end{array}$ & Tungsten (W) & Vanadium (V) & $\begin{array}{l}\text { Zinc } \\
(Z n)\end{array}$ & \\
\hline \multicolumn{9}{|c|}{$\mathrm{mg} \mathrm{kg}^{-1}$} \\
\hline Bosque B & $5.74 \pm 0.78$ & BD & $0.19 \pm 0$ & BD & BD & BD & $0.21 \pm 0.01$ & \\
\hline Bosque A3 & $4.91 \pm 0.75$ & BD & $0 \pm 0$ & BD & BD & BD & $0.2 \pm 0.01$ & \\
\hline Bosque C5 & $7.09 \pm 1.05$ & BD & $0.19 \pm 0$ & $\mathrm{BD}$ & $B D$ & $B D$ & $B D$ & \\
\hline
\end{tabular}




\begin{tabular}{|l|l|l|l|l|l|l|l|l|}
\hline Cho A1 & $5.3 \pm 0.98$ & BD & $0.16 \pm 0$ & BD & BD & BD & $0.21 \pm 0.03$ \\
\hline Cho C5 & $6.49 \pm 0.75$ & BD & $0.17 \pm 0$ & BD & BD & BD & BD & \\
\hline Cho B3 & $5.06 \pm 1.51$ & BD & $0.2 \pm 0$ & BD & BD & BD & $0.34 \pm 0$ \\
\hline Nuff B1 & $3.6 \pm 1.33$ & BD & $0.2 \pm 0.02$ & BD & BD & BD & BD & \\
\hline Nuff B3 & $5.36 \pm 0.34$ & BD & $0 \pm 0$ & BD & BD & BD & BD & \\
\hline Nuff C5 & $5.37 \pm 1.21$ & BD & $0.19 \pm 0.01$ & BD & BD & BD & BD & \\
\hline
\end{tabular}

Table B.4. Mehlich III extractable bioavailable metals concentrations reported in $\mathrm{mg} \mathrm{kg}^{-1}$ for 3 locations for each soil series (mean \pm SE). All measurements were completed in triplicate. BD indicates the element was below the instrument detection of $0.02 \mathrm{mg} \mathrm{kg}^{-1} \mathrm{for}$ all elements except for bromide $(\mathrm{Br})$ which has a detection limit of $0.01 \mathrm{mg} \mathrm{kg}^{-1}$.

\begin{tabular}{|c|c|c|c|c|c|c|c|}
\hline Series & $\begin{array}{l}\text { Aluminum } \\
\text { (Al) }\end{array}$ & Antimony (Sb) & $\begin{array}{c}\text { Arsenic } \\
\text { (As) }\end{array}$ & $\begin{array}{c}\text { Barium } \\
(\mathrm{Ba})\end{array}$ & Beryllium (Be) & $\begin{array}{l}\text { Boron } \\
\text { (B) }\end{array}$ & $\begin{array}{l}\text { Cadmium } \\
\text { (Cd) }\end{array}$ \\
\hline & \multicolumn{7}{|c|}{$\mathrm{mg} \mathrm{kg}^{-1}$} \\
\hline Bosque B & $1.36 \pm 0.19$ & $0.57 \pm 0.1$ & $0.4 \pm 0.01$ & $13.81 \pm 0.14$ & $\mathrm{BD}$ & $76.71 \pm 1.27$ & $0.24 \pm 0$ \\
\hline $\begin{array}{l}\text { Bosque } \\
\text { A3 }\end{array}$ & $61.58 \pm 2.04$ & $0.23 \pm 0$ & $0.29 \pm 0.01$ & $13.17 \pm 0.09$ & $\mathrm{BD}$ & $74.27 \pm 0.7$ & $B D$ \\
\hline $\begin{array}{l}\text { Bosque } \\
\text { C5 }\end{array}$ & $53.58 \pm 0.21$ & $0.34 \pm 0$ & $0.5 \pm 0.04$ & $12.3 \pm 0.05$ & $\mathrm{BD}$ & $75.98 \pm 0.67$ & BD \\
\hline Cho A1 & $25.53 \pm 0.17$ & $0.49 \pm 0.05$ & $0.48 \pm 0.04$ & $17.66 \pm 0.09$ & $\mathrm{BD}$ & $70.91 \pm 0.29$ & $\mathrm{BD}$ \\
\hline Cho C5 & $45.93 \pm 1.65$ & $0.37 \pm 0.07$ & $0.5 \pm 0.07$ & $25.65 \pm 0.58$ & $\mathrm{BD}$ & $74.88 \pm 0.44$ & $\mathrm{BD}$ \\
\hline
\end{tabular}




\begin{tabular}{|c|c|c|c|c|c|c|c|}
\hline Cho B3 & $27.57 \pm 0.76$ & $0.48 \pm 0.02$ & $0.48 \pm 0.11$ & $17.73 \pm 0.22$ & $B D$ & $73.83 \pm 0.06$ & $B D$ \\
\hline Nuff B1 & $138.56 \pm 1.44$ & $0.38 \pm 0.1$ & $0.3 \pm 0.01$ & $34.52 \pm 0.5$ & $B D$ & $71.34 \pm 0.51$ & $B D$ \\
\hline Nuff B3 & $96.67 \pm 1.54$ & $0.33 \pm 0.03$ & $0.47 \pm 0$ & $20.88 \pm 0.05$ & $B D$ & $75.55 \pm 0.47$ & $B D$ \\
\hline Nuff C5 & $75.42 \pm 3.83$ & $0.3 \pm 0.03$ & $0.43 \pm 0.03$ & $21.11 \pm 0.07$ & $B D$ & $74.93 \pm 0.3$ & $B D$ \\
\hline \multirow[t]{2}{*}{ Series } & $\begin{array}{l}\text { Calcium } \\
\text { (Ca) }\end{array}$ & Chromium (Cr) & $\begin{array}{l}\text { Cobalt } \\
\text { (Co) }\end{array}$ & $\begin{array}{c}\text { Copper } \\
\text { (Cu) }\end{array}$ & $\begin{array}{l}\text { Iron } \\
\text { (Fe) }\end{array}$ & $\begin{array}{l}\text { Lead } \\
(\mathrm{Pb})\end{array}$ & $\begin{array}{l}\text { Lithium } \\
\quad(\mathrm{Li})\end{array}$ \\
\hline & \multicolumn{7}{|c|}{ mg kg-1 } \\
\hline Bosque $B$ & $18763.41 \pm 111.29$ & $B D$ & $0.61 \pm 0.03$ & $0.86 \pm 0.14$ & $24.1 \pm 0.2$ & $2.75 \pm 0.15$ & $B D$ \\
\hline Bosque A3 & $12406.67 \pm 104.92$ & $\mathrm{BD}$ & $0.84 \pm 0.02$ & $0.68 \pm 0.02$ & $18.11 \pm 0.41$ & $2.93 \pm 0.08$ & BD \\
\hline Bosque C5 & $12997.59 \pm 86.06$ & $\mathrm{BD}$ & $0.97 \pm 0$ & $1 \pm 0.01$ & $16.71 \pm 0.12$ & $3.38 \pm 0.02$ & $B D$ \\
\hline Cho A1 & $33327.18 \pm 137.64$ & $\mathrm{BD}$ & $0.25 \pm 0$ & BD & $45.35 \pm 0.32$ & $0.49 \pm 0.02$ & $B D$ \\
\hline Cho C5 & $27365.63 \pm 1489.86$ & $\mathrm{BD}$ & $\mathrm{BD}$ & $2.4 \pm 0$ & $43.58 \pm 1.22$ & $0.95 \pm 0.03$ & $B D$ \\
\hline Cho B3 & $27538.84 \pm 554.17$ & $\mathrm{BD}$ & $0.36 \pm 0.01$ & $\mathrm{BD}$ & $42.98 \pm 0.85$ & $0.84 \pm 0.04$ & $B D$ \\
\hline Nuff B1 & $17898.74 \pm 202.36$ & $\mathrm{BD}$ & $0.41 \pm 0.01$ & $0.36 \pm 0.02$ & $20.15 \pm 0.32$ & $1.65 \pm 0.06$ & BD \\
\hline Nuff B3 & $14882.81 \pm 27.06$ & $\mathrm{BD}$ & $0.31 \pm 0.01$ & $0.73 \pm 0.01$ & $23.24 \pm 0.13$ & $2.14 \pm 0.08$ & $B D$ \\
\hline Nuff C5 & $15358.07 \pm 20.98$ & $\mathrm{BD}$ & $0.29 \pm 0.01$ & $0.58 \pm 0.03$ & $21.77 \pm 0.42$ & $1.93 \pm 0.03$ & $B D$ \\
\hline
\end{tabular}




\begin{tabular}{|c|c|c|c|c|c|c|c|}
\hline Series & $\begin{array}{l}\text { Magnesium } \\
\text { (Mg) }\end{array}$ & $\begin{array}{l}\text { Manganese } \\
(\mathrm{Mn})\end{array}$ & $\begin{array}{l}\text { Nickel } \\
\text { (Ni) }\end{array}$ & Phosphorus (P) & $\begin{array}{l}\text { Potassium } \\
\text { (K) }\end{array}$ & Selenium (Se) & $\begin{array}{l}\text { Silicon } \\
\text { (Si) }\end{array}$ \\
\hline & \multicolumn{7}{|c|}{$\mathrm{mg} \mathrm{kg}^{-1}$} \\
\hline Bosque B & $350.33 \pm 2.58$ & $98.16 \pm 2.55$ & $0.42 \pm 0.02$ & $2.71 \pm 0.14$ & $401.91 \pm 4.71$ & $\mathrm{BD}$ & $873.89 \pm 6.76$ \\
\hline Bosque A3 & $329.34 \pm 0.99$ & $111.27 \pm 1.81$ & $0.5 \pm 0$ & $8.07 \pm 0.13$ & $408.49 \pm 1.6$ & $\mathrm{BD}$ & $900.93 \pm 10.93$ \\
\hline Bosque C5 & $304.32 \pm 2.52$ & $141.07 \pm 1.06$ & $0.49 \pm 0.01$ & $10.08 \pm 0.28$ & $529.95 \pm 1.58$ & $0.27 \pm 0$ & $930.69 \pm 15.96$ \\
\hline Cho A1 & $207.67 \pm 1.72$ & $33.7 \pm 0.72$ & $\mathrm{BD}$ & $\mathrm{BD}$ & $202.6 \pm 1.62$ & $\mathrm{BD}$ & $775.23 \pm 6.32$ \\
\hline Cho C5 & $180.69 \pm 4.93$ & $23.86 \pm 0.34$ & $\mathrm{BD}$ & $0.4 \pm 0$ & $120.34 \pm 1.08$ & $\mathrm{BD}$ & $821.01 \pm 1.63$ \\
\hline Cho B3 & $208.42 \pm 2.53$ & $40.25 \pm 0.52$ & $0.27 \pm 0$ & $1.85 \pm 0.21$ & $310.22 \pm 3.26$ & $\mathrm{BD}$ & $780.38 \pm 5.76$ \\
\hline Nuff B1 & $137.86 \pm 1.1$ & $36.35 \pm 0.61$ & $0.25 \pm 0.01$ & $1.78 \pm 0.13$ & $248.12 \pm 3.58$ & $\mathrm{BD}$ & $982.49 \pm 16.56$ \\
\hline Nuff B3 & $283.19 \pm 1.19$ & $38.05 \pm 0.13$ & $0.29 \pm 0.01$ & $4.12 \pm 0.28$ & $310 \pm 0.22$ & $\mathrm{BD}$ & $977.63 \pm 1.61$ \\
\hline Nuff C5 & $162.7 \pm 0.67$ & $32.43 \pm 0.71$ & $0.33 \pm 0.01$ & $3.81 \pm 0.09$ & $224.06 \pm 1.01$ & $\mathrm{BD}$ & $952.7 \pm 5.99$ \\
\hline \multirow[t]{2}{*}{ Series } & $\begin{array}{l}\text { Silver } \\
\text { (Ag) }\end{array}$ & $\begin{array}{l}\text { Sodium } \\
(\mathrm{Na})\end{array}$ & Strontium (Sr) & $\begin{array}{l}\text { Sulfur } \\
\text { (S) }\end{array}$ & $\begin{array}{l}\text { Thallium } \\
\text { (TI) }\end{array}$ & $\begin{array}{l}\text { Tin } \\
\text { (Sn) }\end{array}$ & $\begin{array}{l}\text { Titanium } \\
\text { (TI) }\end{array}$ \\
\hline & \multicolumn{7}{|c|}{$\mathrm{mg} \mathrm{kg}^{-1}$} \\
\hline Bosque B & $\mathrm{BD}$ & $57.64 \pm 2.56$ & $31.38 \pm 0.18$ & $17.88 \pm 3.59$ & $\mathrm{BD}$ & $2.02 \pm 0.11$ & $0.29 \pm 0$ \\
\hline Bosque A3 & $B D$ & $52.94 \pm 0.52$ & $19.73 \pm 0.15$ & $19.98 \pm 0.64$ & $\mathrm{BD}$ & $1.45 \pm 0.01$ & $0.22 \pm 0$ \\
\hline Bosque C5 & $B D$ & $53.45 \pm 0.67$ & $17.23 \pm 0.06$ & $23.18 \pm 1.06$ & $\mathrm{BD}$ & $1.31 \pm 0.03$ & $\mathrm{BD}$ \\
\hline Cho A1 & $\mathrm{BD}$ & $52.88 \pm 0.78$ & $15.6 \pm 0.08$ & $9.31 \pm 0$ & $\mathrm{BD}$ & $2.16 \pm 0.04$ & $0.26 \pm 0$ \\
\hline Cho C5 & $\mathrm{BD}$ & $56.81 \pm 0.58$ & $18 \pm 0.82$ & $4.29 \pm 0.99$ & $\mathrm{BD}$ & $1.91 \pm 0.05$ & $0.24 \pm 0.01$ \\
\hline
\end{tabular}




\begin{tabular}{|c|c|c|c|c|c|c|c|}
\hline Cho B3 & BD & $52.31 \pm 0.64$ & $14.18 \pm 0.52$ & $9.28 \pm 2.13$ & $B D$ & $1.89 \pm 0.02$ & $0.23 \pm 0$ \\
\hline Nuff B1 & BD & $52.75 \pm 0.45$ & $4.98 \pm 0.06$ & $9.37 \pm 0.75$ & $B D$ & $1.58 \pm 0.05$ & $0.22 \pm 0.01$ \\
\hline Nuff B3 & $B D$ & $52.86 \pm 0.29$ & $9.28 \pm 0$ & $17.11 \pm 2.99$ & $B D$ & $1.51 \pm 0.08$ & $0.22 \pm 0$ \\
\hline Nuff C5 & $B D$ & $52.18 \pm 0.53$ & $5.81 \pm 0.04$ & $11.13 \pm 1.98$ & $B D$ & $1.49 \pm 0.04$ & $B D$ \\
\hline \multirow[t]{2}{*}{ Series } & $\begin{array}{l}\text { Tungsten } \\
\text { (W) }\end{array}$ & $\begin{array}{c}\text { Vanadium } \\
\text { (V) }\end{array}$ & $\begin{array}{l}\text { Zinc } \\
(Z n)\end{array}$ & & & & \\
\hline & \multicolumn{3}{|c|}{$\mathrm{mg} \mathrm{kg-1}^{-1}$} & & & & \\
\hline Bosque $B$ & $B D$ & $0.63 \pm 0.01$ & $3.38 \pm 0.1$ & Bosque B & $B D$ & $0.63 \pm 0.01$ & $3.38 \pm 0.1$ \\
\hline Bosque A3 & BD & $0.79 \pm 0.01$ & $0.73 \pm 0.09$ & Bosque A3 & $B D$ & $0.79 \pm 0.01$ & $0.73 \pm 0.09$ \\
\hline Bosque C5 & $\mathrm{BD}$ & $0.69 \pm 0$ & $1.05 \pm 0.03$ & Bosque C5 & $B D$ & $0.69 \pm 0$ & $1.05 \pm 0.03$ \\
\hline Cho A1 & $B D$ & $0.71 \pm 0.01$ & $0.68 \pm 0.07$ & Cho A1 & $B D$ & $0.71 \pm 0.01$ & $0.68 \pm 0.07$ \\
\hline Cho C5 & $B D$ & $1.04 \pm 0.03$ & $0.78 \pm 0.2$ & Cho C5 & $B D$ & $1.04 \pm 0.03$ & $0.78 \pm 0.2$ \\
\hline Cho B3 & $B D$ & $1.17 \pm 0.01$ & $1.35 \pm 0.05$ & & & & \\
\hline Nuff B1 & $B D$ & $1.8 \pm 0.02$ & $0.26 \pm 0.03$ & & & & \\
\hline Nuff B3 & BD & $1.68 \pm 0.01$ & $2.06 \pm 0.39$ & & & & \\
\hline Nuff C5 & $B D$ & $1.95 \pm 0.03$ & $0.35 \pm 0.03$ & & & & \\
\hline
\end{tabular}


Table B.5. Exchangeable cations and oxyanions associated with soil fertility reported in $\mathrm{mg} \mathrm{kg}^{-1}$ (mean $\pm \mathrm{SE}$ ). All measurements were completed in triplicate. BD indicates the element was below the instrument detection of $0.02 \mathrm{mg} \mathrm{kg}^{-1}$ for all elements except for bromide (Br) which has a detection limit of $0.01 \mathrm{mg} \mathrm{kg}^{-1}$.

\begin{tabular}{|c|c|c|c|c|c|c|c|}
\hline Series & $\begin{array}{l}\text { Ammonium } \\
\left(\mathrm{NH}_{4}-\mathrm{N}\right)\end{array}$ & $\begin{array}{l}\text { Bromide } \\
(\mathrm{Br})\end{array}$ & $\begin{array}{l}\text { Chloride } \\
\text { (Cl) }\end{array}$ & $\begin{array}{l}\text { Nitrate } \\
\left(\mathrm{NO}_{3}-1\right)\end{array}$ & $\begin{array}{l}\text { Nitrite } \\
\left(\mathrm{NO}_{2}^{-1}\right)\end{array}$ & $\begin{array}{l}\text { Orthophosphate (Ortho- } \\
\mathrm{PO}_{4}^{-2} \text { ) }\end{array}$ & $\begin{array}{l}\text { Sulfate } \\
\left(\mathrm{SO}_{4}^{-2}\right)\end{array}$ \\
\hline & \multicolumn{7}{|l|}{$\mathrm{mg} \mathrm{kg}^{-1}$} \\
\hline Bosque B & $5.35 \pm 0.33$ & BD & $21.99 \pm 13.57$ & $6.29 \pm 0.28$ & $0.33 \pm 0$ & $0.3 \pm 0.04$ & $3.67 \pm 0.12$ \\
\hline Bosque A3 & $5.01 \pm 0.31$ & $B D$ & $3.25 \pm 0.07$ & $3.24 \pm 0.35$ & $\mathrm{BD}$ & $0.26 \pm 0.02$ & $3.22 \pm 0.21$ \\
\hline Bosque C5 & $4.41 \pm 1.17$ & $\mathrm{BD}$ & $6.58 \pm 0.41$ & $10.83 \pm 0.51$ & $0.31 \pm 0.01$ & $0.47 \pm 0.02$ & $5.56 \pm 0.15$ \\
\hline Cho A1 & $19.37 \pm 0.19$ & BD & $4.81 \pm 0.27$ & $47.32 \pm 0.74$ & $0.24 \pm 0.01$ & $0.23 \pm 0.02$ & $4.7 \pm 0.11$ \\
\hline Cho C5 & $4.58 \pm 0.28$ & BD & $3.15 \pm 0.65$ & $8.01 \pm 0.28$ & $\mathrm{BD}$ & $\mathrm{BD}$ & $8.35 \pm 0.21$ \\
\hline Cho B3 & $22.25 \pm 0.61$ & BD & $3.13 \pm 0.43$ & $15.07 \pm 1.27$ & BD & $0.21 \pm 0$ & $3.48 \pm 0.18$ \\
\hline Nuff B1 & $6.23 \pm 1.41$ & BD & $3.42 \pm 0.06$ & $2.69 \pm 1.08$ & $\mathrm{BD}$ & $\mathrm{BD}$ & $3.3 \pm 0.12$ \\
\hline Nuff B3 & $7.17 \pm 0.43$ & BD & $6.25 \pm 0.12$ & $16.6 \pm 0.57$ & $0.35 \pm 0.04$ & $0.25 \pm 0.01$ & $10.21 \pm 0.16$ \\
\hline Nuff C5 & $6.75 \pm 0.55$ & BD & $3.34 \pm 0.13$ & $9.35 \pm 0.25$ & $1.59 \pm 0$ & $0.22 \pm 0$ & $5.41 \pm 0.15$ \\
\hline
\end{tabular}




\section{Appendix C: Herbicide Mobility Column Study Results}

Figure C.1. Column leaching EC results for the Bosque soil with RU-diesel and RUMSO spiking. $\mathrm{C} / \mathrm{C}_{0}$ is the concentration of analyte measured in the leachate solution (C) divided by the initial spiking concentration $\left(\mathrm{C}_{0}\right)$ and is unitless. Pore volumes are expressed as the volume of leachate collected $(\mathrm{V})$ divided by the maximum pore volume in the column ( $\left.V_{0}\right)$ and is unitless.

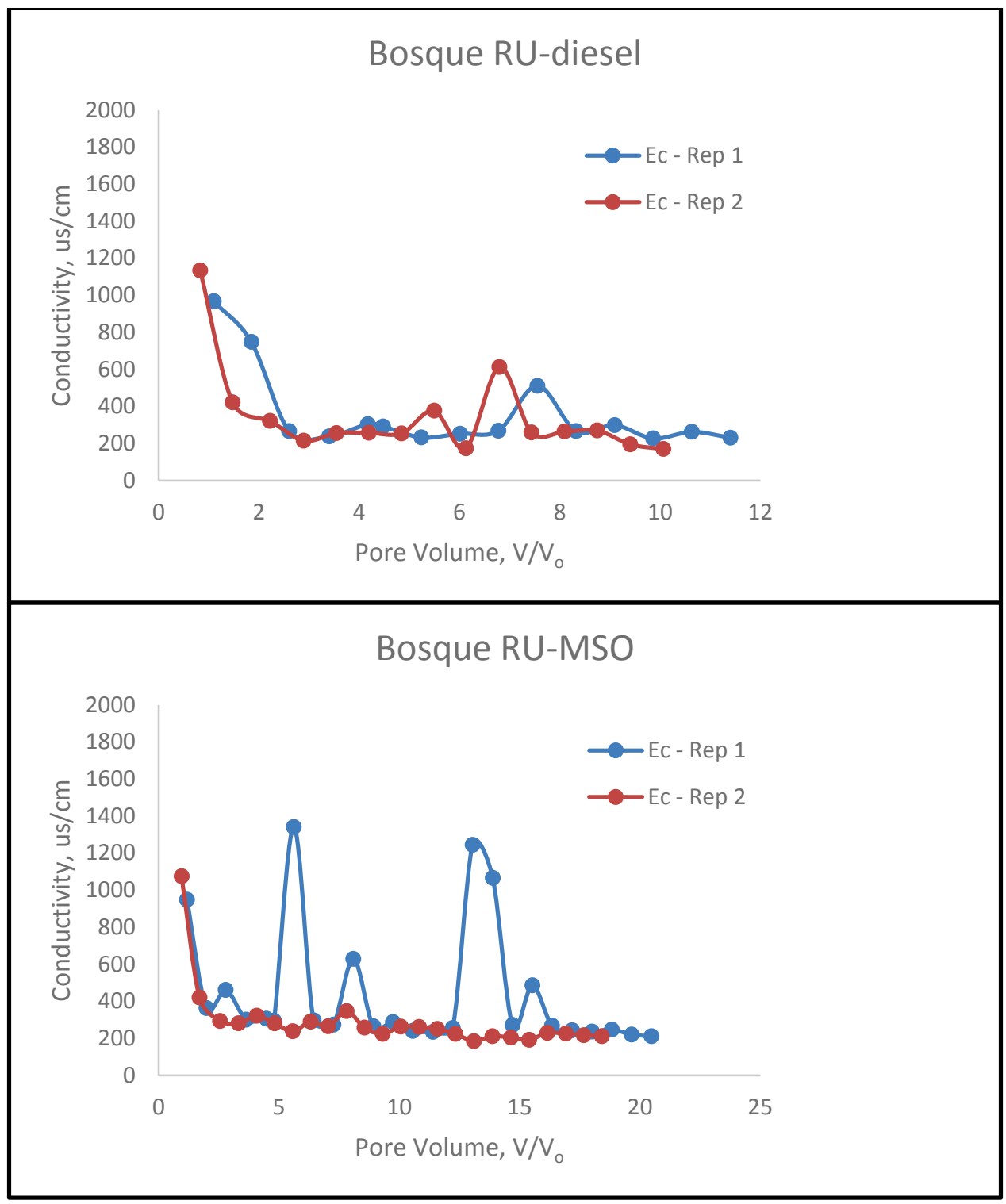


Figure C.2. Column leaching $\mathrm{pH}$ results for the Bosque soil with RU-diesel and RUMSO spiking. $\mathrm{C} / \mathrm{C}_{0}$ is the concentration of analyte measured in the leachate solution (C) divided by the initial spiking concentration $\left(\mathrm{C}_{0}\right)$ and is unitless. Pore volumes are expressed as the volume of leachate collected $(\mathrm{V})$ divided by the maximum pore volume in the column ( $\left.\mathrm{V}_{0}\right)$ and is unitless.

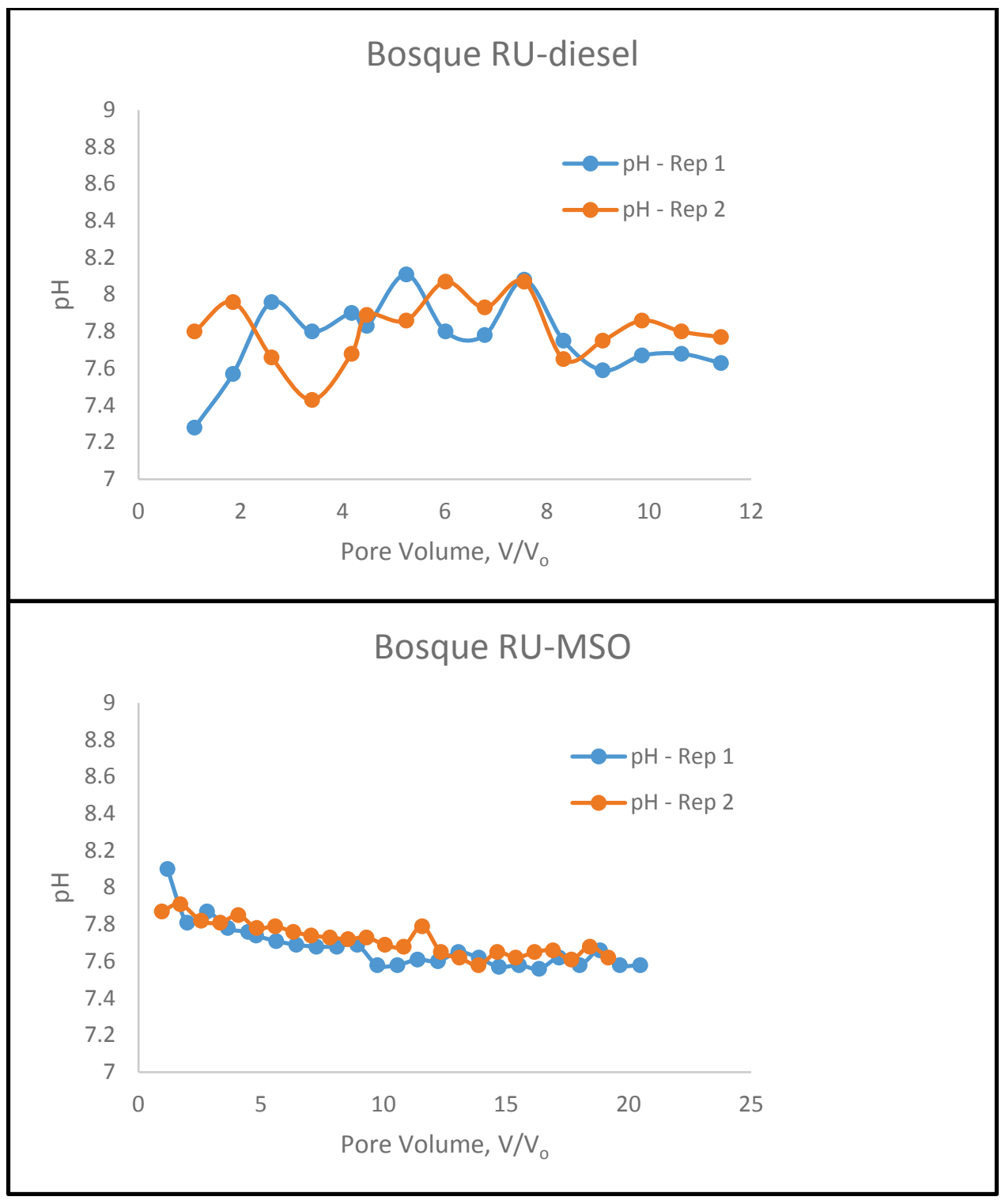


Figure C.3. Column leaching EC results for the Cho soil with RU-diesel and RU-MSO spiking. $\mathrm{C} / \mathrm{C}_{0}$ is the concentration of analyte measured in the leachate solution (C) divided by the initial spiking concentration $\left(\mathrm{C}_{0}\right)$ and is unitless. Pore volumes are expressed as the volume of leachate collected $(\mathrm{V})$ divided by the maximum pore volume in the column ( $\mathrm{V}_{0}$ ) and is unitless.

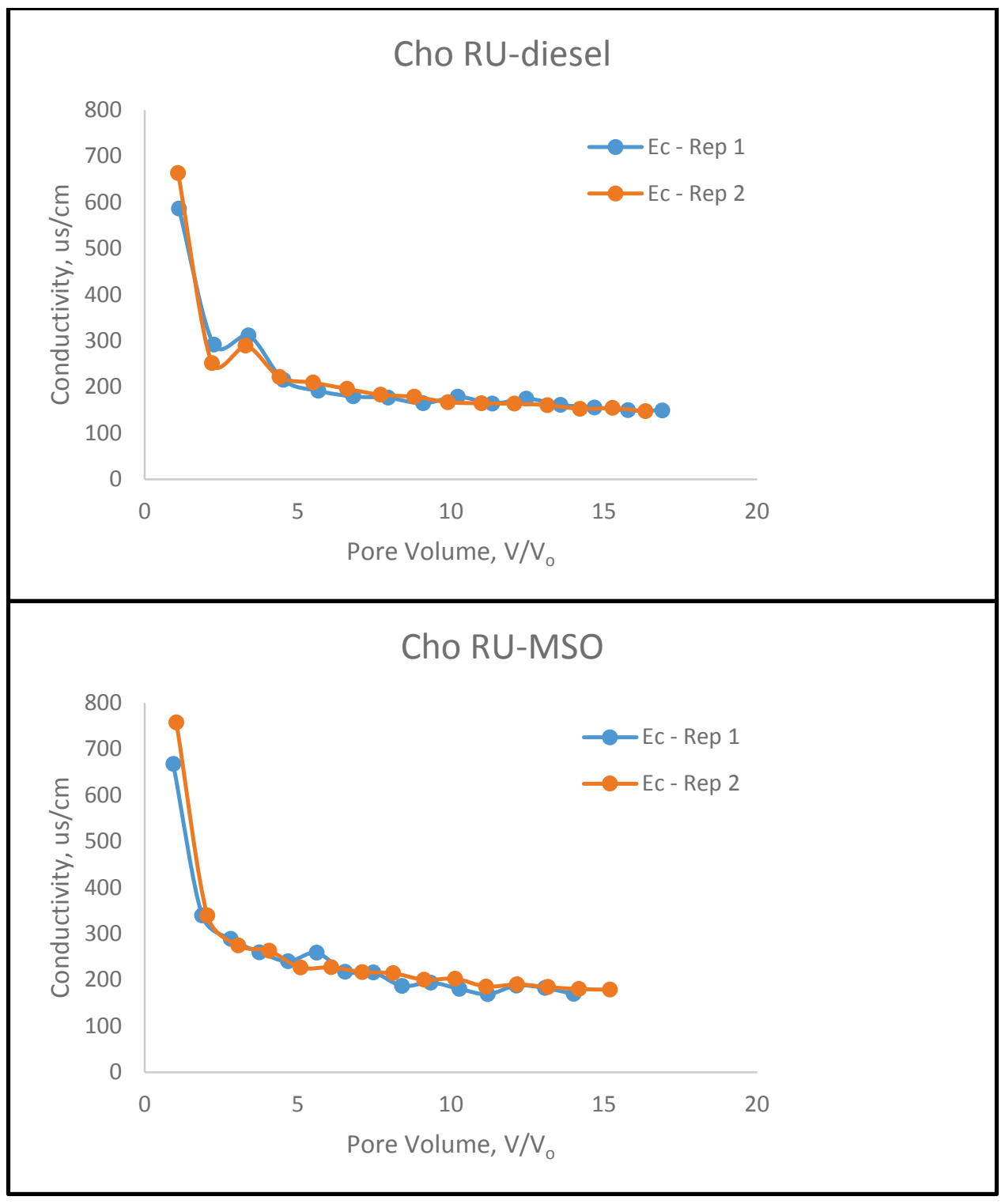


Figure C.4. Column leaching $\mathrm{pH}$ results for the Cho soil with RU-diesel and RU-MSO spiking. $\mathrm{C} / \mathrm{C}_{0}$ is the concentration of analyte measured in the leachate solution (C) divided by the initial spiking concentration $\left(\mathrm{C}_{0}\right)$ and is unitless. Pore volumes are expressed as the volume of leachate collected $(\mathrm{V})$ divided by the maximum pore volume in the column ( $\mathrm{V}_{0}$ ) and is unitless.

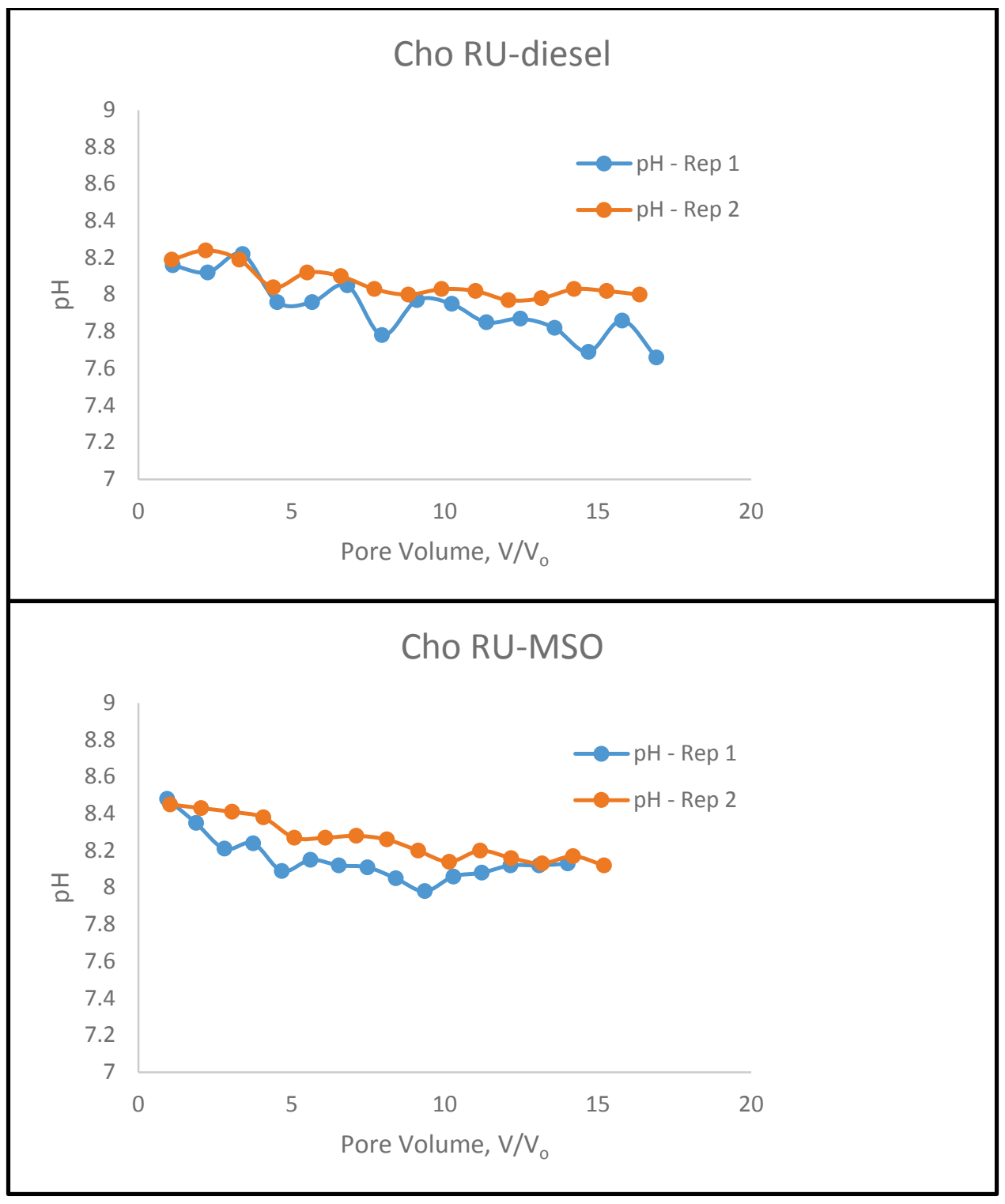


Figure C.5. Column leaching EC results for the Nuff soil with RU-diesel and RU-MSO spiking. $\mathrm{C} / \mathrm{C}_{0}$ is the concentration of analyte measured in the leachate solution (C) divided by the initial spiking concentration $\left(\mathrm{C}_{0}\right)$ and is unitless. Pore volumes are expressed as the volume of leachate collected $(\mathrm{V})$ divided by the maximum pore volume in the column ( $\mathrm{V}_{0}$ ) and is unitless.

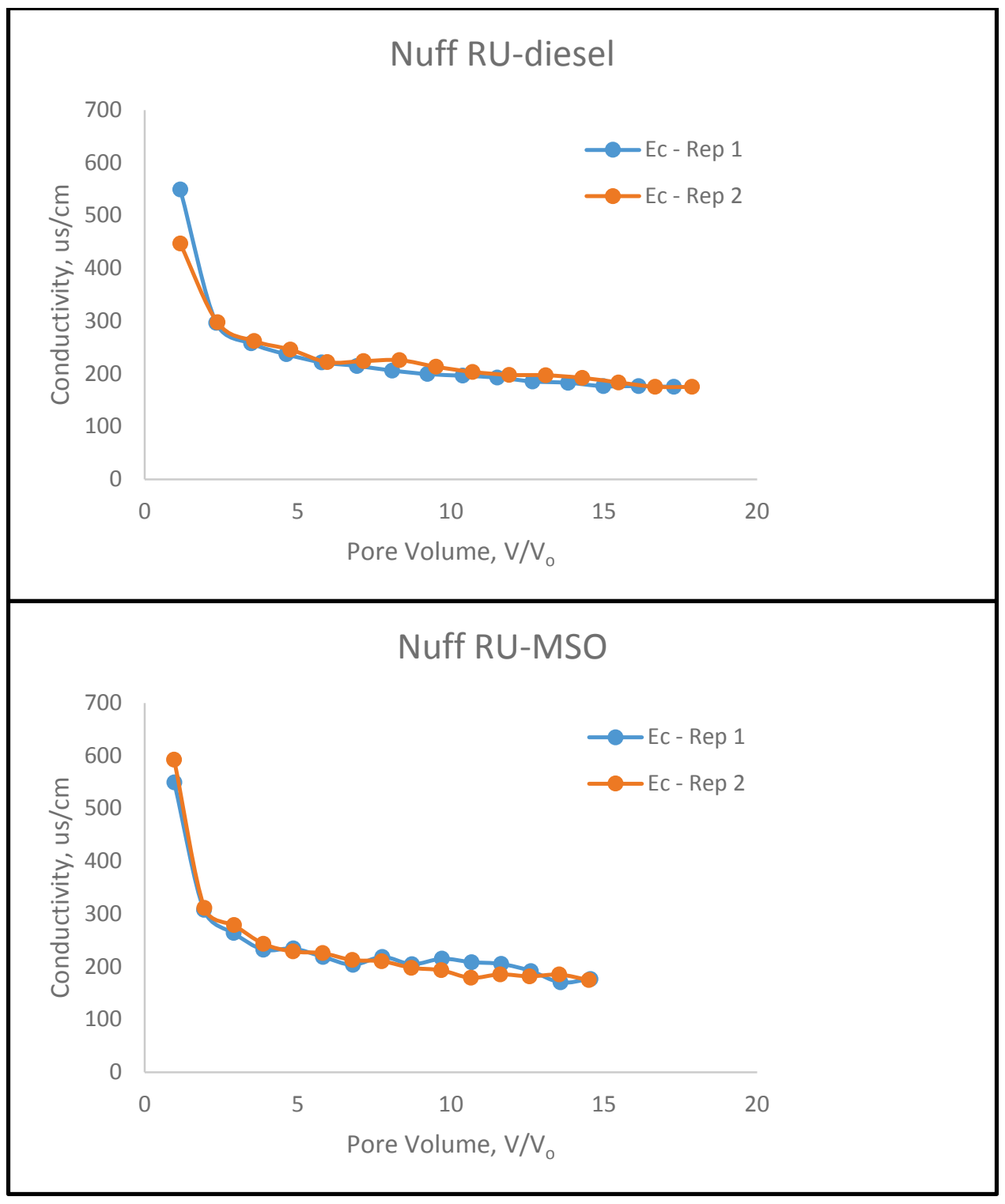


Figure C.6. Column leaching $\mathrm{pH}$ results for the Nuff soil with RU-diesel and RU-MSO spiking. $\mathrm{C} / \mathrm{C}_{0}$ is the concentration of analyte measured in the leachate solution (C) divided by the initial spiking concentration $\left(\mathrm{C}_{0}\right)$ and is unitless. Pore volumes are expressed as the volume of leachate collected $(\mathrm{V})$ divided by the maximum pore volume in the column ( $\mathrm{V}_{0}$ ) and is unitless.

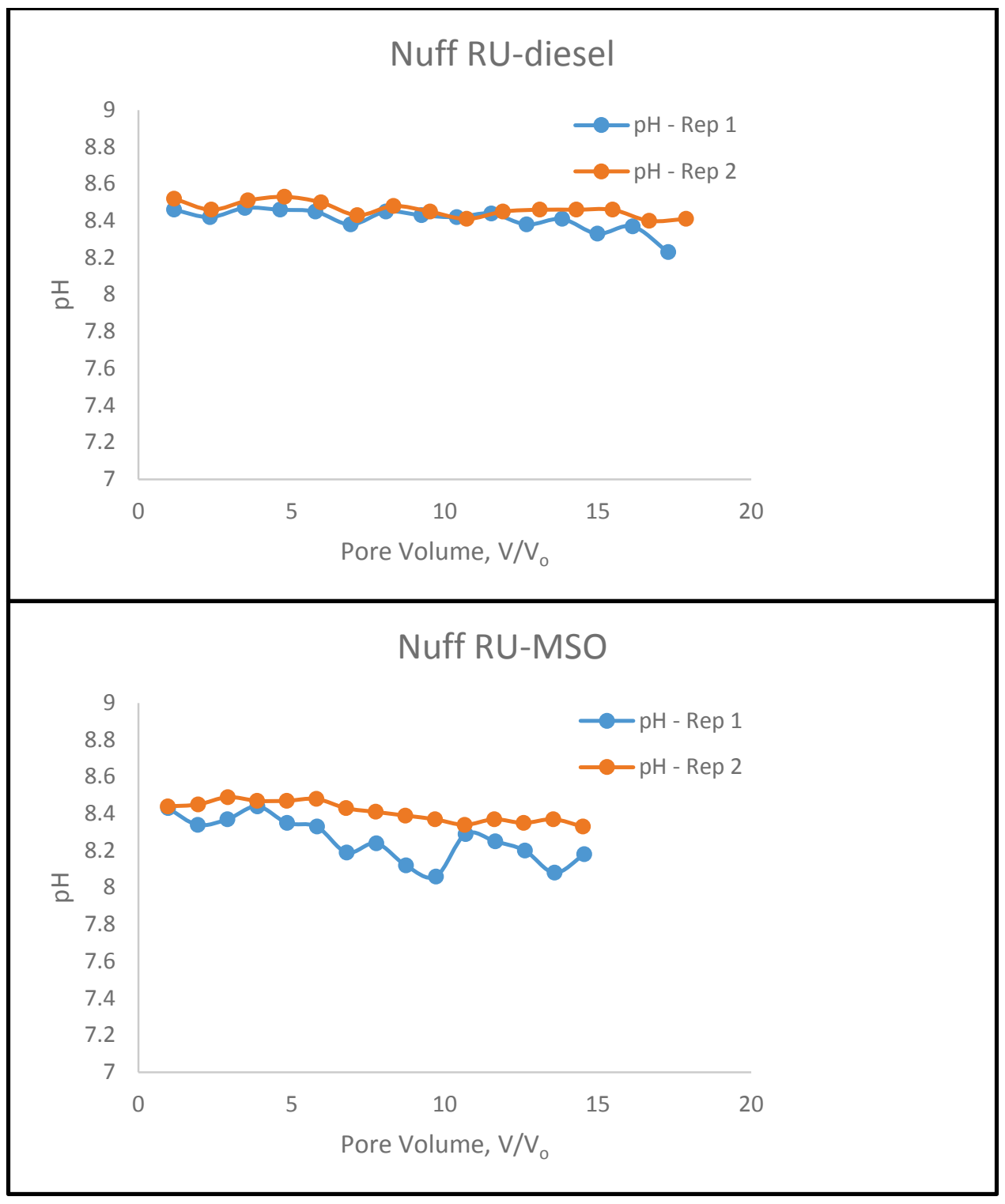




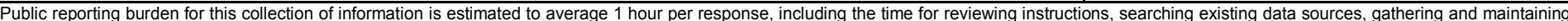

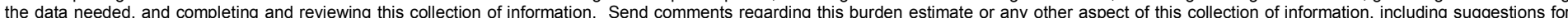

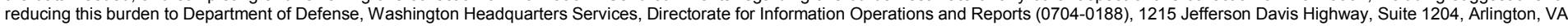

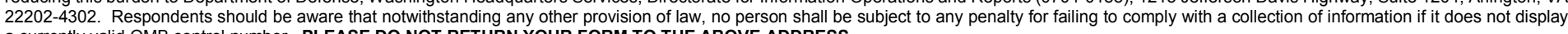
a currently valid OMB control number. PLEASE DO NOT RETURN YOUR FORM TO THE ABOVE ADDRESS.
1. REPORT DATE (DD-MM-YYYY) 2. REPORT TYPE
July 2017 Final report

3. DATES COVERED (From - To)

\section{TITLE AND SUBTITLE}

Integrated Assessment of Vegetation and Soil Conditions Following Herbicide Application

5a. CONTRACT NUMBER

5b. GRANT NUMBER

5c. PROGRAM ELEMENT NUMBER

\section{AUTHOR(S)}

Nathan R. Beane, Christine M. VanZomeren, Cynthia L. Price, Jennifer M. Seiter-Moser, Jeremy L. Conkle, Brooke N. Stevens, and Jacob F. Berkowitz

5d. PROJECT NUMBER

$15-158$

5e. TASK NUMBER

5f. WOK UNIT NUMBER

7. PERFORMING ORGANIZATION NAME(S) AND ADDRESS(ES)

8. PERFORMING ORGANIZATION REPORT NUMBER

U.S. Army Engineer Research and Development Center, Environmental Laboratory 3909 Halls Ferry Road, Vicksburg, MS 39180-6199

ERDC/EL TR-17-??

9. SPONSORING / MONITORING AGENCY NAME(S) AND ADDRESS(ES)

10. SPONSOR/MONITOR'S ACRONYM(S)

Headquarters, U.S. Army Corps of Engineers

Washington, DC 20314-1000

11. SPONSOR/MONITOR'S REPORT NUMBER(S)

\section{DISTRIBUTION / AVAILABILITY STATEMENT}

Approved for public release; distribution unlimited.

\section{SUPPLEMENTARY NOTES}

\section{ABSTRACT}

Vegetation and soil conditions were evaluated prior to- and following herbicide application implemented to control woody vegetation and maintain open grassland areas at Fort Hood, TX. Herbicide application resulted in a decreased rate of vegetation resprout compared with areas where herbicide was not used. Specifically, herbicide mixtures containing Remedy Ultra and methylated seed oil (RU-MSO) outperformed treatments in which no herbicide was applied and areas receiving herbicide and diesel fuel oil treatments (RU-diesel) across each of the three soils evaluated. Field monitoring assessed herbicide concentrations in soil and water. Herbicides were not observed in creeks and ponds adjacent to treatment areas. In soils, herbicide concentrations decreased by $72 \%$ over one month, likely due to microbial degradation, and with distance from the point of application. Monitoring results suggest that limited lateral and/or vertical transport occurred under field conditions. Laboratory studies evaluated potential fate and transport of herbicide compounds, identifying herbicide affinity for the soil surface. Additionally, RU-MSO treatments were strongly bound to soil surfaces at environmentally relevant concentrations. Further, laboratory column studies also suggest that potential transport in soil remained limited. Incorporating periodic herbicide applications into an integrated vegetation management plan will maintain grassland habitats in support of the mission.

\section{SUBJECT TERMS}

Vegitation Management, Herbicides-Environmental Aspects, Water-Pollution, Soils-Herbicide movement, Plants-Effect on herbicides on, Fort Hood (Tex.)

\section{SECURITY CLASSIFICATION OF:}

a. REPORT

UNCLASSIFIED

b. ABSTRACT
UNCLASSIFIED

\section{c. THIS PAGE}

UNCLASSIFIED
17. LIMITATION OF ABSTRACT

SAR

\section{NUMBER} OF PAGES

144 19a. NAME OF RESPONSIBLE PERSON

19b. TELEPHONE NUMBER (include area code) 